\title{
Affordable In-Space Transportation
}

L.A. Curtis, M.K. Van Dyke, R.M. Lajoie, and G.R. Woodcock 


\section{Affordable In-Space Transportation}

L.A. Curtis and M.K. Van Dyke

Marshall Space Flight Center $\bullet$ MSFC, Alabama

R.M. Lajoie and G.R. Woodcock

Boeing $\bullet$ Huntsville, Alabama 


\section{TABLE OF CONTENTS}

Page

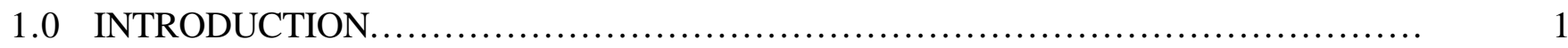

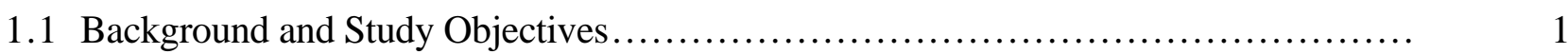

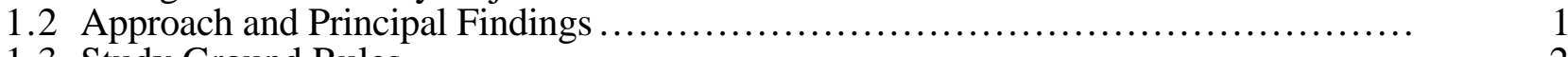

1.3 Study Ground Rules.................................................. 2

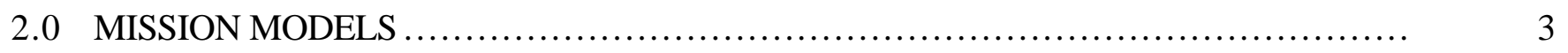

2.1 Payload Traffic Models ..................................................... 3

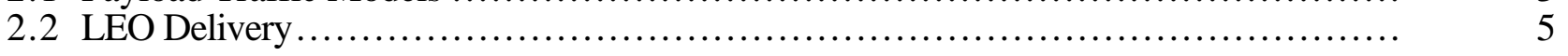

3.0 COST MODELS AND ASSUMPTIONS ..................................... 5

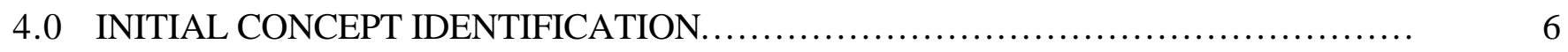

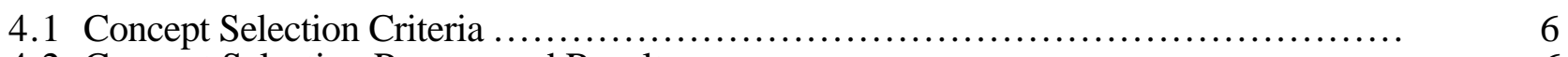

4.2 Concept Selection Process and Results ................................... 6

5.0 CONCEPT SELECTION, PHASE 1, PUGH METHOD ............................. 7

5.1 Concept Selection Process .............................................. 7

5.2 Concept Identification and Descriptions........................................... 7

5.3 Concept Selection Criteria ................................................. 7

5.4 Concept Selection Results ............................................ 9

6.0 CONCEPT FOCUS, PHASE 2, QUICK STUDIES ............................ 10

6.1 Expendable Versus Reusable Solar Thermal .................................. 10

6.2 Laser Electric .............................................................. 10

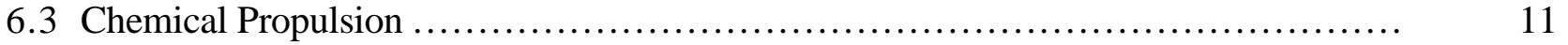

6.4 Tether................................................................. 11

6.5 Concept Selection Results, Final Concepts for Final Study ..................... 12

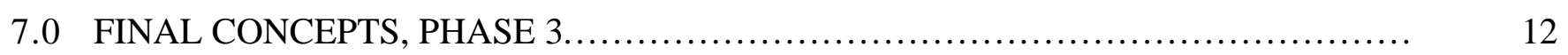

7.1 Solid Propulsion Concepts ............................................... 15

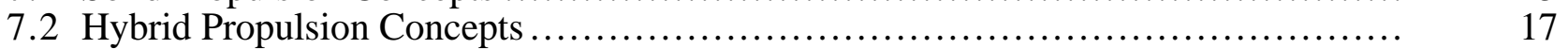

7.3 Cryogen Propulsion Concepts .................................................... 19

7.4 Solar Electric Propulsion Concepts.......................................... 21

7.5 Solar Thermal Propulsion Concepts ............................................ 24

7.6 Nuclear Thermal Propulsion Concepts ....................................... 27

8.0 STUDY RESULTS AND SENSITIVITIES ................................. 30

8.1 Results of Cost Analyses ............................................... 31

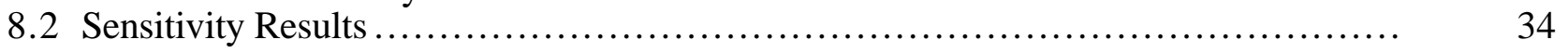




\section{TABLE OF CONTENTS (Continued)}

Page

9.0 CONCLUSIONS AND RECOMMENDATIONS ................................ 38

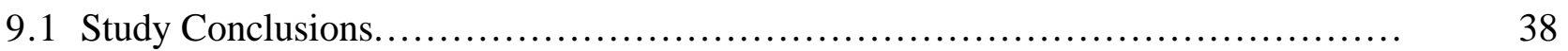

9.2 Recommendations for Future Studies ..................................... 38

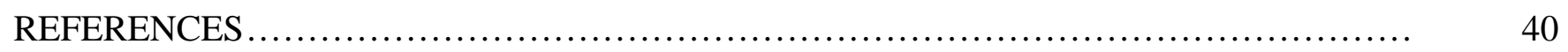

APPENDIX A - STUDY TEAM.............................................. 43

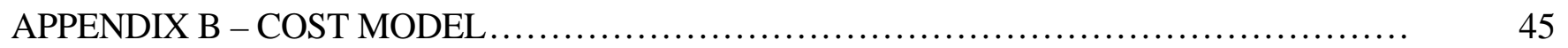

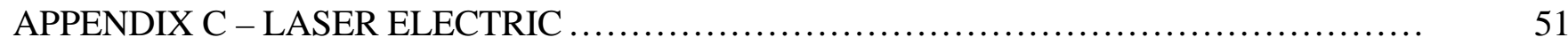

APPENDIX D - CHEMICAL PROPULSION CONCEPT TRADES ....................... 55

APPENDIX E - TETHER CONCEPT EVALUATION .............................. 59

APPENDIX F - OPERATIONS ASSUMPTIONS................................... 61

APPENDIX G - CONCEPT ASSUMPTIONS ..................................... 67

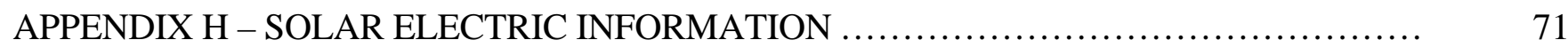

APPENDIX I - LUNAR AND PLANETARY MISSIONS ................................ 75

APPENDIX J - DETAILED COST BREAKDOWN ................................. 79

APPENDIX K - MASS REDUCTIONS ............................................ 113 


\section{LIST OF ILLUSTRATIONS}

Figure

Title

Page

1. Average flights per year by destination................................... 4

2. Average flights per year by payload destination............................. 5

3. Results of chemical propulsion AIST concept quick study $\ldots \ldots \ldots \ldots \ldots \ldots \ldots \ldots \ldots \ldots \ldots \ldots$

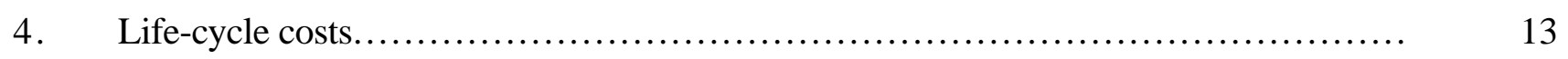

5. DDT $\& E$ costs.................................................... 13

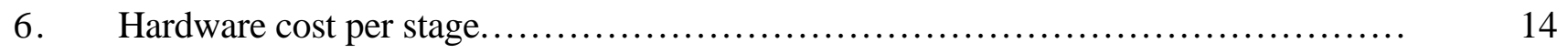

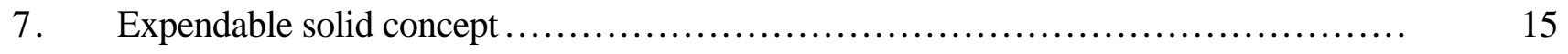

8. Cost distributions for the SRB 3,000-lb payload ............................. 16

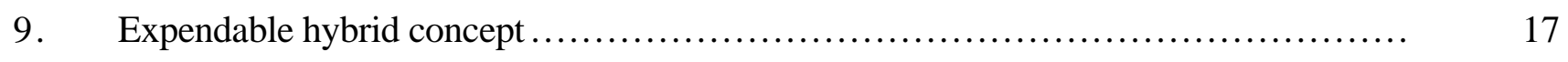

10. Cost distributions for the hybrid motor 3,000-lb payload $\ldots \ldots \ldots \ldots \ldots \ldots \ldots \ldots \ldots \ldots \ldots$

11. Reusable cryogenic concept .......................................... 19

12. Cost distributions for the cryogenic engine $3,000-1 b$ payload $\ldots \ldots \ldots \ldots \ldots \ldots \ldots \ldots . \ldots . \ldots . \ldots$

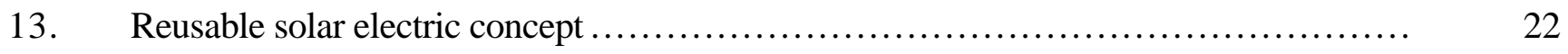

14. Cost distributions for the solar electric engine $3,000-1 b$ payload.................... 24

15. Expendable solar thermal concept...................................... 25

16. Cost distributions for the solar thermal 3,000-lb payload....................... 26

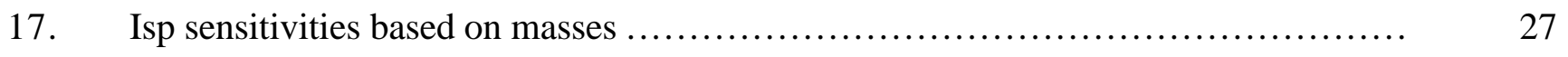

18. Reusable nuclear thermal concept...................................... 28

19. Cost distributions for the nuclear thermal $3,000-1 b$ payload $\ldots \ldots \ldots \ldots \ldots \ldots \ldots \ldots \ldots \ldots$

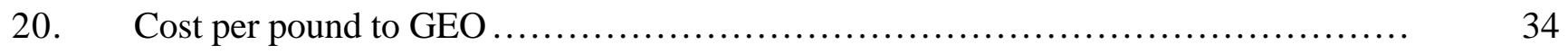

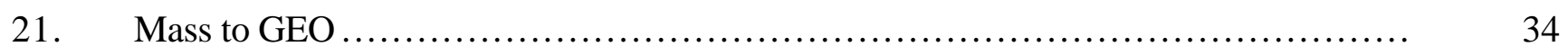

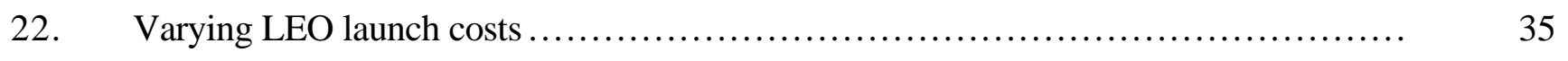

23. GEO delivery cost versus flight rate per year................................ 36

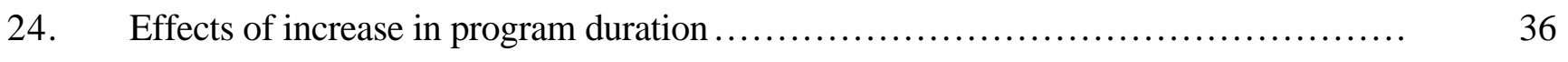

25. Effects of changing operations and facilities cost $\ldots \ldots \ldots \ldots \ldots \ldots \ldots \ldots \ldots \ldots \ldots \ldots \ldots \ldots \ldots \ldots \ldots \ldots$ 


\section{LIST OF ILLUSTRATIONS (Continued)}

Figure

Title

Page

26. Dollars per pound to GEO versus the number of unit reuses.................... 37

C-1. Distribution of laser-electric cost in NAOMI study $\ldots \ldots \ldots \ldots \ldots \ldots \ldots \ldots \ldots \ldots \ldots \ldots . \ldots \ldots$

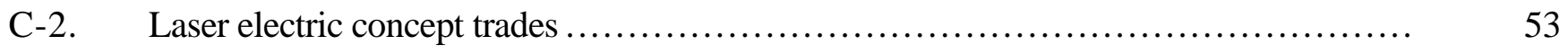

D-1. Results of chemical concept trades at 20 flights per year....................... 57

D-2. Results of chemical concept trades at 50 flights per year....................... 57

D-3. Results of chemical propulsion AIST concept quick study $\ldots \ldots \ldots \ldots \ldots \ldots \ldots \ldots \ldots . \quad 58$

F-1. Operations assembly flowchart...................................... 62

H-1. Specific impulse and trip time preliminary trades $\ldots \ldots \ldots \ldots \ldots \ldots \ldots \ldots \ldots \ldots \ldots \ldots \ldots \ldots \ldots$

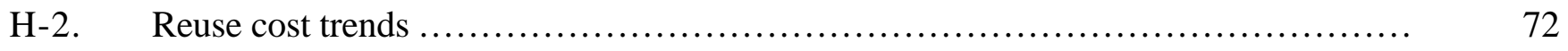

H-3. Solar array mass and vehicle mass summary for 3,000-lb payload solar electric vehicle...

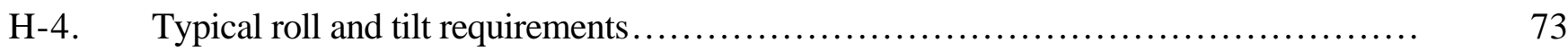

I-1. STCAEM comparison of resupply mass and reusability $\quad$...................... 78

K-1. "Split-payload" equation prediction of reusable cryo launch mass, 3,000-lb payload with AKM 


\section{LIST OF TABLES}

Table

Title

Page

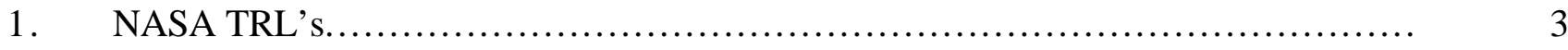

2. Life-cycle cost categories broken down by types of cost ..................... 6

3. Initial candidate concepts for the AIST study............................. 7

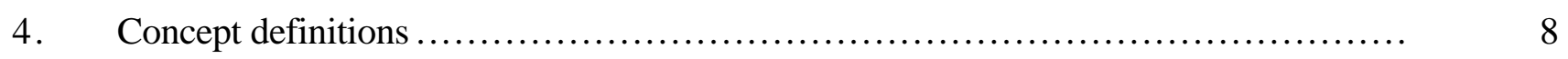

5. Concept selection criteria............................................ 9

6. Pugh concept selection results....................................... 10

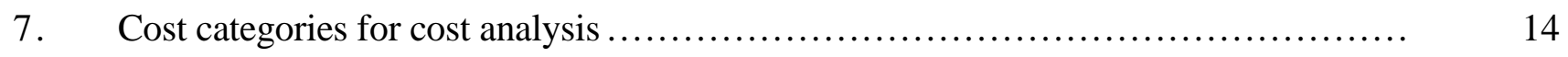

8. Overall weight statement for expendable solid concepts ....................... 15

9. Inert weight statement for expendable solid concepts $\ldots \ldots \ldots \ldots \ldots \ldots \ldots \ldots \ldots \ldots \ldots . \ldots \ldots$

10. Overall weight statement for expendable hybrid concepts ...................... 17

11. Inert weight statement for expendable hybrid concepts $\ldots \ldots \ldots \ldots \ldots \ldots \ldots \ldots \ldots \ldots \ldots . \ldots \ldots$

12. Overall weight statement for reusable cryogen concepts ........................ 19

13. Inert weight statement for reusable cryogen concepts ........................ 20

14. Overall weight statement for reusable solar electric concepts $\ldots \ldots \ldots \ldots \ldots \ldots \ldots \ldots \ldots . . \ldots 22$

15. Inert weight statement for reusable solar electric concepts..................... 22

16. Inert weight statement for solar electric concept refuel tank ..................... 23

17. Overall weight statement for solar electric concept resupply..................... 23

18. Overall weight statement for expendable solar thermal concepts................... 25

19. Inert weight statement for expendable solar thermal concepts.................... 25

20. Overall weight statement for reusable nuclear thermal concepts................... 28

21. Inert weight statement for reusable nuclear thermal concepts.................... 28

22. Inert weight statement for nuclear thermal concept refuel tank .................. 28

23. Overall weight statement for nuclear thermal concept resupply ................... 29

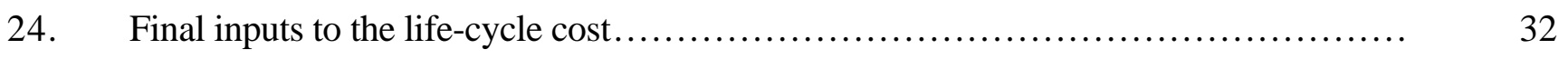

25. Weight summaries and complexity design factors $\ldots \ldots \ldots \ldots \ldots \ldots \ldots \ldots \ldots \ldots \ldots \ldots \ldots \ldots \ldots \ldots \ldots \ldots$ 


\section{LIST OF TABLES}

Table

Title

Page

B-1. NASCOM design complexity factors................................. 45

B-2. NASCOM new design percent factors .................................. 46

B-3. NASCOM production complexity factors................................. 47

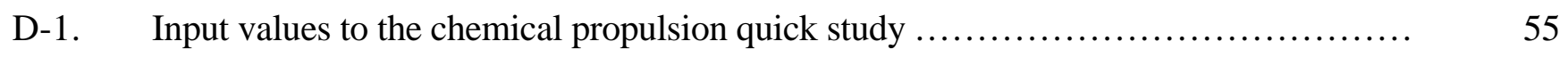

I-1. Applicability of AIST concepts to missions ............................... 76 


\section{ACRONYMS AND ABBREVIATIONS}

\begin{tabular}{|c|c|}
\hline AIST & affordable in-space transportation \\
\hline $\mathrm{AKM}$ & apogee kick motor \\
\hline ASE & airborne support equipment \\
\hline AXAF & advanced x-ray astrophysics facility \\
\hline C\&DH & command and data handling \\
\hline $\mathrm{cm}$ & centimeter \\
\hline DDT\&E & design, development, test, and evaluation \\
\hline DOD & Department of Defense \\
\hline ETO & Earth-to-orbit \\
\hline ELV & expendable launch vehicle \\
\hline $\mathrm{ft}$ & foot \\
\hline GEO & geosynchronous orbit \\
\hline GN\&C & guidance, navigation, and control \\
\hline GSE & ground support equipment \\
\hline GTO & geosynchronous transfer orbit \\
\hline $\mathrm{h}$ & hour \\
\hline HRST & highly reusable space transportation \\
\hline in & inch \\
\hline $\mathrm{I}_{\mathrm{sp}}$ & specific impulse \\
\hline ISS & international space station \\
\hline IUS & inertial upper stage \\
\hline $\mathrm{kg}$ & kilogram \\
\hline $\mathrm{km}$ & kilometer \\
\hline $\mathrm{KSC}$ & Kennedy Space Center \\
\hline $\mathrm{kW}$ & kilowatt \\
\hline $\mathrm{lb}$ & pound \\
\hline
\end{tabular}




\begin{tabular}{|c|c|}
\hline lbf & pound force \\
\hline lbm & pound mass \\
\hline $\mathrm{LH}_{2}$ & liquid hydrogen \\
\hline lox & liquid oxygen \\
\hline N/A & not applicable \\
\hline NASCOM & NASA cost model \\
\hline NTP & nuclear thermal propulsion \\
\hline OCST & Office of commercial space transportation \\
\hline OTV & orbital transfer vehicle \\
\hline PAM & payload assist module \\
\hline PCM & pulse code modulator \\
\hline $\mathrm{RCS}$ & reaction control system \\
\hline RF & radio frequency \\
\hline RLV & reusable launch vehicle \\
\hline SE\&I & system engineering and integration \\
\hline $\mathrm{S}$ & second(s) \\
\hline SEP & solar electric propulsion \\
\hline SRM & solid rocket motor \\
\hline STH & system test hardware \\
\hline STS & space transportation system \\
\hline STUS & solar thermal upper stage \\
\hline TBD & to be determined \\
\hline TOS & transfer orbit stage \\
\hline TRL & NASA technology readiness level \\
\hline W & watts \\
\hline
\end{tabular}




\section{TECHNICAL MEMORANDUM}

\section{AFFORDABLE IN-SPACE TRANSPORTATION}

\subsection{INTRODUCTION}

\subsection{Background and Study Objectives}

Current and proposed launch systems provide access to low-Earth orbit (LEO) and destinations beyond LEO, but the cost of delivering payloads will preclude the use of these services by many users. To develop and encourage revolutionary commercial utilization of geosynchronous orbit (GEO) and to provide an affordable means to continue NASA space science and exploration missions, the transportation costs to in-space destinations must be reduced. Current launch systems can cost $\$ 25,000 / \mathrm{lb}$ for delivery of payloads to GEO (Ariane, Atlas, Titan IV). The reusable launch vehicle (RLV) program is planning to demonstrate technology to allow the U.S. industry to develop a new generation of space launch systems, providing 50 percent or more reduction in LEO transportation costs. These systems will be capable of delivering payloads in the 20,000- to 40,000-lb class to LEO for prices of approximately $\$ 1,000$ to $\$ 2,000 / 1 \mathrm{~b}$. Using today's upper stage technology with the RLV will result in transportation costs to GEO near $\$ 10,000 / \mathrm{lb}$. Most of the cost difference between LEO and GEO is due to the much reduced payload capability to GEO, but one-third to one-half of it comes from the cost of the upper stage itself. New transportation systems must be developed in order to reduce the cost of in-space transportation and to provide the incentive for expanded use of GEO. It is clear that if the benefits of further cost reductions are to be extended to GEO and beyond, an important part of these new space transportation systems must be the inspace segment (i.e., the upper stage). The goal of these new transportation systems is an order of magnitude reduction in transportation costs over RLV costs.

Past studies on in-space transportation have focused on upper stage performance and increased system capability and have not emphasized low cost. These studies needed to be revisited to evaluate inspace transportation systems, with low cost as a major evaluation criterion. In addition, some advanced system concepts have been proposed that were not included in previous trades on in-space transportation. These needed to be included in further system trade studies, with affordable cost as an emphasis.

The principal objective of this study was to conceptually define three to four promising approaches to low-cost in-space transportation for delivery of satellites and other payloads, 3,000- to 10,000-lb class, to GEO destinations. The cost goal for these approaches, in combination with lower cost Earth-to-orbit (ETO) transportation, is $\$ 1,000 / \mathrm{lb}$ from Earth to GEO. The ETO portion of the mission for this study was to be accomplished by a highly reusable space transportation (HRST) system. The goal of this HRST system is to provide access to LEO for $\$ 100$ to $\$ 200 / 1 b$.

\subsection{Approach and Principal Findings}

The study began with an extensive list of candidate upper stage concepts. A three-phase evaluation process of successive elimination and concurrent maturation of concepts was used. Concept maturity included work in the areas of: propulsion systems, structures, avionics, operations, and de-orbit procedures. Systems operation and servicing strategies were investigated. For reusable systems, both spacebased and ground-based servicing were considered. Options for in-space servicing did not include those that require an extensive servicing bay on space station. The level of system concept detail developed was such that cost analysis could be performed on the systems and comparisons made between the top concepts. 
The Affordable In-Space Transportation (AIST) study team consisted of members from both NASA/MSFC and Boeing. Representatives from various disciplines participated in the study as required to mature the concepts and to participate in concept evaluations. A list of participants and responsibilities is included in appendix A.

The principal findings of the study are stated as follows:

1. The cost goal of $\$ 1,000 / \mathrm{lb}$ to GEO is extremely difficult to achieve. LEO transportation cost, even at $\$ 200 / \mathrm{lb}$, is still a dominant contributor to the total cost to GEO. Cost to LEO is immediately multiplied by the ratio (total payload to LEO)/(total payload to GEO) which tended to be about five or more for most of the concepts, leaving little or nothing for other cost categories. Expendable upper stages have the greatest potential to reduce payload ratio, but offer little possibility of reaching the goal which, for a 3,000-lb payload is only $\$ 3$ million, because of their hardware cost.

2. The four top candidates (lowest life-cycle cost) were: expendable solid rocket motor (SRM), expendable hybrid, reusable cryo, and reusable solar electric propulsion (SEP). These systems evaluated at about $\$ 4,000 / \mathrm{lb}$ for a 3,000 -lb payload and about $\$ 2,500 / \mathrm{lb}$ for a 10,000 -lb payload. Reusable nuclear and expendable solar thermal propulsion were also in the final set of concepts, but exhibited somewhat higher costs. Reusable nuclear costs less than the reusable SEP for a 10,000-lb payload, especially at high launch rates.

3. The solar thermal propulsion system could be a more competitive system if it is reusable, or if significant specific impulse (Isp) gains could be met. The stage production cost for the solar thermal concept drove the life-cycle cost of the system. This trend was true for the other expendable concepts as well.

4. Reusable options are sensitive to technology assumptions and achievements. Structures and avionics weight estimates were based upon "business as usual" technology. Since there is no data base for reusable systems, good estimates are difficult to obtain. The high-cost sensitivity to inert weight was not adequately appreciated early in the study, hence, there was no motivation to consider aggressive-technology estimates. Early trades indicated a need for advanced solar array and electric propulsion technology for SEP and appropriate estimates were made for these subsystems. Reusable systems need innovative mission profiles and advanced technology in all subsystems to approach the AIST study cost goals.

5. A dynamic tether scheme could not be adequately analyzed within the scope of the study and there were insufficient data available to achieve parity of definition with other options.

\subsection{Study Ground Rules}

The following ground rules were used for the AIST study:

1. The HRST system is used to deliver each in-space transportation concept to LEO (a circular orbit with an altitude of $100 \mathrm{nmi}$ and an inclination of $28.5^{\circ}$ )

2. In-space transportation systems handle missions from LEO to GEO (a circular orbit with an altitude of 19,323 $\mathrm{nmi}$ and an inclination of zero) 
3. In-space transportation technology must be available, at a NASA technology readiness level (TRL) of 6 or higher, by the year 2005 (see table 1)

4. Payload masses to GEO selected for this study are 3,000- and 10,000-lb

5. A single HRST launch transports $25,000 \mathrm{lb}$ to and from LEO. LEO transportation weight is defined as the LEO delivery weight plus the associated airborne support equipment (ASE) weight

6. HRST ground-to-LEO transportation costs charged to the HRST customer are $\$ 200 / \mathrm{lb}$

7. Space-based reusable concepts will be serviced by HRST; payload and propellant refueling may require separate HRST flights

8. For any in-space transportation concepts which transfer payloads only to GTO (elliptical orbit with a perigee of $100 \mathrm{nmi}$, an apogee of $19,323 \mathrm{nmi}$, and an inclination of $28.5^{\circ}$ ), an apogee kick motor (AKM) completes the zero plane change and obtains GEO velocity.

Table 1. NASA TRL's.

\begin{tabular}{|c|l|}
\hline TRL & \multicolumn{1}{|c|}{ Description } \\
\hline 1 & Basic principles observed and reported \\
2 & Technology concept and application formulated \\
3 & Analytical and experimental critical function and/or proof-of-concept \\
4 & Component and/or breadboard validation in laboratory environment \\
5 & Component and/or breadboard validation in relevant environment \\
6 & System and/or subsystem model or prototype demo in relevant \\
7 & environment (ground or space) \\
8 & System prototype demonstration in a space environment \\
9 & Actual system completed and "flight qualified" through test and \\
\hline
\end{tabular}

\subsection{MISSION MODELS}

\subsection{Payload Traffic Models}

To determine the flight rates and payload sizes for this study, a mission model was developed with data gathered from NASA, Department of Defense (DOD), and commercial sources. The NASA data were extracted from the NASA "Expendable Launch Vehicle (ELV) Manifest and Long Range Planning Status of August, 1995." The time frame for these missions is from 1995 through 2010. The NASA shuttle data were developed from the "Code M STS Manifest" of May 1995, which provides mission data from 1995 to 2002. ${ }^{2}$ Seven space transportation system (STS) flights per year were assumed for 2003 to 2010. The "Air Force Space Command (AFSPC) National Mission Model," May 1995, was used for the DOD missions from 1995 to 1999. The "AFSPC Traffic Rate Projections," August 1995, was used for DOD missions from 2000 to 2020 . $^{4}$ The commercial data were based on two reports provided by the office of the Associate Administrator for Commercial Space Transportation (OCST) ${ }^{5}$ Federal Aviation Administration, Department of Transportation (DOT). The first, "Commercial Spacecraft Mission Model Update," dated May 1995, was developed by COMSTAC and provides GTO data for 1995 to 2010. The second, "LEO 
Commercial Market Projection," dated May 1995, provides an assessment by OCST of LEO markets for 1995 to $2005 .^{6}$ Figure 1 shows the average flights per year by destination for all three payload sources. About half of these payloads have a destination beyond LEO and will require some form of an upper stage. For these payload missions, the major destination of payloads is GEO, although the launch vehicle/upper stage typically delivers the payload to GTO with an AKM performing the final insertion. Although the shuttle has a few missions that deliver payloads going beyond LEO (e.g., Advanced X-Ray Astrophysics Facility (AXAF)), the majority are LEO delivery (e.g., space station assembly and resupply). Therefore, it was assumed that all payloads delivered on shuttle flights have a LEO destination.

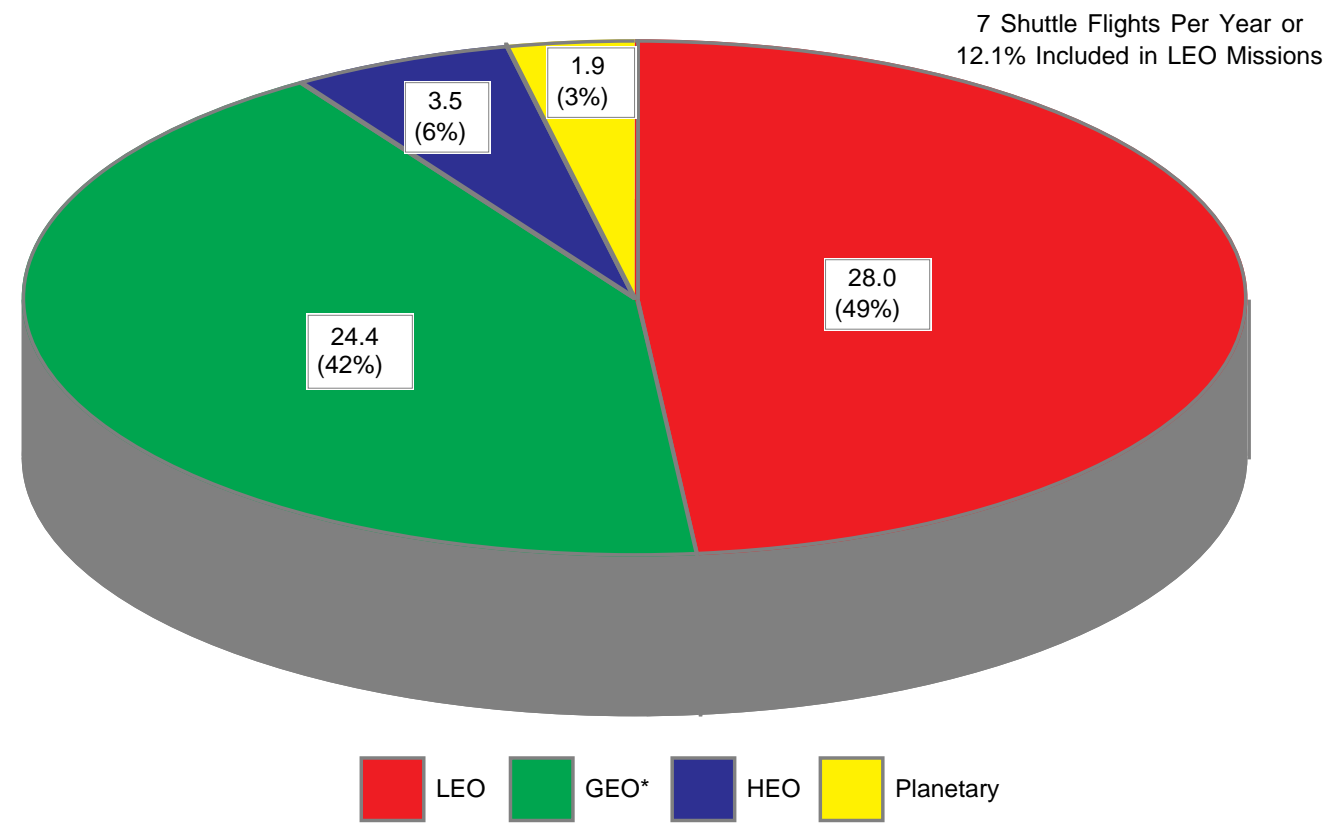

Figure 1. Average flights per year by destination.

To determine the sensitivity of costs to the flight rate, rates that bracket the 30 missions per year that require an upper stage were chosen. The lowest rate chosen was 20 missions per year. The highest rate chosen for the study was 50 missions per year, which might cover traffic rate projections that have not been performed for the NASA and commercial areas.

Figure 2 shows the average flights per year for all three payload sources to each destination. The bars have been stacked to show the size of the payloads that are delivered to these destinations. For the AIST study, two "typical" payloads were defined for system comparison purposes. One was a 3,000-lb payload, which represents the most common class of payloads delivered to GEO. The other was a 10,000-lb payload, which represents the high end of payloads that are delivered to GEO (comparable to the Titan IV/Centaur delivery mission). 


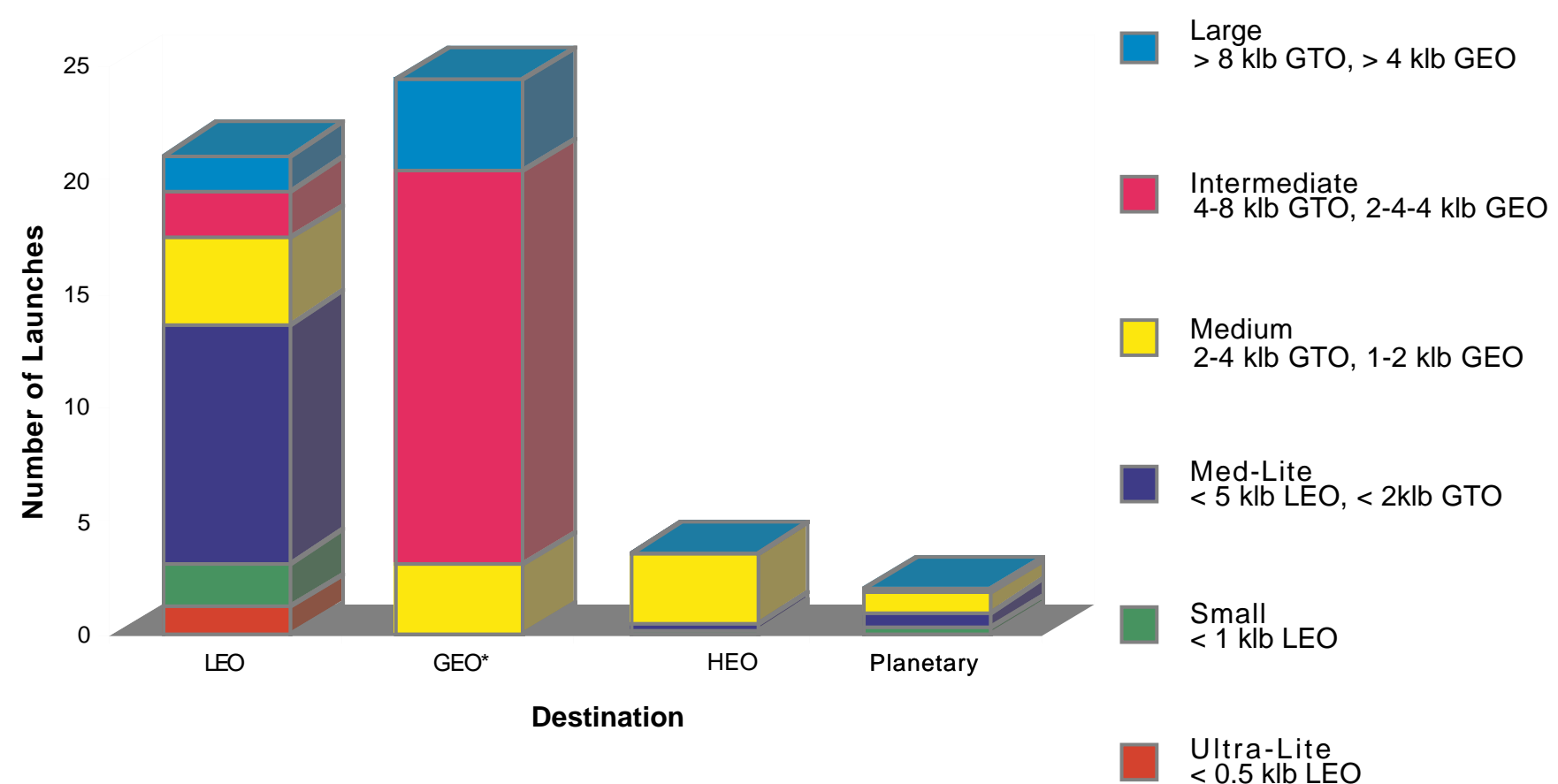

Figure 2. Average flights per year by payload destination.

\subsection{LEO Delivery}

An HRST system will be used to deliver each upper-stage concept and payload to LEO. Multiple launches of the HRST may be required to deliver the upper stage and payload, since some upper-stage and payload combinations exceed the weight constraints of the HRST vehicle. For this study, it was assumed that the HRST operator will charge for the transportation service based on LEO delivery weight alone, regardless of the actual number of HRST launches required to put that weight in LEO. Large upper-stage concepts may, therefore, be underpriced.

\subsection{COST MODELS AND ASSUMPTIONS}

The major emphasis of this study was to explore affordable cost of in-space transportation for payload delivery from LEO to GEO. This study attempted to account for all costs associated with an inspace transportation concept. This included not only design, development, test, and evaluation (DDT\&E) and production costs, but operations and maintenance costs as well. Because this method was extremely time consuming and the information for some of the less developed concepts was not readily available, the cost models were exercised only after the final concepts were chosen (section 7.0). Comparisons between concepts are made using the life-cycle cost, which can be divided into two categories, recurring and nonrecurring. These two categories can further be broken out into types of costs, which are listed in table 2 .

DDT\&E and first-unit costs are calculated using the NASCOM cost model. This cost model uses weights and complexity factors for the following subsystems as a basis for calculating costs for each concept: structures, mechanisms, passive thermal control, active thermal control, electric power, communication and data handling $(\mathrm{C} \& \mathrm{DH})$, guidance navigation and control (GN\&C), reaction control system, propulsion subsystem, SRM's, liquid rocket engines, advanced solar arrays, absorber/gimbal, collector/optics/mechanism, nuclear rocket engine, electric propulsion engine, AKM, and ASE. Every upperstage concept does not necessarily utilize all of these subsystems. A detailed description on the cost calculations for each of the types of cost can be found in appendix B. 
Table 2. Life-cycle cost categories broken down by types of cost.

\begin{tabular}{|l|l|}
\hline Category & \multicolumn{1}{c|}{ Types of cost } \\
\hline Nonrecurring & - DDT\&E for stages/AKM/ASE \\
& - Total ASE production \\
& - Total refuel tank production (if required) \\
& - Facility nonrecurring \\
\hline Recurring & - Total LEO transportation \\
& - Total stage production (no AKM or ASE production included) \\
& - Total AKM production (if required) \\
& - Total replacement parts/spares (if required) \\
& - Total operations labor \\
& - Total facility maintenance \\
& Total propellant \\
\hline
\end{tabular}

\subsection{INITIAL CONCEPT IDENTIFICATION}

\subsection{Concept Selection Criteria}

The intent of the initial identification phase was to capture all propulsion concepts that could be used to deliver payloads from LEO to GEO. The only criterion used for initial selection was that all technologies for a given concept must be at least at TRL 6 by the year 2005 .

\subsection{Concept Selection Process and Results}

To find candidate AIST concepts, in the short amount of time the study allowed, readily available literature was researched..$^{7-24}$ All operational upper stage propulsion concepts were immediately accepted as candidate concepts, including solid, storable, and liquid oxygen/liquid hydrogen $\left(\operatorname{lox} / \mathrm{LH}_{2}\right)$ cryogen propulsion concepts. All other ground-tested and flight-tested propulsion concepts were also accepted, if they could be at TRL 6 by the year 2005, including hybrid, solar thermal, solar electric, solid-core nuclear thermal, nuclear electric, laser thermal, and laser electric propulsion concepts. Dynamic tethers, though not a propulsion concept, were added to the list because of their potential to provide orbit transfer capability through momentum exchange. Some concepts that were considered, but not selected because of either their lack of maturity, extreme environmental problems, or inapplicability to the LEO/GEO mission included solar sails, magsails, exotic liquid propellants (i.e., fluorine, ozone, and borohydrides), fission gas-core, fusion propulsion, nuclear pulse propulsion, electrodynamic tethers, "skyhook" tethers, gun launch, antimatter, and metastable state energy sources.

The concept identification process applied a degree of engineering judgment as to whether a concept should be reusable or expendable, or if both options should be considered. This judgment was mainly based on personal experience of the members on the study team. Table 3 shows the 17 concepts identified for consideration. 
Table 3. Initial candidate concepts for the AIST study.

\begin{tabular}{|c|c|c|c|}
\hline \multicolumn{2}{|c|}{ Chemical } & \multicolumn{2}{|c|}{$\underline{\text { Solar }}$} \\
\hline $\begin{array}{c}\text { Solid, } \\
\text { Expendable }\end{array}$ & $\begin{array}{c}\text { Hybrid, } \\
\text { Expendable }\end{array}$ & $\begin{array}{l}\text { Solar Electric, } \\
\text { Expendable }\end{array}$ & $\begin{array}{l}\text { Solar Thermal, } \\
\text { Expendable }\end{array}$ \\
\hline $\begin{array}{c}\text { Storable, } \\
\text { Expendable }\end{array}$ & $\begin{array}{l}\text { Storable, } \\
\text { Reusable }\end{array}$ & $\begin{array}{l}\text { Solar Electric, } \\
\text { Reusable }\end{array}$ & $\begin{array}{c}\text { Solar Thermal, } \\
\text { Reusable }\end{array}$ \\
\hline $\begin{array}{l}\text { Cryogen, } \\
\text { Expendable }\end{array}$ & $\begin{array}{l}\text { Cryogen, } \\
\text { Reusable }\end{array}$ & & \\
\hline \multicolumn{2}{|c|}{ Nuclear } & \multicolumn{2}{|c|}{ Other } \\
\hline $\begin{array}{l}\text { Nuclear Electric, } \\
\text { Reusable }\end{array}$ & $\begin{array}{c}\text { Nuclear Thermal, } \\
\text { High Thrust, } \\
\text { Reusable }\end{array}$ & \multicolumn{2}{|c|}{ Laser Electric, Partially Reusable } \\
\hline $\begin{array}{c}\text { Nuclear Thermal, } \\
\text { Low Thrust, } \\
\text { Reusable }\end{array}$ & $\begin{array}{l}\text { Nuclear Thermal, } \\
\text { lox Augmented, } \\
\text { Reusable }\end{array}$ & \multicolumn{2}{|c|}{ Dynamic Tethers, Partially Reusable } \\
\hline
\end{tabular}

\subsection{CONCEPT SELECTION, PHASE 1, PUGH METHOD}

\subsection{Concept Selection Process}

A concept selection approach, based on a method formulated by Stuart Pugh, was used to determine if the concepts identified for analyses could be categorized into clear groups of "winners" (concepts selected for further study) and "losers" (concepts dropped from further study). The Pugh selection approach assigns scores to system attributes using a baseline frame of reference concept, and the scores are then tabulated for each concept. The process began by choosing an SRM upper stage system as a frame of reference. A Pugh selection team was assembled (appendix A) to define concept definitions and determine which system attributes would be judged. The definitions are described in table 4 . The attributes listed in table 5 were chosen as the criteria for which to assign scores. For each attribute, a score of "+", "_", or "S" was assigned. A "+" meant that the attribute was better than a solid, a "-" implied that the concept was worse than a solid, and an "S" implied that the concept was equal to a solid. The team identified, by a majority vote, an overall "+", "-", or "S" score for each attribute of each concept.

\subsection{Concept Identification and Descriptions}

Table 4 contains a list of concept definitions the study team used for the Pugh concept selection approach. These definitions were considered to be broad and served only to ensure that all Pugh voters were at a common point of reference in their understanding of each concept. It is possible that concepts chosen for further study would have a minor change made to the concept definition once a more detailed design was accomplished.

\subsection{Concept Selection Criteria}

Table 5 contains a list of concept selection criteria the study team used for the Pugh concept selection approach. These criteria were considered to be broad and served only to ensure that all Pugh voters were at a common point of reference in their understanding of the criteria. 
Table 4. Concept definitions.

\begin{tabular}{|c|c|}
\hline Concept & Definition \\
\hline Solid, expendable & $\begin{array}{l}\text { This system is based on current technology expendable solid upper stages such as the } \\
\text { transfer orbit stage (TOS) and the payload assist module (PAM) DII Solids are simple, } \\
\text { expendable, non-restartable systems. The propellants would be preloaded, requiring no on- } \\
\text { pad fueling. The technology is available for these systems and no new facilities would be } \\
\text { required to process them. }\end{array}$ \\
\hline Storables, expendable & $\begin{array}{l}\text { This system would be an evolution of the Ariane } 5 \text { type upper stage. The hypergolic } \\
\text { propellants have some operations and environmental impacts but have been used for } \\
\text { storable propellants for sometime. The technology is currently available for these systems. }\end{array}$ \\
\hline Storables, reusable & $\begin{array}{l}\text { This system (based on orbital transfer vehicle (OTV)) would be developed to provide a } \\
\text { reusable storable system that would require on-orbit refueling and rendezvous \& docking to } \\
\text { be reusable. Development of space storable propellants and on-orbit operations would be } \\
\text { required. }\end{array}$ \\
\hline Cryogens, expendable & $\begin{array}{l}\text { This system uses } \mathrm{LH}_{2} \text { and lox propellants. It would be an evolution of the Centaur stage } \\
\text { providing high thrust and high Isp. }\end{array}$ \\
\hline Cryogens, reusable & $\begin{array}{l}\text { This system would be based on OTV (with or without an aerobrake). The propellants would } \\
\text { be } \mathrm{LH}_{2} / \text { lox. Development of a highly restartable engine ( }>100 \text { starts) and on-orbit cryo } \\
\text { fluid management for storage and refueling would be required. }\end{array}$ \\
\hline Hybrid, expendable & $\begin{array}{l}\text { This system uses an inert fuel oxidized by lox as its propulsion system. Safety is improved } \\
\text { over a solid system due to the inert nature of the fuel, and its insensitivity to grain cracking. } \\
\text { The system is simple with few moving parts, is capable of multiple starts and stops, and is } \\
\text { environmentally "friendly". The issue of combustion instability needs to be resolved. }\end{array}$ \\
\hline Solar Electric, expendable & $\begin{array}{l}\text { This system uses large deployable solar arrays to power electric thrusters for the stage } \\
\text { propulsion. The solar electric system would require a long time to deliver payloads to GEO } \\
\text { due to the low thrust nature of the electric thrusters. On-orbit deployment of large arrays } \\
\text { would be required. }\end{array}$ \\
\hline Solar Electric, reusable & $\begin{array}{l}\text { This system uses large deployable solar arrays to power electric thrusters for the stage } \\
\text { propulsion. The solar electric system would require a long time to deliver payloads to GEO } \\
\text { due to the low thrust nature of the electric thrusters. On-orbit deployment of large arrays } \\
\text { would be required. This reusable system would require long cell and grid lives. }\end{array}$ \\
\hline Solar Thermal, expendable & $\begin{array}{l}\text { This system uses a deployable concentrator to convert solar energy to thermal energy. The } \\
\text { solar energy is focused into the engine absorber where propellant }\left(\mathrm{H}_{2}\right) \text { is heated to provide } \\
\text { thrust to the stage. The solar thermal upper stage (STUS) requires multiple burns }(300 \text { to } \\
1,000) \text { of the engine, and on-orbit cryogenic fluid management to complete its mission, } \\
\text { which may be lengthy. }\end{array}$ \\
\hline Solar Thermal, reusable & $\begin{array}{l}\text { This system uses a deployable concentrator to convert solar energy to thermal energy. The } \\
\text { solar energy is focused into the engine absorber where propellant }\left(\mathrm{H}_{2}\right) \text { is heated to provide } \\
\text { thrust to the stage. The STUS requires multiple burns }(300 \text { to } 1,000) \text { of the engine, and on- } \\
\text { orbit cryogenic fluid management to complete its mission, which may be lengthy. This } \\
\text { reusable system could get propellant }\left(\mathrm{LH}_{2}\right) \text { resupply either on-orbit or on ground. }\end{array}$ \\
\hline Nuclear Electric, reusable & $\begin{array}{l}\text { This system uses a nuclear reactor to provide power to an electric thruster(s). This high Isp, } \\
\text { low thrust system would take a longtime to deliver payloads to GEO. The development and } \\
\text { testing of a nuclear engine would be required, and the issue of using nuclear propulsion in } \\
\text { space would also have to be addressed. }\end{array}$ \\
\hline $\begin{array}{l}\text { Nuclear Thermal, Hi-Thrust, } \\
\text { reusable }\end{array}$ & $\begin{array}{l}\text { This system uses a nuclear reactor to provide power. This high Isp, high thrust system would } \\
\text { deliver payloads quickly to GEO. The development and testing of a nuclear engine would be } \\
\text { required, and the issue of using nuclear propulsion in space would also have to be addressed. }\end{array}$ \\
\hline $\begin{array}{l}\text { Nuclear Thermal, Lox } \\
\text { Augmented, reusable }\end{array}$ & $\begin{array}{l}\text { This system uses a nuclear particle bed reactor to provide power with the incorporation of } \\
\text { lox afterburners. This high Isp, high thrust system would deliver payloads quickly to GEO. } \\
\text { The development and testing of a nuclear engine would be required, and the issue of using } \\
\text { nuclear propulsion in space would also have to be addressed. }\end{array}$ \\
\hline $\begin{array}{l}\text { Nuclear Thermal, Lo-Thrust, } \\
\text { reusable }\end{array}$ & $\begin{array}{l}\text { This system uses a small nuclear particle bed reactor to provide power. This high Isp, low } \\
\text { thrust system would take a long time to deliver payloads to GEO. The development and } \\
\text { testing of a nuclear engine would be required, and the issue of using nuclear propulsion in } \\
\text { space would also have to be addressed. }\end{array}$ \\
\hline $\begin{array}{l}\text { Laser Electric, partially } \\
\text { reusable }\end{array}$ & $\begin{array}{l}\text { This system uses either a ground-based or space-based laser system to provide energy for } \\
\text { solar cells to power the system. This high Isp, low thrust system would take a long time to } \\
\text { deliver payloads to GEO. Ground-based or space-based laser facilities would have to be } \\
\text { developed. The system would require replacement of cells. }\end{array}$ \\
\hline $\begin{array}{l}\text { Laser Thermal, partially } \\
\text { reusable }\end{array}$ & $\begin{array}{l}\text { This system uses either a ground-based or space-based laser system to provide energy to heat } \\
\text { the propellant }\left(\mathrm{H}_{2}\right) \text { to provide thrust for the system. This system would require development } \\
\text { of ground-based or space-based laser facilities. }\end{array}$ \\
\hline Dynamic Tethers & $\begin{array}{l}\text { This system would use a tether to provide momentum to the upper stage to boost it to the } \\
\text { appropriate orbit. }\end{array}$ \\
\hline
\end{tabular}


Table 5. Concept selection criteria.

\begin{tabular}{|l|l|}
\hline \multicolumn{1}{|c|}{ Selection Criteria } & \multicolumn{1}{c|}{ Definition } \\
\hline DDT\&E Cost of Upper Stage & $\begin{array}{l}\text { DDT\&E for the upper stage. Things to consider include number of new and unique } \\
\text { elements and design and technical complexity. }\end{array}$ \\
\hline Unit Cost of Upper Stage & $\begin{array}{l}\text { Cost of an upper stage using a particular propulsion system. Does not include } \\
\text { operations costs or other recurring costs. }\end{array}$ \\
\hline $\begin{array}{l}\text { Ground Operations } \\
\text { Complexity and Costs: }\end{array}$ & $\begin{array}{l}\text { Includes number and types of fluids and handling issues, purge and special conditioning } \\
\text { requirements, hazardous facility requirements, and environmental concerns. Excludes } \\
\text { initial flight hardware. Includes cost of spares and refurbishment. }\end{array}$ \\
\hline $\begin{array}{l}\text { On-Orbit Complexity and } \\
\text { Costs }\end{array}$ & $\begin{array}{l}\text { Includes on-orbit assembly and/or servicing, refueling of propellants, deployment of } \\
\text { collectors, arrays, etc. }\end{array}$ \\
\hline Performance & $\begin{array}{l}\text { Performance parameters such as: Isp, thrust, power/weight ratio, as appropriate for a } \\
\text { given system. }\end{array}$ \\
\hline Safety and Reliability & Mission completion. Risk to payload, launch system and public. \\
\hline Technology Development & $\begin{array}{l}\text { Current technology readiness level compared to Datum concept. Technology must be at } \\
\text { TRL-6 (System/Subsystem model or prototype demo in relevant environment, ground } \\
\text { or space) by 2005. }\end{array}$ \\
\hline Reusability/Service Life & Number of times system can be reused, and overall lifetime of system. \\
\hline System Flexibility & Capability of system to perform other missions within its design. \\
\hline Evolutionary Potential & $\begin{array}{l}\text { Includes growth capability of system and potential of accommodating more demanding } \\
\text { missions. Capability to incorporate technology upgrades. }\end{array}$ \\
\hline Packaging Efficiency & Size, volume, weight of system. \\
\hline Trip Time & Time it takes to deliver the payload/satellite to destination for it to begin operation. \\
\hline De-Orbit /Debris Issues & $\begin{array}{l}\text { Includes de-orbit of any expendable parts of system and any debris produced by exhaust } \\
\text { plumes and/or leaks. Hazardous disposal as appropriate. }\end{array}$ \\
\hline
\end{tabular}

\subsection{Concept Selection Results}

Once all attributes were scored, a table compiling the amount of "pluses" and "minuses" for each concept was completed. The results, shown in table 6, are grouped into a series of four categories: chemical, solar, nuclear, and other. The chemical systems, with the exception of expendable storable and expendable cryogens, all had five to six pluses. Expendable storables and expendable cryogens were dropped from further study, and the remaining chemical concepts (expendable hybrid, reusable storable, reusable cryogen, and the baseline solid) were advanced to the next phase.

In general, the solar concepts fell into high "plus" categories. Even though there was a difference in the score of the solar thermal expendable and the solar thermal reusable, it was evident that it would be beneficial to consider this concept, so both concepts were advanced to the next phase. A tradeoff study would be completed to examine these differences and identify which concept would advance to the next phase. Additionally, all of the solar electric concepts scored high, so the solar electric reusable was advanced to the next phase. The advanced nuclear systems scored very low, but at the request of some team members that insisted past studies showed this concept to be viable and should be investigated further, the advanced nuclear concepts were also advanced to the next phase. Finally, there were two concepts in which there was either very little information available at the time of the study, or for which past studies clearly conflicted with the team's results. The dynamic tether was not clearly defined at the time of the Pugh voting, so this concept automatically defaulted to the next phase. The laser electric and laser thermal systems scored very low, but at the request of some team members who insisted past studies show this concept to be viable and should be investigated further, the laser electric concepts were also advanced to the next phase. 
Table 6. Pugh concept selection results.

\begin{tabular}{|c|c|c|c|}
\hline & 1 to 3 Pluses & 4 Pluses & 5 to 6 Pluses \\
\hline $\begin{array}{l}0 \text { to } 4 \\
\text { Minuses }\end{array}$ & $\begin{array}{c}\text { Storable, Exp. } \\
\text { Dynamic Tethers }\end{array}$ & Cryogen, Exp. & Hybrid, Exp. \\
\hline $\begin{array}{l}5 \text { to } 6 \\
\text { Minuses }\end{array}$ & Solar Thermal, Exp. & Solar Electric, Exp. & $\begin{array}{c}\text { Storable, Reus. } \\
\text { Cryogen, Reus. } \\
\text { Solar Electric, Reus. } \\
\text { Solar Thermal, Reus. }\end{array}$ \\
\hline $\begin{array}{l}7 \text { to } 8 \\
\text { Minuses }\end{array}$ & $\begin{array}{l}\text { Laser Electric, Reus. } \\
\text { Laser Thermal, Reus. }\end{array}$ & $\begin{array}{l}\text { Nuclear Electric } \\
\text { Nuclear Thermal, Lo-Thrust } \\
\text { Nuclear Thermal, Hi-Thrust } \\
\text { Nuclear Thermal, Lox-Aug. }\end{array}$ & (none) \\
\hline
\end{tabular}

\subsection{CONCEPT FOCUS, PHASE 2, QUICK STUDIES}

In phase 2, quick-trade studies were performed to reduce the concepts to a manageable set where a detailed analysis could be performed.

\subsection{Expendable Versus Reusable Solar Thermal}

The previous phase indicated that although the solar thermal was a feasible alternative, the reusability and expandability issue needed further study. MSFC experts in solar thermal propulsion completed a qualitative tradeoff for expendable versus reusable concepts and chose the expendable concept as the best concept for study (based on past studies and on TRL readiness). Also, based upon trajectory calculations, it was believed that it would be optimistic to reach the necessary TRL for desired engine $\mathrm{I}_{\mathrm{sp}}$ and thrust levels to deliver a 10,000-lb payload to GEO in a reasonable trip time; therefore, only the 3,000-lb payload class was considered for further study.

\subsection{Laser Electric}

A previous study (NAOMI) had indicated cost advantage for a laser-electric propulsion system compared to a reusable cryogenic upper stage of the type considered for this study. The laser electric system uses a high-power ground-based laser to illuminate a photovoltaic receiver on the upper stage at several Suns' intensity. The higher conversion efficiency attainable with monochromatic light, $\sim 50$ percent, and the high intensity give the electric propulsion upper stage very high power generation performance. A disadvantage is that opportunities for power transfer are infrequent when the vehicle is in a low orbit. Extrapolating the information from these studies, it was determined to eliminate the laser electric from further study, since the laser electric advantage disappears when launch cost drops to very low levels. Detailed information on the extrapolation of the NAOMI study to this AIST study can be found in appendix $\mathrm{C}$ of this report. 


\subsection{Chemical Propulsion}

The goal of the chemical propulsion concept trade study was to reduce the four chemical concepts (solid, hybrid, storable, and cryogen) down to one or two. Both the reusable liquid concepts (storable and cryogen) were divided into a propulsion-deboost version and an aerobrake-deboost version. The latter would be modeled as a heavier vehicle not requiring propellant for deboost. (The aerobrake maneuver was not modeled.) For completeness, expendable versions of the storable and cryogen concepts were also assessed. Appendix D contains the detailed analysis for this study.

The quick study did not allow for much vehicle design. Therefore, the design information was limited to specific impulse, stage/propellant mass fraction, and (for reusable concepts) the number of flights per unit. A simple cost model was developed in Pascal that directly computed the life-cycle cost per flight. (This occurred prior to the development of the more detailed cost model used for the final phase of the AIST study.) Cost-per-flight was divided into five components: DDT\&E, production, resupply, delay, and operations.

The results of the chemical propulsion concept quick study (fig. 3) showed that there were no clear winners or losers; thus the selection of the one or two concepts to be studied in detail was difficult. The first concept selected was the reusable cryogen with a propulsive deboost system. Because it was shown better than the version with the aerobrake, the aerobrake version was not chosen. The second concept selected was the expendable solid propulsion concept. After some discussion, a decision was made to also retain the hybrid expendable concept.

3,000-Ib Payload

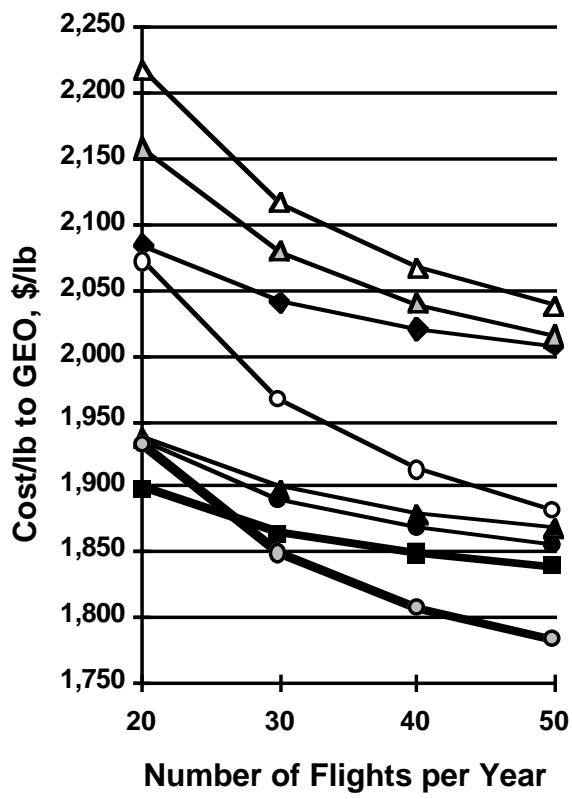

10,000-Ib Payload

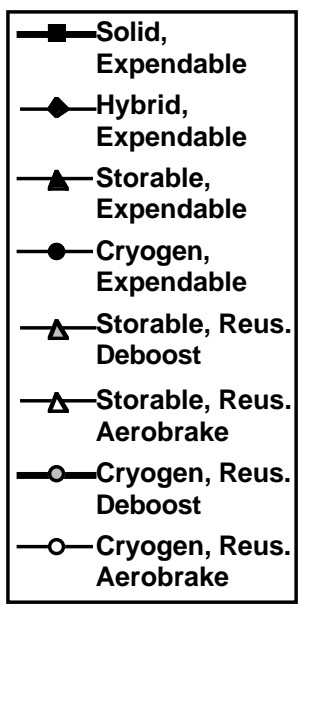

Figure 3. Results of chemical propulsion AIST concept quick study.

\subsection{Tether}

The dynamic tether concept is an extension of small expendable tether technology to a large reusable tether. The tether is deployed by an initial push-off motion of the payload from the support platform, no more than a few meters per second. The mass of the platform is many times that of the payload and tether. Tension on the tether during the deployment is very low so that the payload and unreeling tether continue to move above and aft of the platform until the tether is fully deployed. Since a real simulation of 
the tether system was beyond the scope of the study, and since there are many unanswered questions that can only be answered by detailed analysis and a degree of point design activity, at the present level of understanding the dynamic tether system cannot be considered as a preferred AIST system. A more detailed description and crude analysis of the tether concept are found in appendix E of this report.

\subsection{Concept Selection Results, Final Concepts for Final Study}

Based upon the results of phases 1 and 2, the concepts chosen for a final detailed study are solid (baseline), reusable cryogen, expendable solar thermal, reusable solar electric, reusable nuclear thermal, and expendable hybrids.

\subsection{FINAL CONCEPTS, PHASE 3}

The final concepts for the AIST study consisted of six propulsion types and two payload classes (3,000 and 10,000 lb). The chosen propulsion types are solid (expendable), hybrid (expendable), cryogen (reusable), solar electric (reusable), solar thermal (expendable), and nuclear thermal (reusable). Although no detailed design was performed for the concepts, enough of a design was completed in order to assign preliminary weights and complexity factors. In areas where information was available, designs from previous projects in the MSFC Preliminary Design Office were utilized. The remainder of this section describes similar assumptions made in the cost model for all the concepts.

From an operational standpoint, the payload and ASE are received separately and are integrated with the upper stage according to the flowchart located in appendix F of this report. For expendable versions, only the ASE is refurbished. The stage delivery ASE weight is a fixed 15 percent of the associated total LEO delivery weight for hybrids, solids, solar electric, solar thermal, and nuclear thermal, and a fixed 18 percent for the cryogenic concept.

Some concepts only transfer the payload to GTO using a delta V of $8065 \mathrm{ft} / \mathrm{s}$. For these payloads, an AKM completes the plane change to zero inclination and obtains GEO velocity. The payloads perform the final GEO positioning. The loaded AKM weights are based solely on the associated payload weight according to the methods described in appendix $\mathrm{G}$ of this report. The AIST upper stage arrives at the Kennedy Space Center (KSC) facility as a complete stage with the exception of the payload, kick motor, and if required, liquid propellants. Liquid propellants are loaded while the vehicle is on the launch pad.

Since LEO transportation weight for some of the concepts (e.g., cryo, solar electric 10,000-lb payload, and nuclear thermal) exceed the 25,000-lb carrying capacity of the HRST, it is likely that several HRST launches are required each time a new stage, refuel, or new payload is brought to LEO for these concepts.

For the space-based reusable systems, it is assumed that some form of automated on-orbit assembly, checkout, maintenance, and refuel technology are in existence. It is assumed that any in-space operation is ground controlled and does not require any in-space astronaut interaction. If any problems develop with the upper stage, and if it is desirable to return the stage to Earth, the propellants could be dumped and the upper stage would be returned to Earth by the HRST. (Note: the cost model did not account for such events, which are assumed to be rare.) The replacement parts weight consists of only those upper-stage parts required to be replaced on orbit. In-space refueling and payload replacement takes place by transporting a fuel tank and payload to LEO for each new mission. The refuel tank is the same size as for the upper stage itself, if possible. In some cases (e.g., solar electric), it may be possible that more than one refuel supply launch is required to take place for each new mission. All subsystems required for the refuel tank assembly consist of the same parts as designed for the upper stage. The refuel tank assembly would consist of parts of the upper stage described in detail in appendix $\mathrm{G}$ of this report. 
The life-cycle cost breakdown for the 3,000- and 10,000-lb payloads for all concepts is shown in figure 4. The DDT\&E cost breakdown for the 3,000- and 10,000-lb payloads for all concepts is shown in figure 5. The hardware unit cost per stage breakdown for the 3,000- and 10,000-lb payloads for all concepts are shown in figure 6. The subsystem DDT\&E and the hardware unit cost per stage do not include the system-level wraps (e.g., system test operations, ground support equipment (GSE), SE\&I, and program management). Table 7 describes the cost categories for each figure, along with a description of what type of costs are included in each category. These costs and the following cost discussions in section 7 are based upon a flight rate of 20 per year. Any results that change based upon a flight rate of 50 per year are reflected in section 8 of this report.

Life Cycle Costs for 3,000-Ib Payload

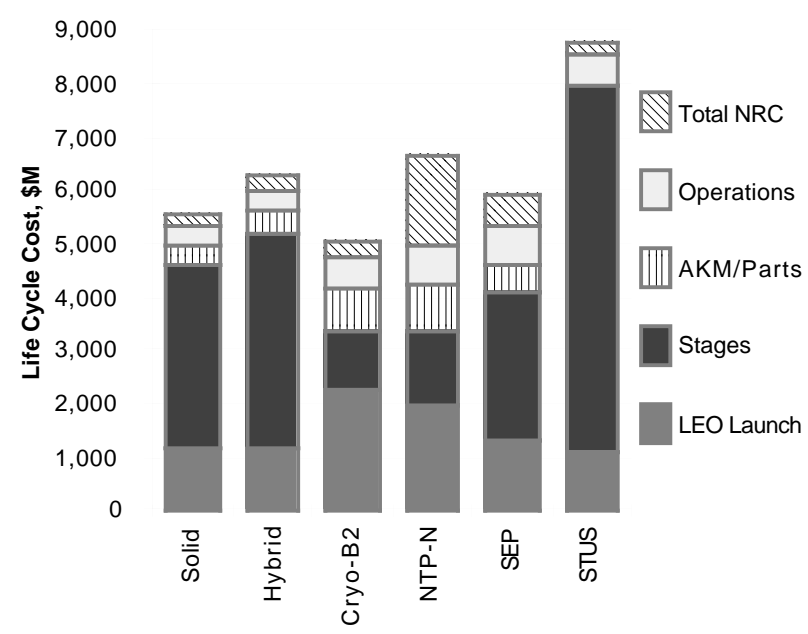

Life Cycle Costs for 10,000-Ib Payload

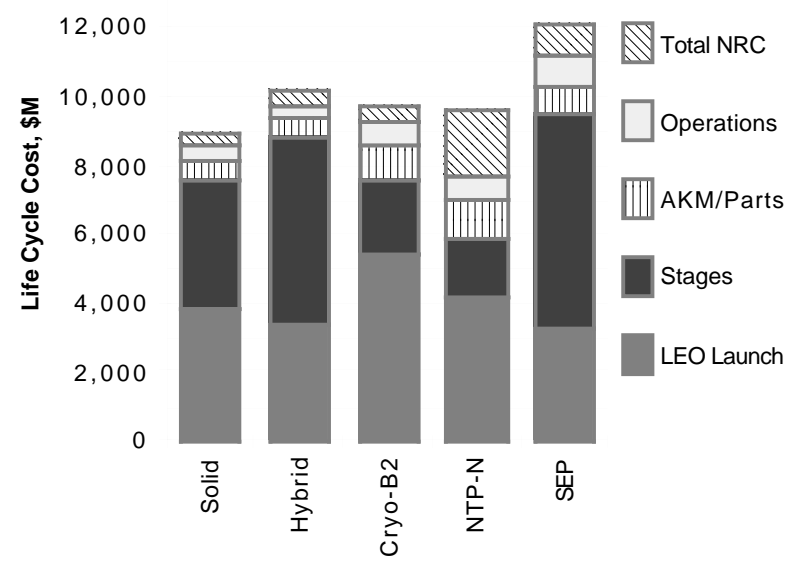

Figure 4. Life-cycle costs.
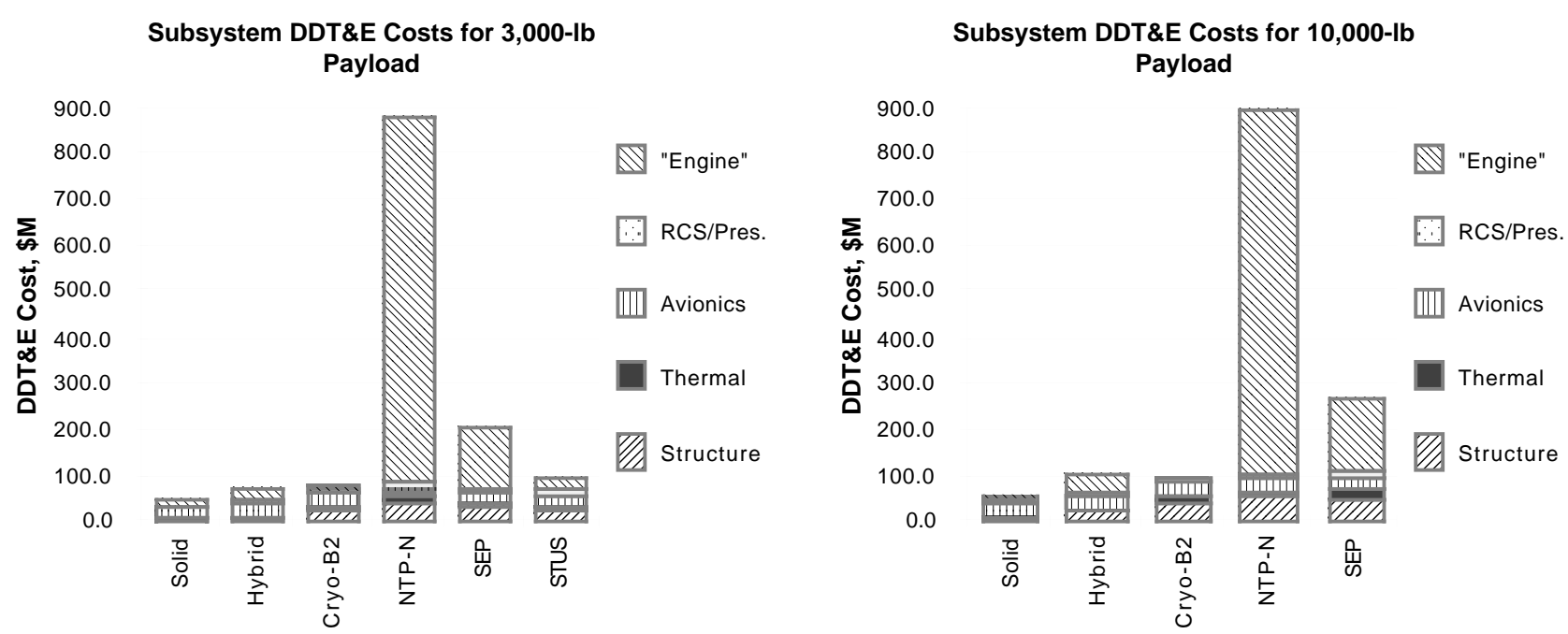

Figure 5. DDT\&E costs. 


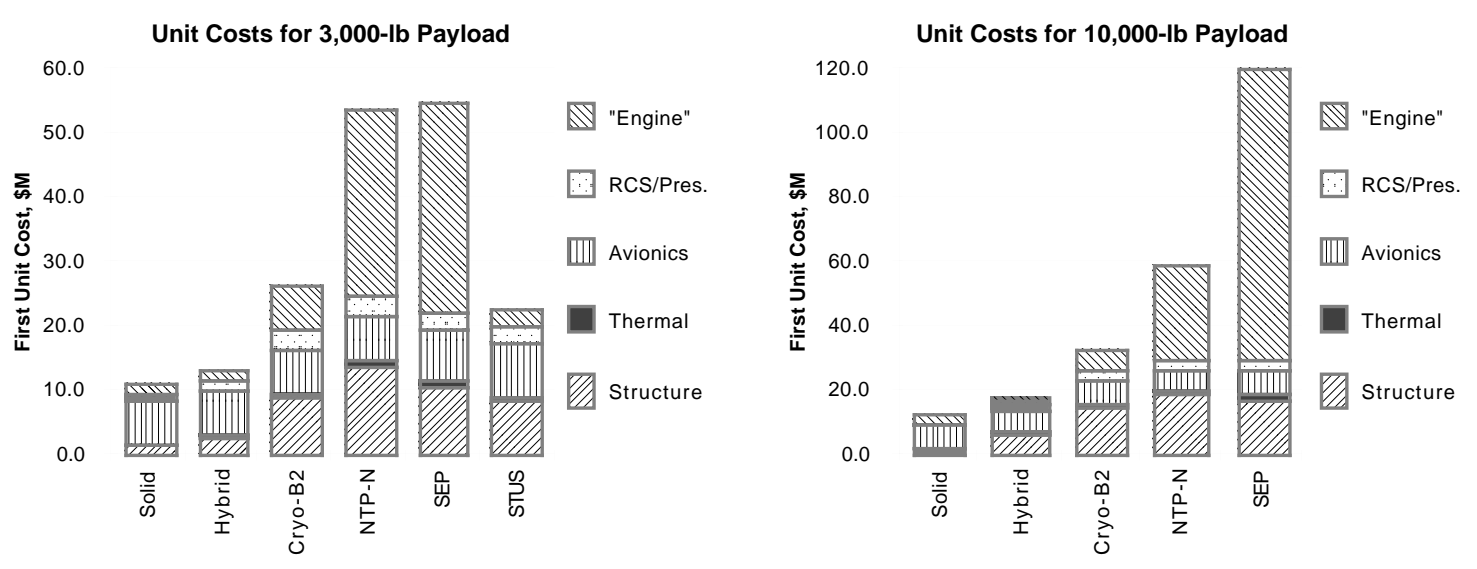

Figure 6. Hardware cost per stage.

Table 7. Cost categories for cost analysis.

\begin{tabular}{|c|c|c|}
\hline Cost & Category & Types of cost \\
\hline \multirow[t]{5}{*}{$\begin{array}{l}\text { Life Cycle - } \\
\text { Figure } 4\end{array}$} & $\begin{array}{l}\text { Total Non- } \\
\text { Recurring } \\
\text { Cost }\end{array}$ & $\begin{array}{l}\text { - Design, development, test and evaluation (DDT\&E) for stages/AKM/ASE } \\
\text { - Total ASE production (includes costs for sys. test ops., GSE, SE\&I, Program mngmnt., etc..) } \\
\text { - Total refuel tank production (if required) } \\
\text { Facility non-recurring }\end{array}$ \\
\hline & Operations & $\begin{array}{l}\text { Total operations labor } \\
\text { - Total facility maintenance } \\
\text { - Total raw propellant }\end{array}$ \\
\hline & AKM/parts & $\begin{array}{l}\text { - Total AKM production (includes costs for sys. test ops., GSE, SE\&I, Program mngmnt., etc..) } \\
\text { - Total replacement parts/spares (includes costs for sys. test ops., GSE, SE\&I, Program mngmnt., etc..) }\end{array}$ \\
\hline & Stages & $\begin{array}{l}\text { - Total stage production (no AKM or ASE production included) (includes costs for sys. test ops., GSE, } \\
\text { SE\&I, Program mngmnt., etc..) }\end{array}$ \\
\hline & $\begin{array}{l}\text { LEO } \\
\text { Launch }\end{array}$ & $\cdot$ Total LEO transportation \\
\hline \multirow[t]{5}{*}{$\begin{array}{l}\text { DDT\&E } \\
\text { (subsystems) * } \\
\text { Figure } 5\end{array}$} & Engine & $\begin{array}{l}\text { - SRMs } \\
\text { - Liquid rocket engines } \\
\text { - Electric propulsion engine } \\
\text { - Advanced solar arrays } \\
\text { - Absorber/gimbal } \\
\text { - Collector/Optics/Mechanism } \\
\text { - Nuclear rocket engine } \\
\end{array}$ \\
\hline & RCS/press. & $\begin{array}{l}- \text { Reaction control subsystem } \\
- \text { Propulsion subsystem } \\
\end{array}$ \\
\hline & Avionics & $\begin{array}{l}- \text { Power } \\
- \text { C\&DH } \\
- \text { GN\&C }\end{array}$ \\
\hline & Thermal & $\begin{array}{l}- \text { Thermal control, passive } \\
\text { - Thermal control, active }\end{array}$ \\
\hline & Structure & $\begin{array}{l}- \text { Structures } \\
- \text { Mechanisms } \\
\end{array}$ \\
\hline \multirow[t]{5}{*}{$\begin{array}{l}\text { Hardware Cost } \\
\text { per Stage } \\
\text { (subsystems) } * *_{-} \\
\text {Figure } 6\end{array}$} & Engine & $\begin{array}{l}\text { - SRMs } \\
\text { - Liquid rocket engines } \\
\text { - Electric propulsion engine } \\
\text { - Advanced solar arrays } \\
\text { - Absorber/gimbal } \\
\text { - Collector/Optics/Mechanism } \\
\text { - Nuclear rocket engine }\end{array}$ \\
\hline & RCS/press. & $\begin{array}{l}\text { - Reaction control subsystem } \\
\text { - Propulsion subsystem }\end{array}$ \\
\hline & Avionics & $\begin{array}{l}- \text { Power } \\
- \text { C\&DH } \\
\cdot \text { GN\&C }\end{array}$ \\
\hline & Thermal & $\begin{array}{l}- \text { Thermal control, passive } \\
\text { - Thermal control, active } \\
\end{array}$ \\
\hline & Structure & $\begin{array}{l}- \text { Structures } \\
\text { - Mechanisms } \\
\end{array}$ \\
\hline
\end{tabular}

* The DDT\&E cost does not include system test operations, GSE, SE\&I, program management, and production learning curve

** The hardware cost per stage represents the cost to produce one stage without the ASE, kick-motor, system test operations, GSE, SE\&I, program management, and production learning curve 
The subsequent sections will discuss cost analysis and recommendations for each concept. The pie charts show a breakout for the life-cycle cost and the cost per stage, or unit cost. Each of these costs include system test operations, GSE, SE\&I, and program management. Additional assumptions applicable to most of the concepts can be found in appendix $\mathrm{F}$ of this report. The integration process flowcharts for the concepts are located in appendix G.

\subsection{Solid Propulsion Concepts}

\subsubsection{Concept Description}

This expendable upper stage concept uses an SRM for main propulsion and is a high-thrust system. A sketch of the concept is shown in figure 7 and weight tables are given in tables 8 and 9.

A delta $\mathrm{V}$ minimizing time for delivery was calculated, and useable propellant and stage weights were determined. The SRM propellant was assumed to be HTBP-based and consisted of a single inertial upper stage (IUS)/Orbus-class SRM casing, nozzle, and igniter. The SRM Isp was assumed to be $290 \mathrm{~s}$ (similar to a STAR 48). A program called "UpStart" (developed at MSFC) was used to estimate the structural weights, where all metal components were assumed to be aluminum 2219 . The passive thermal subsystem assumed a slightly more advanced material than what is in use on the IUS motor today. The RCS, mechanisms, GN\&C, C\&DH, and power subsystems are the same as the cryo concept described in section 7.3.

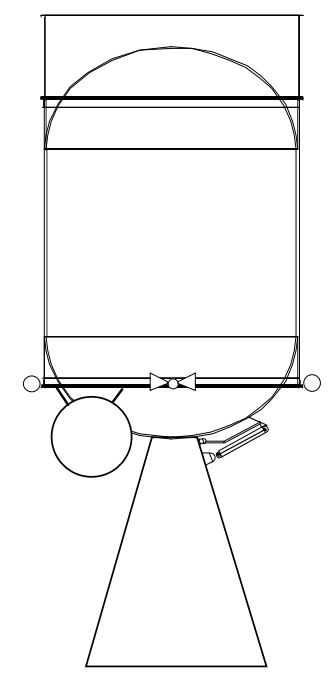

Figure 7. Expendable solid concept.

Table 8. Overall weight statement for expendable solid concepts.

\begin{tabular}{|l|c|c|}
\hline \multicolumn{1}{|c|}{ AIST Concept } & \multicolumn{2}{c|}{ Weight, lbm } \\
Weight Category & $3,000-1 \mathrm{~b}$ payload & $10,000-\mathrm{lb}$ payload \\
\hline Loaded AKM Weight & 2,856 & 9,520 \\
\hline Upper Stage Inert Weight & 1,299 & 1,638 \\
\hline Upper Stage Propellant Weight & 5,175 & 18,687 \\
\hline Total LEO Delivery Weight & 12,330 & 39,845 \\
\hline Stage Delivery ASE Weight & 1,850 & 5,977 \\
\hline Total LEO Transport Weight & 14,180 & 45,822 \\
\hline
\end{tabular}


Table 9. Inert weight statement for expendable solid concepts.

\begin{tabular}{|l|c|c|}
\hline \multicolumn{1}{|c|}{$\begin{array}{c}\text { Upper Stage } \\
\text { Subsystem }\end{array}$} & \multicolumn{2}{c|}{ Inert Weight, lbm } \\
3,000-lb payload & $10,000-\mathrm{lb}$ payload \\
\hline Structures & 169 & 263 \\
\hline Mechanisms & 34 & 112 \\
\hline Passive Thermal Control & 53 & 118 \\
\hline Electric Power & 316 & 316 \\
\hline C\&DH & 175 & 175 \\
\hline GN\&C & 183 & 183 \\
\hline Reaction Control Subsystem & 245 & 267 \\
\hline SRM's & 124 & 204 \\
\hline Total Upper Stage Inert Weight & 1,299 & 1,638 \\
\hline
\end{tabular}

\subsubsection{Concept Mission Profile}

The SRM stage carries a payload with an AKM. The solid stage delivers the payload plus AKM from LEO to GTO. The AKM fires at apogee to complete GEO insertion. The stage will contain enough propellant to de-orbit itself from GTO and become consumed in the atmosphere. The total trip time for the stage from LEO to GTO and de-orbit is approximately $10.5 \mathrm{~h}$.

\subsubsection{Concept Cost Analysis and Recommendations}

Distributions of cost for the 3,000-lb payload are shown in figure 8. The predominant factor affecting life-cycle cost for the 3,000-lb payload is the stage production cost. It is more than half the total life-cycle cost. LEO launch is the second major cost contributor; the other costs are relatively unimportant, and the nonrecurring (which includes DDT\&E) is the least important. The greatest hardware cost item is GN\&C, estimated at \$5.5 million for the first unit. The SRM itself and the AKM are mature technology and probably cannot be reduced significantly. The life-cycle cost distribution for the 10,000-lb payload is very similar to that for the 3,000-lb payload except that the relative contribution of avionics is about half as great. This is because avionics does not increase in size of cost as the system becomes larger.

\section{Distribution of Life Cycle Cost}

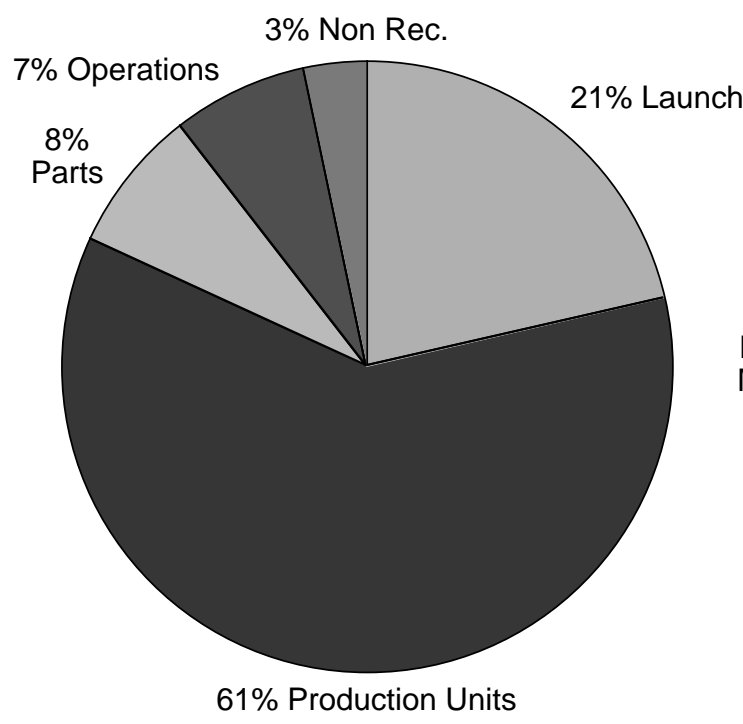

Total $\$ 5,571 \mathrm{M}=\$ 4642 / \mathrm{lb}$

\section{Distribution of Unit Cost}

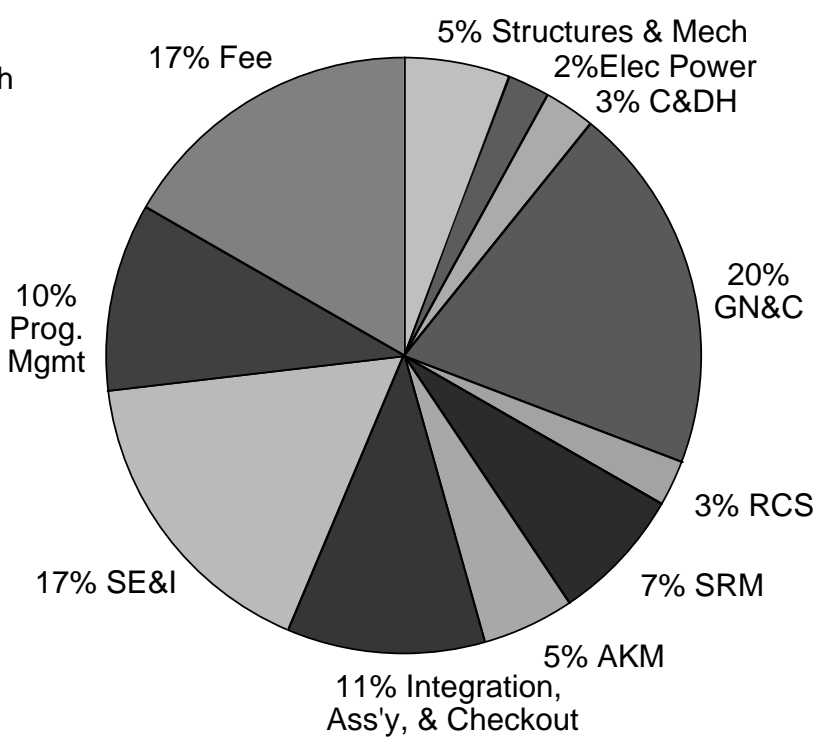

Figure 8. Cost distributions for the SRM 3,000-lb payload. 
Dominance of the stage production cost can be attributed to the number of stages necessary to fulfill the flight demand. Because this concept is expendable, 422 stages are expected to be manufactured (20 flights per year for 20 years plus additional "contingency" stages for a 3,000-lb payload). A detailed cost analysis breakdown can be found in appendix $\mathbf{J}$ of this report.

\subsection{Hybrid Propulsion Concepts}

\subsubsection{Concept Description}

This expendable upper stage concept uses a hybrid rocket motor for main propulsion and is a highthrust system. A sketch of the concept is shown in figure 9 and weight tables in tables 10 and 11.

A delta $\mathrm{V}$ minimizing time for delivery was calculated, and useable propellant and stage weights were determined. Using a previous study completed in the MSFC propulsion lab, ${ }^{23}$ weights were determined using the same configuration with modifications where appropriate. The SRM fuel was HTBPbased, and the oxidizer (which is pump fed) was lox. The Isp was assumed to be approximately $319 \mathrm{~s}$. "UpStart" was used to check the structural weights, where all metal components were assumed to be aluminum 2219. The passive thermal subsystem assumed a highly advanced material for the solid motor portion and was the same as the cryo concept for the lox tank. The reaction control system (RCS), mechanisms, GN\&C, C\&DH, and power subsystems are the same as the cryo concept.

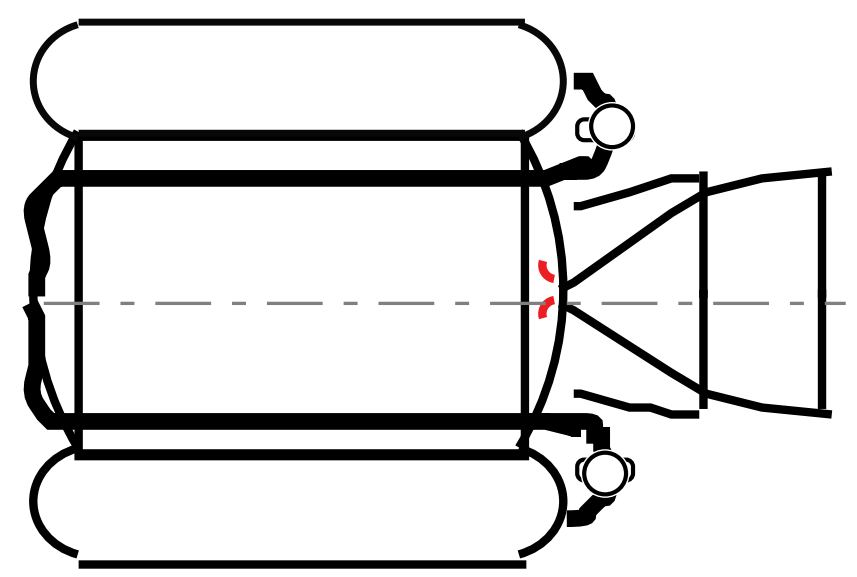

Figure 9. Expendable hybrid concept.

Table 10. Overall weight statement for expendable hybrid concepts.

\begin{tabular}{|l|c|c|}
\hline \multicolumn{1}{|c|}{ AIST Concept } & \multicolumn{2}{c|}{ Weight, lbm } \\
Weight Category & $3,000-1 \mathrm{~b}$ payload & $10,000-1 \mathrm{~b}$ payload \\
\hline Loaded AKM Weight & 2,856 & 9,520 \\
\hline Upper Stage Inert Weight & 1,709 & 3,037 \\
\hline Upper Stage Fuel Weight & 1,585 & 5,480 \\
\hline Upper Stage Oxidizer Weight & 3,015 & 7,447 \\
\hline Total LEO Delivery Weight & 12,165 & 35,484 \\
\hline Stage Delivery ASE Weight & 1,825 & 5,323 \\
\hline Total LEO Transport Weight & 13,990 & 40,807 \\
\hline
\end{tabular}


Table 11. Inert weight statement for expendable hybrid concepts.

\begin{tabular}{|l|c|c|}
\hline \multicolumn{1}{|c|}{$\begin{array}{c}\text { Upper Stage } \\
\text { Subsystem }\end{array}$} & \multicolumn{2}{c|}{ Inert Weight, lbm } \\
& $3,000-1 \mathrm{~b}$ payload & $10,000-\mathrm{lb}$ payload \\
\hline Structures & 477 & 1,439 \\
\hline Mechanisms & 34 & 112 \\
\hline Passive Thermal Control & 18 & 58 \\
\hline Electric Power & 316 & 316 \\
\hline C\&DH & 175 & 175 \\
\hline GN\&C & 182 & 182 \\
\hline Reaction Control Subsystem & 245 & 267 \\
\hline Propulsion Subsystem & 104 & 104 \\
\hline SRM's & 158 & 384 \\
\hline Total Upper Stage Inert Weight & 1,709 & 3,037 \\
\hline
\end{tabular}

\subsubsection{Concept Mission Profile}

The hybrid rocket motor stage carries a payload with an AKM. The hybrid stage delivers the payload and AKM from LEO to GTO. The AKM fires at apogee to complete GEO insertion. The stage will contain enough propellant to de-orbit the stage from GTO and become consumed in the atmosphere. The total trip time for the stage from LEO to GTO and de-orbit is approximately $10.5 \mathrm{~h}$.

\subsubsection{Concept Cost Analysis and Recommendations}

Distributions of cost for the 3,000-lb payload are shown in figure 10. The predominant factor affecting life-cycle cost for the 3,000-lb payload is the stage production cost. It is more than half the total cost. LEO launch is the second major cost contributor; the other costs are relatively unimportant and nonrecurring (which includes DDT\&E, the least important). The greatest hardware cost item is GN\&C, estimated as $\$ 5.5$ million for the first unit. Some cost reduction in structures cost could be obtained through careful design-to-cost. The AKM is mature technology and probably cannot be reduced significantly. The life-cycle cost distribution for the $10,000-1 b$ payload is very similar to that for the 3,000-lb payload except that the relative contribution of avionics is about half as great. This is because avionics does not increase in size of cost as the system becomes larger.

\section{Distribution of Life Cycle Cost}

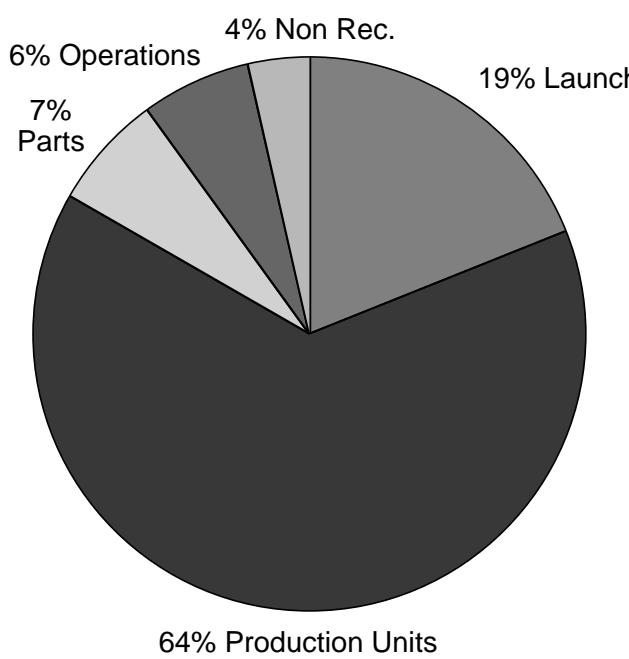

Total $\$ 6,257 \mathrm{M}=\$ 5,214 / \mathrm{lb}$

\section{Distribution of Unit Cost}

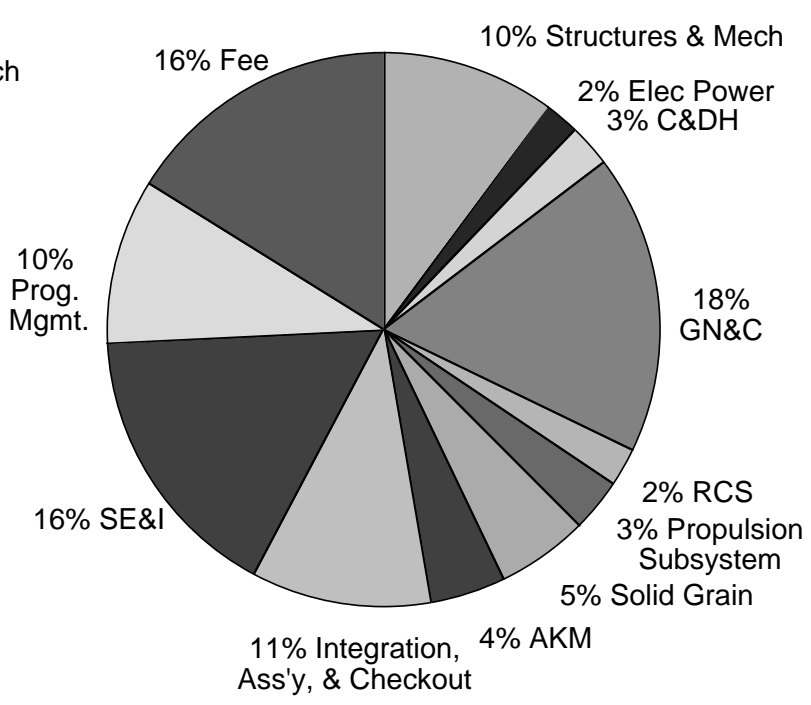

Figure 10. Cost distributions for the hybrid motor 3,000-lb payload. 
Dominance of the stage production cost can be attributed to the number of stages necessary to fulfill the flight demand. Because this concept is expendable, 422 stages are expected to be manufactured (20 flights per year for 20 years plus additional "contingency" stages for a 3,000-lb payload). A detailed cost analysis breakdown can be found in appendix $\mathrm{J}$ of this report.

\subsection{Cryogen Propulsion Concepts}

\subsubsection{Concept Description}

This ground-based reusable upper stage concept used a Pratt \& Whitney RL10-B2 liquid rocket engine for main propulsion and is a high-thrust system. The operating time of the engine is 3,600 s, thus, limiting the life of the stage to 14 missions for the 3,000-lb payload stage and 7 for the 10,000-lb stage. Even though it is possible to replace the engine rather than scrap the stage after the engine life, the stage life was limited to the engine life for this cost model. A sketch of the concept is shown in figure 11 and weight tables are given in tables 12 and 13 .

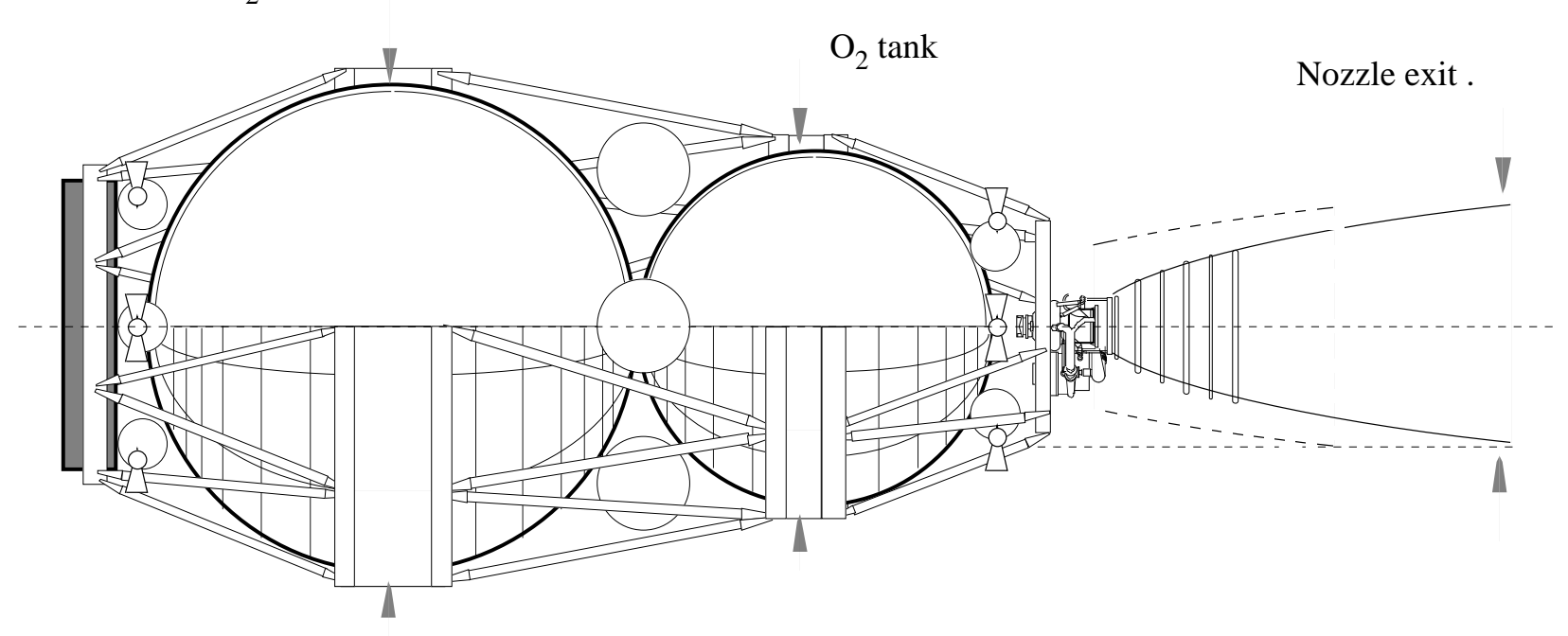

Figure 11. Reusable cryogenic concept.

Table 12. Overall weight statement for reusable cryogen concepts.

\begin{tabular}{|l|c|c|}
\hline \multicolumn{1}{|c|}{ AIST Concept } & \multicolumn{2}{c|}{ Weight, lbm } \\
Weight Category & $3,000-1 \mathrm{~b}$ payload & $10,000-1 \mathrm{~b}$ payload \\
\hline Loaded AKM Weight & 2,856 & 9,520 \\
\hline Upper Stage Inert Weight & 3,771 & 6,064 \\
\hline Upper Stage Fuel Weight & 1,918 & 4,125 \\
\hline Upper Stage Oxidizer Weight & 11,466 & 24,707 \\
\hline Total LEO Delivery Weight & 23,011 & 54,416 \\
\hline Stage Delivery ASE Weight & 4,142 & 9,795 \\
\hline Total LEO Transport Weight & 27,153 & 64,211 \\
\hline
\end{tabular}


Table 13. Inert weight statement for reusable cryogen concepts.

\begin{tabular}{|l|r|r|}
\hline \multicolumn{1}{|c|}{$\begin{array}{c}\text { Upper Stage } \\
\text { Subsystem }\end{array}$} & \multicolumn{2}{c|}{ Inert Weight, lbm } \\
& $3,000-1 \mathrm{~b}$ payload & $10,000-1 \mathrm{~b}$ payload \\
\hline Structures & 1,847 & 3,898 \\
\hline Mechanisms & 34 & 112 \\
\hline Passive Thermal Control & 219 & 364 \\
\hline Electric Power & 426 & 426 \\
\hline C\&DH & 183 & 183 \\
\hline GN\&C & 160 & 160 \\
\hline Reaction Control Subsystem & 213 & 232 \\
\hline Propulsion Subsystem & 180 & 180 \\
\hline Liquid Rocket Engines & 509 & 509 \\
\hline Total Upper Stage Inert Weight & 3,771 & 6,064 \\
\hline
\end{tabular}

The liquid rocket engine includes an RL10-B2 rocket engine (assumed to be available off-the-shelf by the year 2005, with an Isp of 466 s), nozzle, and turbopumps for the liquid fuel (hydrogen) and oxidizer (oxygen). The propulsion subsystem includes a propellant tank pressurization (helium) system; plumbing between the engine, the fuel and oxidizer tanks, and the pressurization system; plus associated flow regulation equipment. The RCS uses 16 small 2-lbf thrusters linked to a set of liquid bipropellant (NTO/MMH) tanks, a propellant tank pressurization (helium) system, plus associated plumbing, and flow regulation equipment. The structures subsystem includes a payload adapter, thrust structure, a lowpressure fuel tank, a low-pressure oxidizer tank, tank support structure, and scar weight associated with reusability. The mechanisms subsystem is a payload/AKM release device. The passive thermal control subsystem consists of MLI-type blanket insulation for the fuel and oxidizer tanks. The GN\&C subsystem includes two Global Positioning System (GPS) receivers with inertial navigation unit, two-axis Sun sensors with electronics, conical Earth sensors with electronics, two control electronics, two guidance and control processors, and interconnect cabling. The C\&DH subsystem includes a command/telemetry transponder, a pulse code modulator (PCM) encoder/decoder, a 1553 interface for PCM encoder/decoder, a radio frequency $(\mathrm{RF})$ power amplifier, signal conditioning boards, command processor, and interconnect cabling. The electric power subsystem uses lithium batteries. Because the reusable cryogen concept is ground-based, the replacement part percentage is higher than for the space-based reusable nuclear thermal and solar electric concepts.

\subsubsection{Concept Mission Profile}

The cryogenic stage carries a payload with an AKM. The cryogenic stage delivers the payload and its AKM from LEO to GTO. The AKM fires at apogee to complete GEO insertion. When the cryo stage completes one full orbit in GTO, it fires its cryogenic engine and shifts the orbit from GTO to a lower, intermediate orbit with a perigee of $100 \mathrm{nmi}$ and an apogee of 3,686 nmi. Here the cryo will have a 2.7-h period (one orbit pass), after which the cryo will again fire its engines to change orbit to where it will rendezvous with the HRST at LEO. (In the total $13.2 \mathrm{~h}$, the HRST would perform nine complete orbits during the upper stage's two transfer orbit passes.) A small plane change maneuver is required during the return transfer from GTO to LEO to correct for differential nodal regression. Once in LEO, the upper stage uses an additional delta V of $330 \mathrm{ft} / \mathrm{s}$ to rendezvous with the HRST, be captured by the HRST, and return to Earth for refurbishment. The total trip time for the stage from LEO to GTO and back to LEO, including phasing and rendezvous, is approximately $15 \mathrm{~h}$.

\subsubsection{Concept Cost Analysis and Recommendations}

Distributions of cost for a 3,000-lb payload are shown in figure 12. The predominant factor (almost 50 percent) affecting life-cycle cost for this system is transportation to LEO. This occurs because the system is reusable and the significance of production cost is, therefore, reduced. Only 42 stages are expected to be manufactured (to cover 20 flights per year for 20 years plus additional "contingency" stages for a 3,000-lb payload). 


\section{Distribution of Life Cycle Cost}

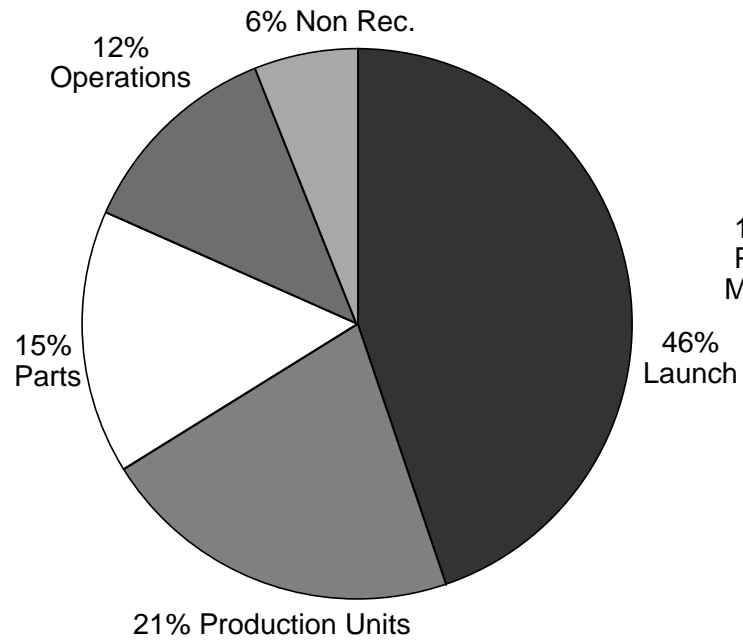

Total $\$ 5,109 \mathrm{M}=\$ 4,258 / \mathrm{lb}$

\section{Distribution of Unit Cost}

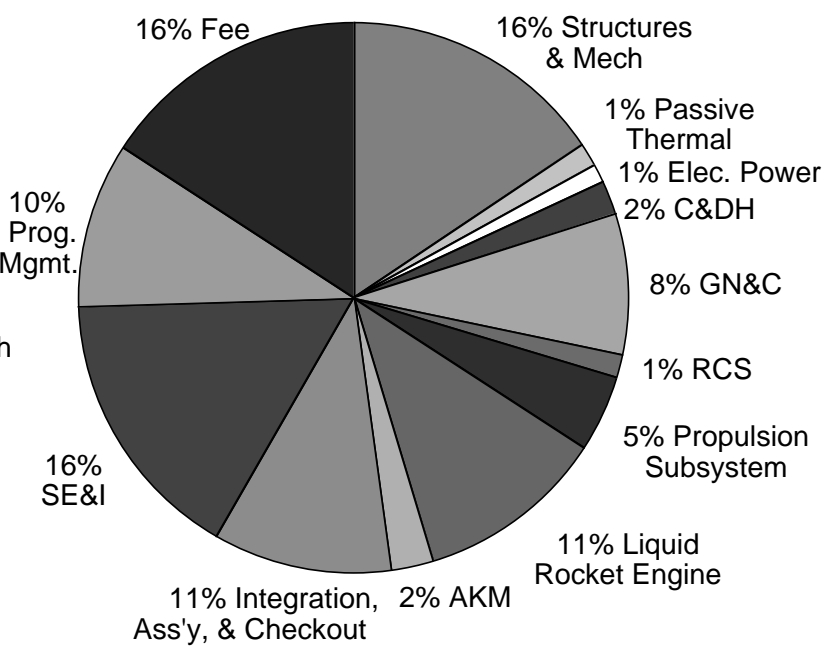

Figure 12. Cost distributions for the cryogenic engine 3,000-lb payload.

Reusability increases the inert weight and, therefore, delivery mass, mainly because the stage must return to LEO. Stage production costs are the next most significant after LEO delivery cost. The stage dry weight is twice that of the hybrid and about three times that of the solid. The predominant factors affecting stage hardware weight are structures and GN\&C; the engine is a significant contributor to unit cost but is assumed available and not a contributor to the nonrecurring cost (which includes DDT\&E). The ASE is the largest contributor to the nonrecurring cost. The predominant factors affecting life-cycle cost for the 10,000-lb payload are the same as for the 3,000-lb payload except that the importance of avionics is reduced, since avionics does not increase in size and cost for the larger payload. The same engine is used for the greater payload. A detailed cost analysis breakdown can be found in appendix $\mathrm{J}$ of this report.

\subsection{Solar Electric Propulsion Concepts}

\subsubsection{Concept Description}

This space-based, reusable upper-stage concept uses a solar electric rocket engine for main propulsion and is a low-thrust system. Since the operable life of the engine was assumed to exceed that of the solar arrays (the arrays may degrade severely due to repeated exposure to the Van Allen Belts), this concept is limited to a total of 10 flights ( 9 reuses). A sketch of the concept is shown in figure 13 and weight summaries are given in tables 14 and 15. Additionally, tables 16 and 17 show the weight statement for the refuel tank and the fuel and payload resupply mission. The solar array power subsystem was posed as an advanced-technology system since trades early in the study showed that current technology solar electric propulsion has no chance of approaching the study cost goals. Appendix H contains some additional information on the technology capabilities of the solar electric system.

The electric propulsion engine subsystem consists of one or more advanced electrothermal or arcjet-type thrusters. The engine, operating at an Isp of 1,500 s (the fuel is liquid hydrazine or highpressure xenon), would have a maximum thrust of about $0.9 \mathrm{lb}$ for the 3,000-lb payload version, and $2.5 \mathrm{lb}$ for the $10,000-\mathrm{lb}$ payload version. The propulsion subsystem consists of plumbing between the engine and the fuel tank, plus associated flow regulation equipment. The mechanisms subsystem consists of a payload release device and a solar array deployment mechanism. The active thermal control subsystem consists of a single-phase fluid system with redundant pumps and a set of heat-pipe radiators. The RCS, structures, GN\&C, C\&DH, and power systems are the same as the cryo system. The advanced solar array 
subsystem consists of multiple arrays of thin gallium-arsenide-based (perhaps dual band gap) solar cells on a substrate backing, plus the associated framework and electrical wiring. Although current arrays deliver a unit power of 60 to $80 \mathrm{~W} / \mathrm{kg}$, an array of $178 \mathrm{~W} / \mathrm{kg}$ is assumed for this study. The arrays would have a maximum power output of $50.7 \mathrm{~kW}$ for the $3,000-\mathrm{lb}$ payload version, and $138.2 \mathrm{~kW}$ for the 10,000-lb payload version.

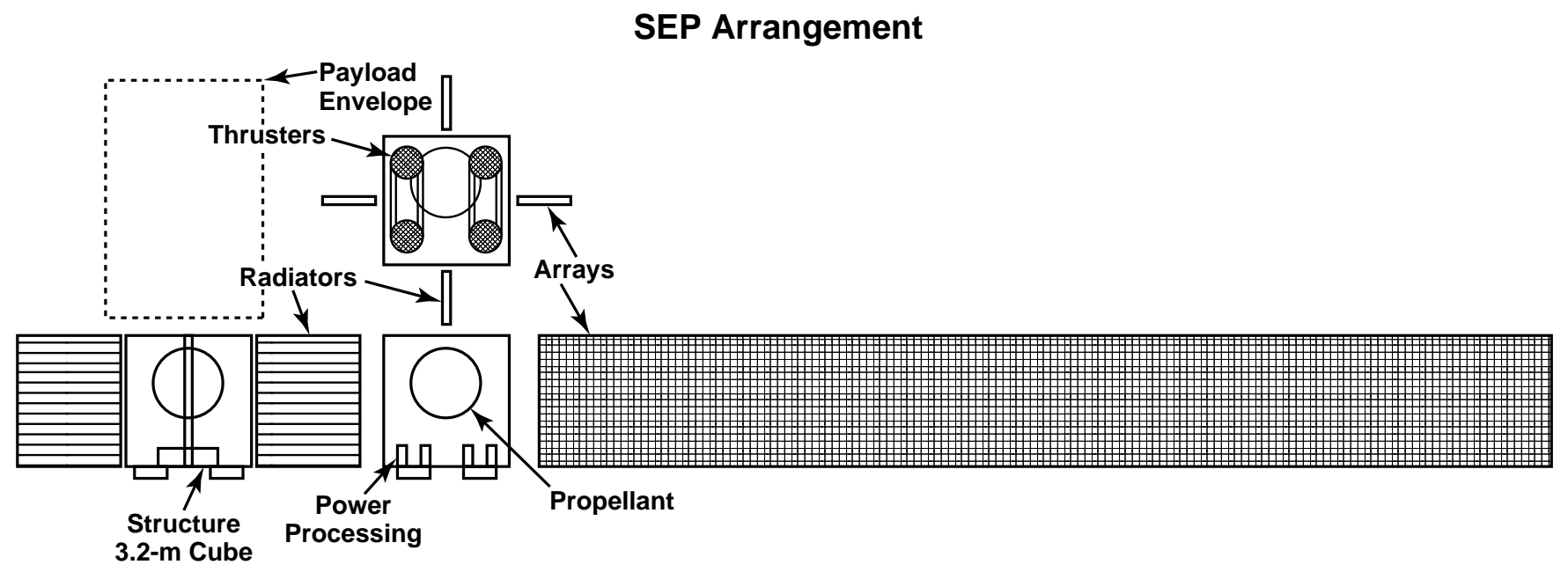

Figure 13. Reusable solar electric concept.

Table 14. Overall weight statement for reusable solar electric concepts.

\begin{tabular}{|l|c|c|}
\hline \multicolumn{1}{|c|}{ AIST Concept } & \multicolumn{2}{|c|}{ Weight, lbm } \\
Weight Category & $3,000-1 \mathrm{~b}$ payload & $10,000-\mathrm{lb}$ payload \\
\hline Upper Stage Inert Weight & 5,202 & 11,019 \\
\hline Upper Stage Fuel Weight & 8,130 & 18,565 \\
\hline Total LEO Delivery Weight & 16,332 & 39,584 \\
\hline Stage Delivery ASE Weight & 2,450 & 5,938 \\
\hline Total LEO Transport Weight & 18,782 & 45,522 \\
\hline
\end{tabular}

Table 15. Inert weight statement for reusable solar electric concepts.

\begin{tabular}{|l|r|r|}
\hline \multirow{2}{*}{ Upper Stage } & \multicolumn{2}{c|}{ Inert Weight, lbm } \\
Subsystem & $3,000-1 b$ payload & $10,000-1 \mathrm{~b}$ payload \\
\hline Structures & 2,574 & 5,169 \\
\hline Mechanisms & 29 & 83 \\
\hline Active Thermal Control & 269 & 733 \\
\hline Electric Power & 275 & 275 \\
\hline C\&DH & 183 & 183 \\
\hline GN\&C & 224 & 224 \\
\hline Reaction Control Subsystem & 255 & 465 \\
\hline Propulsion Subsystem & 93 & 233 \\
\hline Electric Propulsion Engine & 681 & 1,875 \\
\hline Advanced Solar Arrays & 619 & 1,779 \\
\hline Total Upper Stage Inert Weight & 5,202 & 11,019 \\
\hline
\end{tabular}


Table 16. Inert weight statement for solar electric concept refuel tank.

\begin{tabular}{|l|r|r|}
\hline \multicolumn{1}{|c|}{$\begin{array}{c}\text { Refuel Tank Assembly } \\
\text { Subsystem }\end{array}$} & \multicolumn{2}{c|}{ Inert Weight, lbm } \\
\hline Structures & 1,930 & $4,000-1 b$ payload \\
\hline Mechanisms & 29 & 83 \\
\hline Propulsion Subsystem & 93 & 233 \\
\hline Total Refuel Tank Inert Weight & 2,052 & 4,823 \\
\hline
\end{tabular}

Table 17. Overall weight statement for solar electric concept resupply.

\begin{tabular}{|l|c|c|}
\hline \multicolumn{1}{|c|}{ AIST Concept } & \multicolumn{2}{c|}{ Weight, lbm } \\
Weight Category & $3,000-1 \mathrm{~b}$ payload & $10,000-1 \mathrm{~b}$ payload \\
\hline Refuel Tank Inert Weight & 2,052 & 4,823 \\
\hline Resupply Fuel Weight & 8,130 & 18,565 \\
\hline Replacement Parts Weight & 114 & 232 \\
\hline Total LEO Delivery Weight & 13,296 & 33,620 \\
\hline Refuel Delivery ASE Weight & 1,995 & 5,044 \\
\hline Total LEO Transport Weight & 15,291 & 38,664 \\
\hline
\end{tabular}

\subsubsection{Concept Mission Profile}

The solar electric stage delivers the customer payload to GEO without an AKM. Once delivered to LEO, the stage orients its solar arrays to maximize power production and successfully demonstrates its engine's ability to generate thrust. If a problem develops with the upper stage, the solar panels could be either retracted or ejected, and the upper stage could then be returned to Earth by the HRST. (Note: the cost model did not account for such events, which were assumed to be rare.) The upper stage fires its solar electric engine and slowly shifts the orbit from LEO to GEO, using a low-thrust spiral-with-plane-change transfer maneuver. At low altitudes, its RCS subsystem may be used to compensate for atmospheric drag if Earth's upper atmosphere is expanded due to high solar activity. The one-way delta V is estimated at $19,030 \mathrm{ft} / \mathrm{s}$. For the 3,000-lb payload concept, the required burn time is estimated at 82.2 days (during 109.6 days); for the 10,000-lb concept, 79.2 days (during 105.6 days). Burn time is less than transit time because of time spent in Earth's shadow.

Following payload separation, the upper stage fires its solar electric engine and slowly shifts the orbit from GEO back to LEO, using a low-thrust reverse-spiral-with-plane-change transfer maneuver requiring the same delta V, 19,030 ft/s. For the 3,000-lb payload concept, the required burn time is estimated at 36.7 days (during 48.9 days); for the 10,000-lb concept, 30.5 days (during 40.7 days). Once in LEO, the upper stage reorients its solar arrays to minimize atmospheric drag and the upper stage enters a sleep mode orbiting the Earth until rendezvous with the next HRST vehicle for refuel and payload attachment. The upper stage uses its RCS subsystem to rendezvous with the arriving HRST launch vehicle. For the last mission (e.g., 10th use) the upper stage reorients its solar arrays upon return to LEO to maximize atmospheric drag, and speed its reentry into the Earth's atmosphere. Additionally, the RCS subsystem may be used to tumble the stage to facilitate complete atmosphere burnup.

\subsubsection{Concept Cost Analysis and Recommendations}

Distributions of cost for the 3,000-lb payload are shown in figure 14. The cost distribution for the 10,000-lb payload is similar. The predominant factor affecting life-cycle cost for the SEP is the stage (production) cost - nearly 50 percent of total life-cycle cost. Although the system is reusable, production units are expensive. The number of stages manufactured is 53 for the 3,000-lb payload (to cover 20 flights per year for 20 years plus additional contingency units). The first unit cost for this system is 60 percent more than for the cryogenic system and three times that of the solid and hybrid systems. The cost distribution is similar to the solid and hybrid expendable systems, except that operations and nonrecurring are more important. The predominant factor affecting unit costs is the electric propulsion subsystem, which accounts for half the first unit cost. The main contributor to propulsion subsystem cost is the solar arrays. 
This occurs even though the solar arrays were estimated at $\$ 600 / \mathrm{W}$, based on the large production quantity compared to historical space array production.

The SEP as estimated in this study did not exhibit economies of scale as strongly as the other systems. It shows only modest cost-per-pound reduction at 10,000 lb of payload and is the most expensive of the five systems estimated (solar thermal propulsion was not estimated for the larger payload). This occurs because costs are dominated by solar arrays and array cost estimates per unit power were not reduced for the larger system. Trades early in the study indicated that solar array unit mass and cost would need to be about $200 \mathrm{~W} / \mathrm{kg}$ and $\$ 600 / \mathrm{W}$, respectively, for SEP to be roughly competitive with alternatives. Those predictions were borne out by these later results.

Because a design was not produced, a relatively large allocation was made for stage structural weight. Structures are approximately half the total dry weight estimate, thus any savings in structural weight would have an effect on the overall cost of the stage (and launch costs). However, it is difficult to compare such a very advanced SEP system with the other concepts discussed in this report. A detailed cost analysis breakdown can be found in appendix $\mathbf{J}$ of this report.

\section{Distribution of Life Cycle Cost}

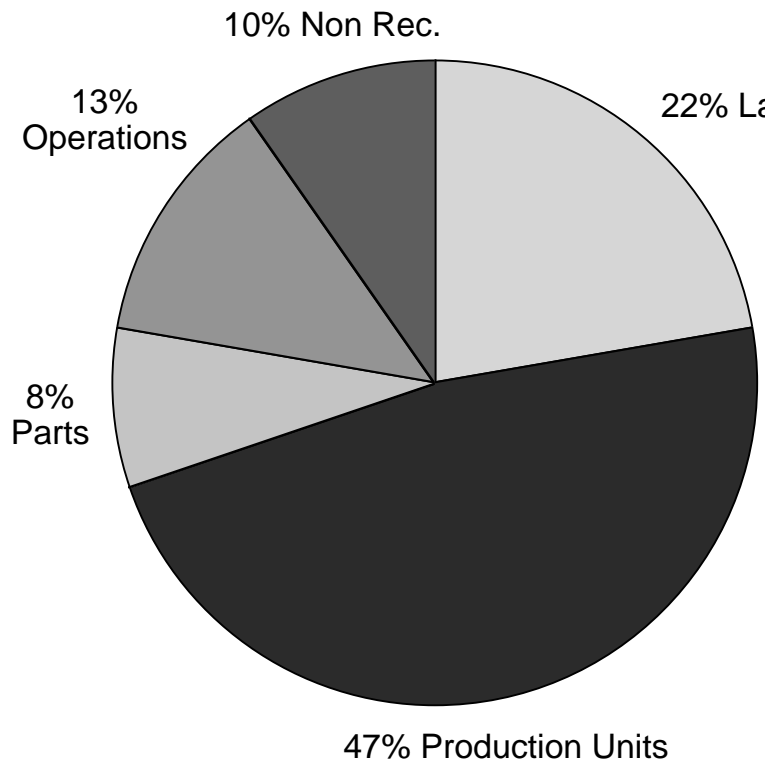

Total $\$ 5,931 \mathrm{M}=\$ 4,943 / \mathrm{lb}$

\section{Distribution of Unit Cost}

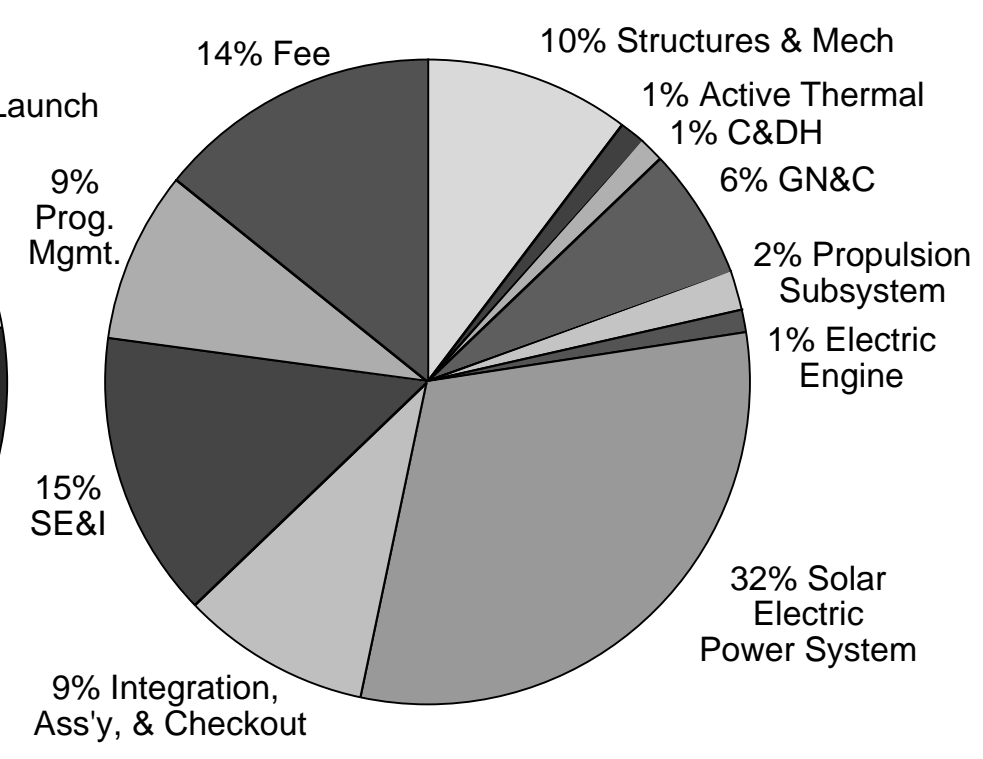

Figure 14. Cost distributions for the solar electric engine 3,000-lb payload.

\subsection{Solar Thermal Propulsion Concepts}

\subsubsection{Concept Description}

This expendable upper stage concept uses a solar thermal rocket engine for main propulsion and is a low-thrust system, although its thrust-to-weight ratio may be several times higher than for electric propulsion. A sketch of the concept is shown in figure 15, and weight summaries are given in tables 18 and 19. Only a 3,000-lb payload was considered since a $10,000-1 b$ payload version was deemed unfeasible due to the size of concentrators and thrust level required. 


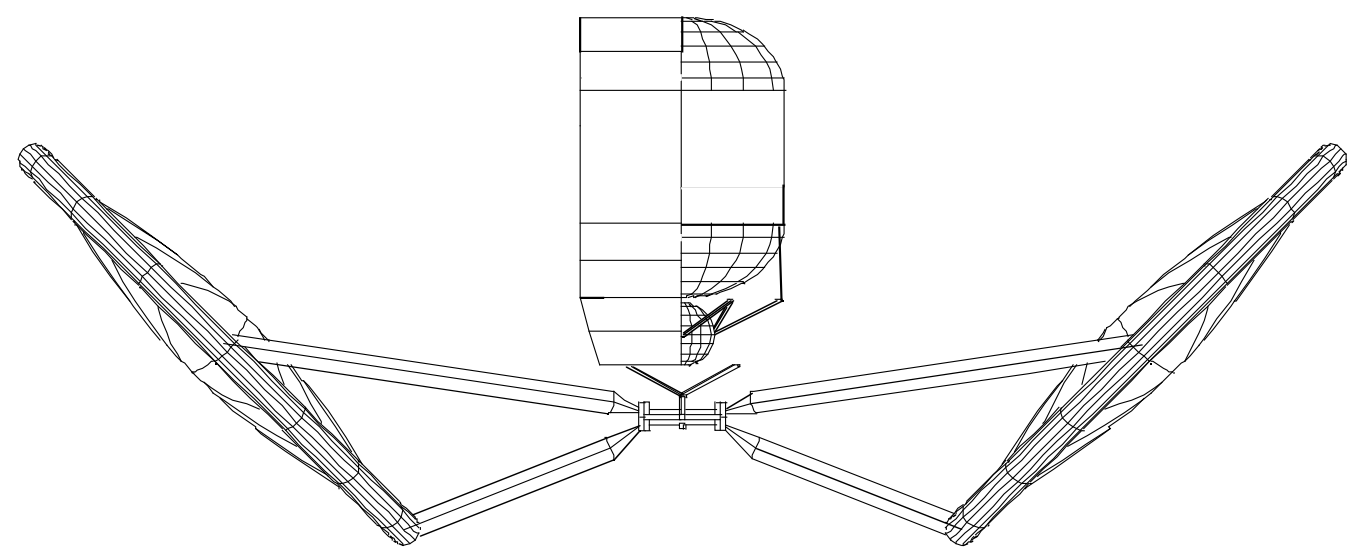

Figure 15. Expendable solar thermal concept.

Table 18. Overall weight statement for expendable solar thermal concepts.

\begin{tabular}{|l|c|c|}
\hline \multicolumn{1}{|c|}{ AIST Concept } & \multicolumn{2}{c|}{ Weight, lbm } \\
Weight Category & $3,000-1 \mathrm{~b}$ payload & $10,000-\mathrm{lb}$ payload \\
\hline Upper Stage Inert Weight & 3,346 & - \\
\hline Upper Stage Fuel Weight & 5,076 & - \\
\hline Total LEO Delivery Weight & 11,422 & - \\
\hline Stage Delivery ASE Weight & 1,713 & - \\
\hline Total LEO Transport Weight & 13,135 & - \\
\hline
\end{tabular}

Table 19. Inert weight statement for expendable solar thermal concepts.

\begin{tabular}{|l|r|c|}
\hline \multicolumn{1}{|c|}{ Upper Stage } & \multicolumn{2}{c|}{ Inert Weight, lbm } \\
Subsystem & 3K-lb payload & 10K-lb payload \\
\hline Structures & 2,004 & - \\
\hline Passive Thermal Control & 113 & - \\
\hline Electric Power & 178 & - \\
\hline C\&DH & 175 & - \\
\hline GN\&C & 254 & - \\
\hline Reaction Control Subsystem & 198 & - \\
\hline Propulsion Subsystem & 95 & - \\
\hline Absorber/Gimbal & 115 & - \\
\hline Collector/Optics/Mechanism & 214 & - \\
\hline Total Upper Stage Inert Weight & 3,346 & - \\
\hline
\end{tabular}

A delta $\mathrm{V}$ based on the optimization of trip time and performance was calculated, and useable propellant and stage weights were determined. Since the solar thermal propulsion concept has higher thrust than the electric propulsion concept, it is practical to use a perigee and apogee kick approach to the orbit transfer, reducing delta $\mathrm{V}$ compared to electric propulsion. Using a previous study completed in Preliminary Design (MSFC In-House Feasibility Study for Solar Thermal Upper Stage, August 1994), weights were determined by comparison. The total stage weight for the 3,000-lb payload was calculated from a trajectory analysis and was compared against the weight from the August 1994 study to determine a multiplication factor. This factor was applied to all the subsystems in the August 1994 study to get a weight estimate for the 3,000-lb payload concept. It is assumed that the two concepts (i.e., configurations) are the same with the exception of the GN\&C.

Solar energy is focused onto an absorber (main engine) mouth via a solar concentrator. Propellant (liquid hydrogen) flows into the absorber and is heated by the focused solar energy transferred through an 
absorber wall. The propellant exits out of the absorber via a nozzle, creating thrust to drive the stage. ${ }^{15}$ The solar thermal concept is expected to have an Isp of $860 \mathrm{~s}$. The GN\&C equipment includes two GPS receivers with inertial navigation unit, two-axis Sun sensors with electronics, conical Earth sensors with electronics, six reaction wheels, eight photo detectors, two control electronics, two guidance and control processors, and interconnect cabling.

\subsubsection{Concept Mission Profile}

The expendable solar thermal stage delivers its payload from LEO to GEO using a series of perigee and apogee burns to provide a low-thrust elliptic spiral-with-plane-change transfer maneuver. It delivers the customer's payload to GEO without an AKM. The delta V required is about 16,077 ft/s. Because the absorber would not be consumed by atmosphere reentry, disposal of the stage is accomplished by carrying extra propellant to insert the stage into an orbit higher than GEO, where the stage will remain. The total trip time for the stage from LEO to GEO is approximately 60.7 days.

\subsubsection{Concept Cost Analysis and Recommendations}

Distributions of cost for the 3,000-lb payload are shown in figure 16. A 10,000-lb payload version was not analyzed. The predominant factor affecting life-cycle cost is the stage (production) cost. A total of 222 stages is manufactured to support the flight program. The life-cycle cost distribution is similar to that for the other (solid and hybrid) expendable concepts. Since the unit cost is 50 percent greater than these and the LEO delivery mass is less, the dominance of production cost is more exaggerated. The solar thermal subsystem, as costed for this study at $\$ 7,300 / \mathrm{lb}$, is not competitive with the other finalist concepts.

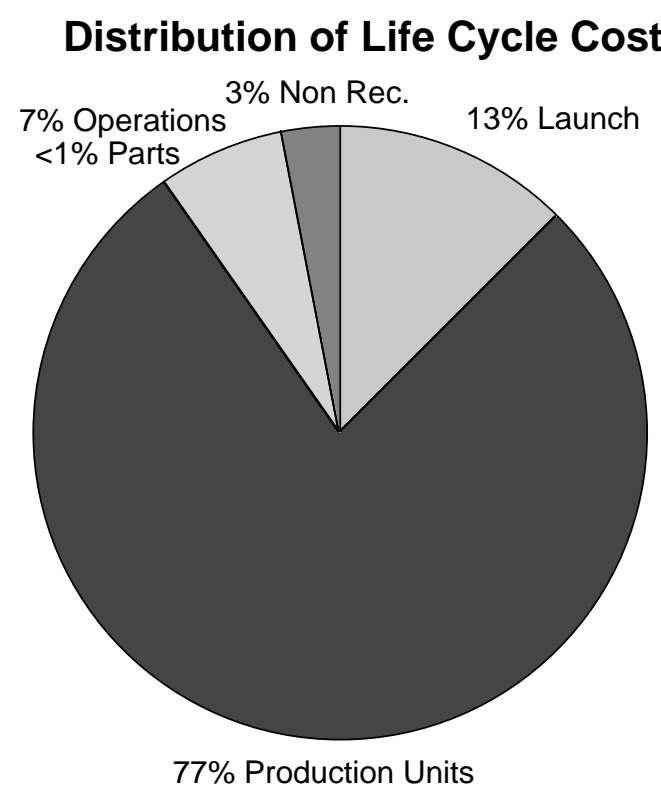

Total $\$ 8,799 \mathrm{M}=\$ 7,333 / \mathrm{lb}$

\section{Distribution of Unit Cost}

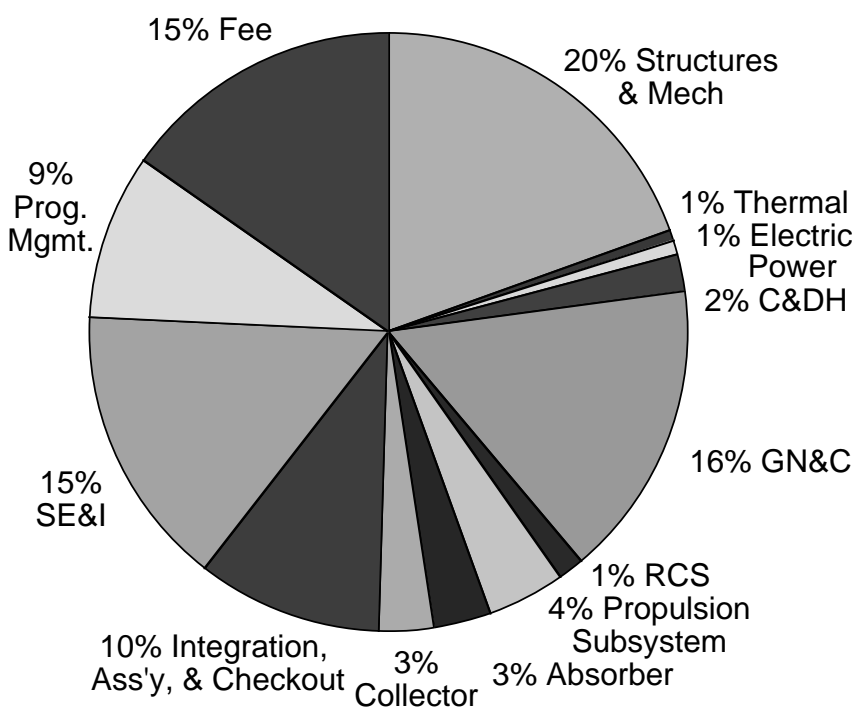

Figure 16. Cost distributions for the solar thermal 3,000-lb payload.

The solar thermal system unit cost estimate is less than for the reusable concepts-only half that for the solar electric and nuclear systems, and significantly less than for the cryogenic system. This indicates that the solar thermal system might hold promise as a reusable. However, with a return-to-LEO requirement, the solar thermal propulsion system becomes very sensitive to Isp, as illustrated in figure 17. 
(calculations using the "split-payload" equation). Resupply mass shown in the figure includes payload and propellant but not ASE or tankers. A resupply mass below 15,000 lb is reasonably competitive, and a resupply mass below $10,000 \mathrm{lb}$ has at least a chance of meeting study goals. This indicates that a concept for a reusable solar thermal system should strive for an Isp of 1,000 s or better. If the production quantity can be reduced to about 50 units without significantly increasing LEO transportation cost, the life-cycle cost for solar thermal would drop to about $\$ 2,500 / 1 \mathrm{~b}$ and the system would become highly competitive. A detailed cost analysis breakdown can be found in appendix $\mathrm{J}$ of this report.

\section{Solar Thermal Propulsion Parametrics}

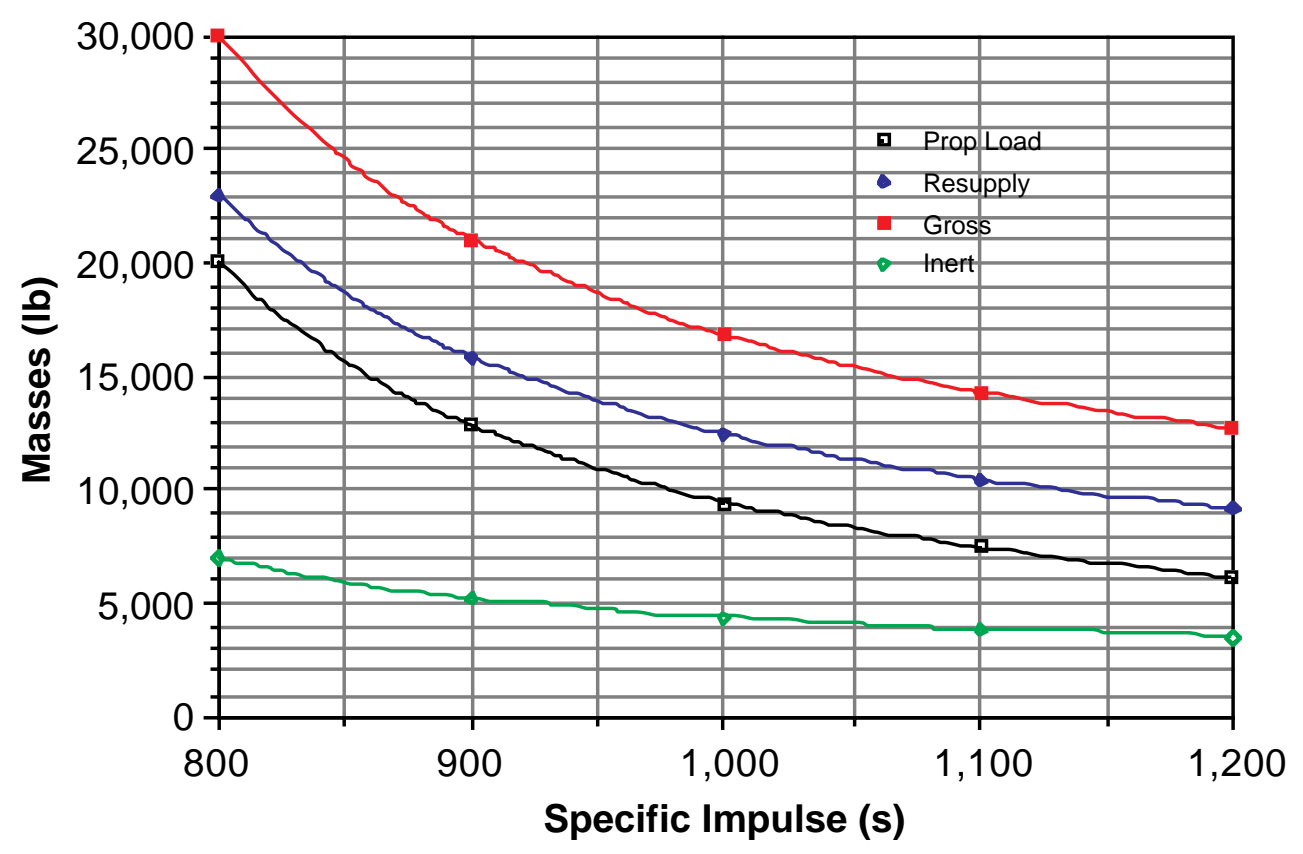

Figure 17. Isp sensitivities based on masses.

\subsection{Nuclear Thermal Propulsion Concepts}

\subsubsection{Concept Description}

This space-based, reusable upper-stage concept uses a nuclear thermal rocket engine for main propulsion and is a high-thrust concept. The estimated operable life of the engine is $10 \mathrm{~h}(36,000 \mathrm{~s})$, after which time both the engine and upper stage would no longer be reused. It is estimated that the 3,000-lb payload nuclear concept could perform about 50 missions, and the 10,000-lb concept, 32 missions. Note that this operable life is several times that predicted for the cryogenic chemical engine and can be justified in suspecting differences in optimism on the part of propulsion specialists.

Nuclear thermal propulsion enables a high-thrust system at about twice the Isp of cryogenic chemical propulsion. However, the propulsion installation is massive compared to a chemical rocket. A quick trade study indicated that the best advantage of nuclear thermal Isp could be obtained by operating the same way as the reusable cryo, placing the payload and an AKM in a geosynchronous transfer orbit. Because of the comparatively great inert mass of the nuclear stage, operating it all the way to GEO and back, eliminating the AKM, requires nearly twice the propellant and, therefore, greatly increases the resupply mass for a repeat mission. A sketch of the concept is shown in figure 18 and a weight summary in tables 20 and 21. Additionally, tables 22 and 23 show the weight statement for the refuel tank and the fuel and payload resupply mission. 


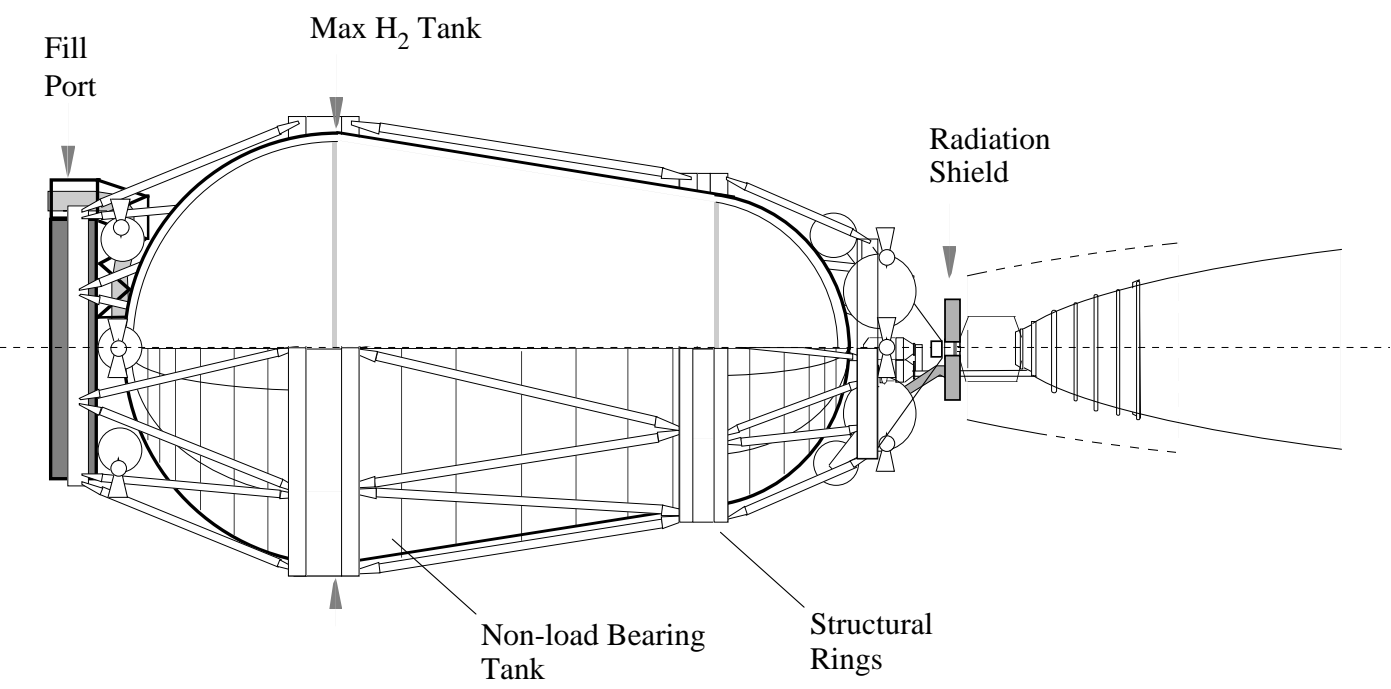

Figure 18. Reusable nuclear thermal concept.

Table 20. Overall weight statement for reusable nuclear thermal concepts.

\begin{tabular}{|l|r|r|}
\hline \multicolumn{1}{|c|}{ AIST Concept } & \multicolumn{2}{|c|}{ Weight, lbm } \\
Weight Category & $3,000-1 \mathrm{~b}$ payload & $10,000-1 \mathrm{~b}$ payload \\
\hline Loaded AKM Weight & 2,856 & 9,520 \\
\hline Upper Stage Inert Weight & 10,819 & 13,017 \\
\hline Upper Stage Fuel Weight & 10,612 & 17,263 \\
\hline Total LEO Delivery Weight & 27,287 & 49,800 \\
\hline Stage Delivery ASE Weight & 4,093 & 7,470 \\
\hline Total LEO Transport Weight & 31,380 & 57,270 \\
\hline
\end{tabular}

Table 21. Inert weight statement for reusable nuclear thermal concepts.

\begin{tabular}{|l|r|r|}
\hline \multicolumn{1}{|c|}{ Upper Stage } & \multicolumn{2}{c|}{ Inert Weight, lbm } \\
Subsystem & $3,000-1 \mathrm{lb}$ payload & $10,000-\mathrm{lb}$ payload \\
\hline Structures & 3,889 & 5,823 \\
\hline Mechanisms & 34 & 112 \\
\hline Passive Thermal Control & 446 & 616 \\
\hline Electric Power & 300 & 300 \\
\hline C\&DH & 182 & 182 \\
\hline GN\&C & 160 & 160 \\
\hline Reaction Control Subsystem & 223 & 239 \\
\hline Propulsion Subsystem & 175 & 175 \\
\hline Nuclear Rocket Engines & 5,410 & 5,410 \\
\hline Total Upper Stage Inert Weight & 10,819 & 13,017 \\
\hline
\end{tabular}

Table 22. Inert weight statement for nuclear thermal concept refuel tank.

\begin{tabular}{|l|r|c|}
\hline \multicolumn{1}{|c|}{$\begin{array}{c}\text { Refuel Tank Assembly } \\
\text { Subsystem }\end{array}$} & \multicolumn{2}{c|}{ Inert Weight, lbm } \\
St,000-lb payload & $10,000-\mathrm{lb}$ payload \\
\hline Structures & 3,189 & 4,891 \\
\hline Mechanisms & 34 & 112 \\
\hline Passive Thermal Control & 446 & 616 \\
\hline Propulsion Subsystem & 175 & 175 \\
\hline Total Refuel Tank Inert Weight & 3,844 & 5,794 \\
\hline
\end{tabular}


Table 23. Overall weight statement for nuclear thermal concept resupply.

\begin{tabular}{|l|r|r|}
\hline \multicolumn{1}{|c|}{ AIST Concept } & \multicolumn{2}{c|}{ Weight, lbm } \\
Weight Category & $3,000-1 \mathrm{~b}$ payload & $10,000-\mathrm{lb}$ payload \\
\hline Loaded AKM Weight & 2,856 & 9,520 \\
\hline Refuel Tank Inert Weight & 3,844 & 5,794 \\
\hline Resupply Fuel Weight & 10,612 & 17,263 \\
\hline Replacement Parts Weight & 172 & 240 \\
\hline Total LEO Delivery Weight & 20,484 & 42,817 \\
\hline Refuel Delivery ASE Weight & 3,073 & 6,423 \\
\hline Total LEO Transport Weight & 23,557 & 49,240 \\
\hline
\end{tabular}

The nuclear rocket engine subsystem consists of a single, NERVA-derived, solid nuclear thermal rocket engine, nozzle, radiation shielding, and turbopump for the liquid fuel. The engine would have a maximum thrust of $15,000 \mathrm{lbf}$ at an Isp of $900 \mathrm{~s}$, which results in a fuel mass flow rate of $16.7 \mathrm{lb} / \mathrm{s}(7.6$ $\mathrm{kg} / \mathrm{s}$ ). Its fuel was liquid hydrogen stored in a single insulated tank. No oxidizer was required since the engine heated the fuel directly. The design of the structure, RCS, mechanisms, thermal, GN\&C, C\&DH, and power subsystems are the same as the cryo system. Because the nuclear concept is space-based, the replacement percentages are lower than for the ground-based reusable cryogen concept.

\subsubsection{Concept Mission Profile}

The nuclear thermal stage carries a payload with an AKM. The nuclear stage delivers the payload and its AKM from LEO to GTO. For the 3,000-lb payload concept, the required burn time is estimated at $374 \mathrm{~s}$; for the 10,000-lb concept, $695 \mathrm{~s}$. Following the burn, the upper stage shuts down the nuclear reactor, but continues to flow fuel (4 percent of that burned) for several minutes to cool the engine. At GTO, the AKM fires.

When the stage completes one full orbit in GTO, it fires its nuclear engine and shifts the orbit from GTO back to LEO. A small plane change maneuver is required during the return transfer from GTO to LEO to correct for differential nodal regression. For the 3,000-lb payload concept, the required burn time is estimated at $203 \mathrm{~s}$; for the 10,000-lb concept, $248 \mathrm{~s}$. Following the burn, the upper stage shuts down the nuclear reactor, but continues to flow fuel (4 percent of that burned) for several minutes to cool the engine. Once in LEO, the upper stage enters sleep mode orbiting the Earth until rendezvous with the next HRST vehicle for refuel and payload attachment (the upper stage uses an additional delta-V of $330 \mathrm{ft} / \mathrm{s}$ to rendezvous with the HRST). For the last mission the upper stage uses its delta-V capability to either escape Earth's gravity or to enter a safe circular Earth orbit at an unoccupied, intermediate altitude between LEO and GEO. Because of the radiation hazard associated with the used nuclear reactor, the spent upper stage is not allowed to reenter the Earth's atmosphere.

\subsubsection{Concept Cost Analysis and Recommendations}

Distributions of cost for the 3,000-lb payload is shown in figure 19. Life-cycle cost for the nuclear stage (3,000-lb payload) includes three principal and roughly equivalent contributors: transport to LEO, production units, and nonrecurring cost (which includes DDT\&E). The main contributor to the nonrecurring cost is the DDT\&E. DDT\&E and unit production is less significant for the 10,000-lb payload case, and launch cost accounts for 43 percent of the total life-cycle cost. The predominant factor affecting DDT\&E cost is the engine cost, which accounts for 90 and 88 percent, respectively, of the DDT\&E cost for the small and large stages. The predominant factor affecting first unit cost is the engine cost, which accounts for about half of the first unit cost in both cases. 


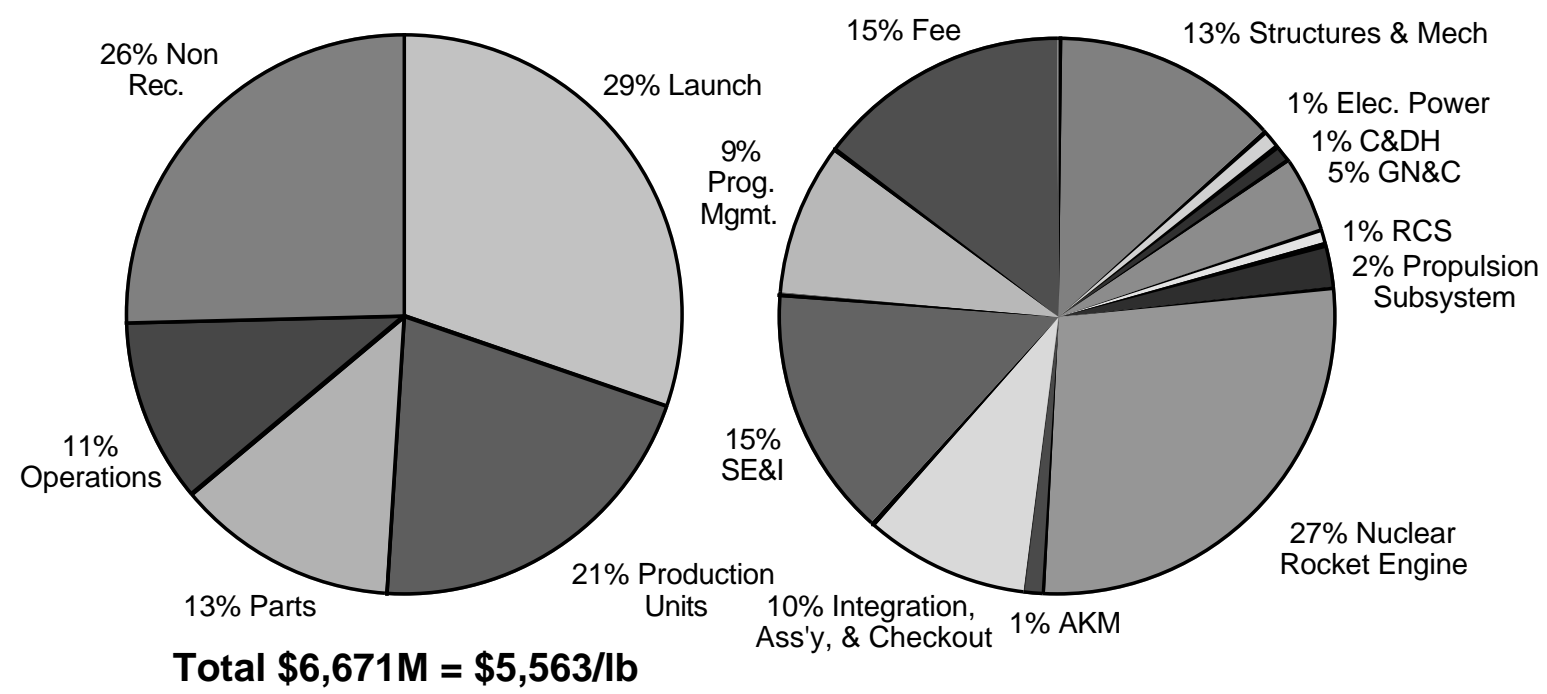

Figure 19. Cost distributions for the nuclear thermal 3,000-lb payload.

The engine cost totally dominates the cost of both DDT\&E and stage (production). The high development cost affects the nonrecurring cost making it comparable to all other costs in the life-cycle cost analysis. Since this stage is reusable, only 24 units need to be built, and the production cost does not dominate other categories in the life-cycle cost analysis. Because the high engine cost dominates all other costs, the ASE did not play a significant factor in the overall cost. The predominant contributor to DDT\&E and unit cost is the nuclear rocket engine, and the predominant contributor to life-cycle cost, about 40 percent of the total, is transportation to LEO. The nuclear stage was assigned a lifetime of 50 uses based on projected engine life. As noted, this is greater than most of the other concepts and reduces the contribution of vehicle production to life-cycle cost.

The initial thrust-to-weight for a nuclear upper stage in this application should be about 0.2 . This translates to a thrust of about 2,500 lb for the 3,000-lb payload and about twice that for 10,000 lb. Reducing the thrust of the nuclear engine probably offers little weight reduction since a certain size is needed for nuclear criticality. An advanced core construction, such as particle bed or the Russian twisted metallic element, could help on the weight, but would probably reduce life and might not save cost.

A more promising approach would be multiple manifesting so that the delivery weight to GTO is increased. In combination with multiple manifesting, reducing the size of the AKM and using electric propulsion on the satellite payload for part of the GEO insertion could be considered (this assumes that most will be equipped with electric propulsion for stationkeeping). Even with these improvements, the nuclear stage appears to have less cost reduction potential than the other reusable candidates. In view of public safety issues, operations costs for the nuclear system may be substantially underestimated A detailed cost analysis breakdown can be found in appendix J of this report.

\subsection{STUDY RESULTS AND SENSITIVITIES}

There were several limitations to the study that have some impact on the results. The study team tried to bring all the concepts to the same level of detail in their design but, due to the study scope and manpower limitations, this could not be done. The following comments should be taken into account when reviewing the results of the study. 
Since a detailed design was not made for each of the concepts considered in this study, there is a difference in the level of detail for some of the concepts. Some of the concepts were based on existing systems where a lot of information was available. Other concepts have been studied previously, while some of the concepts were much more immature. This difference in the level of detail available on the concepts has an impact on the weight estimations, complexity factors, manufacturing costs, and other factors that affect the life-cycle cost of the systems.

The NASCOM cost estimating tool, which provides DDT\&E, production, and first unit costs, is based on weight and complexity factors. Since a heavily machined part would weigh less than an unmachined part, the lighter, heavily machined part would be costed less. In addition, less complex systems that may be heavy would be costed higher than more complex systems. Therefore, full accounting for complex machining, expensive manufacturing processes, and full credit for simple design may not be included in this study.

Since all concepts were assumed to be capable of being at TRL 6 by the year 2005, no accounting of maturing the technologies to this TRL was done. This study assumes that all necessary technologies to enable a given concept will be in place. It was out of the scope of this study to estimate the cost to mature the technologies to TRL 6.

Since a detailed design approach was not taken (and could not have been within the scope and manpower of this study), there may not be enough detail to delineate between a reusable and expendable system. In other words, it was not evident that the design for the reusable systems took into account all reusability issues. Reusable systems may need to be designed to accommodate easy tank replacement, micrometeroid shielding, and docking/grappling systems. In addition, indepth analyses for required activities such as propellant resupply and payload integration for in-space reusable systems, repair and change out of parts, and diagnostic techniques for determining the health of a reusable system were not performed.

Reliability differences between the systems should be taken into account, especially since there is such a large difference in the TRL's of the concepts today. For example, there was no reliability delineation between the solid and the nuclear thermal concept, even though solids have been used for over 20 years and nuclear concepts have yet to be used in flight. In addition, the sensitivity to reliability for each concept was calculated based on just changing the percent reliability and looking at its effect on the number of replacement vehicles required. Due to the constraints of the study, changes to the designs of the vehicles, to account for increased reliability, was not done. Therefore the total cost impact of increasing a systems reliability was not included in this study.

Finally, this study assumes that services provided by current launch vehicles to their payloads will also be provided by the HRST to its payloads (i.e., power, air conditioning, etc.).

\subsection{Results of Cost Analyses}

The final input data for the cost analyses are presented in tables 24 and 25 . The tables include mass properties input to the NASCOM and life-cycle cost models, cost-related design parameters, NASCOM top-level results (DDT\&E and first unit costs), and operations and life cycle system parameters. When comparing concepts, caution should be made when making conclusions regarding absolute dollar values (e.g., first unit costs), since this study was conducted at a very high systems level and many assumption had to be made in all areas of costing.

Graphical life-cycle cost comparisons of the concepts was shown in figure 4. Although the magnitudes of the various components of the life-cycle costs vary for the different concepts, there is not a large difference between the total life-cycle costs of the concepts. For all the concepts, launch costs and hardware costs are the dominant contributors.

Since stage (production) seems to be the predominant factor in costing, in most cases, the reusable concepts seemed less expensive over an expendable concept simply based upon the number of stages needed to be produced. In all cases except the nuclear thermal, the total nonrecurring cost and operations 
cost were quite insignificant. Each of these costs usually amounted to less than 10 percent of the total lifecycle cost. Since LEO launch costs played a predominant role in the life-cycle cost, reduction of weight is a desirable quality. Structure is the primary contributor to this weight for all systems except the small payload nuclear system where the smallest postulated available engine is much larger than needed for this payload class. Structure includes propellant tanks. Nuclear thermal rocket engines do not scale down well to very low thrust levels. For the smaller systems, avionics (includes electrical power on these graphs) is also a major contributor. Competitiveness of the SEP degrades with the larger payload size because its production cost is mainly driven by solar array cost. Array unit costs were not decreased in view of the greater production for the larger systems. The other systems benefit more, in terms of unit cost, from larger payloads because avionics costs are a more significant part of the total and do not increase as vehicles are made larger. DDT\&E is significant for the nuclear vehicle.

For the 3,000-lb payload at 20 flights per year, the best systems at about $\$ 5.1$ billion life-cycle costs are forecast at about $\$ 4,300 / 1 b$ to GEO, as shown in figure 20 . For the 10,000-lb payload, the best systems are about $\$ 2,200 / \mathrm{lb}$. The study target is $\$ 1,000 / \mathrm{lb}$. Higher flight rates reduce per pound cost as expected. Note that with the assumed $\$ 200 / \mathrm{lb}$ launch cost, the total launched mass must be less than five times the payload mass or launch cost alone will exceed the target. Referring to figure 21, only the expendable systems satisfied this criterion at the 3,000-lb payload. At the 10,000-lb payload, the expendable systems and the SEP meet the criterion.

The solar thermal concept was surprisingly high when compared to the other expendable concepts. This may be because the stage costing was based upon a lot of direct input due to the unusual nature and lack of historical information existing for the stage.

Table 24. Final inputs to the life-cycle cost.

\begin{tabular}{|c|c|c|c|c|c|c|c|c|c|c|c|c|c|c|c|}
\hline Concept Name & Solid & Hybrid & Cryogen & Nuclear & Solar Elec. & Solar Thermal & Solid & Hybrid & Cryogen & Nuclear & Solar Elec. & Solar Thermal & Solar Thermal & Nuclear & Nuclear \\
\hline Expendable or Reusable & Expendable & Expendable & Reusable & Reusable & Reusable & Expendable & Expendable & Expendable & Reusable & Reusable & Reusable & Expendable & "Reusable" & Reusable " & "Expendable" \\
\hline Engine Type & HTPB & HTPB/LOX & RL10-B2 & NERVA & Plasma & Heat & HTPB & HTPB/LOX & RL10-B2 & NERVA & Plasma & Heat & Heat & NERVA & NERVA \\
\hline Payload Mass, lbm & 3,000 & 3,000 & 3,000 & 3,000 & 3,000 & 3,000 & 10,000 & 10,000 & 10,000 & 10,000 & 10,000 & 3,000 & 3,000 & 3,000 & 3,000 \\
\hline Vehicle Mass Properties & Value & Value & Value & Value & Value & Value & Value & Value & Value & Value & Value & Value & Value & Value & Value \\
\hline Total Stage Unit Dry Mass, Ibm & 1,299 & 1,709 & 3,771 & 10,819 & 5,202 & 3,346 & 1,638 & 3,037 & 6,064 & 13,017 & 11,019 & 3,346 & 3,346 & 10,819 & 10,819 \\
\hline Total AKM Unit Dry Mass, Ilbm & 200 & 200 & 200 & 200 & 0 & 0 & 666 & 666 & 666 & 666 & 0 & 0 & 0 & 200 & 200 \\
\hline Total ASE Unit Dry Mass, Ibm & 1,850 & 1,825 & 4,142 & 7,166 & 4,444 & 1,713 & 5,977 & 5,323 & 9,795 & 13,893 & 10,981 & 1,713 & 3,170 & 7,166 & 4,093 \\
\hline Stage Fuel Mass / Flight & 5,175 & 1,585 & 1,918 & 10,612 & 8,130 & 5,076 & 18,687 & 5,480 & 4,125 & 17,263 & 18,565 & 5,076 & 5,076 & 10,612 & 10,612 \\
\hline Stage Oxidizer Mass / Flight & 0 & 3,015 & 11,466 & 0 & 0 & 0 & 0 & 7,447 & 24,707 & 0 & 0 & 0 & 0 & 0 & \\
\hline AKM Propellant Mass / Flight & 2,656 & 2,656 & 2,656 & 2,656 & 0 & 0 & 8,854 & 8,854 & 8,854 & 8,854 & 0 & 0 & 0 & 2,656 & 2,656 \\
\hline LEO Mass per New Stage Flight & 12,330 & 12,165 & 23,011 & 27,287 & 16,332 & 11,422 & 39,845 & 35,484 & 54,416 & 49,800 & 39,584 & 11,422 & 11,422 & 27,287 & 27,287 \\
\hline ASE Mass per New Stage Flight & 1,850 & 1,825 & 4,142 & 4,093 & 2,450 & 1,713 & 5,977 & 5,323 & 9,795 & 7,470 & 5,938 & 1,713 & 1,713 & 4,093 & 4,093 \\
\hline LEO Mass per Reuse Flight & 0 & 0 & 23,011 & 20,484 & 13,296 & 0 & 0 & 0 & 54,416 & 42,817 & 33,620 & 0 & 9,709 & 20,484 & 0 \\
\hline ASE Mass per Reuse Flight & 0 & 0 & 4,142 & 3,073 & 1,994 & 0 & 0 & 0 & 9,795 & 6,423 & 5,043 & 0 & 1,456 & 3,073 & 0 \\
\hline Vehicle Design Parameter & Value & Value & Value & Value & Value & Value & Value & Value & Value & Value & Value & Value & Value & Value & Value \\
\hline Unit Design Life (in Flights) & 1 & 1 & 14 & 50 & 10 & 1 & 1 & 1 & 7 & 32 & 10 & 1 & 2 & 50 & 1 \\
\hline Number of Backup Stages & 1 & 1 & 1 & 1 & 1 & 1 & 1 & 1 & 1 & 1 & 1 & 1 & 1 & 1 & \\
\hline Number of ASE Units Required & 2 & 2 & 2 & 3.50 & 3.63 & 2 & 2 & 2 & 2 & 3.72 & 3.70 & 2 & 3.70 & 3.50 & 2.00 \\
\hline Refuel Tank Design Life (in Flights) & 0 & 0 & 0 & 100 & 100 & 0 & 0 & 0 & 0 & 100 & 100 & 0 & 100 & 100 & 0 \\
\hline Number of Backup Refuel Tanks & 0 & 0 & 0 & 1 & 1 & 0 & 0 & 0 & 0 & 1 & 1 & 0 & 1 & 1 & 0 \\
\hline Num. of Refuel Tanks Required & 0 & 0 & 0 & 5 & 5 & 0 & 0 & 0 & 0 & 5 & 5 & 0 & 5 & 5 & 0 \\
\hline Vehicle Cost Parameter & Value & Value & Value & Value & Value & Value & Value & Value & Value & Value & Value & Value & Value & Value & Value \\
\hline Stage/ASE/AKM DDT\&E Costs & 135.5 & 175.9 & 227.3 & $1,359.8$ & 393.5 & 202.1 & 201.2 & 267.7 & 323.0 & 1,431.1 & 547.8 & 202.1 & 202.1 & $1,359.8$ & $1,359.8$ \\
\hline HW "Total System" Unit Cost, \$M & 30.4 & 33.6 & 61.4 & 103.3 & 97.1 & 45.1 & 47.4 & 53.6 & 88.6 & 122.3 & 208.3 & 45.1 & 45.1 & 103.3 & 103.3 \\
\hline HWW "Subtotal" Unit Cost, \$M & 20.0 & 22.1 & 40.4 & 68.0 & 63.7 & 29.7 & 31.2 & 35.3 & 58.3 & 80.6 & 136.9 & 29.7 & 29.7 & 68.0 & 68.0 \\
\hline Main ASE Unit Hardware Cost, \$M & 7.4 & 7.3 & 12.9 & 12.8 & 9.0 & 7.0 & 16.7 & 15.4 & 23.6 & 19.6 & 16.6 & 7.0 & 7.0 & 12.8 & 12.8 \\
\hline AKM Unit Hardware Cost, \$M & 1.4 & 1.4 & 1.4 & 1.4 & 0.0 & 0.0 & 2.0 & 2.0 & 2.0 & 2.0 & 0.0 & 0.0 & 0.0 & 1.4 & 1.4 \\
\hline Refuel Tank Unit Hardware Cost, \$M & 0.0 & 0.0 & 0.0 & 23.3 & 14.7 & 0.0 & 0.0 & 0.0 & 0.0 & 30.5 & 27.4 & 0.0 & 14.0 & 23.3 & 0.0 \\
\hline Spares Cost per Reuse Flight, \$M & 0.0 & 0.0 & 2.0 & 2.3 & 2.6 & 0.0 & 0.0 & 0.0 & 2.8 & 3.2 & 5.0 & 0.0 & 2.0 & 2.3 & 0.0 \\
\hline Stage Fuel Cost / Pound, \$ & 3.00 & 3.00 & 2.50 & 2.50 & 30.00 & 2.50 & 3.00 & 3.00 & 2.50 & 2.50 & 30.00 & 2.50 & 2.50 & 2.50 & 2.50 \\
\hline Stage Oxidizer Cost / Pound, \$ & 0.00 & 1.00 & 1.00 & 0.00 & 0.00 & 0.00 & 0.00 & 1.00 & 1.00 & 0.00 & 0.00 & 0.00 & 0.00 & 0.00 & 0.00 \\
\hline AKM Propellant Cost / Pound, \$ & 3.00 & 3.00 & 3.00 & 3.00 & 0.00 & 0.00 & 3.00 & 3.00 & 3.00 & 3.00 & 0.00 & 0.00 & 0.00 & 3.00 & 3.00 \\
\hline Ops. Design Parameter, $20 \mathrm{fl}$ & Value & Value & Value & Value & Value & Value & Value & Value & Value & Value & Value & Value & Value & Value & Value \\
\hline Number of Flights per Year & 20 & 20 & 20 & 20 & 20 & 20 & 20 & 20 & 20 & 20 & 20 & 20 & 20 & 20 & 20 \\
\hline Ground Ops Personnel Size & 49 & 50 & 118 & 85 & 70 & 43 & 49 & 50 & 118 & 85 & 70 & 43 & 43 & 85 & 85 \\
\hline Mission Ops Personnel Size & 60 & 60 & 80 & 90 & 130 & 123 & 60 & 60 & 80 & 90 & 130 & 123 & 123 & 90 & 90 \\
\hline Facility Non-Recurring Costs & 35.0 & 35.0 & 50.0 & 100.0 & 20.0 & 35.0 & 35.0 & 35.0 & 50.0 & 100.0 & 20.0 & 35.0 & 35.0 & 100.0 & 100.0 \\
\hline Facility Main. Costs per Year, $\$ M$ & 3.5 & 3.5 & 5.0 & 10.0 & 2.0 & 3.5 & 3.5 & 3.5 & 5.0 & 10.0 & 2.0 & 3.5 & 3.5 & 10.0 & 10.0 \\
\hline Round 3 Trade Parameter & Value & Value & Value & Value & Value & Value & Value & Value & Value & Value & Value & Value & Value & Value & Value \\
\hline Total Number of Years & 20 & 20 & 20 & 20 & 20 & 20 & 20 & 20 & 20 & 20 & 20 & 20 & 20 & 20 & 20 \\
\hline LEO Launch Cost per Pound, \$ & 200 & 200 & 200 & 200 & 200 & 200 & 200 & 200 & 200 & 200 & 200 & 200 & 200 & 200 & 200 \\
\hline Upper Stage Overall Reliability & 0.950 & 0.950 & 0.950 & 0.950 & 0.950 & 0.950 & 0.950 & 0.950 & 0.950 & 0.950 & 0.950 & 0.950 & 0.950 & 0.950 & 0.950 \\
\hline Learning Curve Percentage & $90 \%$ & $90 \%$ & $90 \%$ & $90 \%$ & $90 \%$ & $90 \%$ & $90 \%$ & $90 \%$ & $90 \%$ & $90 \%$ & $90 \%$ & $90 \%$ & $90 \%$ & $90 \%$ & $90 \%$ \\
\hline Ground Ops. Person Cost $/ \mathrm{hr}, \$$ & 50 & 50 & 50 & 50 & 50 & 50 & 50 & 50 & 50 & 50 & 50 & 50 & 50 & 50 & 50 \\
\hline Mission Ops. Person Cost $/ \mathrm{hr}, \$$ & 100 & 100 & 100 & 100 & 100 & 100 & 100 & 100 & 100 & 100 & 100 & 100 & 100 & 100 & 100 \\
\hline Avg. Hours Worked per Year & 1840 & 1840 & 1840 & 1840 & 1840 & 1840 & 1840 & 1840 & 1840 & 1840 & 1840 & 1840 & 1840 & 1840 & 1840 \\
\hline Ops. Design Parameter, $50 \mathrm{fl}$ & Value & Value & Value & Value & Value & Value & Value & Value & Value & Value & Value & Value & Value & Value & Value \\
\hline Number of Flights per Year & 50 & 50 & 50 & 50 & 50 & 50 & 50 & 50 & 50 & 50 & 50 & 50 & 50 & 50 & 50 \\
\hline Ground Ops Personnel Size & 49 & 50 & 118 & 85 & 70 & 43 & 49 & 50 & 118 & 85 & 70 & 43 & 43 & 85 & 85 \\
\hline Mission Ops Personnel Size & 90 & 90 & 110 & 120 & 175 & 157 & 90 & 90 & 110 & 120 & 175 & 157 & 157 & 120 & 120 \\
\hline Facility Non-Recurring Costs & 35.0 & 35.0 & 50.0 & 100.0 & 20.0 & 35.0 & 35.0 & 35.0 & 50.0 & 100.0 & 20.0 & 35.0 & 35.0 & 100.0 & 100.0 \\
\hline Eacility Main. Costs per Year. \$M & 3.5 & 3.5 & 5.0 & 10.0 & 2.0 & 3.5 & 3.5 & 3.5 & 5.0 & 10.0 & 2.0 & 3.5 & 3.5 & 10.0 & 10.0 \\
\hline
\end{tabular}




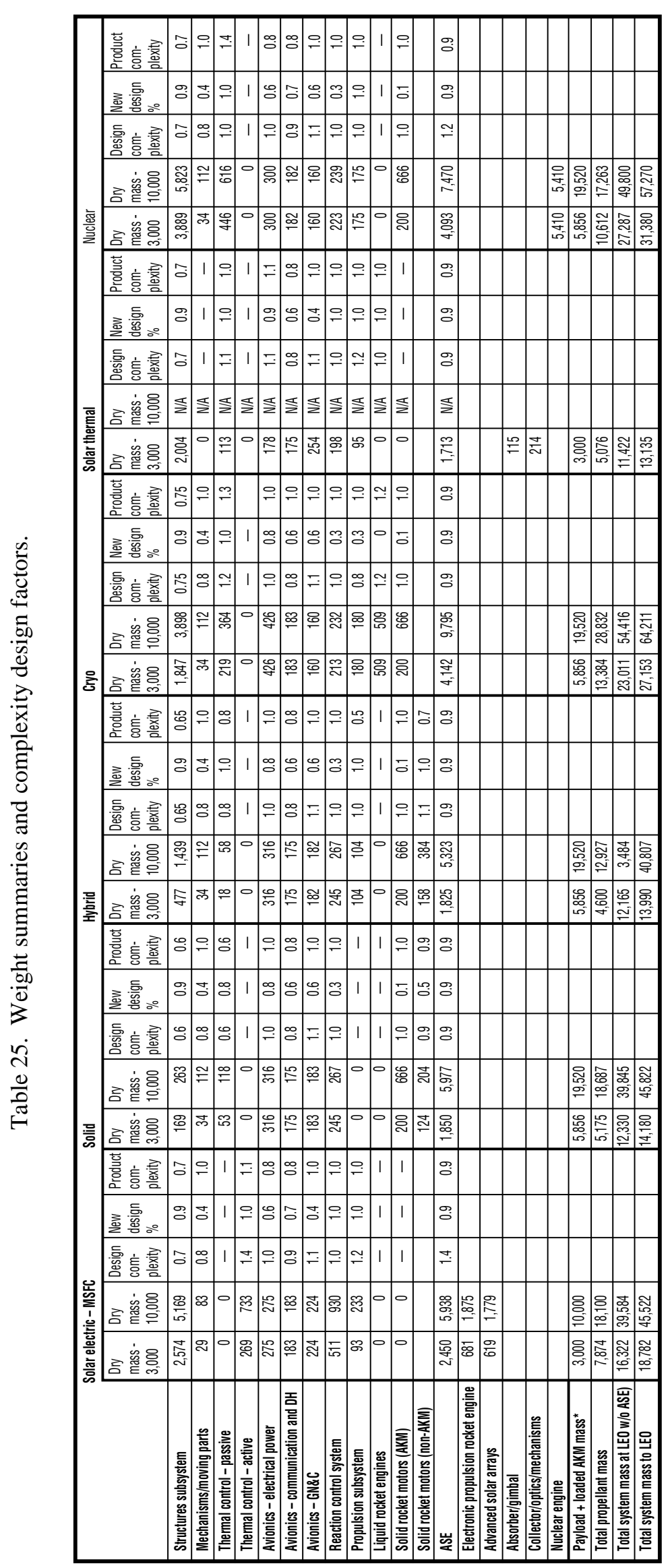


GEO Delivery Cost/lb for 3,000-lb Payload

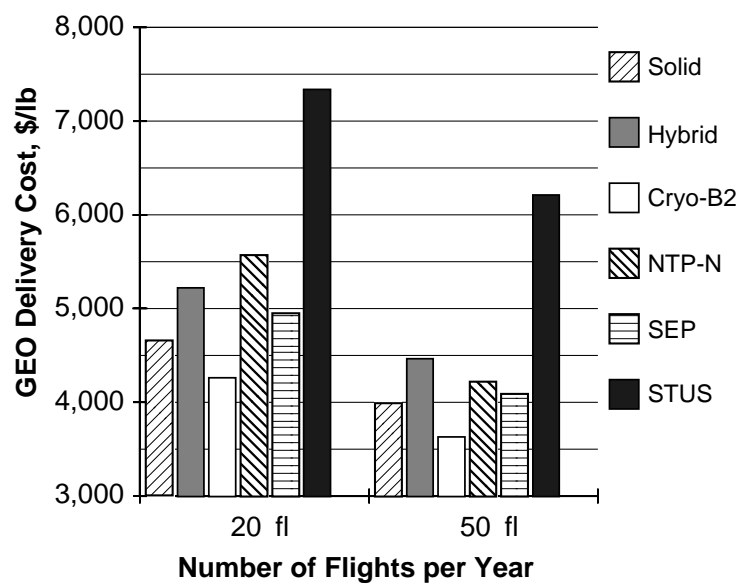

GEO Delivery Cost/lb for 10,000-Ib Payload

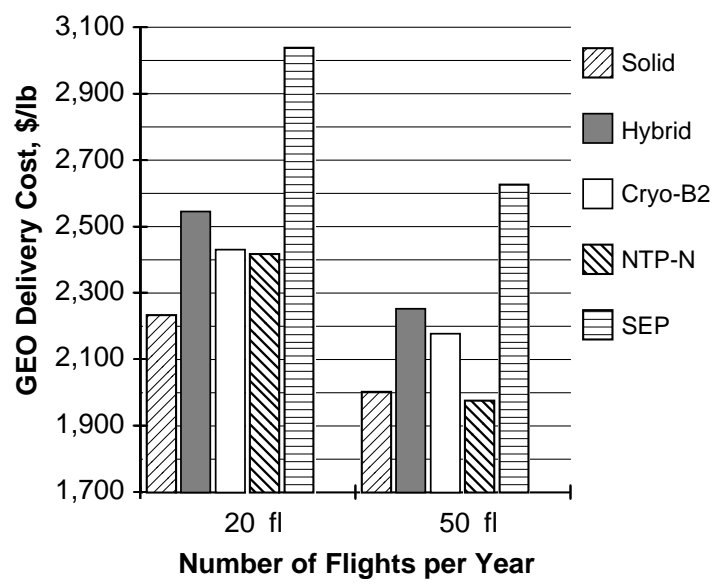

Figure 20. Cost per pound to GEO.

Launch Weights for 3,000-lb Payload

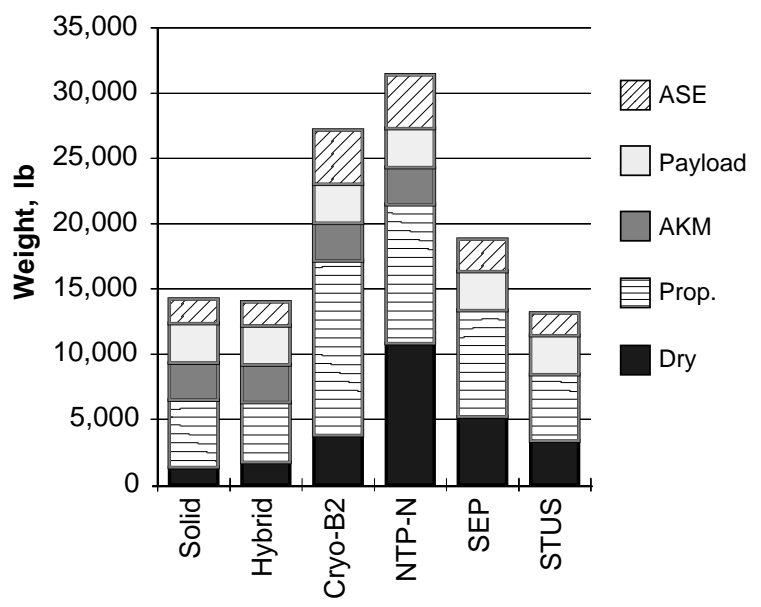

Launch Weights for 10,000-Ib Payload

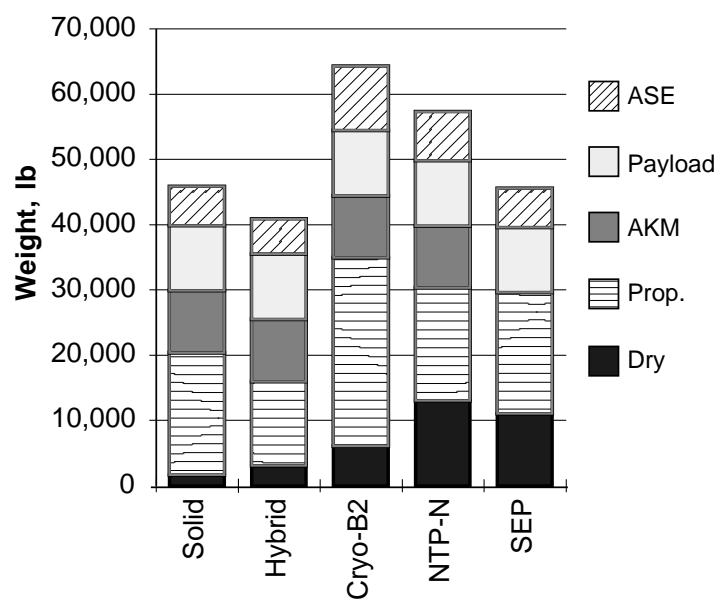

Figure 21. Mass to GEO.

\subsection{Sensitivity Results}

Several sensitivity analyses were completed to identify significant variables and their effects on the life-cycle cost of a concept. These analyses were conducted to determine the effect of changing a given variable on the life-cycle cost. Also of interest was whether the order of the concepts, from lowest to highest life-cycle cost, changed when a given variable was changed.

As shown in figure 22, changing the LEO launch costs (in dollars per pound) had a significant effect on the order of the concepts when using the 3,000-lb payload at a flight rate of 20 per year. While the $\$ 4,000 / \mathrm{lb}$ to LEO places the cryo and nuclear concepts at the highest life-cycle costs, decreasing the LEO launch costs to $\$ 100 / \mathrm{lb}$ makes these concepts competitive to the other concepts. Once launch price rises above $\$ 500 / \mathrm{lb}$, systems with greater launch mass begin to be penalized relative to those with less. For high LEO per pound launch cost, the GEO delivery cost is driven primarily by system mass. As LEO launch costs are lowered to the HRST goal, the effect of system mass on GEO launch costs is reduced. 


\section{GEO Delivery Cost/lb for 3,000-lb Payload}

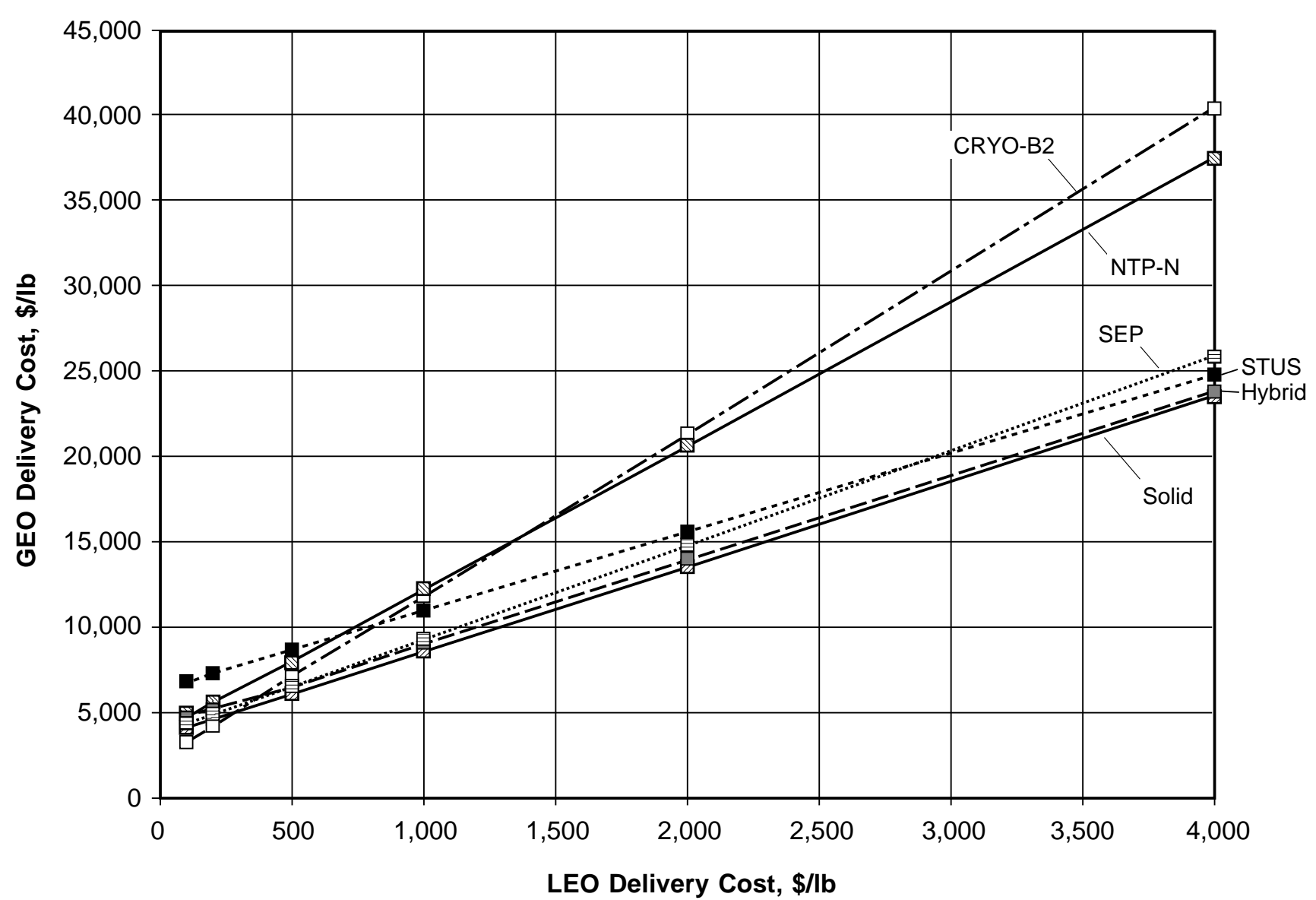

Figure 22. Varying LEO launch costs.

When the flight rate for each of the concepts was changed to 50 per year (instead of 20 per year), there was no change in the order of the concepts when listed from lowest to highest life-cycle cost for a $3,000-1 b$ payload. The only change for the 10,000-lb payload is for the nuclear concept. This concept dropped slightly below the solid concept.

Increasing the program duration spreads the DDT\&E cost over a greater number of flights and delivers small gains in unit cost due to any improvement in production learning. Figure 23 illustrates this sensitivity. Commercial investors want to see returns on investment in 10 years or less. Changing the cost of operations and facilities by a factor of two has relatively little influence on cost, as indicated in figure 24. 
3,000-Ib Payload to GEO

(LEO Delivery @ \$200/lb)

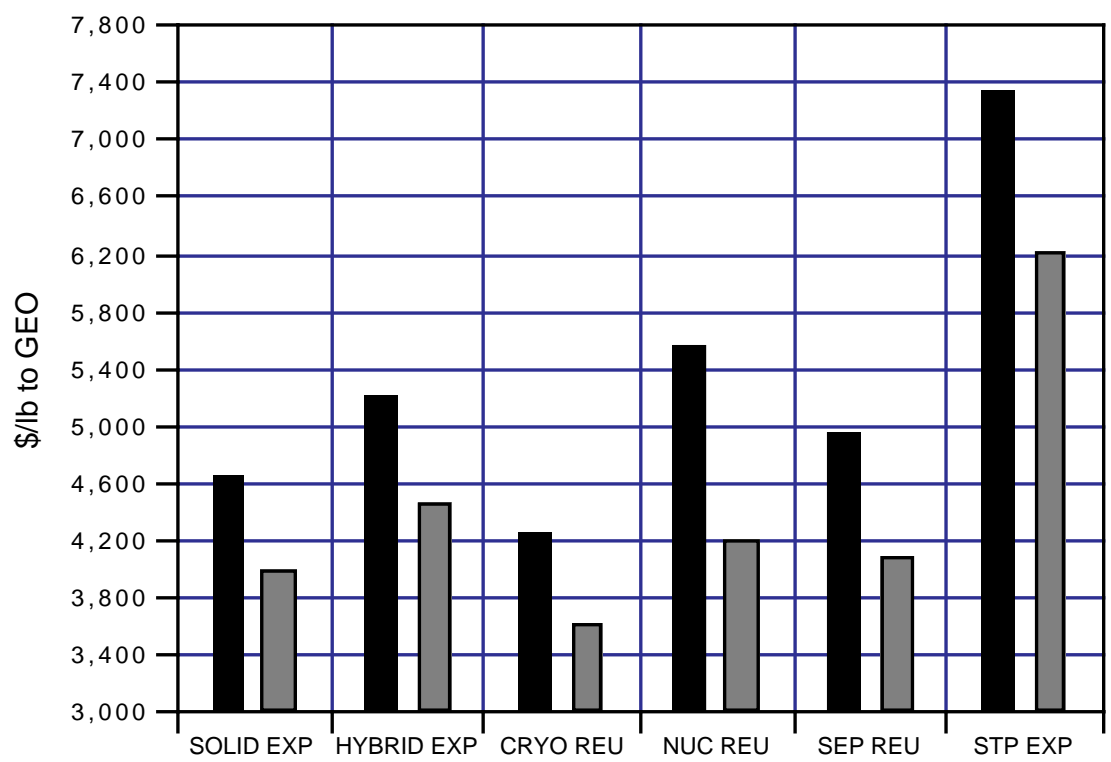

Figure 23. Effects of increase in program duration.

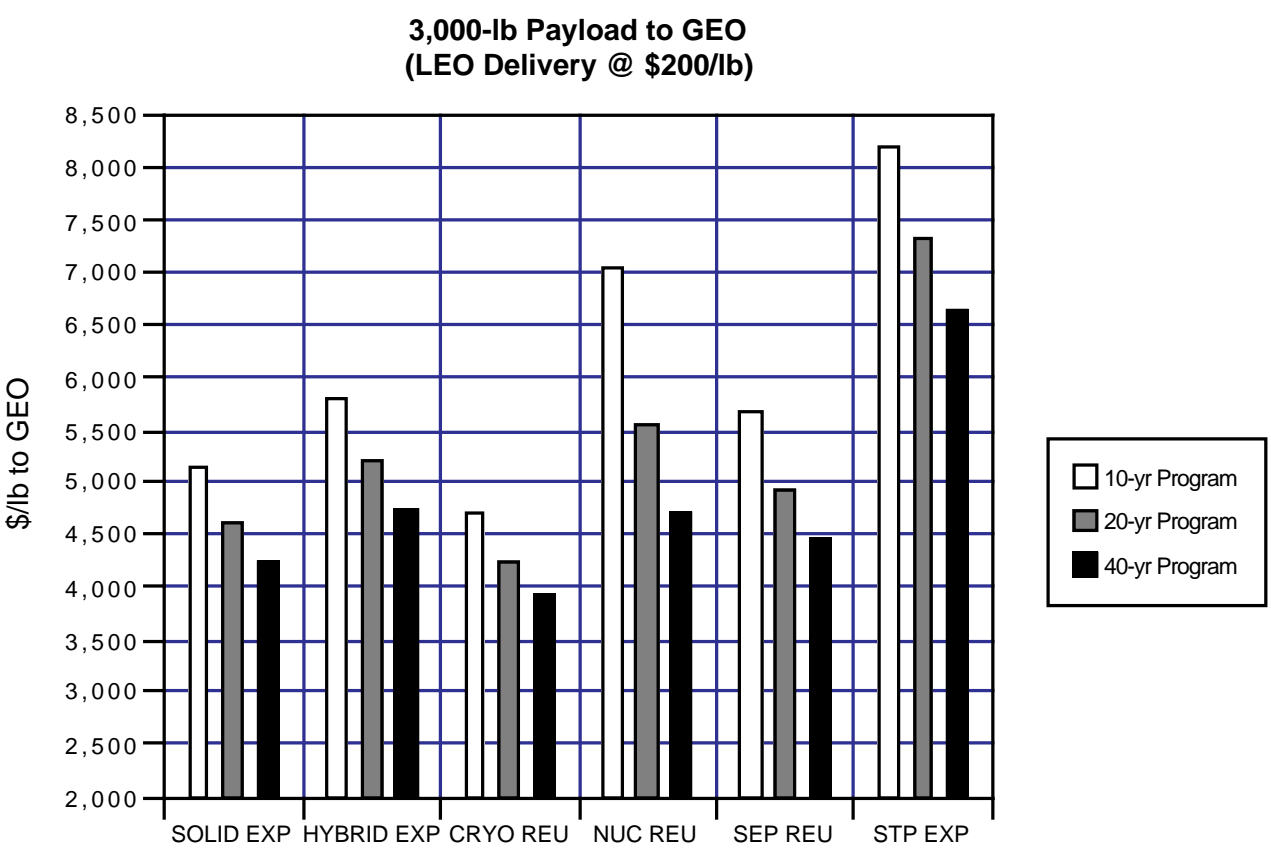

Figure 24. Effects of changing operations and facilities cost. 
Looking at varying the number of reuses for the concepts reveals a very significant effect on the dollars per pound to GEO. Care should be taken when interpreting these results, since reuse issues were only addressed by including "spare parts" for the costing for additional uses of the systems. Full consideration for the reusable designs to accommodate easy tank replacement, micrometeroid shielding, and docking/grappling systems was not taken into account. Also, required activities such as propellant resupply and payload integration for in-space reusable systems, repair and change out of parts, and diagnostic techniques for determining the health of a reusable system were not done indepth. Figure 25 shows dollars per pound to GEO versus the number of unit reuses (up to 10 reuses), for the reusable concepts from this study. Expendable systems are plotted only for one use. Reusable systems reach a roughly competitive range in 10 uses. However, even with this limited information, it is evident that with even one reuse of the unit, a significant cost savings is incurred. The graph appears to have a logarithmic shape, which indicates that there is a limit to the number of reuses that would provide any significant cost savings. Higher reusability rates offer some additional reductions, but with the other assumptions in this study (operations cost and spares requirements), most of the benefits of reuse are obtained in 10 uses. In general, the higher the first-unit cost, the higher the number of reuse flights required to be cost competitive. If operations and spares costs can be driven to low levels, as is the case for aircraft, greater numbers of reuses, at least up to thousands, offer significant payoff.

Combining projected improvements for rate, reliability, facilities, and reuse results in a cost for the reusable cryo system at the 3,000-lb payload of a little over $\$ 3,000 / 1 b$. Thus, combinations of the sensitivities do not enable reaching the study goal. The two greatest leverages for life-cycle cost, apart from launch cost, are launch mass and hardware production cost. A cursory examination of cost graphs in the preceding sections, especially those showing contributions to total cost per pound, indicates that launch mass and hardware production cost must be attacked to have any chance of reaching the cost goals. Appendix $\mathrm{K}$ identifies some areas where mass reduction could be accomplished.

\section{3,000-Ib Payload to GEO (LEO Delivery @ \$200/lb)}

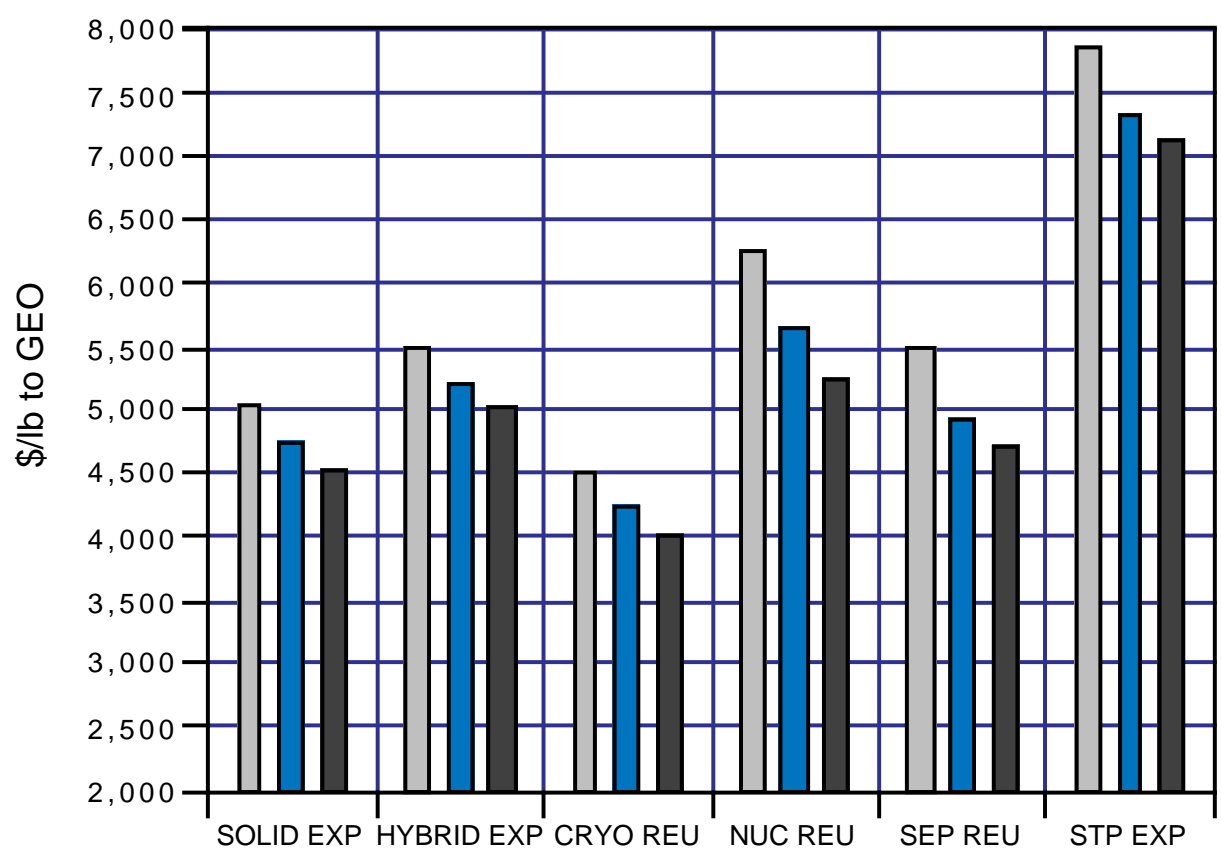

Figure 25. Dollars per pound to GEO versus the number of unit reuses. 


\subsection{CONCLUSIONS AND RECOMMENDATIONS}

\subsection{Study Conclusions}

A. LEO transportation costs, even at $\$ 200 / \mathrm{lb}$, was still a dominant cost (first or second highest) in the life of every concept evaluated. Sensitivity studies reveal that launch costs must drop below $\$ 100 / 1 b$ before LEO transportation costs become less significant. Efforts must also be made to further reduce the weight to be launched_especially the stage dry weight and the ASE weight.

B. Stage production costs, even with a 90-percent learning curve, was also a dominate cost (first or second highest) in the life of every concept evaluated. Sensitivity studies reveal that the learning curve must drop below 80 percent before stage production costs become less significant. For all of these systems, especially the reusable systems, incorporating technologies and practices that would increase the reliability of the systems to a desirable level would lower the need for replacement vehicles and lower the stage production costs effect on life-cycle costs. Efforts must also be made to further reduce the first unit cost-especially for the structures, GN\&C, and advanced solar arrays subsystems (note that this is based upon costing using weights and complexity factors).

C. The specified HRST design, as specified in this study, cannot provide a single launch for any of the concepts to deliver a 10,000-lb payload to GEO. A single launch is required just for the payload and AKM (if required). The HRST should be able to provide a single launch for the solid, hybrid, SEP, and STUS concepts to deliver a 3,000-lb payload to GEO. A slightly larger version should be able to provide a single launch for the cryogen concept. Note that this is based upon weight values alone; volumes of the systems with the payloads were not investigated.

D. Total nonrecurring costs were four to ten times lower than total recurring costs for the concepts evaluated.

E. Investments need to be made in automated or semi-automated on-orbit refueling, assembly, and payload processing if the HRST is to accommodate the 3,000-lb payload nuclear concept, as well as the 10,000-lb payload concepts.

\subsection{Recommendations for Future Studies}

A. Explore indepth the issues and technological requirements of reusable systems. A comparison could then be made between reusability and expendability for the solar thermal system, and an understanding gained of the complexities and potential cost savings of reusability.

B. Study in more detail what could be done to reduce the costs further.

C. Examine in more detail the tether systems. This study looked at the dynamic tether, however not enough information was available to do an indepth analysis of this concept. More careful study is required to understand the cost saving potential of a tether concept. Study of other tether concepts is also recommended including the electro dynamic tether concept and a mechanical momentum exchange concept. These additional concepts should be examined to understand their orbit transfer capability and limits. 
D. The life-cycle cost model that was developed and used in this study could be used as a tool to look at previous studies on in-space systems. Previous cost analyses have not included an indepth analysis of complete life-cycle costs. This life-cycle cost model could also be used for further studies. Some refinement of the model is recommended, especially in the area of operations, including ground and in-space operations and facility requirements. 


\section{REFERENCES}

1. "NASA Code XL Expendable Launch Vehicle (ELV) Manifest and Long Range Planning Status." August 16, 1995.

2. "NASA Code MO STS Flight Assessment Working Group Planning Manifest." May 19, 1995.

3. “Air Force Space Command National Mission Model.” POM-In Requirements, May 1, 1995.

4. "Air Force Space Command Traffic Rate Projection." Fax provided by AFSPC Launch Services Office, August 3, 1995.

5. “Commercial Spacecraft Mission Model Update." COMSTAC, May 18, 1995.

6. "LEO Commercial Market Projection." Office of the Associate Administrator for Commercial Space Transportation, Federal Aviation Association, Department of Transportation, May 16, 1995.

7. "RLV Upper Stage Study." Final Presentation, January 1995, an in-house study by NASA Marshall Space Flight Center.

8. Fitzsimmons, Major J.: “Advanced Upper Stage Options for Future DOD Missions." AIAA Technical Paper 94-4585.

9. Fitzsimmons, Major J.: "Technology Considerations for Future Upper Stages." AIAA Technical Paper 94-4636.

10. Isakowitz, S.J.: "International Reference Guide to Space Launch Systems." American Institute of Aeronautics and Astronautics (AIAA), Inc., Washington, DC, 1991.

11. Wilson, A.: “Jane's Space Directory.” Ninth edition, 1993-1994, Jane's Information Group, Inc., Alexandria, VA.

12. "Advanced Propulsion System Concepts for Orbital Transfer Study: Final Report," vol. II. Study Technical Results, 1981, Boeing document D180-26680-1.

13. Palaszewski, B.: "Lunar Missions Using Advanced Chemical Propulsion: System Design Issues." Journal of Spacecraft and Rockets, vol. 31, No. 3, May-June 1994, AIAA, Inc., pp. 459-469.

14. "Centaur: Monthly Letter Progress Report." August 15, 1962, General Dynamics document AE620069-8, Declassified in 1965.

15. "Solar Thermal Upper Stage (STUS)." Presentation/Report, vol. 1, Technical, August 1994, an inhouse study by NASA Marshall Space Flight Center.

16. Palac, D.T., and Rawlin, V.K.: "Solar Electric Propulsion: A Technology for Increasing Value in the Era of Space Vehicle Down-Sizing." AIAA Technical Paper, 1994.

17. Landis, G.A., Bailey, S.G., et al.: "Advances in Solar Cell Technology." AIAA Technical Paper, January 1995.

18. Kingsbury, N.R.: "Space Nuclear Propulsion: History, Cost, and Status of Programs." United States General Accounting Office Report 949235, October 1, 1992. 
19. Borowski, S.K., and Corban, R.R.: "A Revolutionary Lunar Space Transportation System Architecture Using Extraterrestrial Lox-Augmented NTR Propulsion.” AIAA Technical Paper 94-3343, presented June 1994.

20. Powell, J.R., Todosow, M., and Ludewig, H.: "Small Low Mass Advanced PBR's for Propulsion." Brookhaven National Laboratory Paper 49696, January 1994.

21. Koehlinger, M.W., et al.: "Gas Core Nuclear Thermal Rocket Engine Research and Development in the Former USSR.” EG and G Energy Measurements, Inc., document EGG-NE-10391, September 1992.

22. "National Advanced Optical Mission Initiative (NAOMI) Laser Beamed Power Studies: Final Report." Performance and Economics Analysis, Boeing document D683-30027-1, January 1995.

23. “X-34 Hybrid Upper Stage Proposal.” NASA/MSFC Solid Propulsion Branch, March 27, 1995.

24. “Inertial Upper Stage Operations Manual.” Boeing document D290-10554-1. 


\section{APPENDIX A}

\section{STUDY TEAM}

The AIST study team consisted of members from both NASA MSFC and Boeing. Participants are listed below:

\author{
NASA Study Team Members \\ Robert Armstrong \\ Leslie Curtis \\ John Fikes \\ Scott May \\ Jim McCarter \\ Jeff Morton \\ Mahmoud Naderi \\ Saroj Patel \\ Alan Philips \\ James Thompson \\ Stephen Tucker \\ Melissa Van Dyke \\ Ron White \\ Jim Wiser

\section{Boeing Study Team Members} \\ Patricia Buddington \\ Benjamin Donahue \\ Ronnie Lajoie \\ Monte Perry \\ Jim Turney \\ Irwin Vas \\ Gordon Woodcock
}

\section{Pugh Concept Selection Team Members:}

NASA:

Alan Adams

Robert Armstrong

Norman Brown

Janet Crawford

Leslie Curtis

James Thompson

Boeing:

Patricia Buddington

Benjamin Donahue

Ronnie Lajoie

Monte Perry

Irwin Vas

Gordon Woodcock

\section{NASA Responsibilities}

- Determination of mission models

- Final documentation (final report) of study results

- Operations queing model program

- Assignment of complexity factor for all concepts

- All details associated with the solar thermal, solid, and hybrid concepts

- NASCOM costing of all concepts

\section{Boeing Responsibilities}

- Phase 2 and Phase 3 costing (except for NASCOM)

- All details associated with cryogenic, nuclear, tether, solar electric, and laser concepts

- Operations (except for queing model)

- Sensitivity cost results

- Chemical propulsion trades

- Lunar and Planetary, and Mass Reductions Appendices

\section{Joint Responsibilities}

- Concept assumptions

- Pugh concept process and results

- Operations assumptions

- Recommendations and analysis

- Conclusions and recommendations

- Initial concept identification and selections 



\section{APPENDIX B}

\section{COST MODEL}

\section{B.1 Nonrecurring Costs}

\section{B.1.1 Design, Development, Test, and Evaluation Cost Model}

Since the AIST concepts incorporate only those technologies that are at TRL-6 or higher by the year 2005, the DDT\&E cost does not include any research and development (R\&D) cost to bring current (1995) pre-TRL-6 concept technologies up to TRL-6 or beyond. Subsystems costed are structures, mechanisms, passive thermal control, active thermal control, electric power, C\&DH, GN\&C, reaction control system, propulsion, SRM's, liquid rocket engines, advanced solar arrays, electric propulsion engine, nuclear rocket engine, absorber/gimbal, collector/optics/mechanism, AKM, and ASE. Each upper stage concept does not necessarily utilize all of these subsystems.

NASCOM was used to compute, where feasible, the DDT\&E cost (in 1995 dollars) associated with each upper stage concept. This cost is the sum of the design and development (D\&D) and the system test hardware cost. (The D\&D cost is the summation of the costs for design and development for each specified subsystem, ground support equipment (GSE), system engineering and integration (SE\&I), and program management. The system test hardware cost is the summation of the costs of the system test hardware for each specified subsystem, integration, assembly, and check-out (IA\&CO), system test operations, GSE, system engineering and integration (SE\&I), and program management.) Typical Government-funded contract fees, program support, and contingency, were not included since the upper stage was assumed to be a commercial development for the AIST study.

For subsystems contained in the NASCOM data base/model, the DDT\&E cost for each subsystem is computed with the following equation:

$$
C D=a * W^{b} * f_{D C} * f_{N D},
$$

where $W$ is the weight of the subsystem, $a$ and $b$ are subsystem DDT\&E cost coefficients from the NASCOM model, $f_{D C}$ is a user-specified subsystem design complexity factor, $f_{N D}$ is a user-specified subsystem new design percent factor.

For the structures, passive thermal, active thermal, avionics (power, C\&DH, GN\&C), reaction control system (RCS), propulsion, liquid rocket engines, and ASE subsystems, the coefficients $a$ and $b$ are based on those provided for the Atlas Centaur-G upper stage. For the main SRM's subsystem, the coefficients $a$ and $b$ are based on those provided for the Boeing inertial upper stage (IUS). For the AKM subsystem, the coefficients $a$ and $b$ are based on those provided for the average unmanned Earth orbital spacecraft. For each subsystem, the design complexity factor is based on the design difficulty when compared to the design complexity of a reference vehicle (i.e., Centaur-G, a reference vehicle is assigned a factor of one). Table B-1 describes the design complexity factors. The percent new design factor indicates the percentage of new design for the vehicle as compared to a frame of reference vehicle (i.e., a 1 indicates a 100 percent new design). Table B-2 describes the new design percent factors.

Table B-1. NASCOM design complexity factors.

\begin{tabular}{|l|l|}
\hline Factor Range & \multicolumn{1}{c|}{ Explanation } \\
\hline 0.1 to 0.2 & Extremely low complexity compared to the NASCOM reference \\
0.3 to 0.5 & Very low complexity compared to the NASCOM reference \\
0.6 to 0.9 & Moderately low complexity compared to the NASCOM reference \\
1.0 & Equivalent complexity compared to the NASCOM reference \\
1.1 to 1.5 & Moderately high complexity compared to the NASCOM reference \\
1.6 and up & Very high complexity compared to the NASCOM reference \\
\hline
\end{tabular}


Table B-2. NASCOM new design percent factors.

\begin{tabular}{|l|l|}
\hline Factor Range & \multicolumn{1}{c|}{ Explanation } \\
\hline 0.0 & Totally off the shelf; hardware may be purchased; no qualification needed \\
0.1 to 0.2 & Mostly off the shelf; requires very minor modifications and qualifications \\
0.3 to 0.4 & Mostly designed; requires minor modifications and qualifications \\
0.5 to 0.6 & Basic design exists, but requires significant modifications (about half) \\
0.7 to 0.8 & Similar design exists, but requires major modifications (mostly new) \\
0.9 & Almost equivalent DDT\&E effort compared to the NASCOM reference \\
1.0 & Equivalent DDT\&E effort compared to the NASCOM reference \\
1.1 and up & Additional DDT\&E effort compared to the NASCOM reference \\
\hline
\end{tabular}

For subsystems not contained in the NASCOM data base/model, the DDT\&E cost is determined by outside means. These subsystems include solar thermal absorber, concentrator, gimbals, struts, solar electric advanced solar arrays, electric propulsion engine, and nuclear thermal propulsion engine. The solar thermal absorber, concentrator, gimbals, and struts costs are based on previous work performed by NASA MSFC for a solar thermal upper stage study. The solar electric advanced solar arrays cost is set to twice the associated first-unit production cost. The electric propulsion engine cost is set equal to the solar thermal absorber cost. The nuclear thermal propulsion engine cost is based on previous work performed by NASA Lewis Research Center for a NERVA-derived 15,000-lb-thrust engine study.

\section{B.1.2 ASE Production}

ASE production cost is equal to the number of ASE units required multiplied by the associated first-unit production cost. The number of ASE units is expected to be low, so no production efficiency factor is applied.

\section{B.1.3 Refuel Tank Production}

Since the refuel tank for the reusable concepts is the same as the fuel tank for a new stage, there is no (or very negligible) additional DDT\&E cost for the refuel tank. Refuel tank production cost is equal to the number of refuel tanks required multiplied by the associated first-unit production cost. The number of refuel tanks is expected to be low, so no production efficiency factor is applied.

\section{B.1.4 Facility Nonrecurring}

Facility nonrecurring cost is based on whether the stage concept is expendable, reusable, or reusable nuclear. Facility nonrecurring cost for expendable upper stage concepts is equal to $\$ 35 \mathrm{M}$; $\$ 15 \mathrm{M}$ to cover construction of buildings and installation of basic essentials (power, water, heating, etc.), and \$20M to cover the purchase and installation of furniture, phones, computers, and other equipment. Facility nonrecurring cost for reusable upper stage concepts (except nuclear) is equal to 1.4 times that of expendable concepts, to $\$ 50 \mathrm{M}$, to cover the additional facilities required for refurbishment of engines and/or refuel tanks. Facility nonrecurring cost for reusable nuclear upper stage concepts is equal to 2.0 times higher that of nonnuclear reusable concepts, to $\$ 100 \mathrm{M}$, to cover the additional facilities required for handling nuclear engines.

\section{B.2 Recurring Costs}

\section{B.2.1 LEO Transportation}

The cost for LEO transportation is equal to the total weight to be transported to LEO multiplied by the HRST LEO transportation cost per pound. For the expendable upper stage concepts, the total weight transported to LEO is the summation of the weight delivered to LEO (including the associated ASE weight), multiplied by the number of flights. For the reusable upper stage concepts, the total weight transported to LEO for new stages is the summation of the total weight transported to LEO for new stages (including the associated ASE weight) multiplied by the number of flights which deliver new stages, and 
the total weight transported to LEO for reused stages (including the associated ASE weight) multiplied by the number of flights which deliver reused stages.

\section{B.2.2 Upper Stage Production}

The subsystems are structures, mechanisms, passive thermal control, active thermal control, electric power, C\&DH, GN\&C, reaction control system, propulsion, SRM's, liquid rocket engines, electric propulsion engine, advanced solar arrays, absorber/gimbal, collector/optics/mechanism, nuclear rocket engine, apogee kick motors, and airborne support equipment. Each upper stage concept does not necessarily utilize all of these subsystems.

NASCOM was used to compute, where feasible, first-unit production cost (in 1995 dollars) associated with each upper stage concept. This cost is the sum of the costs for each specified subsystem, SE\&I, and program management. Typical Government-funded contract fees, program support, and contingency were not included since the upper stage is assumed to be a commercial development.

For subsystems which are contained in the NASCOM data base/model, the first-unit production cost for each subsystem is computed with the following equation:

$$
C D=a * W^{b} * f_{P C},
$$

where $W$ is the weight of the subsystem, $a$ and $b$ are subsystem first-unit production cost coefficients from the NASCOM model, $f_{P C}$ is a user-specified subsystem production complexity factor.

For the structures, passive thermal, active thermal, avionics (power, C\&DH, GN\&C), RCS, propulsion, liquid rocket engines, and ASE subsystems, the coefficients $a$ and $b$ are based on those provided for the Atlas Centaur-G upper stage. For the main SRM's subsystem, the coefficients $a$ and $b$ are based on those provided for the Boeing IUS. For the AKM subsystem, the coefficients $a$ and $b$ are based on those for the average unmanned Earth orbital spacecraft. For each subsystem, the production complexity factor is based on the manufacturing difficulty when compared to the manufacturing complexity of a reference vehicle (i.e., Centaur-G, a reference vehicle is assigned a factor of one). Table B-3 describes the production complexity factors.

Table B-3. NASCOM production complexity factors.

\begin{tabular}{|l|l|}
\hline Factor Range & \multicolumn{1}{|c|}{ Explanation } \\
\hline 0.1 to 0.2 & Extremely low complexity compared to the NASCOM reference \\
0.3 to 0.5 & Very low complexity compared to the NASCOM reference \\
0.6 to 0.9 & Moderately low complexity compared to the NASCOM reference \\
1.0 & Equivalent complexity compared to the NASCOM reference \\
1.1 to 1.5 & Moderately high complexity compared to the NASCOM reference \\
1.6 and up & Very high complexity compared to the NASCOM reference \\
\hline
\end{tabular}

For subsystems not contained in the NASCOM data base/model, the first-unit production cost is determined by outside means. These subsystems include solar thermal absorbers, concentrators, gimbals, and struts, solar electric advanced solar arrays, and electric propulsion engines, and nuclear thermal propulsion engines. The solar thermal absorber, concentrator, gimbals, and struts costs are based on previous work performed by NASA MSFC for a solar thermal upper-stage study. The solar electric advanced solar arrays are produced at $\$ 600 / \mathrm{W}$. The electric propulsion engine cost is equal to the solar thermal absorber first-unit production cost. The nuclear thermal propulsion engine cost is based on previous work performed by NASA Lewis for a NERVA-derived 15,000-lb-thrust engine study.

A production efficiency factor was used for those subsystems contained in the NASCOM data base/model. The factor was based on a production learning curve (LC) percent as follows:

$$
f_{P E}=\left[\left((N+0.5)^{E}-1.5^{E}\right) / E+1\right] / N
$$


where $N$ is the number of upper stages or AKM's required or the number of "reused stage" flights requiring replacement parts, and

$$
E=\ln (L C) / \ln (2)+1
$$

Upper-stage production cost for each concept is equal to the number of upper stages required multiplied by the first-unit production cost as computed via NASCOM, multiplied by a production efficiency factor. AKM production cost is equal to the number of AKM's required multiplied by the first-unit production cost as computed via NASCOM, multiplied by a production efficiency factor.

\section{B.2.3 Replacements/Spares}

For reusable upper-stage concepts, the replacement parts/spares are the same as those produced for the stages, so there is no additional DDT\&E cost. Production cost is equal to the number of replacement part sets required multiplied by the associated first-unit production cost as computed via NASCOM, multiplied by a production efficiency factor.

\section{B.2.4 Operations/Labor}

For all upper stage concepts, the average burdened hourly wage for ground operations personnel is $\$ 50 / \mathrm{h}$ (based on discussions with Boeing IUS management). This wage accounts for the average perworker cost of technician-level salary, benefits (i.e., holidays, vacations), and overhead (i.e., ground operations administrative support and management oversight). The average burdened hourly wage for mission operations personnel is $\$ 100 / \mathrm{h}$ (based on discussions with Boeing IUS management). This wage accounts for the average per-worker cost of engineer-level salary, benefits, and overhead (i.e., mission operations administrative support and management oversight). Based on standard Boeing cost-estimation practices, the average number of hours worked per year per worker is 1,840 $\mathrm{h}$. All facility-related costs are handled separately (i.e., wages do not pay for the average per-worker cost of building and equipment maintenance and depreciation, nor utilities).

Operations labor cost is equal to the sum of the ground operations labor cost and the mission operations labor cost. Ground operations labor cost is equal to the number of ground operations personnel required, multiplied by the appropriate burdened hourly wage, multiplied by the number of hours worked per year, and multiplied by the number of years required details the operations labor cost model. Mission operations labor cost is equal to the number of mission operations personnel required, multiplied by the appropriate burdened hourly wage, multiplied by the number of hours worked per year, and multiplied by the number of years required. Appendix F details the operations/labor cost model.

\section{B.2.5 Facility Maintenance}

Facility maintenance cost is equal to the number of years required multiplied by the annual facility maintenance cost. Annual facility maintenance cost for each upper stage concept is 10 percent of the associated facility nonrecurring cost. This pays for the average annual cost of building and equipment maintenance and depreciation, and utilities (electricity, water, phone, etc.).

\section{B.2.6 Raw Propellant}

The cost for solid propellants is $\$ 3 / 1 b$. This cost encompasses the solid and hybrid concepts as well as the AKM's. The cost for liquid hydrogen is $\$ 2.50 / \mathrm{lb}$. This encompasses the cryogen, solar thermal, and nuclear thermal concepts. The cost for lox propellant is $\$ 1 / \mathrm{lb}$. This encompasses the hybrid, storable, and cryogen concepts. The cost for all other liquid propellants is $\$ 10 / 1 b$. This includes the liquid xenon or hydrazine used by solar electric propulsion upper stage concepts. 
Propellant cost is equal to the sum of upper stage propellant and AKM cost. For each concept, the total propellant cost is computed as the total propellant weight required per flight, multiplied by the number of flights, and multiplied by the raw propellant cost per pound. 



\section{APPENDIX C}

\section{LASER ELECTRIC}

A previous study (NAOMI) had indicated cost advantage for a laser-electric propulsion system compared to a reusable cryogenic upper stage of the type considered for this study. The laser electric system uses a high-power ground-based laser to illuminate a photovoltaic receiver on the upper stage at several suns' intensity. The higher conversion efficiency attainable with monochromatic light, 50 percent, and the high intensity, give the electric propulsion upper stage very high power generation performance. A disadvantage is that opportunities for power transfer are infrequent when the vehicle is in a low orbit.

\section{C.1 Laser Electric Concept}

The laser electric concept is derived from the SELENE and NAOMI studies. The laser electric system uses one or more high-power ground-based lasers to illuminate a photovoltaic receiver on the upper stage at several Suns' intensity. The higher conversion efficiency attainable with monochromatic light, 50 percent at reference temperature, and the high intensity, give the electric propulsion upper stage very high power generation performance. The reference system of these studies used four to six ground-based laser sites.

The actual efficiency achieved in the baseline system is about 30 percent because it is optimal to operate the photovoltaic array at several Suns' intensity which drives its efficiency down due to thermal coefficient of the photovoltaics. The reference system operated at 7 Suns, with a gallium arsenide array temperature about $200{ }^{\circ} \mathrm{C}$. The laser power on the array is $300 \mathrm{~kW}$, which requires a total laser light output (on the ground) between 1 and $2 \mathrm{~mW}$. The electric output is $91 \mathrm{kWe}$, which rates this system nearly twice the power of the SEP evaluated in this study. The array output is about $3,000 \mathrm{~W} / \mathrm{m}^{2}$ compared to about $240 \mathrm{~W} / \mathrm{m}^{2}$ for the SEP.

The overall upper stage dry mass was estimated at $1,783 \mathrm{lb}$, which is very light compared to the SEP considered in this study at over 5,000 lb. The total propellant load was 2,630 lb. The payload was 4,000 lb. The initial mass in Earth orbit was 8,413 lb. Because the laser electric system has higher power and less mass it tends to optimize at higher Isp; the NAOMI study of orbit transfer used $800 \mathrm{~s}$ for leg 1, from $500 \mathrm{~km}$ circular to 5,000 km circular, and 3,000 s for leg 2 and the entire return profile.

The low inert mass compared to the present study arose from very aggressive technology projections in addition to the high performance of the photovoltaic collection and conversion system. It was assumed, for example, that the laser electric vehicle would be assembled on orbit and its structure therefore would not have to carry launch loads. Avionics were assumed to be "new millennium" class. Technology levels for the electric propulsion system and its thermal control system were, by comparison, less aggressive. The propellant system was assumed 15 percent of propellant mass, which is reasonably conservative unless the propellant is hydrogen.

Two legs are used on the ascent mission because the laser electric propulsion stage, in a LEO, is in a line-of-sight position relative to one of the lasers only about 2 percent of the time. Therefore, thrusting opportunities are infrequent. Use of reduced Isp and high efficiency resistojet thrusters for the early part of ascent increases the thrust available by about a factor of 6 compared to the 3,000 Isp system. This reduces the time spent in leg 1 by this factor. Once altitude of a few thousand kilometers is achieved, the illumination duty factor is much improved and the system switches to high Isp. It can be shown that under this illumination situation, a dual-Isp approach gives less initial mass for any specified trip time. Continuously variable Isp offers further improvement, but implementation of continuously variable Isp might prove difficult. 
A point design was not created, as study resources were very meager.

\section{C.2 Reusable Cryogenic Concept}

The reusable cryogenic concept was the same as chosen for the present study, i.e., a reusable hydrogen-oxygen system which delivers a payload plus AKM to geosynchronous transfer, and then returns to LEO for reuse. The stage was assumed left in LEO and refueled there for the next mission instead of returned to Earth for reuse processing as in the present study.

A significant difference was the lower cryo stage inert weight assumed for the NAOMI studies. At the time this trade was done, inerts estimates for the present study were not available so the earlier NAOMI values were used. The propellant fraction was 0.85 compared with approximately 0.77 in the present study. A propellant fraction near 0.85 is believed achievable with advanced technology structures and avionics.

\section{C.3 Cost Leverages of the Laser System}

The laser system has a low resupply mass compared to the cryogenic system. Since the laser system delivers the payload to GEO (not to GTO) it does not need an AKM. The resupply requirement to fly a "next" mission is propellant and delivery of the payload. The total delivery mass, according to the reference study, was 6,630 lb plus propellant container mass and payload transfer provisions. The reusable cryo stage was predicted by the reference study to require resupply mass over 21,000 lb. Since the range of launch (to LEO) cost for the reference study was $\$ 1,600 / \mathrm{lb}$ to $\$ 5,000 / \mathrm{lb}$, the mass advantage of the laser system translated to a very important cost advantage.

\section{C.4 Cost Model Discussion}

The reference cost model considered cost of transportation to LEO, amortization of upper stage hardware, and trip time cost. Under the ground rules of the NAOMI study, which focused on relatively high transportation cost to LEO, operations costs were not seen as important to the trade. Almost all the cost is in transport to LEO and trip time cost as shown in figure C-1. It is important to note that trip time cost was very significant in the NAOMI study and not included in the AIST study. The NAOMI study also considered effects of nonrecurring cost, but separately as an investment analysis. Life-cycle costs were not calculated. Results of investment analysis indicated that the nonrecurring investment in the laser electric system, including R\&D of the lasers, was justified at modest traffic under current launch costs. At projected RLV cost, traffic on the order of 50 payloads per year is needed to amortize the laser electric system nonrecurring cost.

\section{C.5 How Does the Trade Come Out With HRST?}

The referenced study indicated a significant trend of reducing benefit with reducing Earth-to-orbit cost. The laser electric advantage is about 2:1 at current launch cost and about 20 percent with projected RLV cost at $\$ 1,600 / 1 b$, as shown in figure $\mathrm{C}-2$, the laser electric advantage disappears under the assumptions of the reference study at a representative HRST cost of $\$ 200 / \mathrm{lb}$. At this preliminary stage of the AIST study, this result was taken as reason to eliminate the laser system from further consideration.

\section{C.6 How Can the Laser Concept Be Made More Competitive?}

The large impact of trip time cost in the reference study indicates that the laser system could be reoptimized for shorter trip time, using more power and less Isp, to become more cost competitive. Earlier laser electric parametric studies indicated feasibility of trip times as short as 20 days. The laser system 
might become competitive with the other AIST options simply by removing the trip time cost from consideration as was the norm for the AIST study.

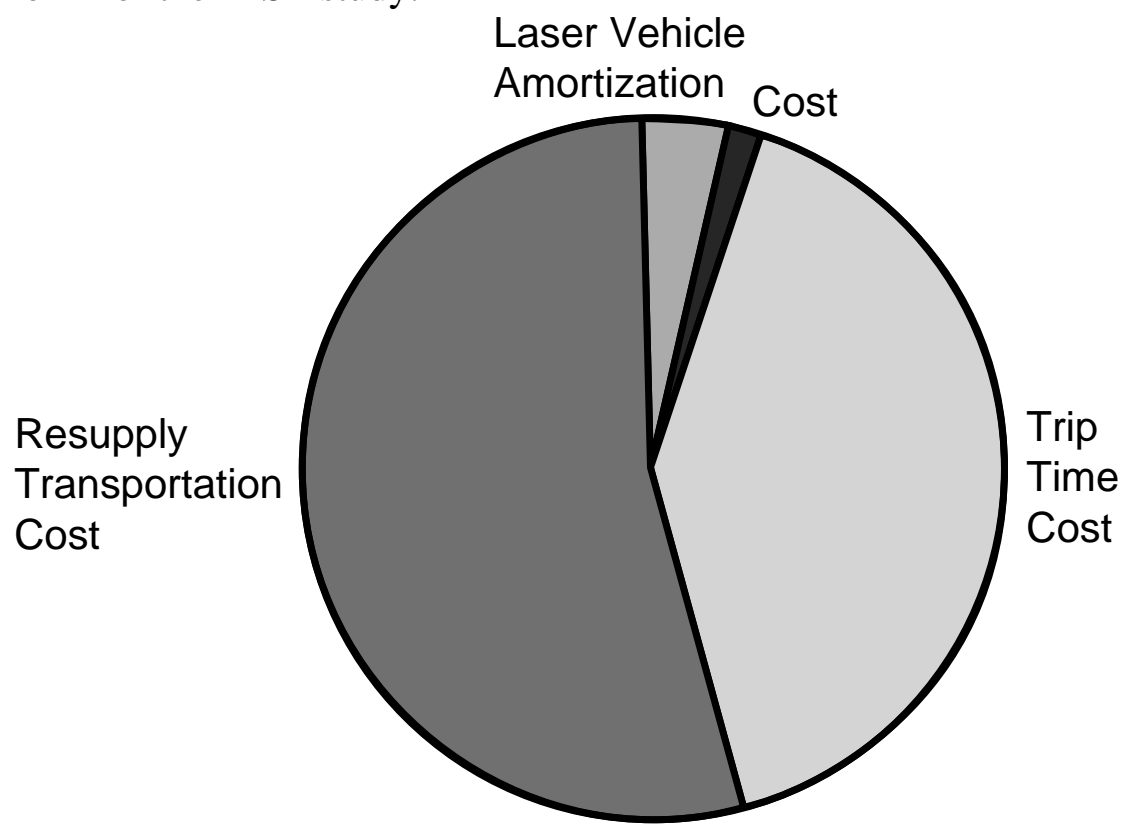

Figure C-1. Distribution of laser-electric cost in NAOMI study.

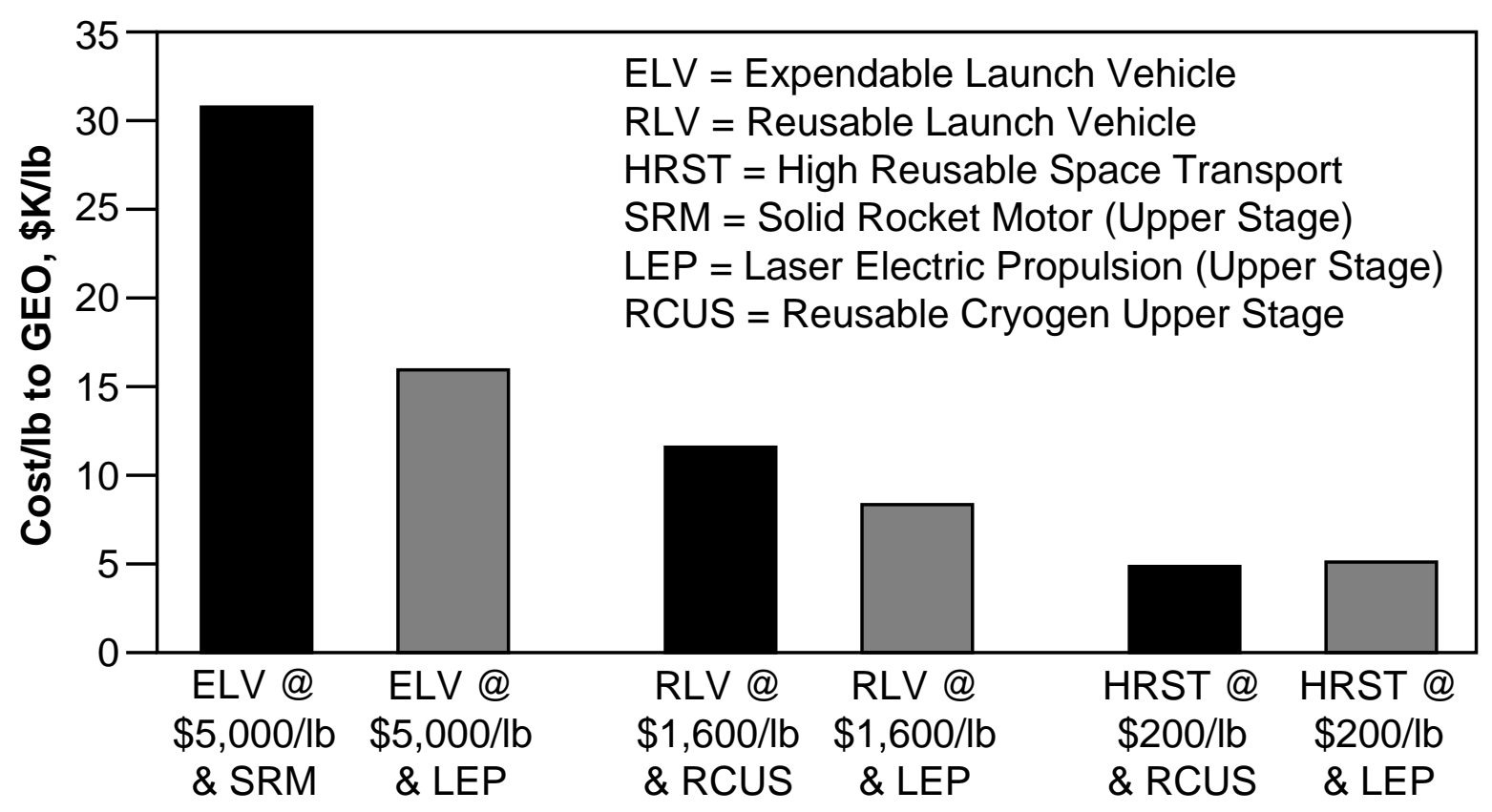

Figure C-2. Laser electric concept trades. 



\section{APPENDIX D}

\section{CHEMICAL PROPULSION CONCEPT TRADES}

The following ground rules and assumptions were used in this quick study:

- Examine payload weight of 3,000 lb and 10,000 lb.

- Launch cost-per-pound for delivery to LEO will be $\$ 200$.

- The time to recoup DDT\&E cost will be 5 years. All chemical concepts will perform the same LEO to GTO Hohmann transfer maneuver, and use the same AKM to deliver the payload from GTO to GEO.

- All ground and mission operations personnel will be full-time employees with an average cost of $\$ 100,000$ per year.

Based on current AKM design trends, ${ }^{1011}$ the AKM specific impulse was set to $310 \mathrm{~s}$, and the stage mass fraction was set to 0.90. (This was later revised for the final phase of the AIST study.) The required GTO-to-GEO delta $\mathrm{V}$ was computed to be $1,837 \mathrm{~m} / \mathrm{s}$. Inverting the rocket equation yielded a loaded AKM weight so close to the payload weight that a decision was made to set them equal for the quick study. This allowed each concept to be sized to deliver a 6,000- and 20,000-lb "payload" to or from LEO to GTO.

The quick study did not allow for much vehicle design. Therefore, the design information was limited to specific impulse, stage/propellant mass fraction, and (for reusable concepts) the number of flights per unit. Specific impulse ranged from a low of $310 \mathrm{~s}$ (for the solid concept) to a high of $480 \mathrm{~s}$ (for the cryogen concepts). Propellant mass fraction ranged from a low of 0.82 (for the cryogen-aerobrake concept) to a high of 0.92 (for the solid concept). No distinction was made between the versions which delivered a 3,000-lb payload to the ones which delivered a 10,000-lb payload. All reusable concepts were assumed to be space-based. The number of uses for each reusable concept was set at 10, by a group decision. Design-related values for all of the concepts are contained in table D-1.

Table D-1. Input values to the chemical propulsion quick study.

\begin{tabular}{|c|c|c|c|c|c|c|c|c|}
\hline & \multicolumn{4}{|c|}{ Expendable Concepts } & \multicolumn{4}{|c|}{ Reusable Concepts } \\
\hline & $\begin{array}{c}\text { Solid } \\
\text { Exp }\end{array}$ & $\begin{array}{c}\text { Hybrid } \\
\text { Exp }\end{array}$ & $\begin{array}{c}\text { Storable } \\
\text { Exp }\end{array}$ & $\begin{array}{c}\text { Cryogen } \\
\text { Exp }\end{array}$ & $\begin{array}{c}\text { Storable } \\
\text { Prop }\end{array}$ & $\begin{array}{c}\text { Storable } \\
\text { Aero }\end{array}$ & $\begin{array}{c}\text { Cryogen } \\
\text { Prop }\end{array}$ & $\begin{array}{c}\text { Cryogen } \\
\text { Aero }\end{array}$ \\
\hline Specific Impulse: & $310 \mathrm{~s}$ & $340 \mathrm{~s}$ & $350 \mathrm{~s}$ & $480 \mathrm{~s}$ & $390 \mathrm{~s}$ & $390 \mathrm{~s}$ & $480 \mathrm{~s}$ & $480 \mathrm{~s}$ \\
\hline Prop. Mass Fraction: & 0.92 & 0.88 & 0.92 & 0.90 & 0.88 & 0.84 & 0.86 & 0.82 \\
\hline Propellant Cost / lb & $\$ 20$ & $\$ 10$ & $\$ 30$ & $\$ 1$ & $\$ 5$ & $\$ 5$ & $\$ 1$ & $\$ 1$ \\
\hline Manu. Cost / lb: & $\$ 2 \mathrm{k}^{*}$ & $\$ 2 \mathrm{k} *$ & $\$ 3 \mathrm{k}^{*}$ & $\$ 5 \mathrm{k} *$ & $\$ 7 \mathrm{k}$ & $\$ 8 \mathrm{k}$ & $\$ 9 \mathrm{k}$ & $\$ 10 \mathrm{k}$ \\
\hline DDT\&E / Manu. Ratio: & $3+1 *$ & $5+1 *$ & $3+1 *$ & $3+1 *$ & 5 & 6 & 5 & 6 \\
\hline No. Flights / Vehicle: & 1 & 1 & 1 & 1 & 10 & 10 & 10 & 10 \\
\hline Parts/Prop Mass Ratio: & 0 & 0 & 0 & 0 & 0.04 & 0.05 & 0.04 & 0.05 \\
\hline Delay Time per Flight: & 0 & 0 & 0 & 0 & 3 days & 4 days & 3 days & 4 days \\
\hline Operations Staff Size: & 45 & 45 & 50 & 50 & 55 & 55 & 55 & 55 \\
\hline Facility Cost per Year: & $\$ 500 \mathrm{k}$ & $\$ 600 \mathrm{k}$ & $\$ 750 \mathrm{k}$ & $\$ 800 \mathrm{k}$ & $\$ 750 \mathrm{k}$ & $\$ 750 \mathrm{k}$ & $\$ 800 \mathrm{k}$ & $\$ 800 \mathrm{k}$ \\
\hline Delta Ops. Cost / Flt: & $\$ 86 \mathrm{k}$ & $\$ 96 \mathrm{k}$ & $\$ 86 \mathrm{k}$ & $\$ 86 \mathrm{k}$ & $\$ 14 \mathrm{k}$ & $\$ 14 \mathrm{k}$ & $\$ 14 \mathrm{k}$ & $\$ 14 \mathrm{k}$ \\
\hline
\end{tabular}

* Manufacturing Cost reduced by half via investment in automation for high-rate production.

For the reusable concepts, replacement parts weight was computed using a specified parts-topropellant weight ratio. (This was later revised to a dry weight percentage, by subsystem, for the final phase of the AIST study.) This ratio was set to 0.04 for the propulsive-deboost versions and 0.05 for the 
aerobrake versions. Assuming that reusable concepts take longer to process than expendable ones, a customer-incurred downtime-delay cost penalty was invoked to make the trade study more fair (this was dropped from the final phase of the AIST study). To cover payload-to-spacecraft space-based integration, the delay was set to 3 days for propulsive-deboost versions and 4 days for the aerobrake versions.

The size of operations salaried personnel, required for either ground or mission operations, was estimated to be between 45 and 50 for expendable concepts; and 55 for reusable (space-based) concepts.

For this quick study, a simple cost model was developed in Pascal that directly computed the lifecycle cost per flight. (This occurred prior to the development of the more detailed cost model used for the final phase of the AIST study.) Cost-per-flight was divided into five components: DDT\&E, production, resupply, delay, and operations.

DDT\&E cost was computed from the unit production cost using a specified DDT\&E-tomanufacturing cost ratio, which varied from 4 to 6 . DDT\&E cost was distributed evenly over 5 years. Cost-per-flight was then based on the number of flights per year which, for this quick study, were allowed to vary between 20 and 50, in steps of 10 .

Unit production cost was computed by multiplying the computed vehicle dry weight by a manufacturing cost per pound, which ranged from $\$ 2,000$ to $\$ 5,000 / 1 \mathrm{~b}$ for expendable vehicles, and from $\$ 7,000$ to $\$ 10,000 / 1 b$ for reusable vehicles. ${ }^{1011}$ The savings in production costs for expendable vehicles was assumed to result from automation. The DDT\&E-to-manufacturing cost ratio was increased by one for these concepts to cover this additional investment.

Resupply costs consisted of AKM, propellant, and replacement part costs. AKM dry weight and replacement parts were costed at $\$ 2,000 / \mathrm{lb}$ AKM and solid propellant was costed at $\$ 20 / \mathrm{lb}$. Cryogen propellant was costed at $\$ 1 / \mathrm{lb}$. Hybrid propellant, a mixture of the two, was costed at $\$ 10 / \mathrm{lb}$, half of the solid. Ground-based storable propellant (NTO and MMH) was costed at $\$ 30 / \mathrm{lb}$. Space-based storable propellant (lox and methane) was costed at $\$ 5 / \mathrm{lb}$. Customer-incurred delay costs were costed at $\$ 200,000$ per day. ${ }^{22}$

Operations costs consisted of salaried personnel, facility, and per-mission costs. Personnel costs were costed at $\$ 100,000$ per person per year. Facility costs were estimated to range between $\$ 500,000$ and $\$ 800,000$ per year. Additional per-mission costs, mainly to cover ground operations, ranged from $\$ 86,000$ to $\$ 96,000$ per flight for expendable AIST concepts; and was estimated at $\$ 14,000$ per flight for reusable (space-based) AIST concepts.

The results of the chemical propulsion concept quick study is shown in figures D-1 through D-3. The first observation which can be made is that no AIST concept was able to achieve the goal of only $\$ 1,000 / \mathrm{lb}$ to GEO. The second observation was that there was not a lot of variance between the concepts. The lowest cost system, at about $\$ 1,600 / \mathrm{lb}$, was a reusable cryogen with propulsive deboost AIST carrying 10,000-lb payloads to GEO 50 times per year. The highest cost system, at about $\$ 2,200 / 1 b$, was a reusable storable with aerobrake deboost AIST carrying 3,000-lb payloads to GEO 20 times per year. 
Cost/lb to transport a payload from ground to GEO for various expendable (first 4) and reusable (last 4) AIST concepts

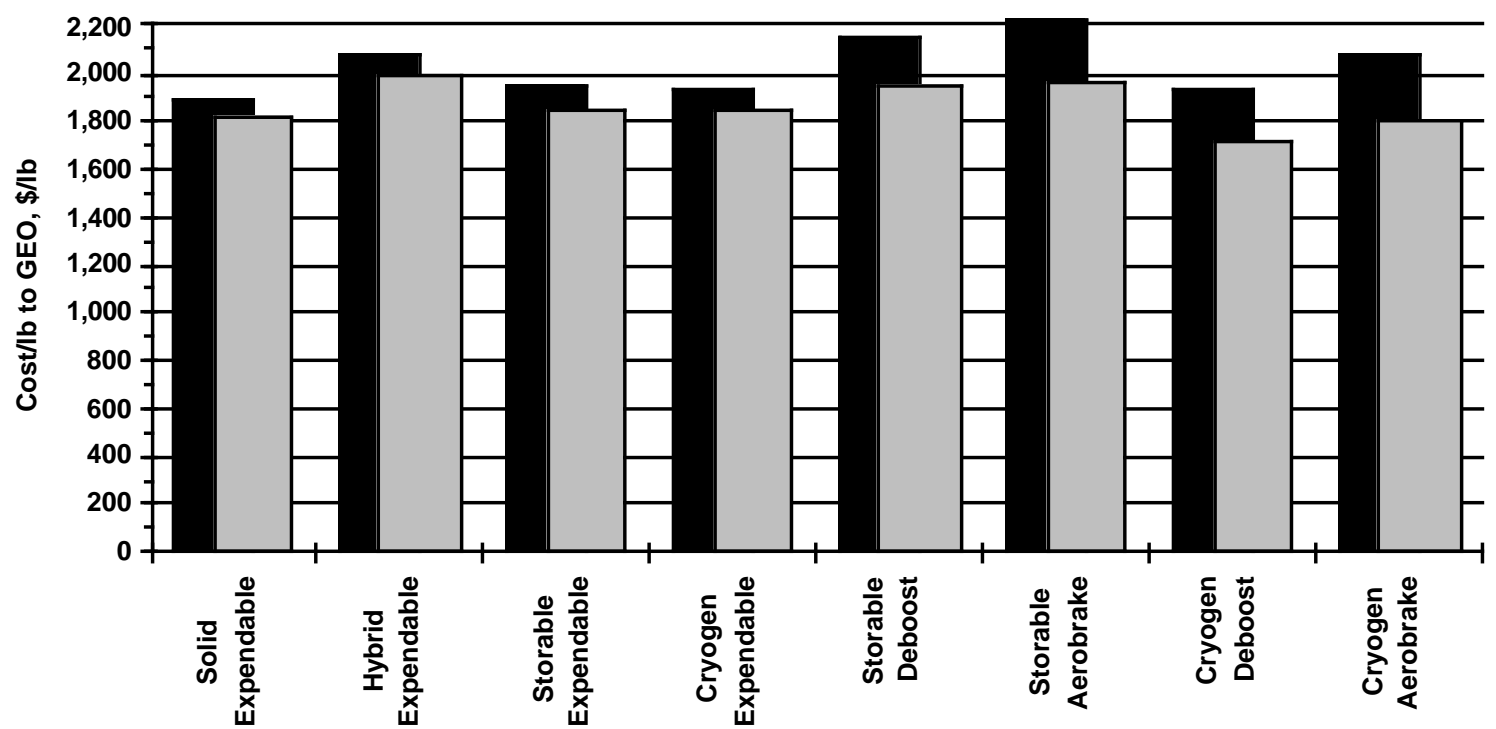

Figure D-1. Results of chemical concept trades at 20 flights per year.

Cost/lb to transport a payload from ground to GEO for various expendable (first 4) and reusable (last 4) AIST concepts

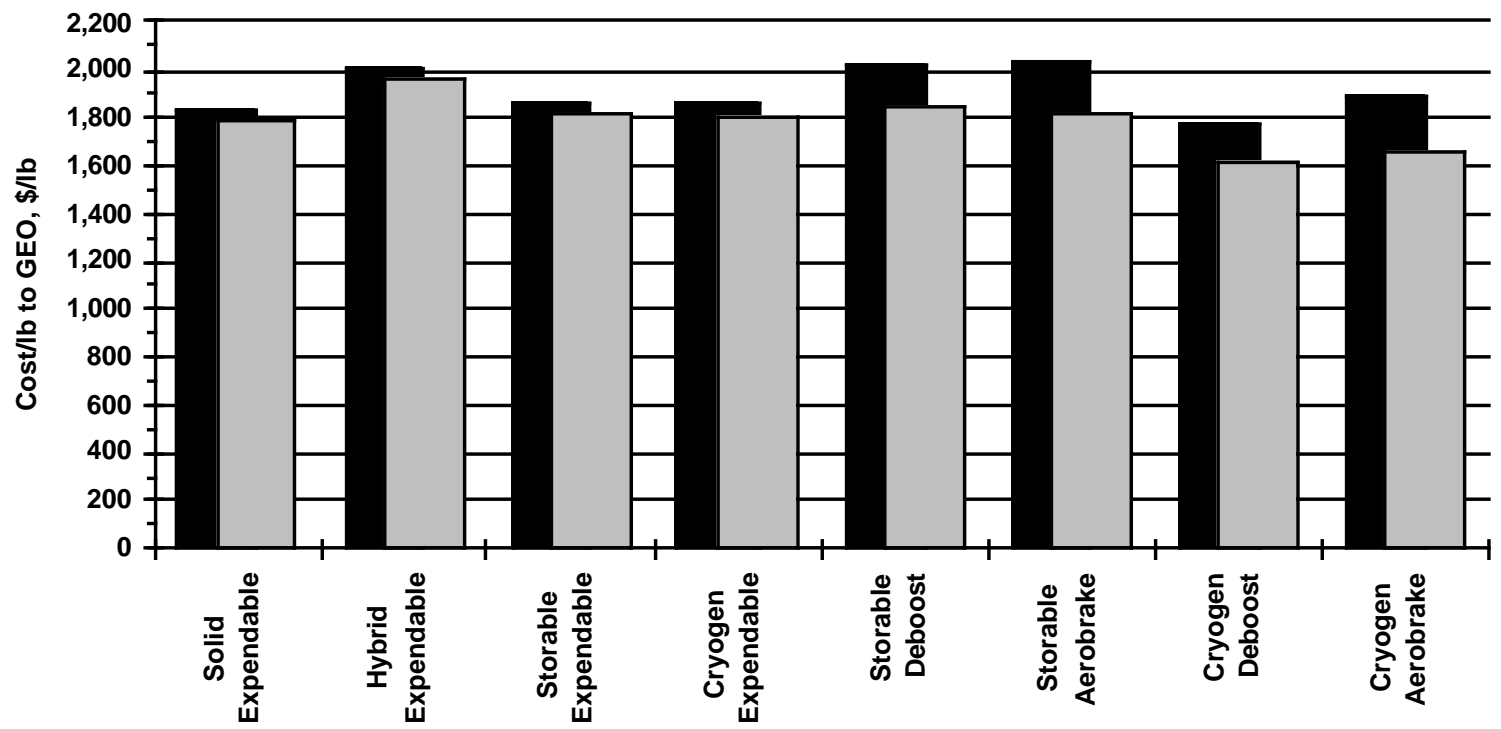

Figure D-2. Results of chemical concept trades at 50 flights per year. 
3,000-Ib Payload

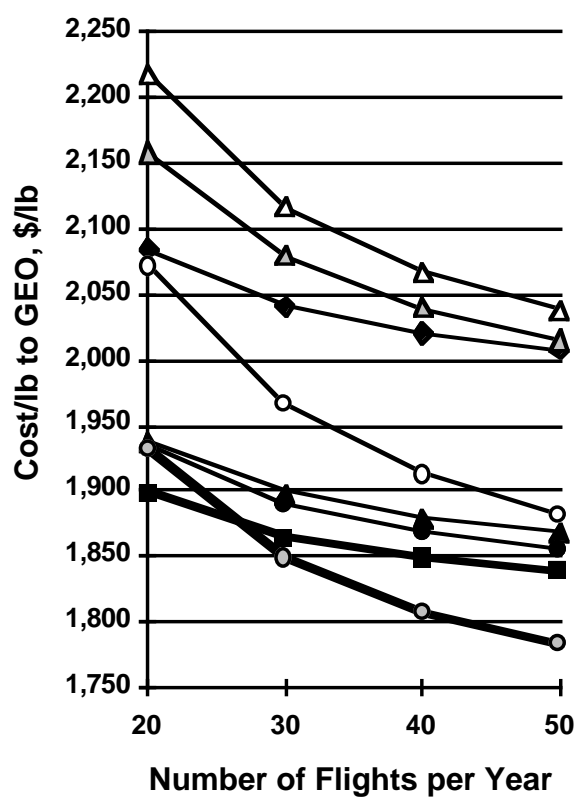

10,000-lb Payload

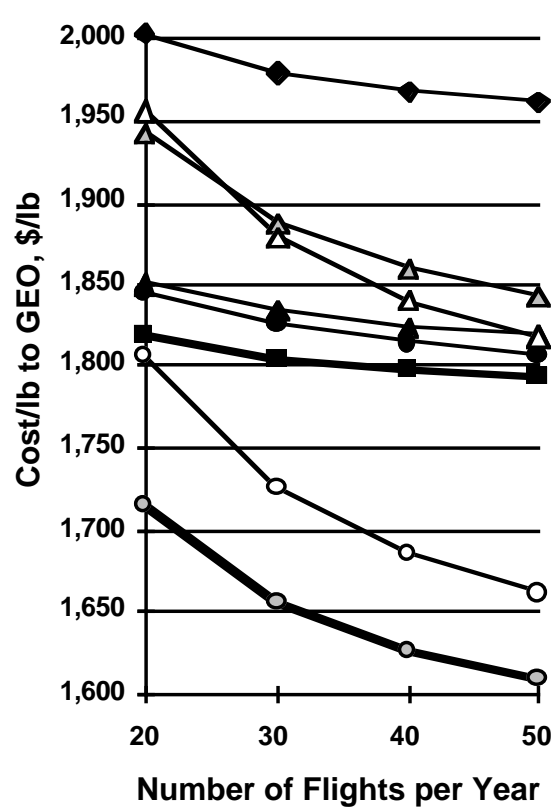

Figure D-3. Results of chemical propulsion AIST concept quick study. 


\section{APPENDIX E}

\section{TETHER CONCEPT EVALUATION}

\section{E.1 Concept Description}

The dynamic tether concept is an extension of small expendable tether technology to a large reusable tether. The tether is deployed by an initial push-off motion of the payload from the support platform, no more than a few meters per second. The mass of the platform is many times that of the payload and tether. Tension on the tether during the deployment is very low so that the payload and unreeling tether continue to move above and aft of the platform until the tether is fully deployed.

As the tether nears full deployment, tension is increased to slow the deployment to zero. This causes an increase in velocity of the tether and payload relative to Earth, which brings gravity gradient forces into play. The tether and payload begin to rotate toward the local vertical and accelerate. When the tether tip and payload reach local vertical the payload velocity relative to Earth has reached a high enough value to enter a geosynchronous transfer orbit. The tether tension is slacked by additional unreeling and the payload is released. The duration of the swing to the release point is 15 to $20 \mathrm{~min}$. The tether is retrieved by reeling in, a process which may take several days to damp out tether motions.

An accurate simulation has not been done. Crude analysis indicates a tether length between 500 and $1,000 \mathrm{~km}$. This means that unlike the 20 to $30 \mathrm{~km}$. "downmass tether," the mass of this tether is probably in the range $\times 5$ to $\times 10$ payload mass. This assumes the tether may be tapered; a fixed-section tether would be more massive. Analyses of slowly rotating tethers (one to two revolutions per orbit) indicate they can achieve GTO launch with shorter tethers but require a tether "crawler" to deliver the payload to the end of the tether.

The tether reeler mass has not been estimated but presumably must be at least that of the tether (i.e., also the $\times 5$ to $\times 10$ payload). The platform mass needs to be great enough that transfer of momentum to the payload does not deorbit the tether system. Presently, it is assumed this is on the order of $\times 100$ payload, but again there is no valid analysis. Platform ballast mass could be provided by water tanks or other low-cost means. The platform must include an electric propulsion system to restore its orbital momentum before the next payload is launched, and enough additional electric power for reeling in the tether. Reeler power is probably on the order to 10 to $20 \mathrm{kWe}$. Reboost power is considerably greater, on the order of $150 \mathrm{kWe}$ for 20 payloads per year.

\section{E.2 Analysis Notes}

A real simulation of the tether system was beyond the scope of the study. Note that the gravity gradient angular acceleration torque acting on a long slender object is

$$
T=3 \mu / r^{3} I_{x x} \sin \theta \cos \theta,
$$

where $I_{z z}$ is assumed zero, and theta measures the angular attitude relative to a gravity gradient neutral or stable attitude. $\sin \theta \cos \theta$ may be recognized as a sinusoidal function with amplitude $\pm 1 / 2$ and period $\pi$. Since the angular acceleration of an object (again assuming $I_{z z}$ zero and $I_{y y}=I_{x x}$ ) is T/I, the angular rotation of geometrically similar objects under influence of gravity gradient is independent of size, disregarding the effect of decrease in gravitational acceleration with distance. This permits a very crude analysis assuming the platform, tether, and payload move as a rigid object. Such analysis led to a tether length roughly 1,200 $\mathrm{km}$, and an end acceleration $0.5 \mathrm{~g}$, adequate to enable the payload to enter a GEO transfer orbit. 


\section{E.3 Cost Questions}

The mass delivered to orbit for a 3,000-lb payload appears to exceed $\times 100$ payload, or 300,000 to $500,000 \mathrm{lb}$. A significant part of this is ballast, but the tether reeler mass is probably of order 50,000 lb., and the power/propulsion system of order $(50 \mathrm{~kg} / \mathrm{kWe} \times 170 \mathrm{kWe})=20,000 \mathrm{lb}$.

The cost of this system is dominated by $R \& D$ cost. There is insufficient definition of the system to do a proper cost estimate. A significant amount of space testing might be required. By rough analogy to other AIST systems, an R\&D cost may be in the range $\$ 50,000$ to $\$ 100,000 / \mathrm{lb}$ for the active portions of the system (reeler and power/ propulsion system). This leads to R\&D costs in the range $\$ 3$ to $\$ 6$ billion, more than any other AIST system (nuclear thermal is second at about $\$ 2$ billion).

The tether system is, in effect, an electric propulsion system wherein use of a tether conserves energy and momentum except that transferred to the payload. By comparison, the solar electric upper stage transfers more momentum and energy to the stage and its propellant than to the payload; it is not recovered. Thus the tether offers a possibility of low operating cost per flight. Mass delivered to orbit for one payload delivery appears to be less than for any other system and there is nominally no hardware expended except an apogee kick motor. The tether system is speculated as:

- The most expensive of the options to develop;

- The least expensive in recurring cost.

This must be leavened with a concern for tether breakage due to orbital debris. The probability of this may be significant, and repair/replacement of a broken tether would be quite expensive.

There are many unanswered questions that can only be answered by detailed analysis and a degree of point design activity. At the present level of understanding it is not recommended to consider the dynamic tether system as a preferred AIST system, but it is interesting and deserves further analysis. 


\section{APPENDIX F}

\section{OPERATIONS ASSUMPTIONS}

\section{F.1 Ground Operations}

The manpower estimates for all upper stage concepts was "deltad" off an indepth study of what was required for the reusable cryogenic upper stage $\left(\mathrm{LH}_{2} / \mathrm{LO}_{2}\right)$. The time and number of ground operations personnel for each known major task was analyzed step by step through the ground operations processes of receiving, inspection, fit check, mating, checkout, launch, flight support, removal and safing on landing, cleaning, refurbishment and ready for shipment to the launch facility. The estimate of the duration and manpower needed for the tasks was based on the experience gained by individuals who have worked such processes and records of these processes from IUS, Saturn, Centaur and other systems.

From the process flow, the number of man-hours per process was created, and the number of personnel required to support the entire operation (processing and refurbishment) determined. A task utilization factor for preflight processing was calculated by dividing the total number of man-hours for processing by the number of hours per shift (i.e., 8 hours), and also by the total number of personnel required to support the entire pre-flight processing operation (i.e., 52 people). This task utilization factor represents the number of major tasks, on the average, each person has to complete per vehicle (i.e., 6.3). For the other concepts, the cryo timeline was adjusted to reflect the system of interest, and the total number of man-hours for pre-flight processing was calculated. The total number of personnel needed was determined by dividing the total number of man-hours by the number of hours per shift and also by the task utilization factor determined in the cryo system.

The following assumptions are used for ground operations:

A. Upper-stage and payload processing will be performed off-line from vehicle processing.

B. Late access to payload will be limited, with exception of the crew.

C. Personnel rate for computation cost of ground operations and mission operations is based on an average hourly rate. There is no attempt to break out skilled and unskilled personnel.

D. Operations personnel and ground personnel are already trained in their area of expertise

E. Schedule efficiency is not included. Improvements in overall schedule due to arrangement of tasks and staffing are not taken into account.

\section{F.2 Mission Operations}

The mission operations covers the portion of operations associated with console personnel who monitor and control the upper stage flight. Using the current Boeing IUS mission operations as a guideline ${ }^{24}$ it is assumed the number of people at the console during each shift would be 20 for a flight rate of 20 per year and 50 for a flight rate of 50 per year. Depending on the number of shifts required, and the number of stages in orbit at any given time, the number of operations personnel required per year is calculated by multiplying the number of shifts required to monitor each concept during flight by the number of personnel required for each shift, and then adding an engineer for each flight to support the payload design (e.g., adding either 20 personnel or 50 personnel).

The number of shifts required for the solid, hybrid, cryo, solar thermal, solar electric, and nuclear thermal, regardless of flight rate, is 2, 2, 3, 5, 5, and 3, respectively. Since the solar thermal and solar electric concepts have a long trip time associated with traveling from LEO to GEO, an additional 3 people for the solar thermal and 10 for the solar electric would be added to the number of personnel required for a 
flight rate of 20 per year to monitor each vehicle flying. An additional 7 for the solar thermal and 25 for the solar electric would be added for a flight rate of 50 per year. Finally, the nuclear thermal requires 2 additional shifts of 5 people.

\section{F.3 Operations Flowchart}

Figure F-1 shows the operational flowchart for the assembly of each upper stage upon arrival at the launch site.

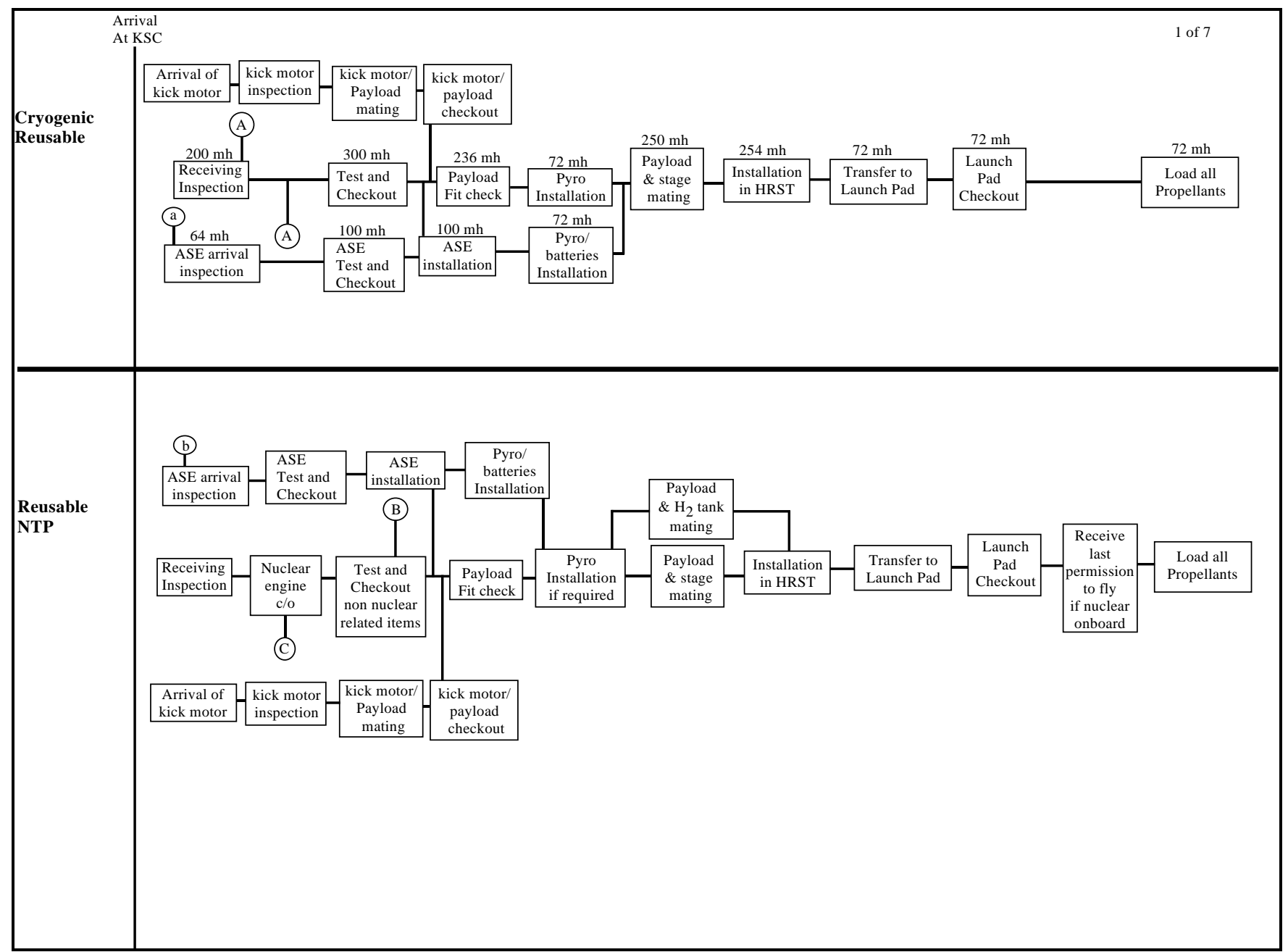

Figure F-1. Operations assembly flowchart. 

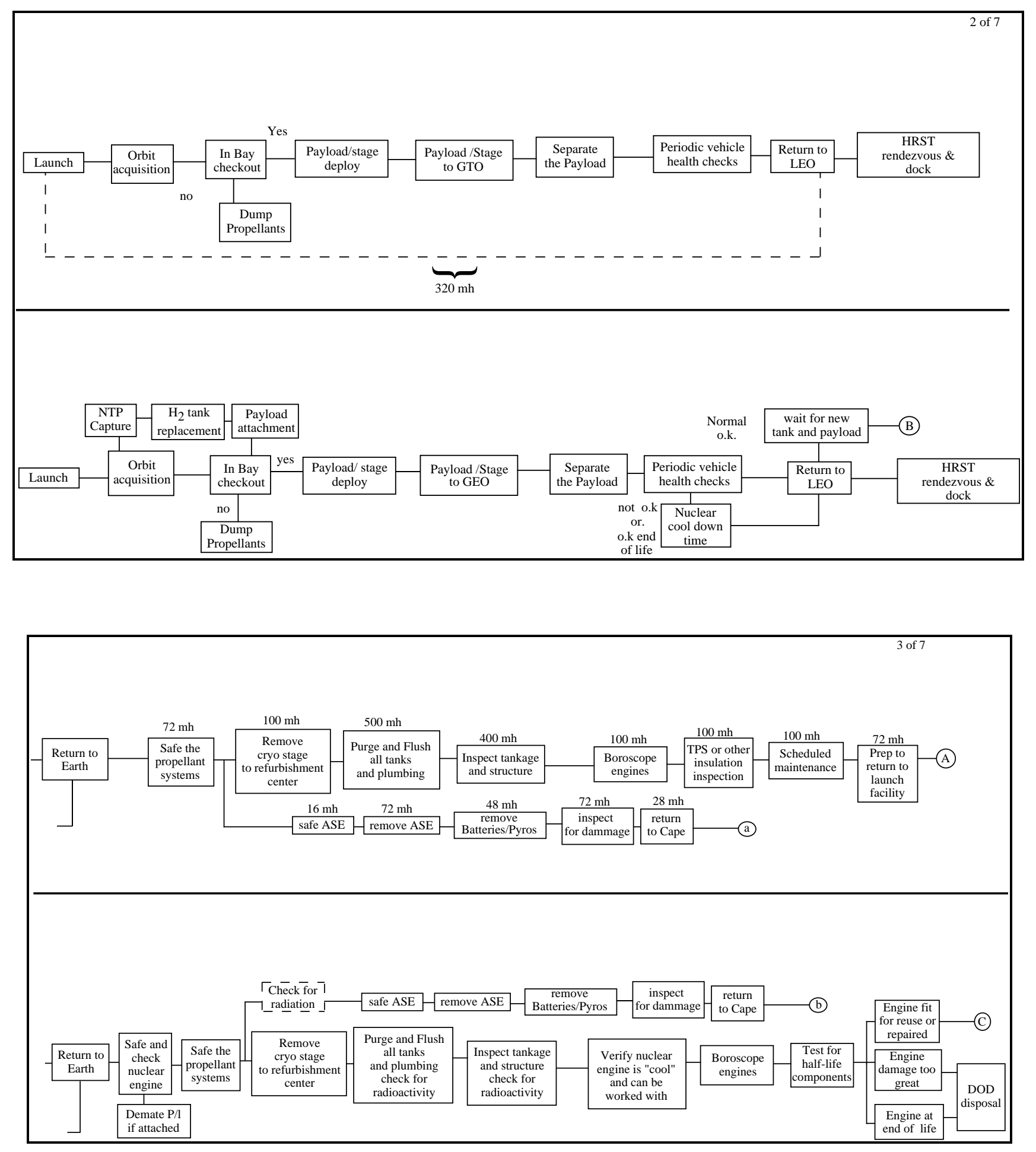

Figure F-1. Operations assembly flowchart (continued). 

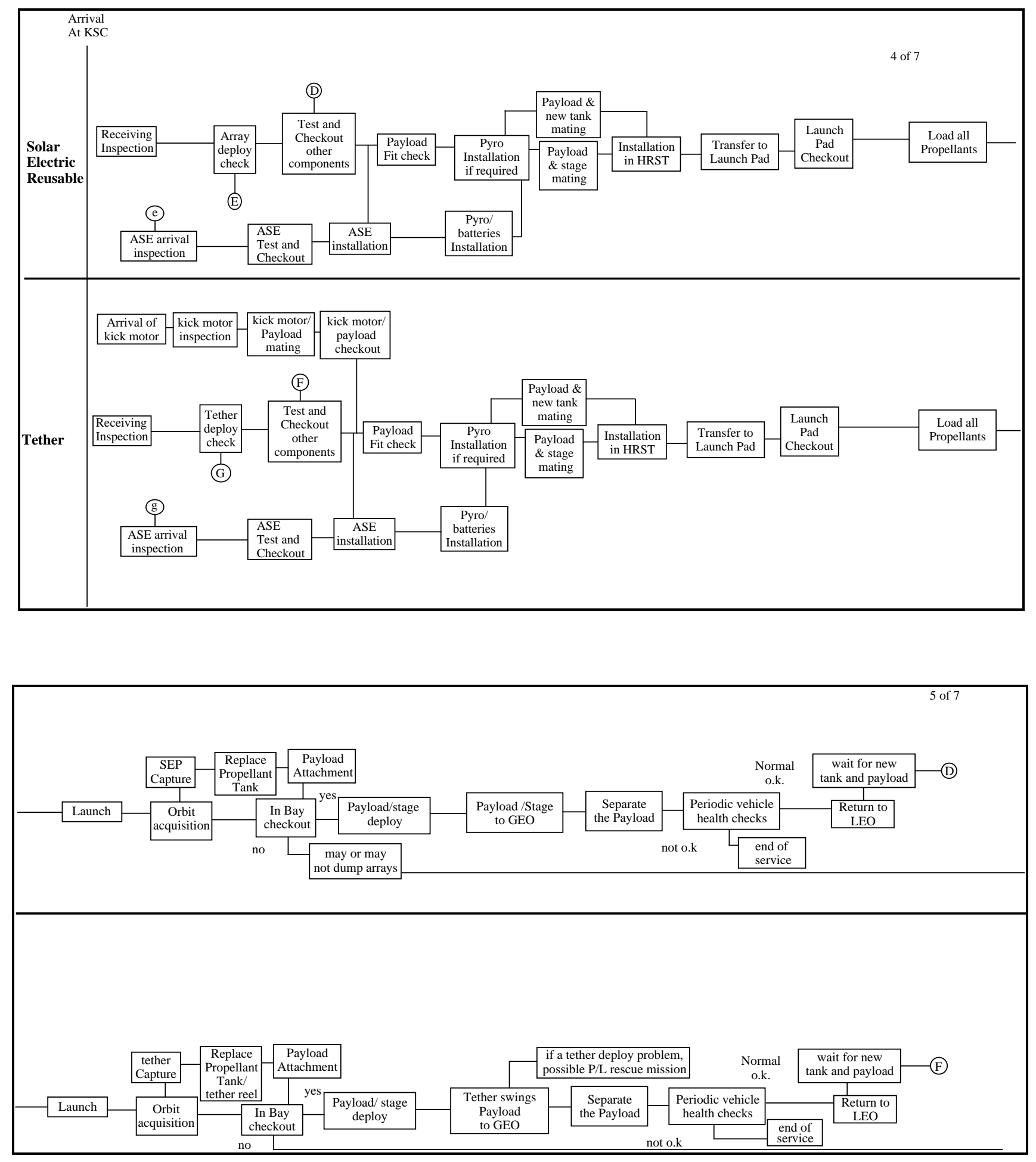

Figure F-1. Operations assembly flowchart (continued). 

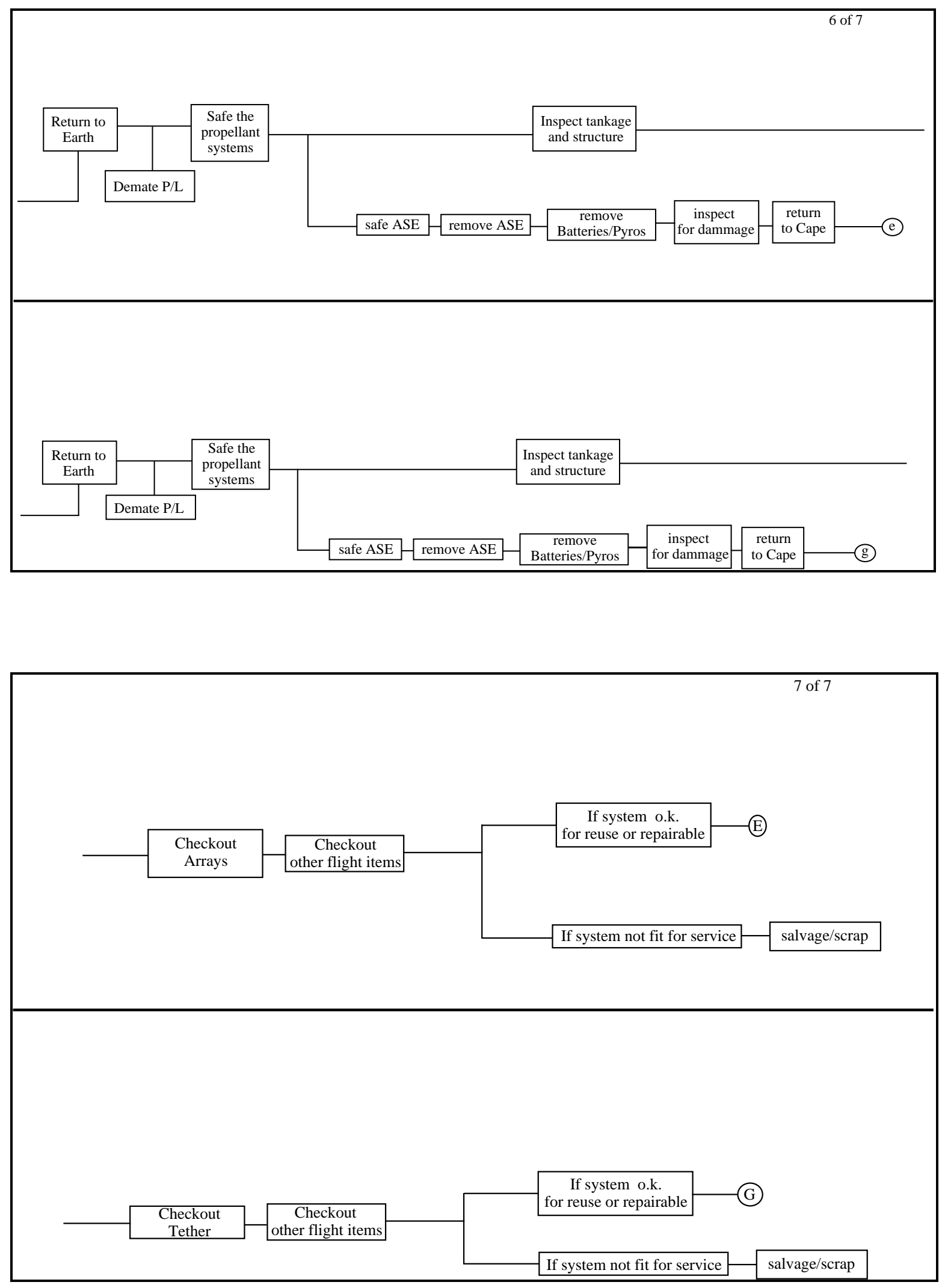

Figure F-1. Operations assembly flowchart (continued). 



\section{APPENDIX G}

\section{CONCEPT ASSUMPTIONS}

\section{G.1 General Assumptions}

The following assumptions are used for all of the upper stage concept designs:

A. The number of upper stages is set to an estimated value plus one backup unit. The backup unit assures that one is always available for launch.

B. The estimated number of upper stages required is set to the total number of flights required divided by the expected life of the upper stage (a function of its design life and its overall mission reliability), rounded up to a whole number.

C. The expected life of the upper stage is computed using the following formula: $E=R *\left(1-R^{D}\right) /$ $(1-R)$, where $E$ is the expected life, $D$ is the design life, and $R$ is the overall mission reliability.

D. The overall mission reliability of each upper stage is set to 0.95 . This is traded during sensitivity analysis.

E. For each reusable upper-stage concept, the upper-stage design life is set equal to the design life of its most expensive subsystem, which is usually the main engine (for cryogen, storable, solar thermal, and nuclear propulsion concepts) or the solar arrays (for solar and laser electric concepts). Thus, when this critical subsystem fails, the upper stage is abandoned.

F. For those concepts that go only to GTO, an AKM is used to deliver the payload from GTO to GEO. To ensure a fair trade, the same AKM model is used for all upper-stage concepts in the same payload-weight class.

G. Although all concepts are required to be at a TRL 6 by the year 2005, not all concepts are at an equal TRL at 2005, as some concepts are already currently past that level. For this study, however, all concepts are costed as though they are at the same TRL (i.e., all concepts are costed for DDT\&E and first unit costs. TRL advancement from six to nine was not costed).

H. For each upper-stage concept, a weight-growth factor of 15 percent is added to the estimated weight of any subsystem or subsystem part which must be developed and tested. Thus, "available off-the-shelf" items, such as the new RL10-B2 liquid rocket engine, will not have such a weight-growth factor applied.

I. In an effort to remain consistent with the assignment of factors for NASCOM, a team was assembled with a representative assigned to each subsystem. The representatives were responsible for assigning percent new design, design complexity, and production complexity factors for all of the concepts for their respective disciplines. The factors were assigned based upon engineering judgment and experience by each of the representatives.

\section{G.2 Mechanisms Subsystem}

For each upper-stage concept, the weight of the payload deployment mechanism is computed as 0.5 percent of the total payload and AKM (if any) weight; based on data from the original Atlas Centaur upper stage.

\section{G.3 Avionics Subsystem}


The following assumptions are used for the electrical power, $C \& D H$, and GN\&C subsystems:

A. Upper stage electronics are for the upper stage only, and not the launch vehicle.

B. Power is available at the site, and all concepts are charged from the ground site until launch.

C. The C\&DH is redundant communications (dual)

- S-band for communications with Tracking and Data Relay Satellite System (TDRSS) and ground

- UHF system for communications with the launch vehicle.

D. The GN\&C weight includes GPS antenna and RF cables, but not GPS receiver.

E. The flight control computer weight and weight for commanding mission critical functions, and for acquiring related telemetry for on-board use, are included in the GN\&C weight. Cable weight is believed to make up a larger percentage of the C\&DH weight as compared to the CER. Therefore, factors of 0.8 for design and production complexity were assigned.

F. Sixty-percent new design effort was based on assumptions that the effort will be about the same with respect to antennas, cables, and passive RF components; that transponders and power amp designs will exist but need new subsystem integration; and that the command processor and data will require minor mods and new subsystem integration.

G. There is no automated capture/docking capability of the upper stage for GN\&C; therefore, no docking/capture targets and mechanisms are carried in GN\&C.

$\mathrm{H}$. The GN\&C is two strings, but may not be fully redundant (depends on how it is implemented).

I. Guidance and control processors handle $\mathrm{C} \& \mathrm{DH}$ function. Control electronics are used by the C\&DH.

$\mathrm{J}$. There is no health monitoring system available for the upper stage.

\section{G.4 Apogee Kick Motor}

The AKM subsystems are not modeled. Instead, a propellant mass fraction and a specific impulse were chosen based upon reasonable improvements of similar AKM designs available in 1994. Combined with the required GTO-to-GEO delta V $(1,837 \mathrm{~m} / \mathrm{s})$, a ratio of payload weight to preburn weight-at-GTO was computed by inverting the basic rocket equation:

$$
W_{P L} / W_{G T O}=1 / P M F ¥\left[\exp \left(-\mathrm{D} V / g I_{s p}\right)+P M F-1\right],
$$

where $W_{P L}$ is the weight of the payload alone, $W_{G T O}$ is the weight of the payload and loaded AKM, PMF is the propellant mass fraction of the AKM, $I_{s p}$ is the specific impulse of the AKM, DV is the required GTO-to-GEO delta V, and $g$ is the gravity constant.

The ratio of the AKM loaded weight to the payload weight was then computed as:

$$
k_{A K M}=W_{G T O} / W_{P L^{-1}} æ Æ W_{A K M}=k_{A K M} ¥ W_{P L} .
$$

The AKM loaded weight was set to 0.952 times the payload weight, and the AKM dry weight was set to 0.07 times the AKM loaded weight, based on the above equations. The propellant mass fraction of the $\mathrm{AKM}$ is 0.93 and the specific impulse of the AKM motor is $310 \mathrm{~s}$. Thus, for a 3,000-lb payload, the 
loaded weight of the AKM was 2,856 lb, its propellant weight was 2,656 lb, and its dry weight was 200 $\mathrm{lb}$; and for a 10,000-lb payload, the loaded weight of the AKM was 9,520 lb, its propellant weight was $8,854 \mathrm{lb}$, and its dry weight was $666 \mathrm{lb}$.

Additionally, the following assumptions are used for the AKM:

A. For each upper stage concept which requires an AKM, the number of AKM's required is calculated as the number of flights flown divided by the overall mission reliability of the upper stage (nominally 0.95).

B. The AKM consists of a small, but efficient, SRM and a minimal amount of structure, avionics, and RCS.

C. For concepts that require a kick motor; weight for the solid motor will be included but additional weight for additional structure to incorporate the motor will not be included.

\section{G.5 Airborne Support Equipment}

The following assumptions are used for the ASE:

A. Each ASE unit is designed to last indefinitely, with proper maintenance.

B. For each expendable or ground-based reusable upper-stage concept, the number of ASE units is set to one nominal plus one backup unit, for a total of two. The backup unit assures that one is always available for launch.

C. For each space-based reusable upper-stage concept, the number of ASE units is set to one nominal plus one backup unit for both the new stage mission and the refuel mission, for a total of four. The backup units assure that one is always available for launch. NASCOM will not directly cost the refuel mission ASE; therefore, for costing purposes, the ratio of the refuel mission ASE weight to the new stage mission ASE weight (e.g., 0.75) is used to determine an equivalent total number of ASE units to price at the NASCOM-computed new stage first-unit production cost. (For example, two whole units plus two 0.75 units yields an equivalent number of 3.50 units.)

\section{G.6 Refuel Tank Design}

A refuel tank, housed safely in the HRST payload bay, was chosen as the means for resupplying propellants to a space-based reusable upper stage concept. A replacement tank was also considered, but abandoned due to the perceived increased complexity in upper stage design and manufacture (which would increase its DDT\&E and production costs). Other proposed propellant resupply options included a groundbased propellant tanker, made by purchasing an HRST and replacing its payload bay with fuel tanks; and a space-based propellant farm, where $\mathrm{LH}_{2}$ and lox would be produced from water transported from the Earth. The additional DDT\&E and production costs associated with these options are perceived to be more than their potential operational cost savings; however, these options were not quantitatively assessed to verify this supposition.

The following assumptions are used for the refuel tank:

A. For each space-based reusable upper-stage concept, the number of refuel tanks is set to an estimated value plus one backup unit. The backup unit assures that one is always available for launch.

B. The estimated number of refuel tanks required is calculated as the number of refuel flights required divided by the expected life of the refuel tank (a function of its design life and its overall mission reliability), rounded up to a whole number. 
C. Each refuel tank will have an overall mission reliability very close to one, since even a small leak should not result in either tank or upper stage mission failure; thus, the expected life of the refuel tank is set equal to the design life of 100 flights (with proper maintenance). Design life is based on pressure and thermal cycles typically encountered per flight.

E. Since no refuel tank subsystem category exists in NASCOM, the refuel tank is comprised of the "tankage," "tank support structure," and "payload adapter" parts of the structures subsystem, plus the mechanisms (payload deployer), passive thermal (tank insulation), and propulsion subsystems.

\section{G.7 Replacement Parts/Spares}

The following assumptions are used for the replacement parts/spares:

A. For each reusable upper-stage concept, the number of replacement part sets is set to the number of "reused stage" flights, computed as the number of flights minus the number of new stage flights (i.e., the estimated number of upper stages).

B. It is assumed that new upper stages leave the production facility with no defects; that any replacement of defective parts will occur during production and thus is covered by the production costs.

C. It is assumed that new upper stages are not damaged during integration; thus no replacement of damaged parts is required.

D. For each upper-stage concept, a pre-defined set of replacement parts is applied on each "reused stage" flight. The parts set is defined based on expected "wear and tear" per flight and accessibility.

E. Large, expensive subsystems, such as engines or solar array panels, will not be subjected to major maintenance. Time-to-failure of those parts define the design life of the upper stage.

F. Since no replacement parts subsystem category exists, the replacement parts set is comprised of fractions of each subsystem, with the assumption that the fraction of weight to be replaced is equal to the fraction of the associated subsystem first-unit production cost. 


\section{APPENDIX H}

\section{SOLAR ELECTRIC INFORMATION}

This space-based, reusable upper-stage concept uses a solar electric propulsion system for main propulsion. The vehicle flies low-thrust spiral trajectories from LEO to GEO and return. Upon return to LEO, it is resupplied with propellant and supplied with a new payload for delivery. Unlike the high-thrust systems, SEP upper stages deliver payloads to geosynchronous orbit, not to a transfer orbit. It is impractical to fly a low-thrust system to a highly elliptical transfer orbit.

The generic advantages and disadvantages for solar electric propulsion are:

- Benefits

High specific impulse, low propellant consumption

Delivery all the way to destination orbit

Inherently reusable; long life achievable

Reliable and safe; can use non-hazardous propellant

High potential for advanced interplanetary missions

- Drawbacks

Long trip times for LEO-GEO missions

Relatively high stage cost; must reuse to be economic

Significant Van Allen Belt radiation exposure for LEO-GEO

Large array area leads to high drag; may require special operations procedures below 400- to 500-

$\mathrm{km}$ altitude.

The reasons for considering SEP for AIST application are:

- Cost Reduction Potential-

High specific impulse of electric propulsion enables combination of reuse and low propellant consumption

- Safety and Reliability-

Vehicle inherently safe to launch

Power and propulsion inherently multi-string

Low thrust avoids high loads on payloads

No sudden critical events

- Technology Status-

In commercial use today

Technology not near physical limits as is chemical propulsion

Performance improvements and cost reduction needed.

Preliminary investigations were performed to select technology levels with potential to reach AIST targets. It was quickly concluded that solar array performance near $200 \mathrm{~W} / \mathrm{kg}$ is needed to reach the competitive inert mass range. Present systems based on silicon photovoltaics are in the 60 to $80 \mathrm{~W} / \mathrm{kg}$ range. Improved technology characterized as thin film photovoltaics with 20 percent or better efficiency is indicated as capable of the desired performance.

Preliminary trades were also conducted on specific impulse, trip time, and number of uses. For a low-thrust propulsion system there is always an optimum specific impulse (more is not necessarily better). The optimum specific impulse reaches the best compromise between propellant mass, reduced by high specific impulse, and inert mass, increased by high specific impulse. Longer trip times reduce power requirements and inert mass; specific cost, not including penalties for trip time, decreases with increasing trip time. Representative results of these trades are shown in figure H-1. Solar electric propulsion systems 
are expensive compared to conventional propulsion systems. Solar electric systems cannot be cost competitive without reuse. The economy effects of reuse are illustrated in figure H-2.
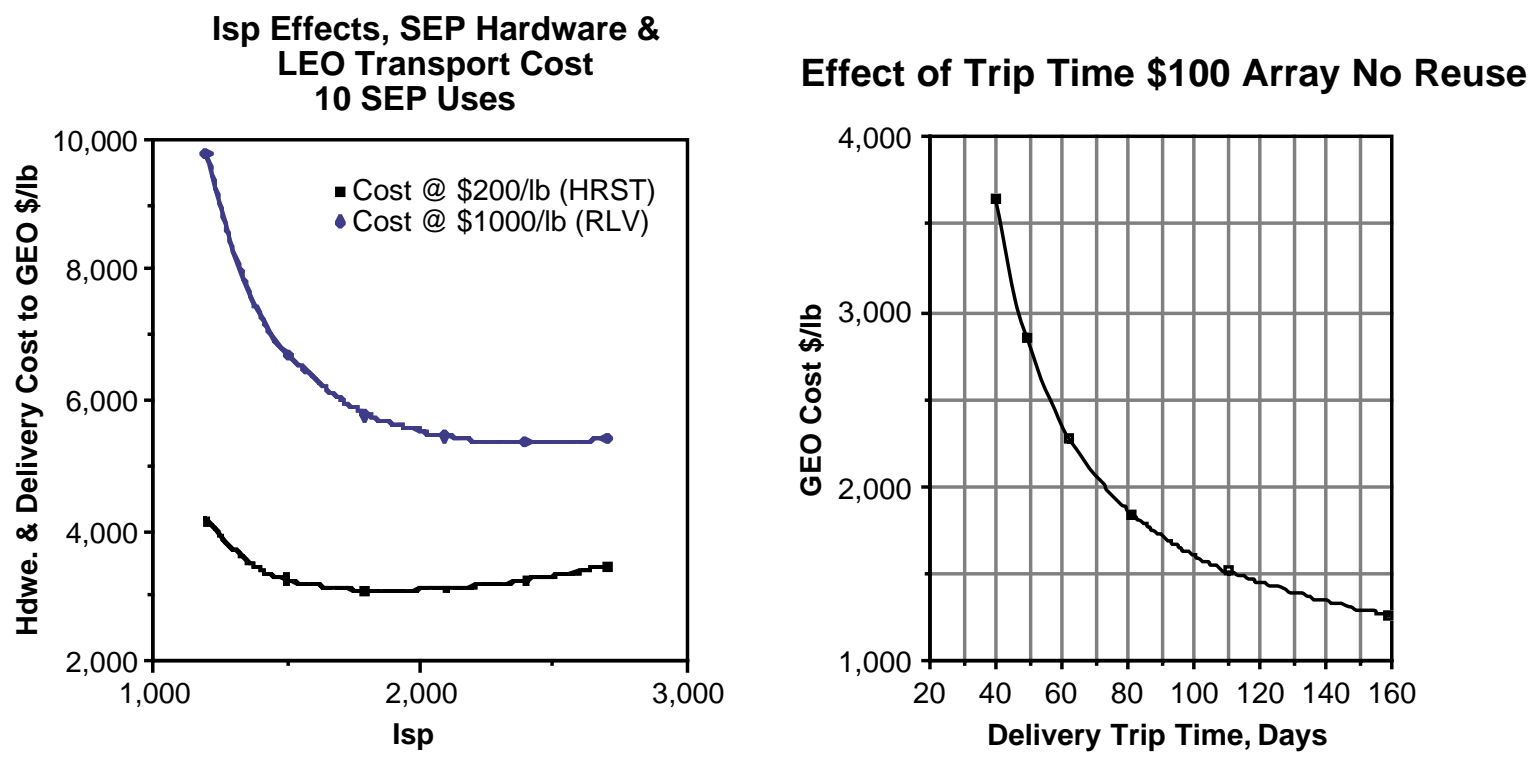

Figure H-1. Specific impulse and trip time preliminary trades.
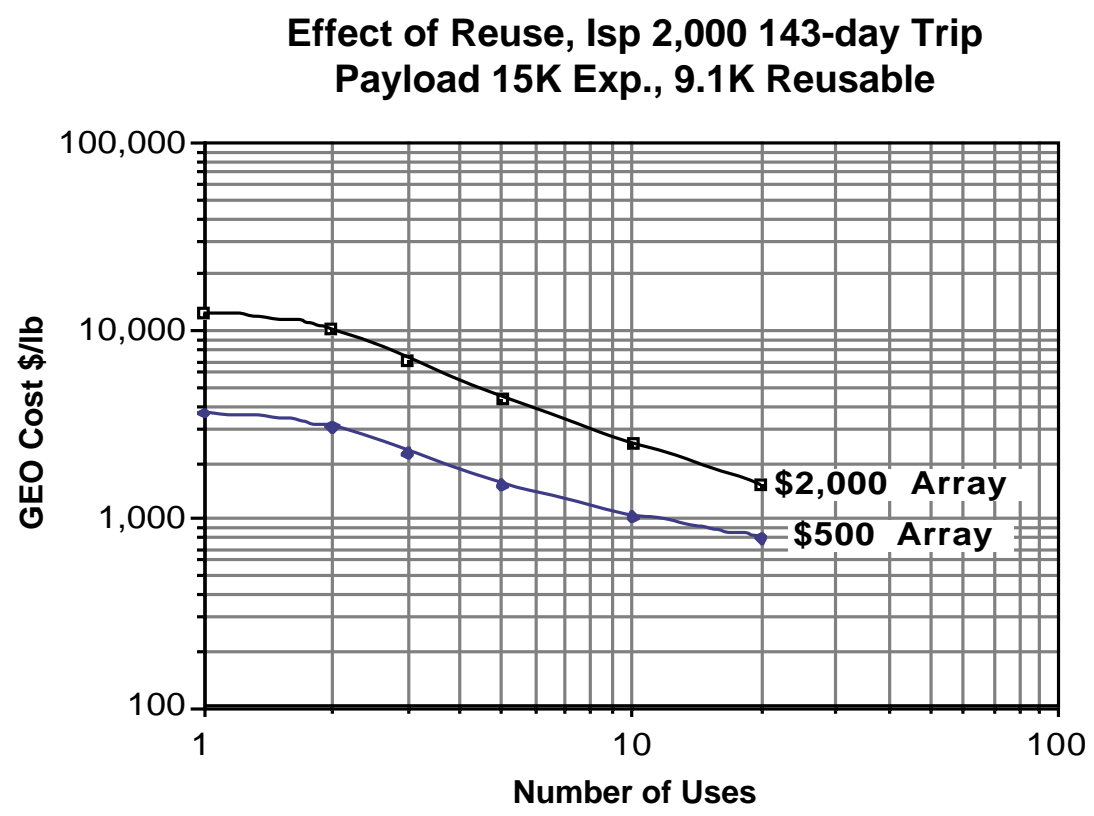

Note: Trend only; cost indicator does not include all costs

Figure H-2. Reuse cost trends.

The advanced solar arrays subsystem consists of multiple arrays of thin-film gallium-arsenidebased or dual band gap solar cells on a substrate backing, plus the associated framework and electrical wiring. Nominal efficiency was set at 20 percent, with mass per unit area $1.46 \mathrm{~kg} / \mathrm{m}^{2}$ for a unit power of $178 \mathrm{~W} / \mathrm{kg}$. SEP projected performance is summarized in figure $\mathrm{H}-3$. The arrays would have a maximum power output of $50.7 \mathrm{~kW}$ for the 3,000-lb payload version, and $138.2 \mathrm{~kW}$ for the 10,000 -lb payload version. The operable life of the arrays was assumed to be 10 flights, after which time both the arrays and upper stage would no longer be reused. 
- Array performance projected near $200 \mathrm{~W} / \mathrm{kg}$ with $20 \% 1$-mil cells (dual band gap thin film)

- Power processing 4 kg/kW plus thermal control; $90+\%$ efficiency

- Thermal control assumed $15 \mathrm{~kg} / \mathrm{m}^{2}$ radiator area @ eff. ht rej temp $25^{\circ} \mathrm{C}$

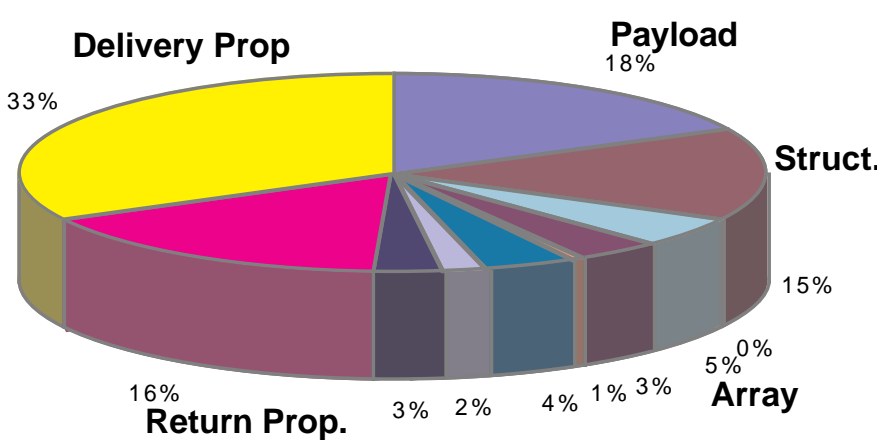

\begin{tabular}{|c|c|}
\hline Array Mass Model & \\
\hline Cell Thickness Mils & 1 \\
\hline Cell Density $\mathrm{g} / \mathrm{cm} 3$ & 5 \\
\hline Substrate Thickness Mils & 1 \\
\hline Substrate Density $\mathrm{g} / \mathrm{cm} 3$ & 5 \\
\hline Coverglass Thickness Mils & 4 \\
\hline Coverglass Density $\mathrm{g} / \mathrm{cm} 3$ & 3 \\
\hline Backing Thickness Mils & 6 \\
\hline Backing Density $\mathrm{g} / \mathrm{cm} 3$ & 1.6 \\
\hline Copper Current $\mathrm{A} / \mathrm{cm} 2$ & 100 \\
\hline Conductor Length & 3201.83023 \\
\hline Cross-Section & 0.011829 \\
\hline Copper Vol & 0.00378745 \\
\hline Copper Mass & 30.2995708 \\
\hline Cell Unit Mass & 0.127 \\
\hline Substrate Unit Mass & 0.127 \\
\hline Coverglass Unit Mass & 0.3048 \\
\hline Backing Unit Mass & 0.24384 \\
\hline Copper Unit Mass & 0.11775774 \\
\hline Frame Area m2 & 1 \\
\hline Frame Depth cm & 10 \\
\hline Frame Flange $\mathrm{cm}$ & 13 \\
\hline Frame Matl Dens $\mathrm{g} / \mathrm{cm} 3$ & 1.6 \\
\hline Frame thickness mm & 0.5 \\
\hline Frame Unit Mass & 0.32 \\
\hline $\begin{array}{l}\text { Deployment Mechanisms \% } \\
\text { Deployment Mechanisms U/M }\end{array}$ & $\begin{array}{r}15 \\
0.21889372\end{array}$ \\
\hline Total Array Unit Mass & 1.45929146 \\
\hline Array $\mathrm{W} / \mathrm{kg}$ & 178.331815 \\
\hline
\end{tabular}

Figure H-3. Solar array mass and vehicle mass summary for 3,000-lb payload solar electric vehicle.

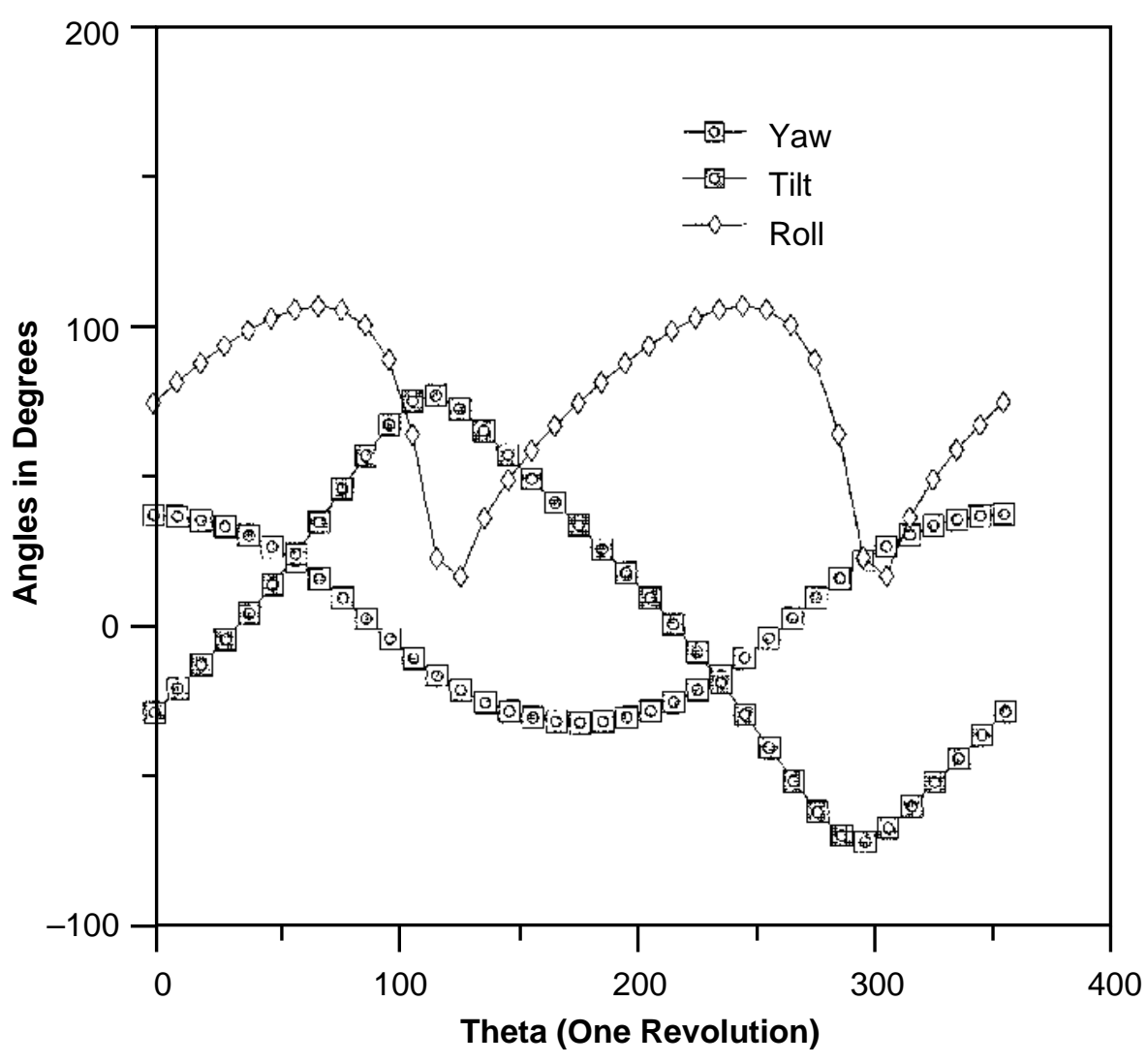

Figure H-4. Typical roll and tilt requirements. 
Low-thrust solar electric ascent to GEO and return requires two degrees of freedom for the solar array. Thrust direction follows a yaw steering pattern to optimize plane change during altitude raising. At the same time the solar arrays must be oriented toward the Sun. The yaw steering is roughly sinusoidal with a period of one orbit. Two degrees of freedom are provided by rolling the entire vehicle while tilting the arrays. Figure H-4 illustrates typical roll and tilt requirements. When the tilt angle is near $\pm 90^{\circ}$, the actual roll angle is not very important since the SEP is nearly foresighted on or away from the Sun. This fact may be used to ameliorate rapid roll maneuvers.

Past studies of SEP systems have typically dealt with technology as it existed or with highconfidence near-term projections of the technology. Most of these studies did not succeed in defining system concepts so attractive that the technical and program risks of SEP could be accepted. The single significant exception is instructive: the use of SEP for commercial communications satellites stationkeeping. Here the thruster technology was developed incrementally and the power system was "free," i.e., power already available on the satellite. Solar electric power at $\$ 2,000 / \mathrm{W}$ or more, if it must be paid for to obtain the benefits of solar electric propulsion, has never been worth it.

This study attempted to set a technology and cost level which could be competitive. The level was about twice the performance and one-third the cost of today's space arrays. The limits of SEP technology are ill-defined. The technology set-points of this study were power somewhat less than $200 \mathrm{~W} / \mathrm{kg}$ and cost of $\$ 600 / \mathrm{W}$. Technology forecasts have thrown out numbers as high as $1,000 \mathrm{~W} / \mathrm{kg}$ and values from 300 to 500 are at least marginally credible. Terrestrial arrays, even high-technology ones, sell for a tiny fraction of $\$ 600 / \mathrm{W}$. Because SEP technology limits are ill-defined, it makes sense to embark on a modest technology program to better define them. It also makes sense to conduct thruster and power processing technology developments that would benefit the communications satellite industry. This could be nearly all laboratory work. It is unclear what should sensibly be done in a flight program that will not be covered by continuing developments in commercial satellite propulsion. 


\section{APPENDIX I}

\section{LUNAR AND PLANETARY MISSIONS}

Applicability of alternative propulsion systems and technologies to lunar and planetary missions depends on the mission definitions. Low-performance systems such as solid-propellant rockets can and have served well for robotic missions. Examples are the Magellan and Galileo missions. In the case of the relatively massive Galileo spacecraft, the low performance of the IUS required gravity assists at Venus and Earth to attain a Jupiter encounter trajectory. Large and/or higher performance systems are needed for human missions. For both robotic and human missions, careful attention should be paid to the launch opportunities for planetary trips. In the Mars case, the delta V required can vary up to 100 percent depending on the time frame for when the vehicle is launched.

\section{I.1 Robotic Missions}

Advanced robotic missions such as Mars sample return can also operate with low-to-moderate performance systems. The most significant performance leverage for a Mars sample return mission comes from production of return propellant on Mars, e.g., using the methane/oxygen production concepts advanced by Zubrin and others. Use of higher performance propulsion can significantly reduce initial mass in Earth orbit, but with the low ETO costs of an HRST this mass reduction does not have much cost leverage.

For expendable upper stages applied to robotic lunar and planetary missions, it is expected to see cost trends very similar to the LEO-GEO mission. Because of the generally higher energy, higher performance has a slight edge compared to the LEO-GEO mission. Reusable upper stages, if a "standard" (i.e., designed for LEO-GEO) system can be used, also trend similarly to the LEO-GEO mission with two caveats. First, if the reusable system is launched to a high-energy planetary insertion, it probably cannot be returned to Earth orbit for reuse. Therefore, kick motors or some similar device should be considered. Second, low-thrust systems will reach a near-Earth-escape condition far from Earth before the kick motor can be used. This leads to a much larger kick motor requirement (for the same insertion condition) compared to a high-thrust system which reaches a near escape condition deep in Earth's gravity well.

Particular mention of nuclear electric propulsion needs to be made here. Nuclear electric propulsion was dropped from the main part of the AIST study in view of high cost and public safety concerns associated with extended operations in Earth orbit. Nuclear electric propulsion has two unique attributes for missions to the outer planets and beyond. First, it provides a source of power and thermal control heat both necessary for spacecraft to survive and operate at great distances from the Sun. Second, it offers performance advantages for outer planet missions compared to any other system feasible with known technology. These advantages cannot be easily quantified in terms of cost, since some mission profiles and operations are not possible without nuclear electric propulsion.

\section{I.2 Human Missions}

Human lunar and planetary missions present a different picture. First, much larger masses are involved. Second, trip time is important. Lengthy mission profiles involving sequences of gravity assists, such as used for Galileo, would not be considered. Third, human missions are much more likely to be repetitive so system reuse becomes an important factor. Fourth, human safety places requirements on systems of different character than the normal cost-effects-of-reliability factors applied to the selection of systems for automated missions.

Extensive studies and comparisons of propulsion systems for human lunar and planetary missions were conducted during the Space Exploration Initiative (SEI) activities from 1989 to 1993. A small amount of work continued after SEI. The results and conclusions of these studies are applicable and sufficient to draw conclusions regarding the relative merits of the AIST propulsion systems to human lunar and planetary missions. 


\section{I.3 HRST Support of Human Missions}

The premise of the present study is that a modest-capability fully reusable launch vehicle can bring launch costs down 1.5 orders of magnitude from today's prices. Nearly all studies of human lunar and planetary missions have assumed development and use of a heavy lift launch vehicle. Earth orbit assembly has been eschewed for lunar missions and minimized for Mars missions. Some studies (Zubrin's Mars Direct and the 1993/1994 Johnson Space Center (JSC) studies) have gone so far as to substitute Mars surface rendezvous for Earth orbit assembly. This could be viewed as a Saturn-Apollo mindset. The prior studies give little guidance how best to use an HRST-class launcher for human exploration missions.

The general sizing of lunar vehicles is such that with suitable design, an HRST could launch the major components including propellant tanks. Oxygen tanks would be partially loaded then topped off on orbit. Fully loaded hydrogen tanks could be launched late in the sequence to minimize boiloff. Mars vehicles are much too large. Nuclear thermal systems with their large hydrogen propellant loads present the worst problem. A nuclear thermal Mars vehicle might require 20 to 50 tanks of a size suitable for HRST launch.

A Mars lander/ascent vehicle is about the size of a lunar vehicle and could be similarly assembled. The heat shield for a Mars lander presents an assembly problem not encountered on a lunar vehicle, but studies during the SEI activity indicated reasonable ways to assemble heat shields.

Most Mars mission studies have selected habitat size about 6 meters diameter for the interplanetary vehicle crew module. Volume limits of an HRST would require the crew module to be made up of a cluster of space station-sized modules. Trade studies during SEI indicated this is feasible with a moderate mass penalty.

Solar electric appears to present the least problem. The propellant could be contained in two tanks. On-orbit topoff would be required because of launch mass limits. The solar array would require on the order of a dozen launches but assembly of a large planar array seems a straightforward problem. The general conclusion of this study is that assembly of a solar electric Mars vehicle is comparable in difficulty to assembly of the International Space Station.

\section{I.4 Application of AIST Technologies}

A general conclusion can be drawn that solid rocket propulsion is not useful for any of the human lunar or planetary applications. Table I-1 indicates the applicability of the remaining AIST systems to elements of lunar and Mars mission profiles. While hybrid propulsion is not applicable to translunar or planetary injection, two design studies have specified storable propulsion (equivalent performance) for

Table I-1. Applicability of AIST concepts to missions.

$\begin{array}{lcccccc}\begin{array}{c}\text { Translunar/ } \\ \text { Propulsion } \\ \text { System }\end{array} & \begin{array}{c}\text { Lunar/ } \\ \text { Injection }\end{array} & \begin{array}{c}\text { Mars } \\ \text { Landing }\end{array} & \begin{array}{c}\text { Mars } \\ \text { Capture }\end{array} & \begin{array}{c}\text { Lunar } \\ \text { Ascent }\end{array} & \begin{array}{c}\text { Mars } \\ \text { Ascent }\end{array} & \begin{array}{c}\text { TransEarth } \\ \text { Injection }\end{array} \\ \text { Hybrid Propulsion } & & \mathrm{X} & \mathrm{X} & \mathrm{X} & \mathrm{X} & \mathrm{X} \\ \text { Cryogenic Propulsion } & \mathrm{X} & \mathrm{X} & \mathrm{X} & \mathrm{X} & \mathrm{X} & \mathrm{X} \\ \text { Solar Thermal } & \mathrm{X} & & \mathrm{X} & & & \mathrm{X} \\ \text { Solar Electric } & \mathrm{X} & & \mathrm{X} & & \mathrm{X} \\ \text { Nuclear Thermal } & \mathrm{X} & & \mathrm{X} & & \mathrm{X}\end{array}$


this. These were the original Von Braun Mars project papers and a recent study at Stanford University which used a high-energy elliptical Earth parking orbit to minimize the energy imparted by the injection stage. The argument in the latter study was that using a hydrogen-oxygen upper stage on the launch vehicle to reach the elliptic parking orbit obtained most of the benefits of cryogenic performance while permitting use of storables in the space vehicle.

\section{I.5 Human Lunar Missions}

Few studies have selected anything other than cryogenic propulsion for translunar injection, capture, and landing. Storable propellants are frequently specified for return to Earth from the Moon to avoid the issue of cryogenic boiloff on the lunar surface. Current thinking is toward the use of cryogenics with production of return propellant on the Moon. Lunar oxygen can be produced from regolith, with a preference for "mature" regolith with its higher ilmenite content. Yield is about 5 percent. If water ice is present at the south lunar pole, both hydrogen and oxygen can be produced there. Hydrogen can be extracted from the regolith; again, mature regolith is preferred. Its hydrogen content is about 50 parts per million; the hydrogen can be extracted by heating to about $600{ }^{\circ} \mathrm{C}$. A typical lunar return requires about $3 \mathrm{t}$. hydrogen. To obtain this quantity, 30,000 $\mathrm{m}^{3}$ of regolith must be processed. Since oxygen yields are a thousand times greater, the amount of regolith that must be handled to obtain oxygen for a typical lunar return is modest.

A few studies have considered solar or nuclear electric propulsion for lunar cargo. Greater mass efficiency is obtained, but the nonrecurring cost for developing a low-thrust system in addition to the highthrust system needed for reasonable lunar crew travel times was not justified in those studies that considered the question. If a low-thrust system were available (e.g., from prior development for another mission), it could be profitably used.

\section{I.6 Human Mars Missions}

The principal Mars studies have, at one time or another, selected different propulsion systems. The SEI "90-Day Study" selected cryogenic propulsion with aerocapture at Mars. The selection was based on requiring the least new development. Zubrin's Mars Direct and the JSC studies cited above selected direct injection to Mars by the launch vehicle (which had a cryogenic upper stage) and production of propellant (oxygen and methane) on Mars. The Synthesis Group and the Boeing/MSFC Space Transportation Concepts and Analyses for Exploration Missions (STCAEM) study recommended nuclear thermal propulsion. These recommendations were both influenced by a perceived need to perform opposition-class profiles in unfavorable years.

The STCAEM study also identified solar electric propulsion as promising if the cost of solar arrays could be driven down. At the time little evidence was available, with the exception of the low cost of terrestrial arrays, that cost could come down. Since that time, commercial purchases of space arrays indicate that they, like other products, could be on a 70 to 80 percent production rate slope. Projected price for a 5-mW Mars transfer vehicle array is $\$ 100$ to $\$ 400 / \mathrm{W}$. While this is highly speculative, it indicates the potential for a Mars transfer system to be very competitive with other alternatives regarding nonrecurring cost. As a fully reusable system with potential for 20 -year life, a solar electric Mars transfer system could be the technology of choice for human Mars exploration.

Two things should be noted about solar electric propulsion for Mars missions: First, optimal specific impulse is between 3,000 and 5,000 s. For LEO-GEO transfer it is 1,200 to 2,000 s. This may point to a different thruster technology at best. Second, mission profile and economics studies have indicated that a Mars transfer solar electric system should operate between high-Earth and Mars orbits and be serviced by other systems operating between the surfaces, or low orbits, and the SEP parking orbits. At Mars it is practical to operate the Mars lander/ascent vehicle from the surface to an SEP parking orbit at, for instance, $100,000 \mathrm{~km}$. At Earth, a lunar transport system works well for transport between LEO and a high orbit. The lunar L2 libration point is well suited as an SEP parking orbit because the delta V to reach it is lower (through benefit of lunar gravity assist) than comparable locations. 
The question of in-space transportation selection for Mars missions is quite complex. It includes issues of mission definition (surface mission characteristics and requirements; opposition versus conjunction profile), vehicle architecture as well as profile sub-options, and overall objectives and scenarios for human Mars exploration and development. Figure I-1 illustrates a trade chart from the STCAEM study showing relative initial mass and degree of reuse for a range of options. This trade chart is incomplete, however, as additional profile and vehicle variants have been identified and proposed since the chart was made.

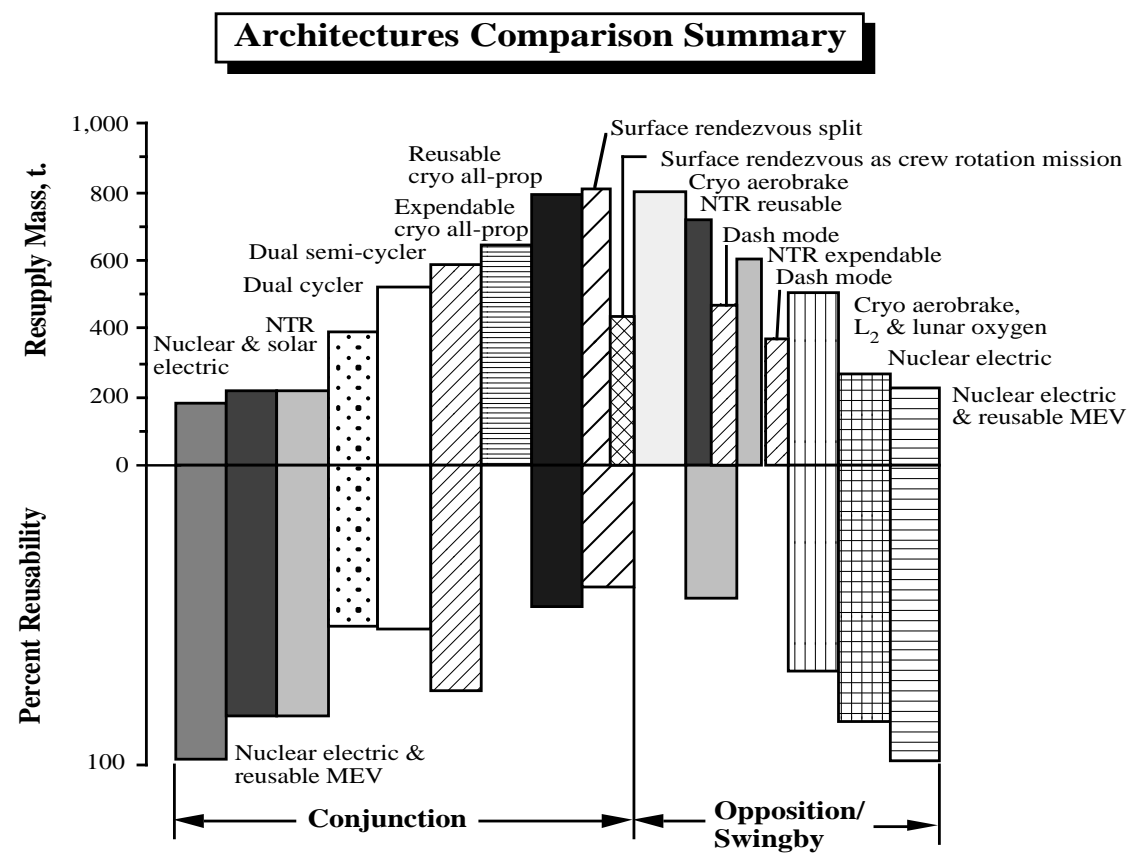

Figure I-1. STCAEM comparison of resupply mass and reusability.

It is also important to note a sea change in thinking about Mars exploration that occurred gradually during and since the SEI studies. At the beginning of SEI, Mars mission scenarios were strongly influenced by the notion that early missions should be short-duration dashes to Mars and back and that long surface stays would occur much later. This placed great emphasis on propulsion performance for the opposition profile. Today the view is that if it is worth sending humans to Mars at all, "serious" time should be spent on the surface from the beginning. Enough facilities should be placed on Mars before the first human visit to make the Mars surface a safe haven. Conjunction is the preferred profile, and the question is how much propulsive effort should be invested in reducing transit time.

\section{I.7 Recommendations}

Further important considerations for the present study are compatibility of in-space propulsion technology with HRST as an Earth launch system; availability/status of propulsion technology from alternative, especially commercial, applications; and the priority assigned human exploration utility as a factor in selecting technologies for advancement funding.

Suffice to say that cryogenic chemical propulsion appears clearly preferred for lunar missions, and that reasonable cases can be made for cryogenic, nuclear thermal, or solar electric propulsion for Mars transfer. With decreasing emphasis on the opposition profile, preferences for nuclear thermal propulsion are softening. A long-term commitment to human Mars activities and compatibility with HRST both suggest solar electric propulsion as the final choice, but this choice is conditional on achieving the cost and performance targets set for solar electric in this study. 


\section{APPENDIX J}

\section{DETAILED COST BREAKDOWN}

The information in appendices B and F are complimentary to the information in this appendix. 


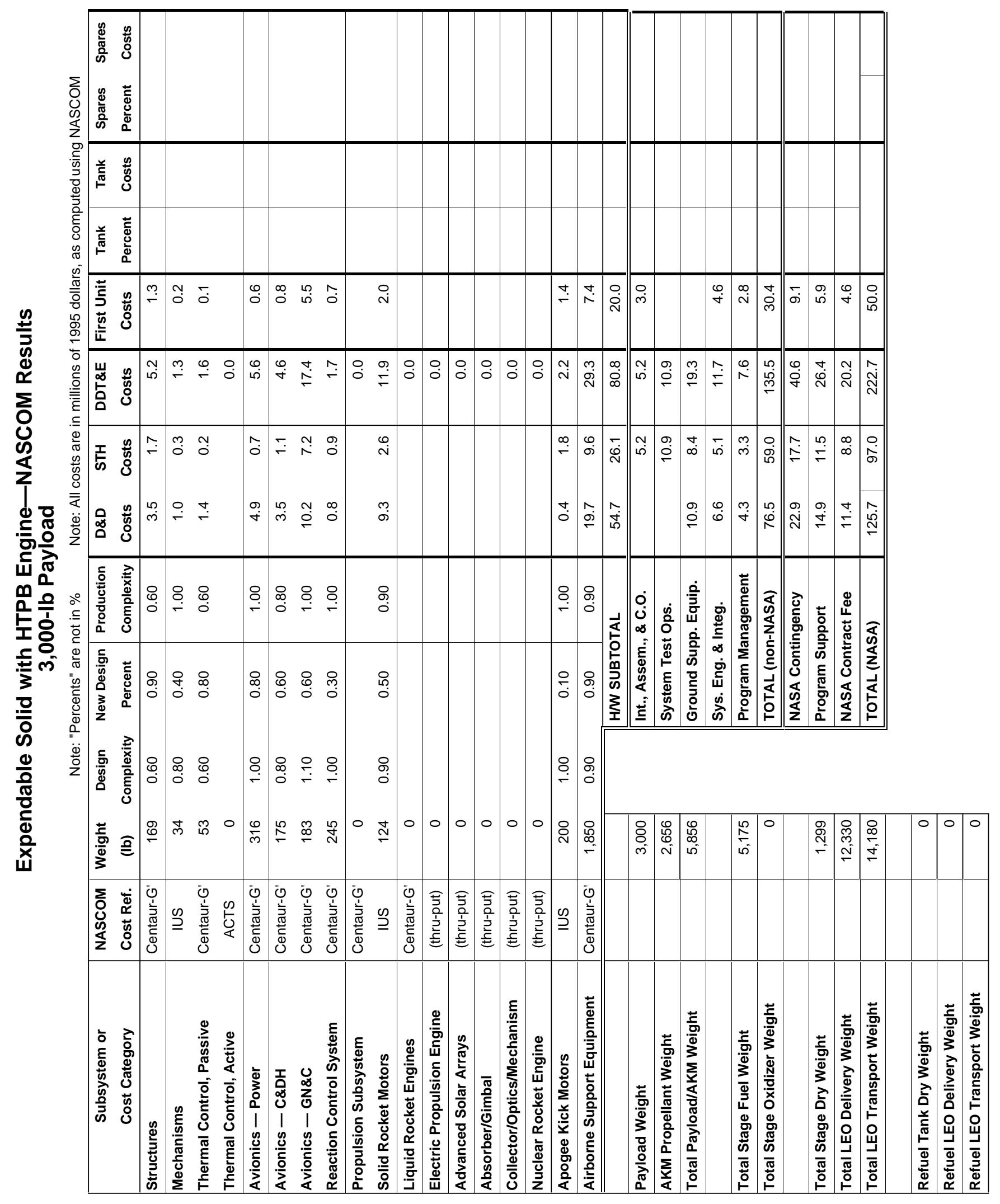




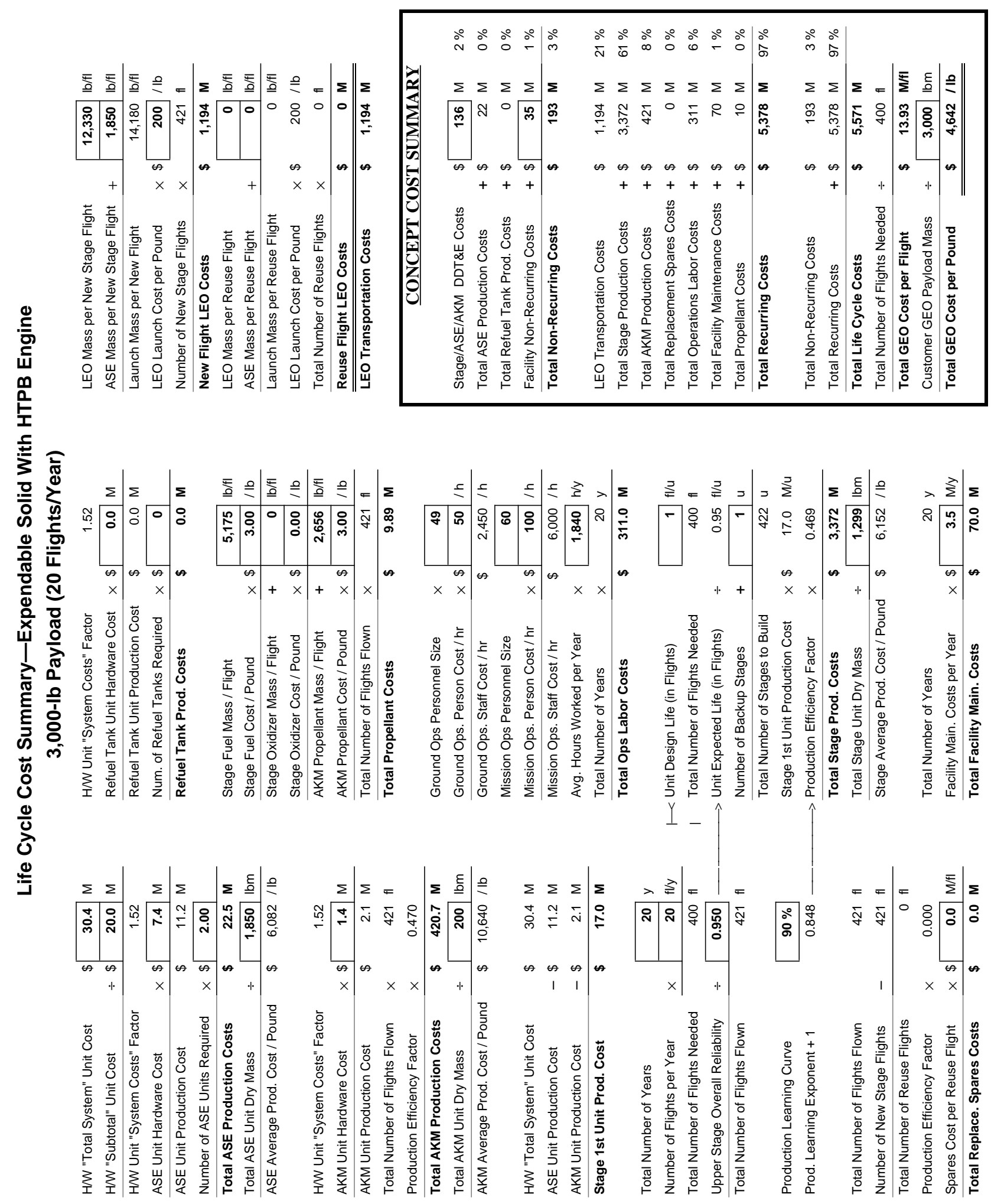




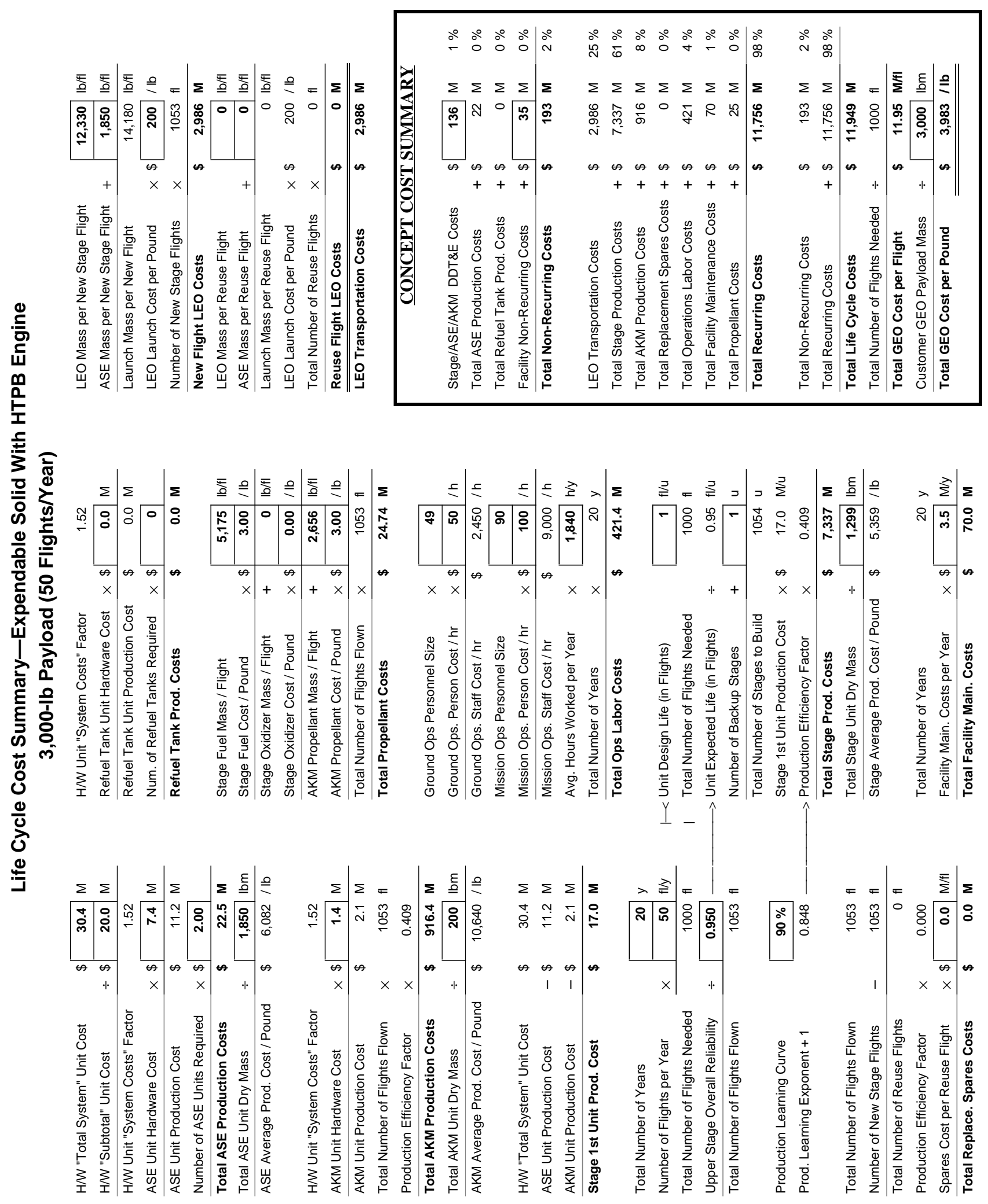




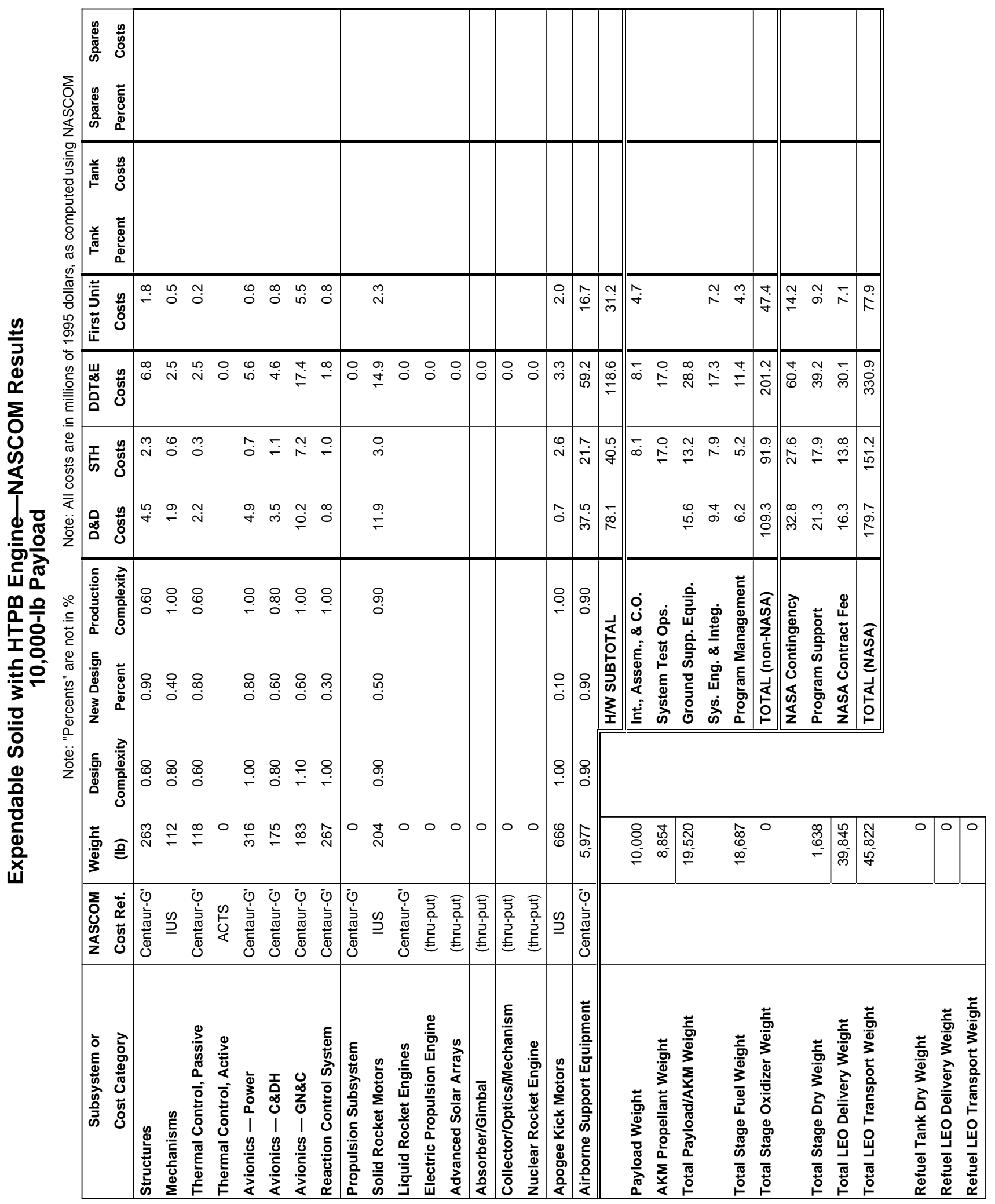




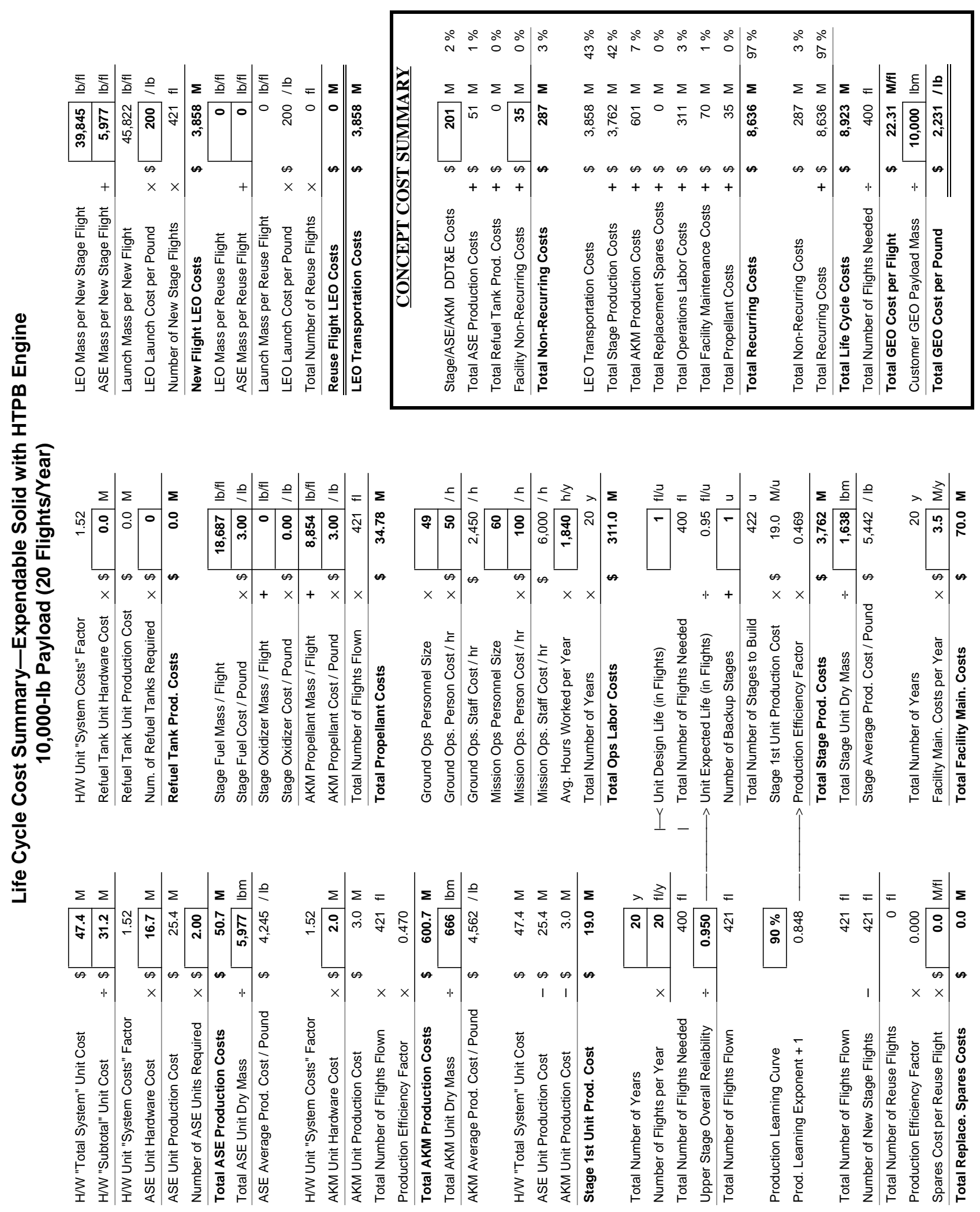




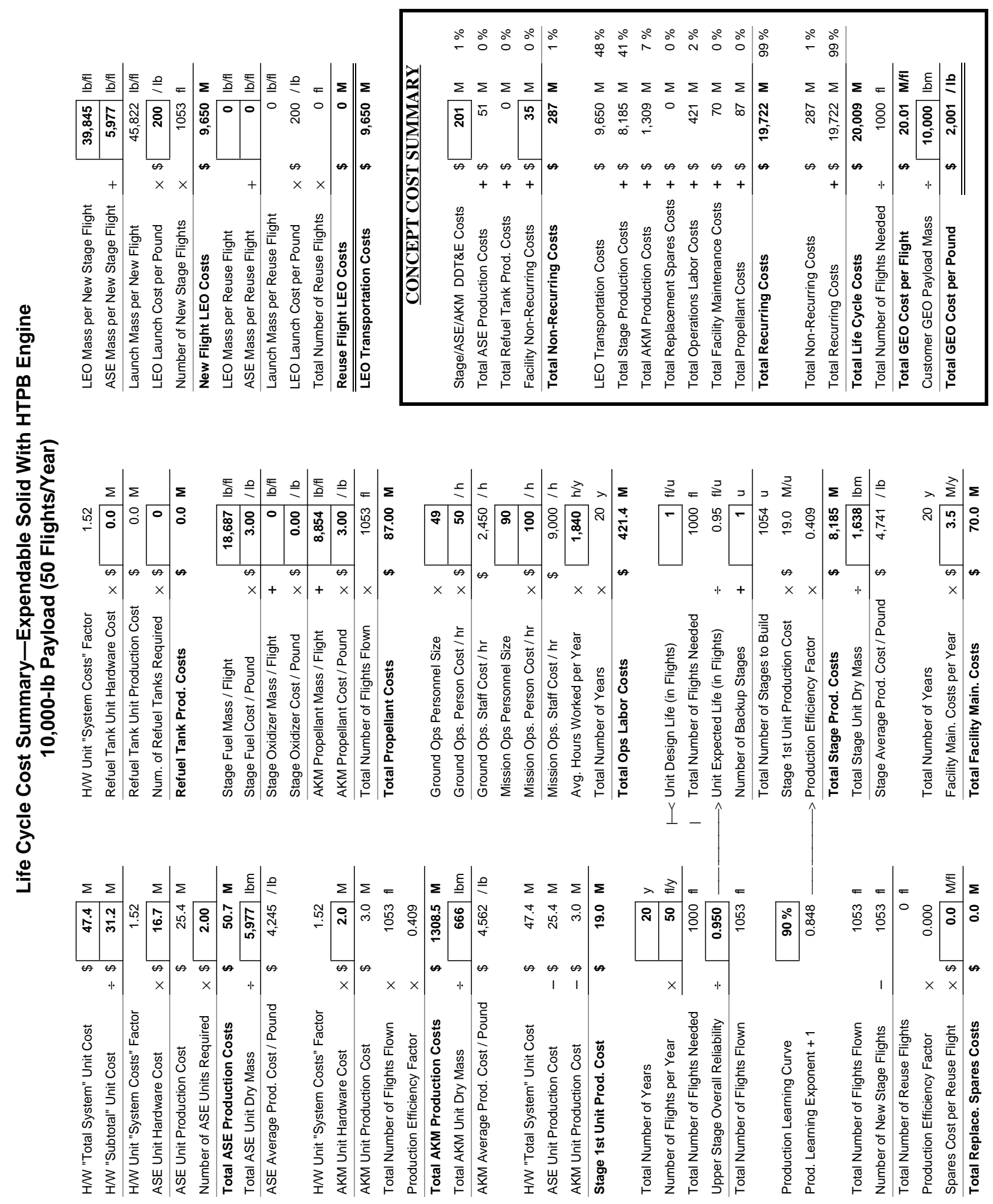




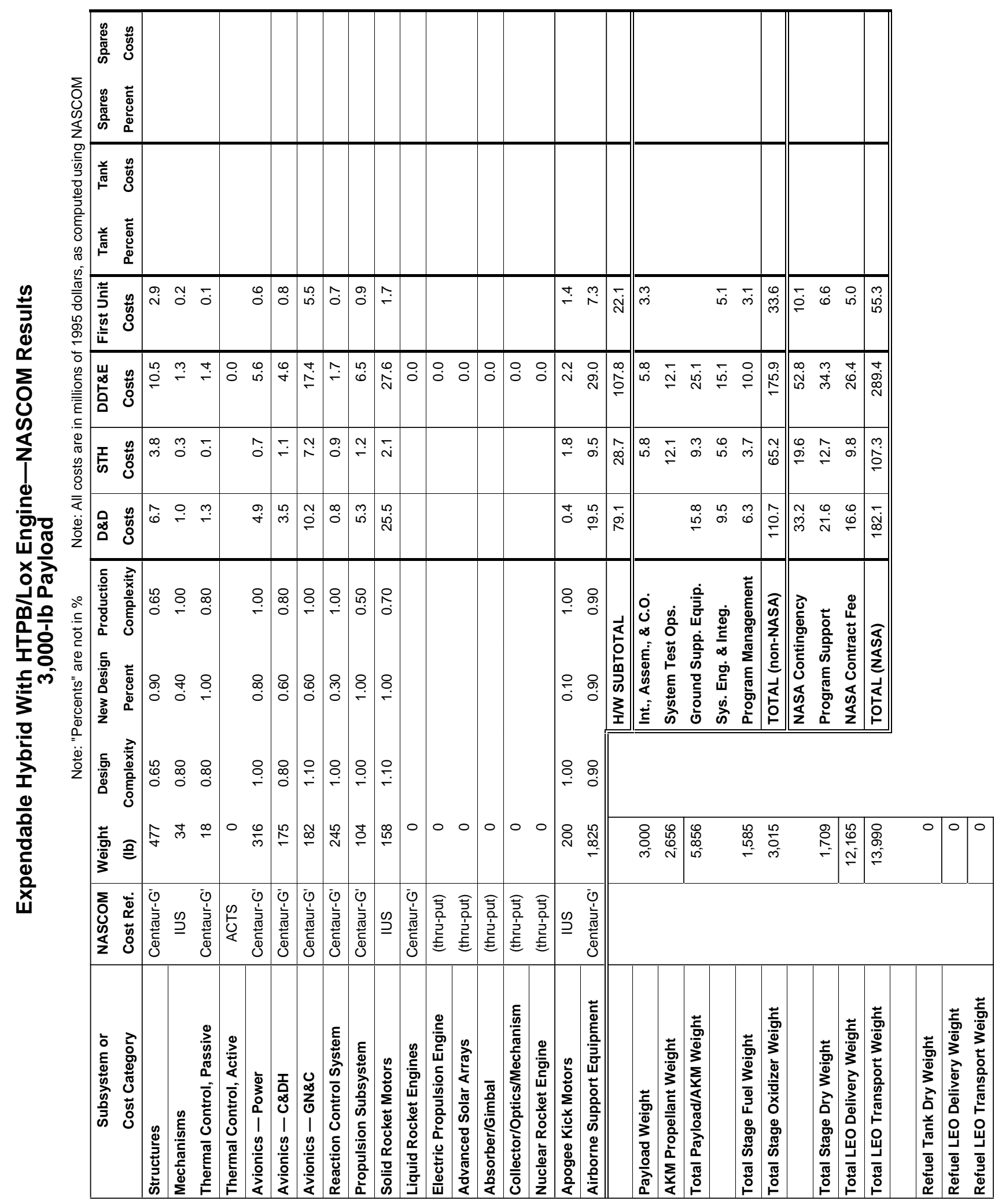




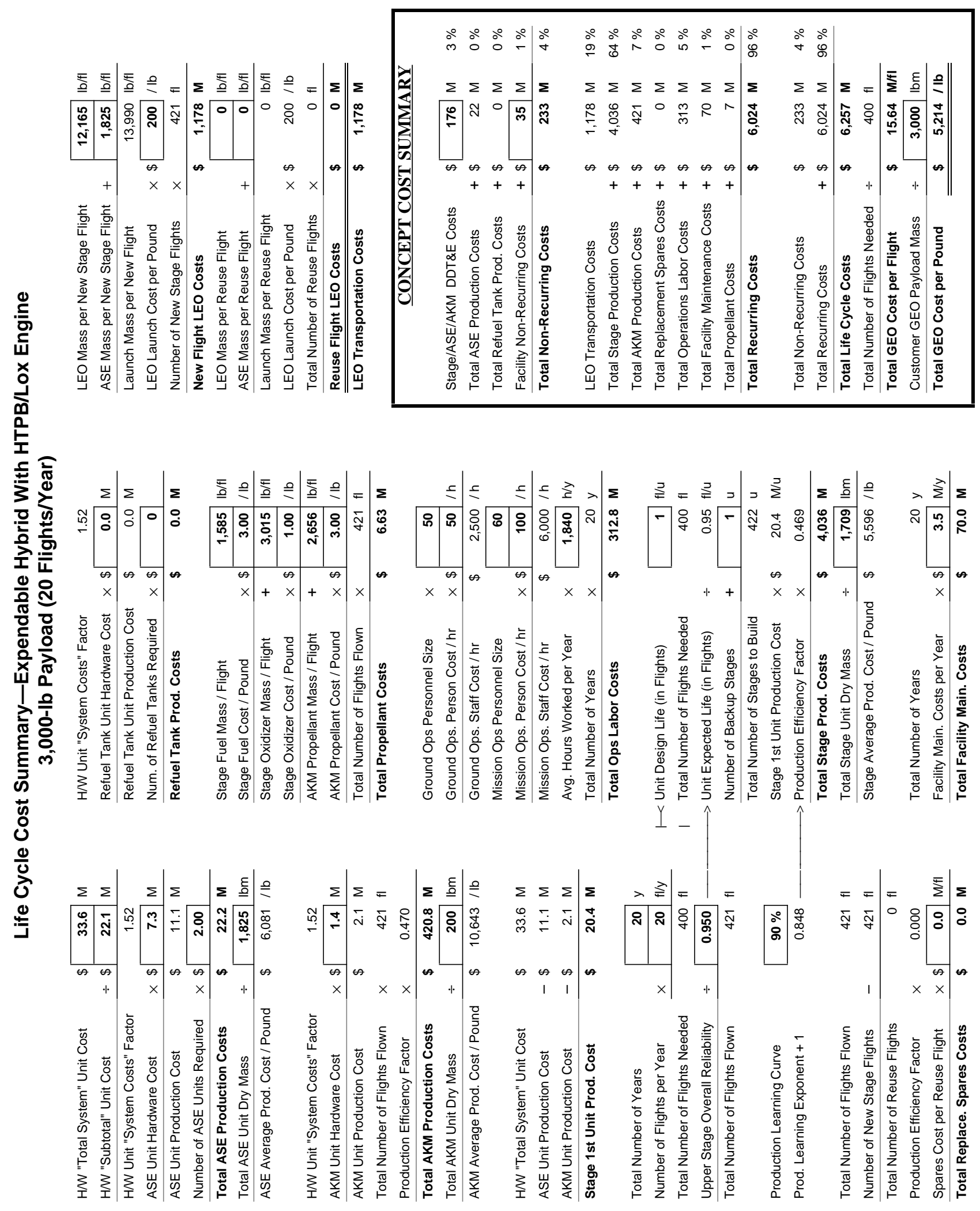




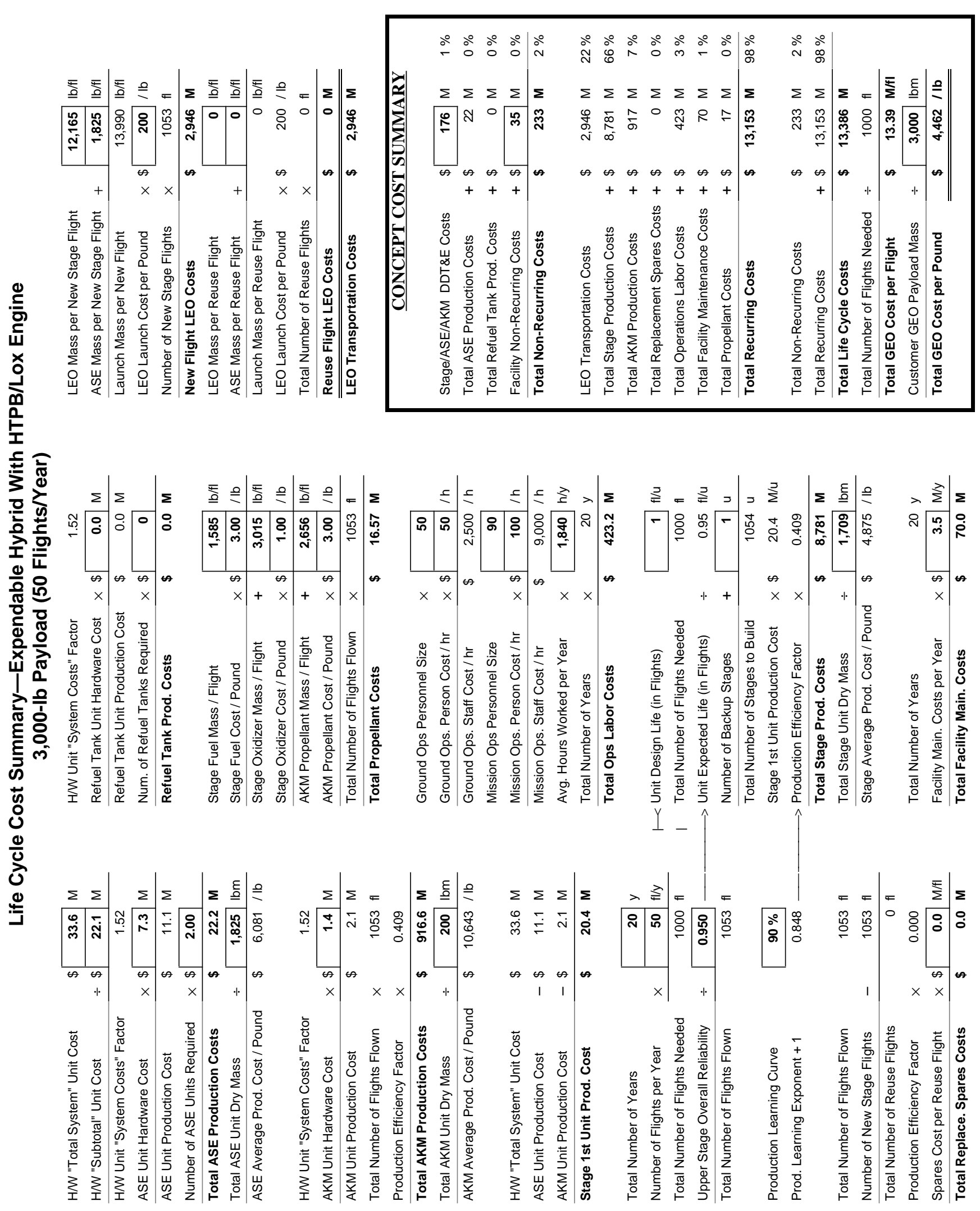




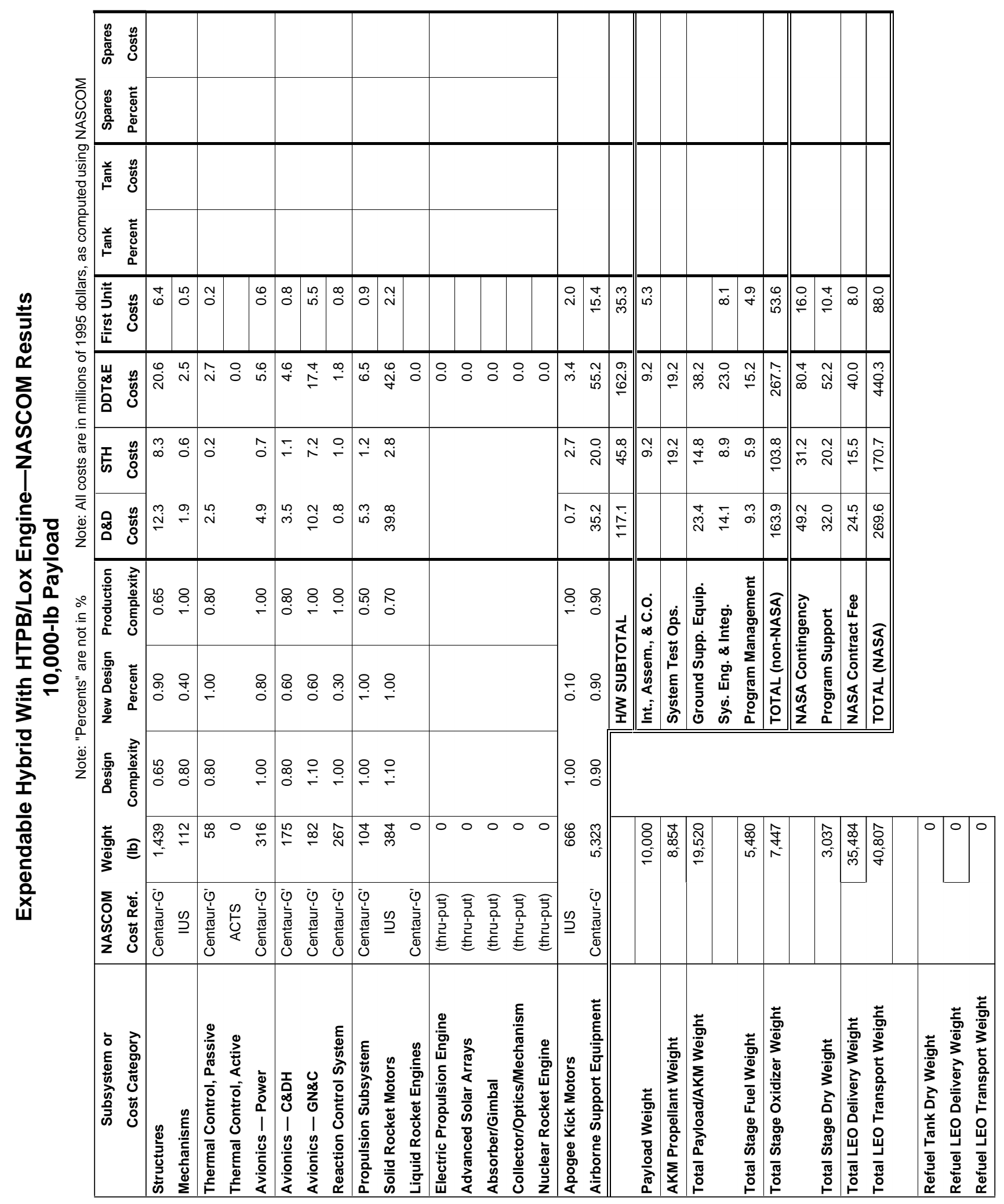




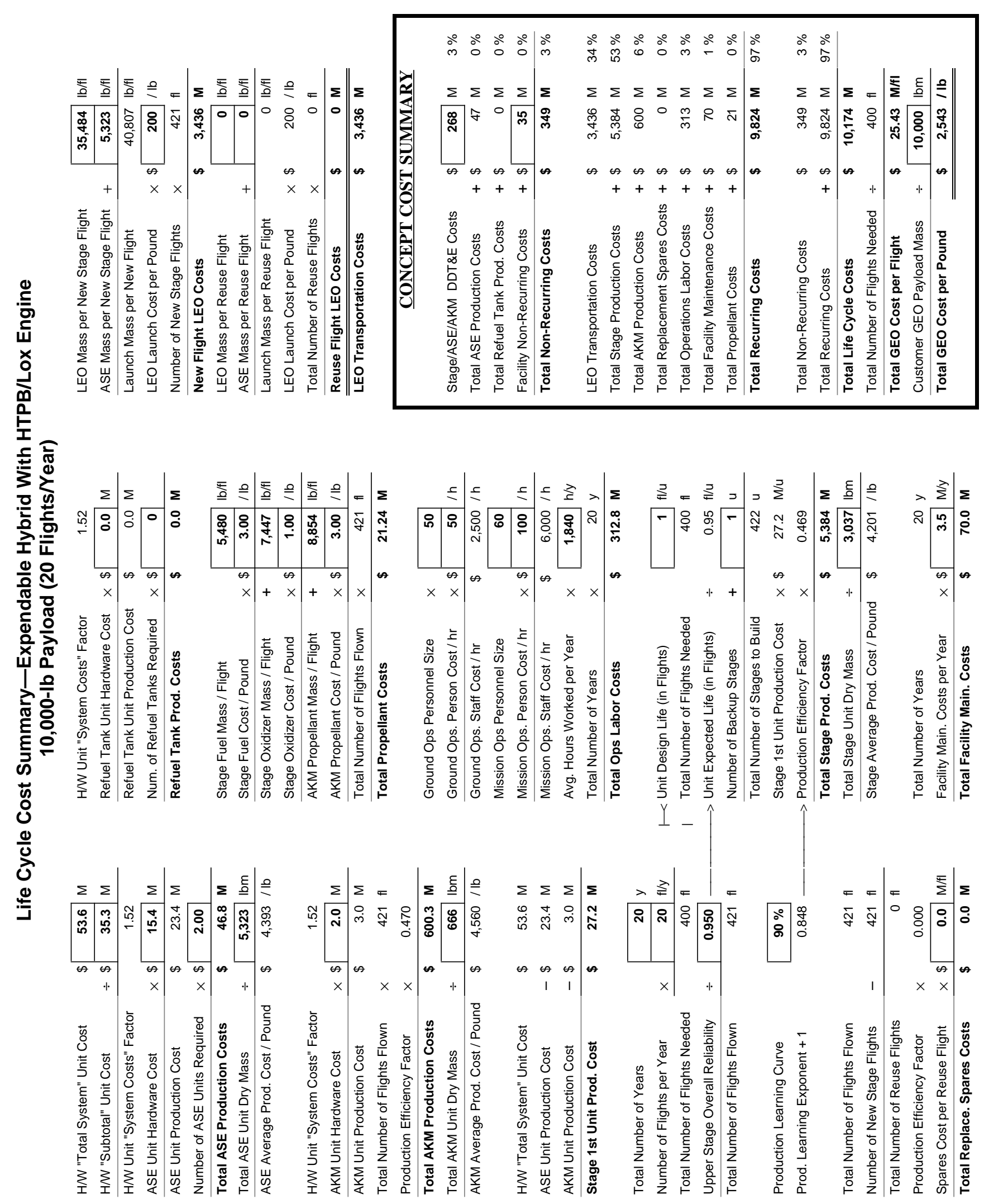




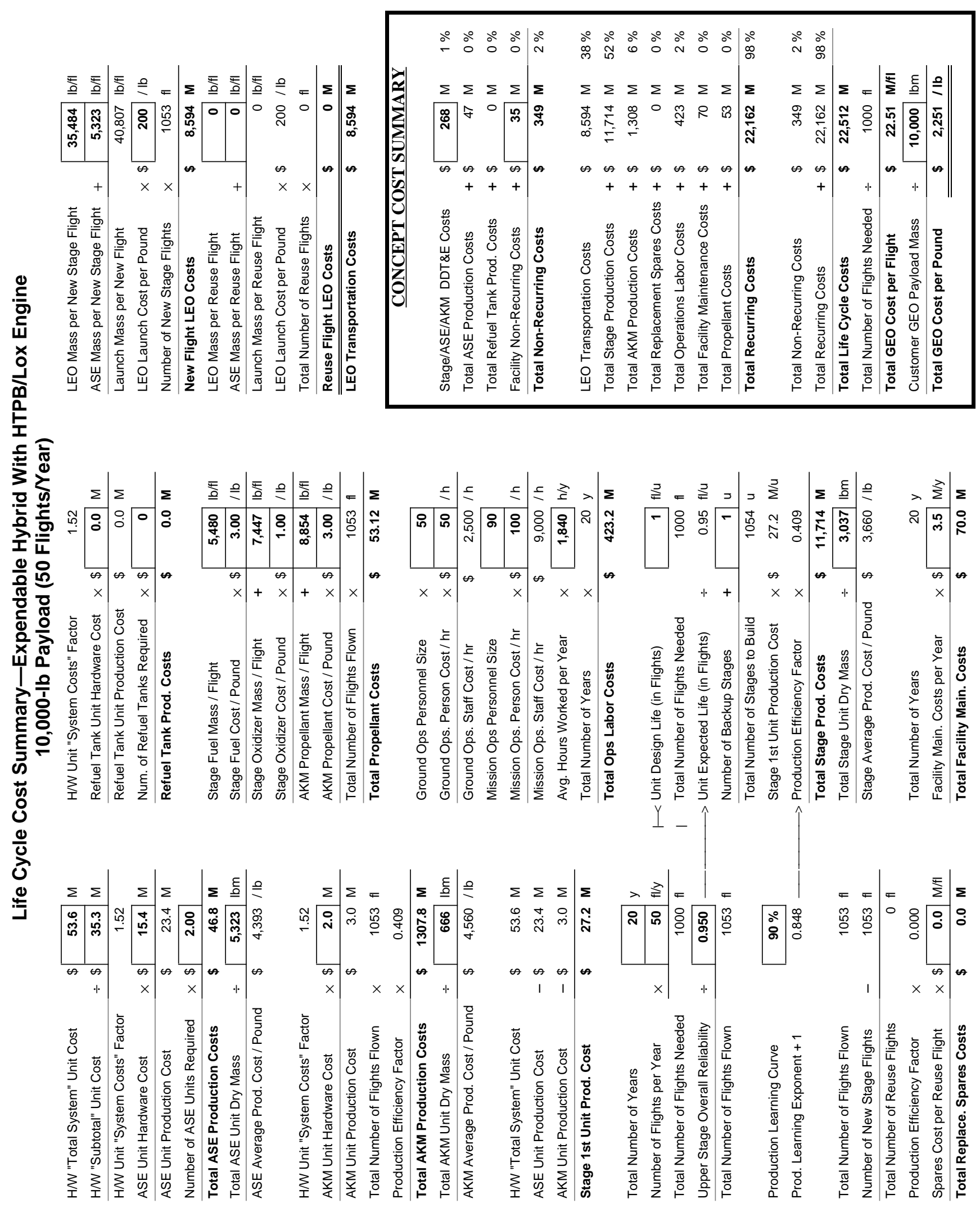




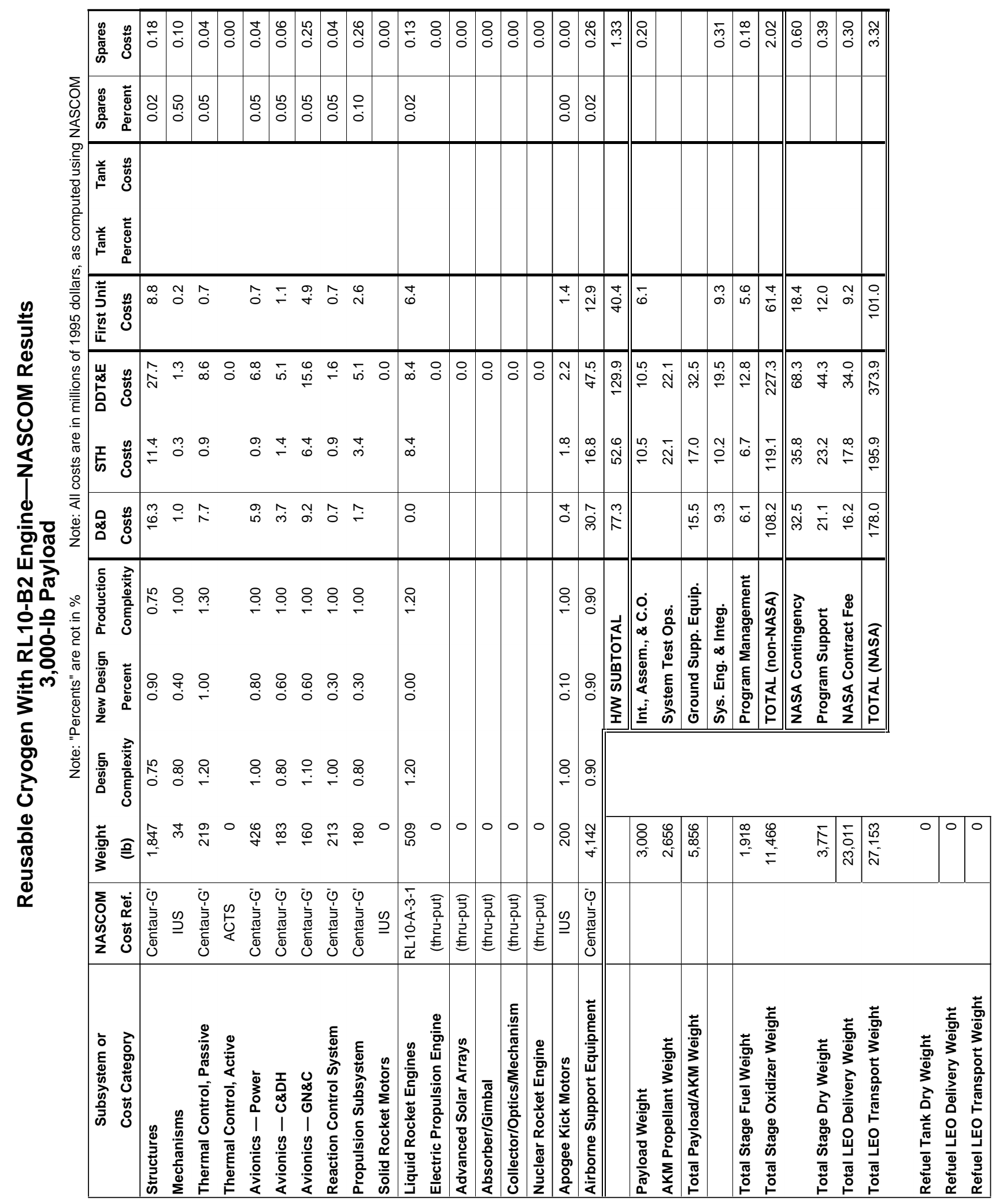




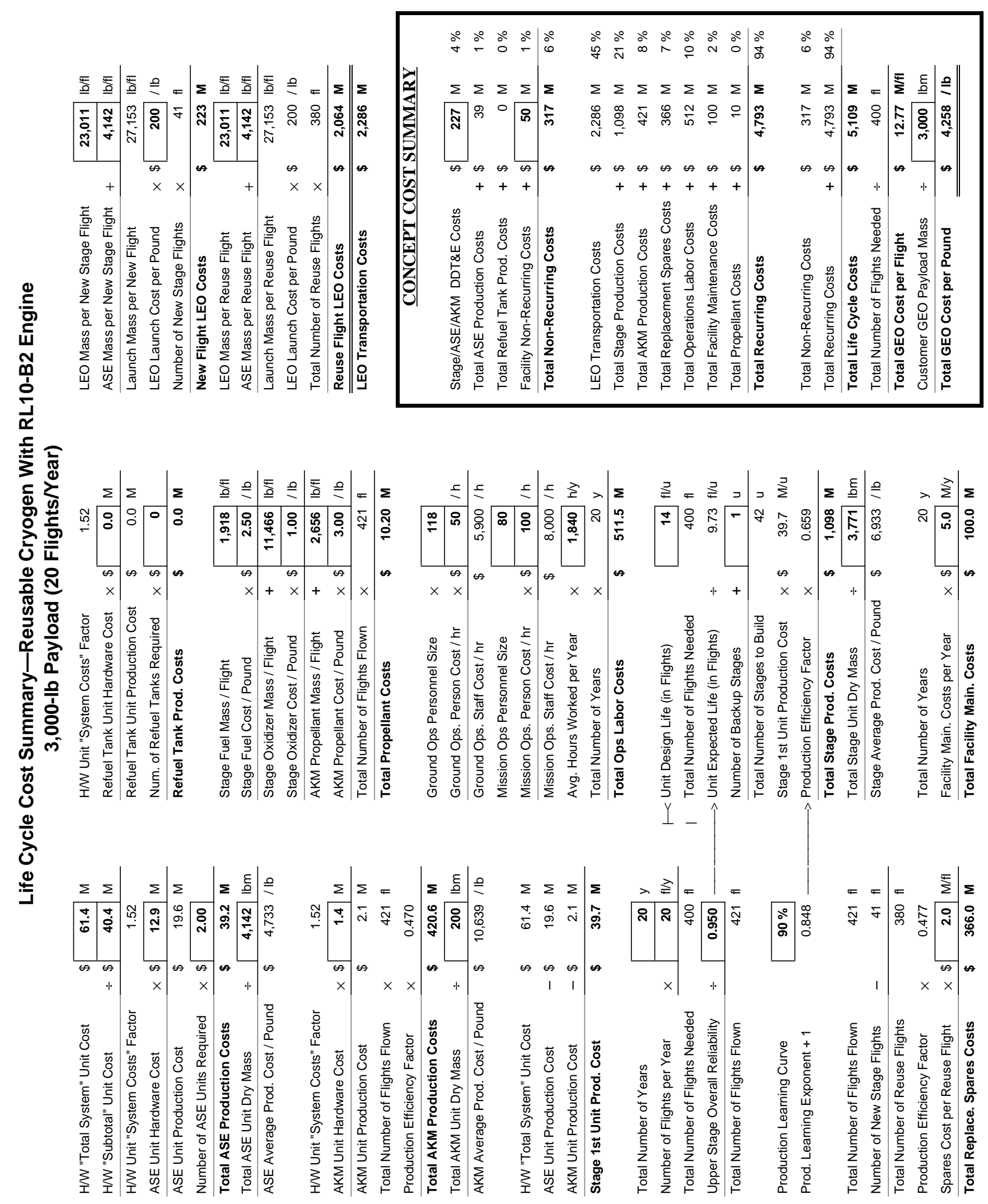




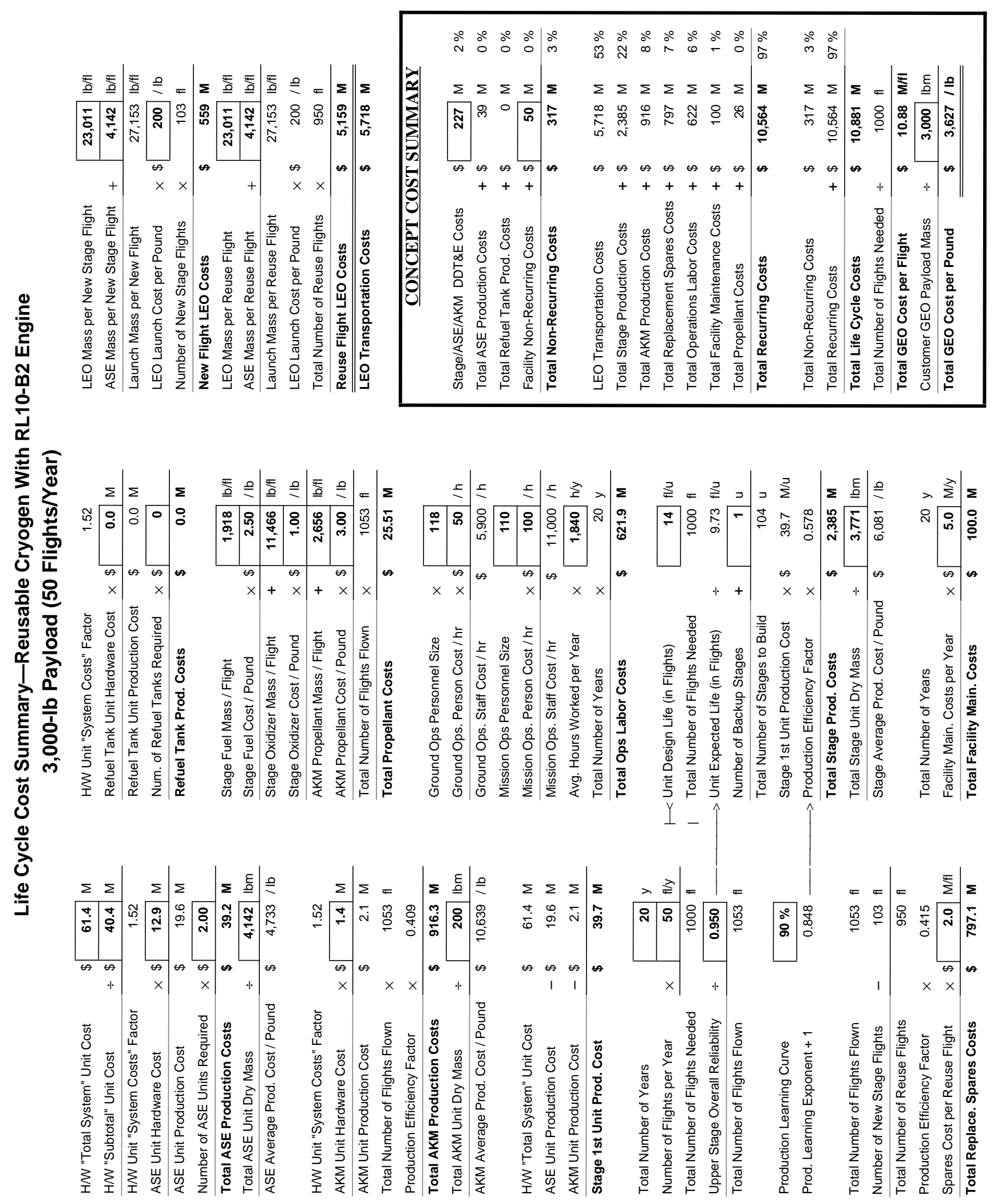




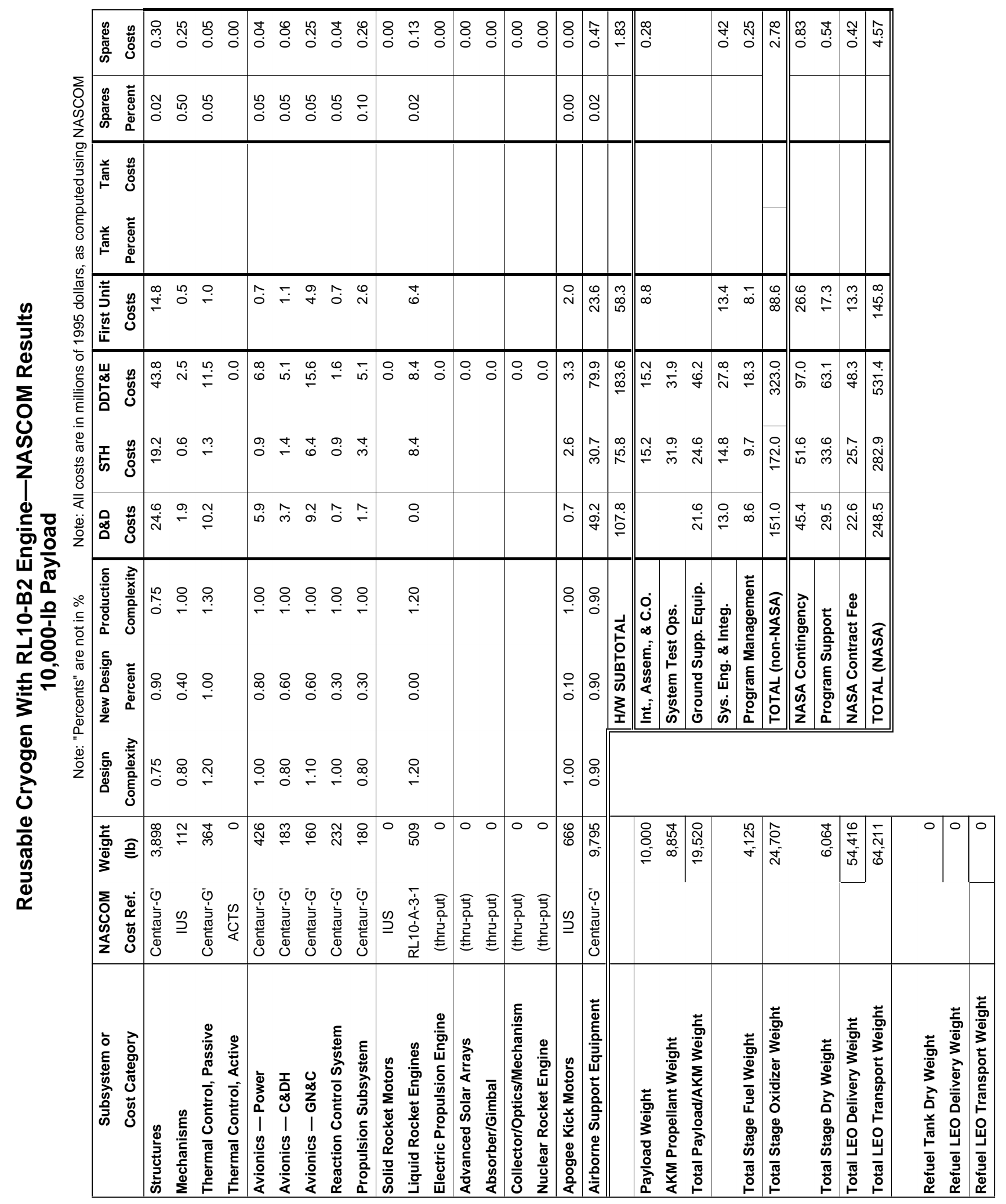




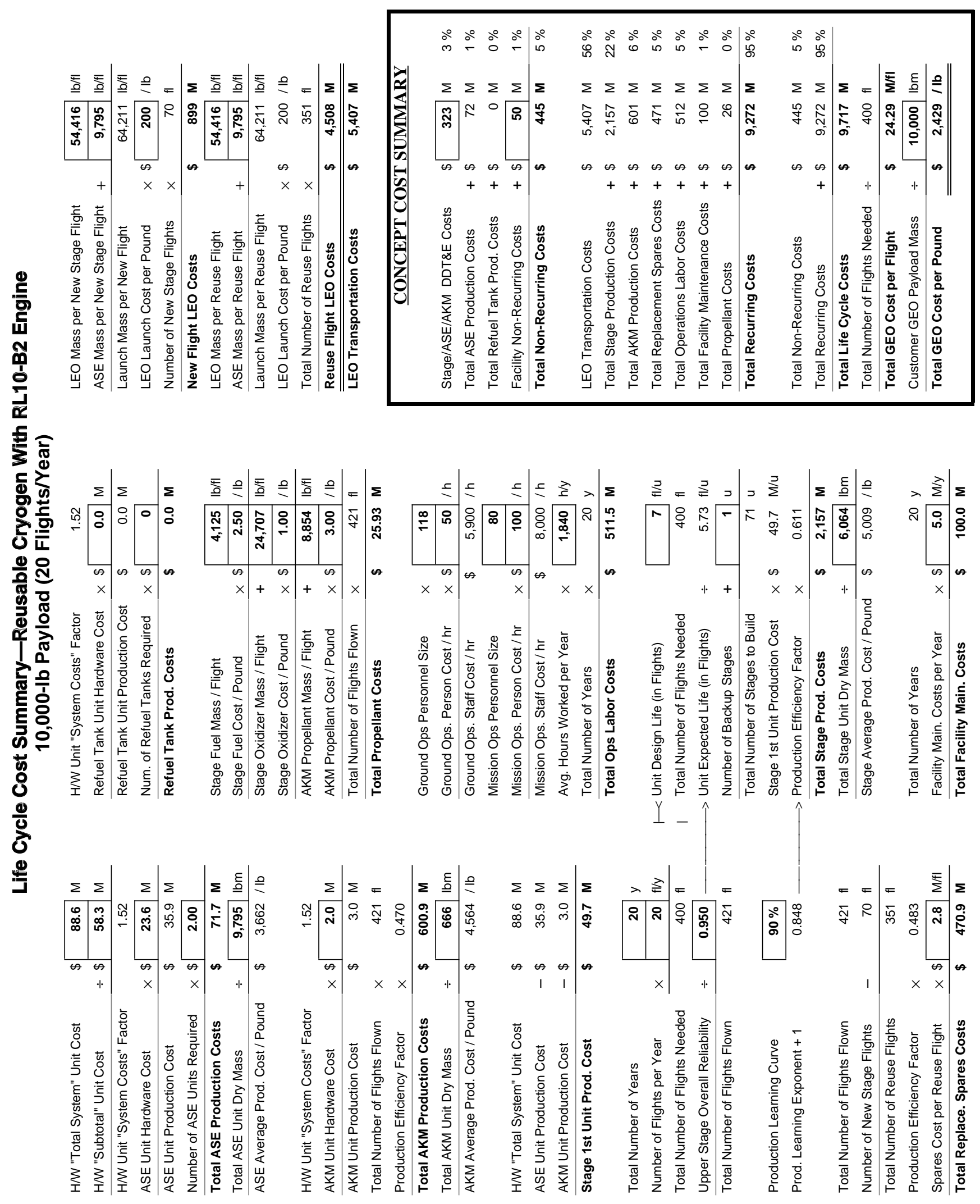




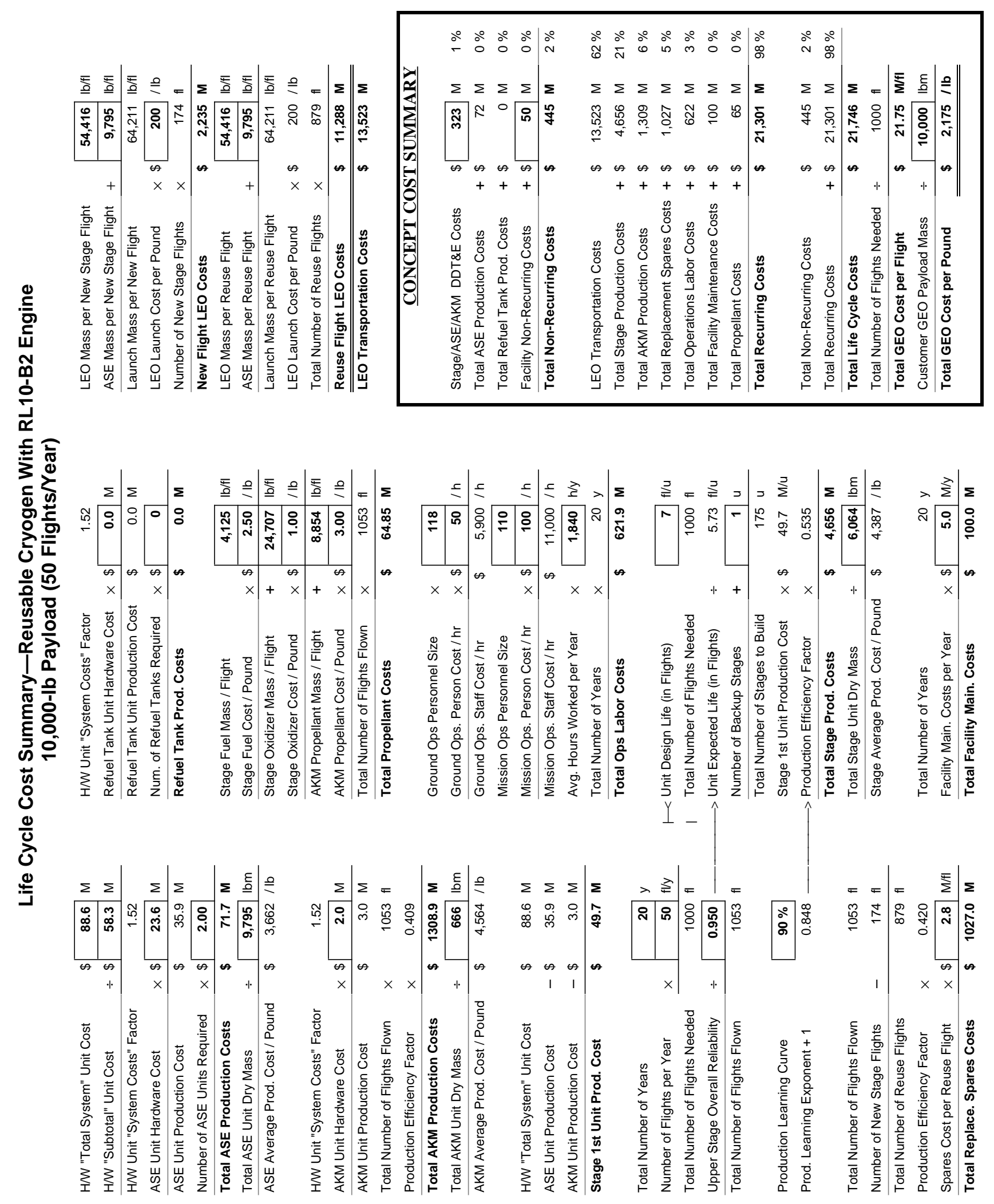




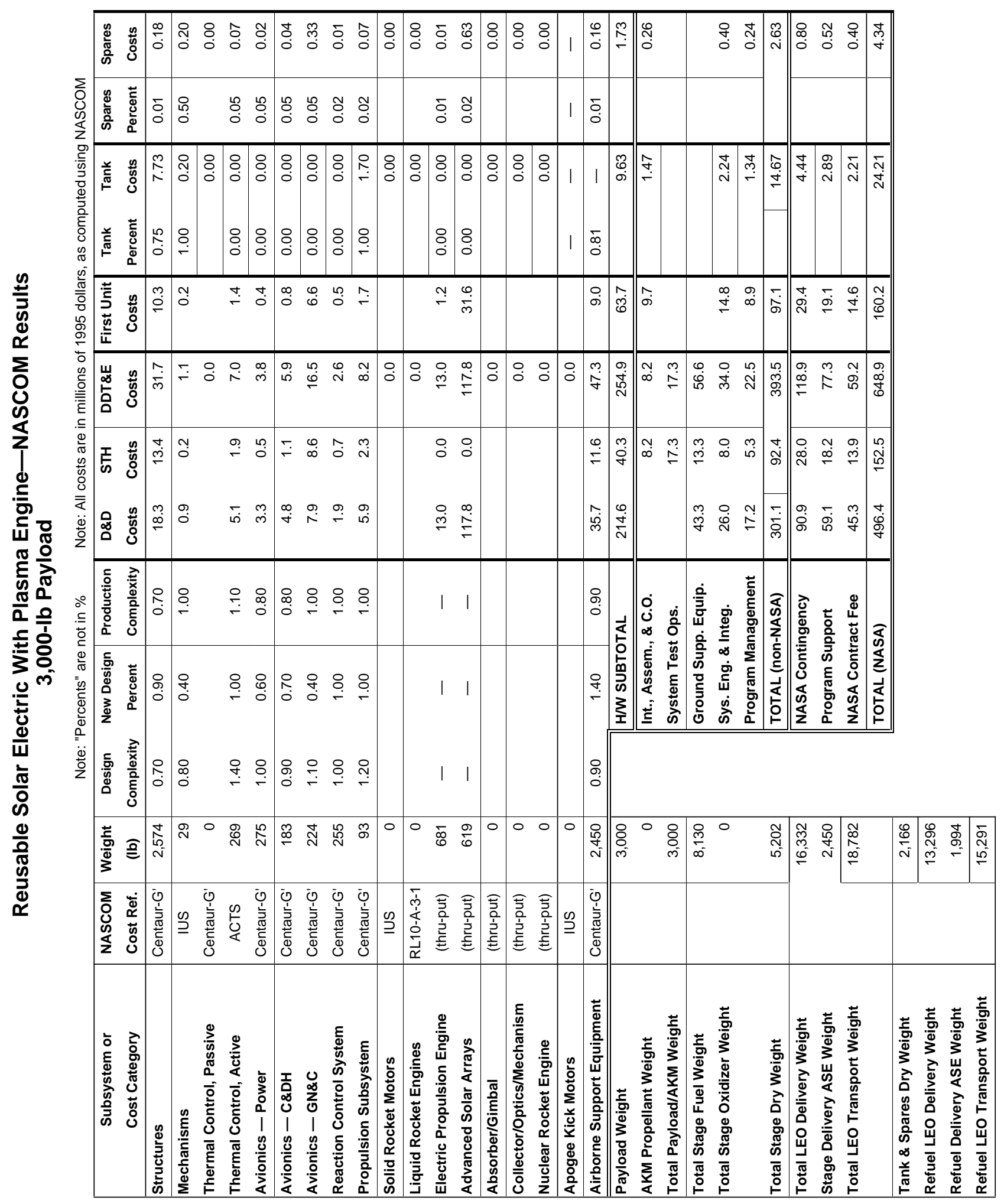




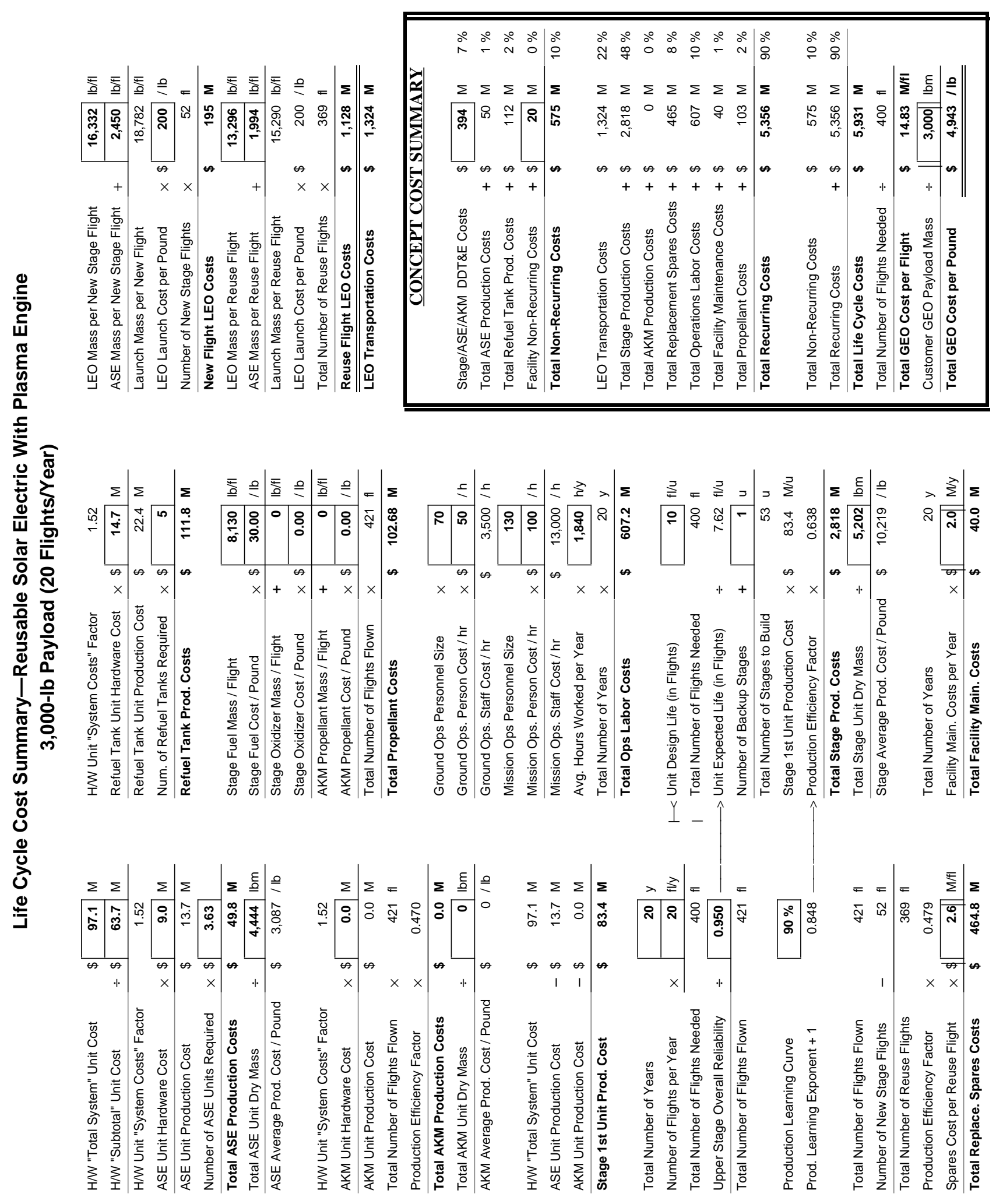




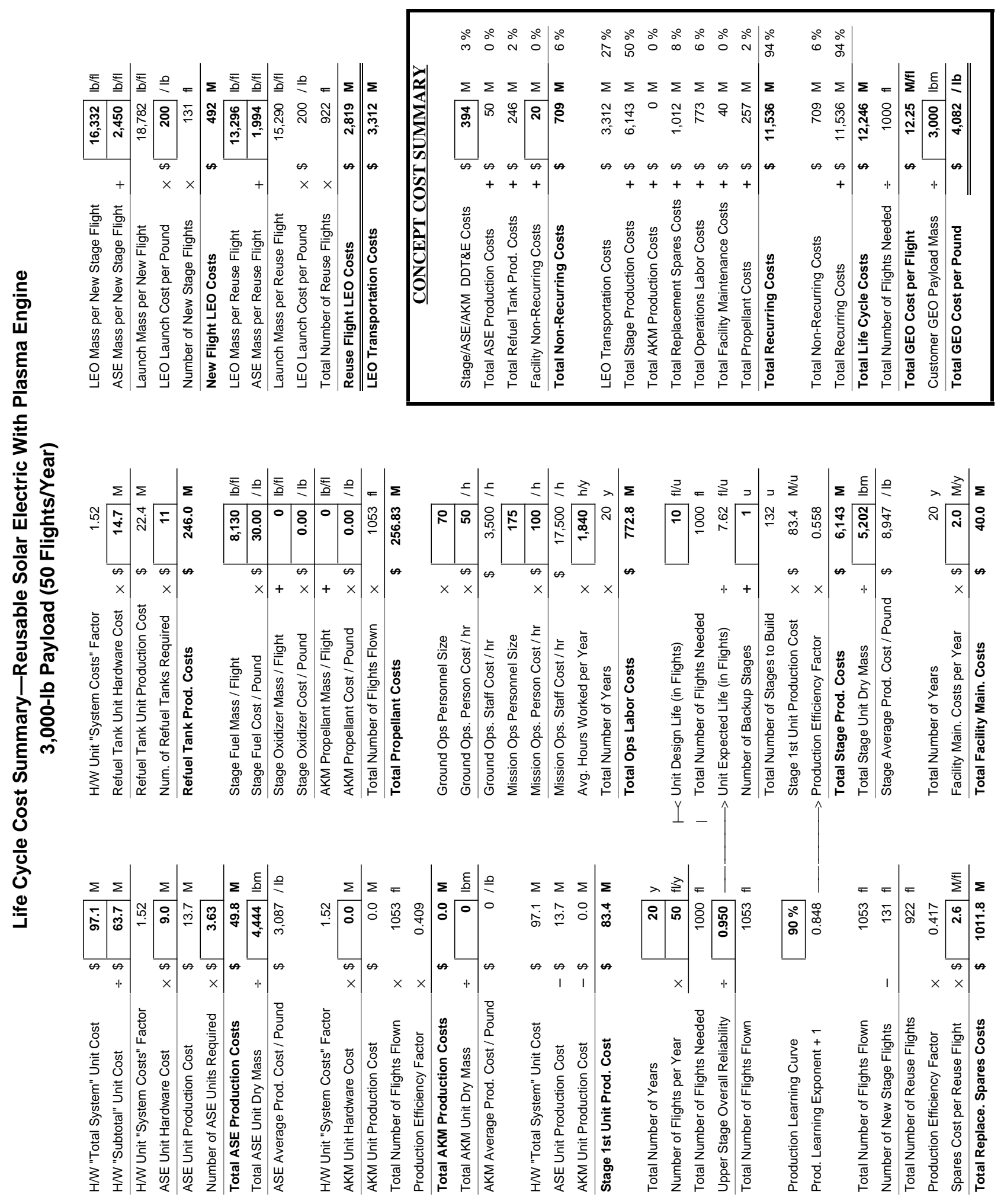




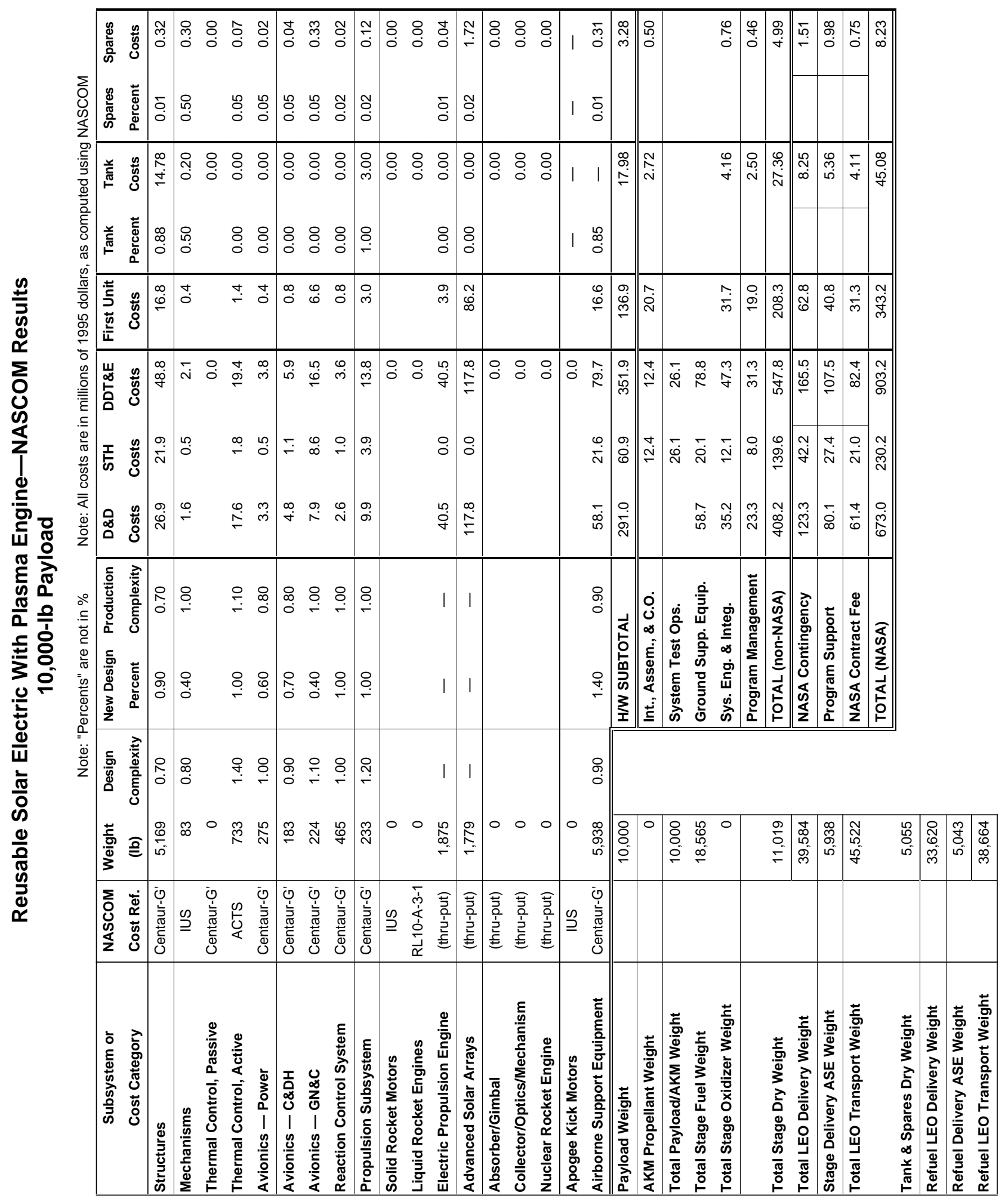




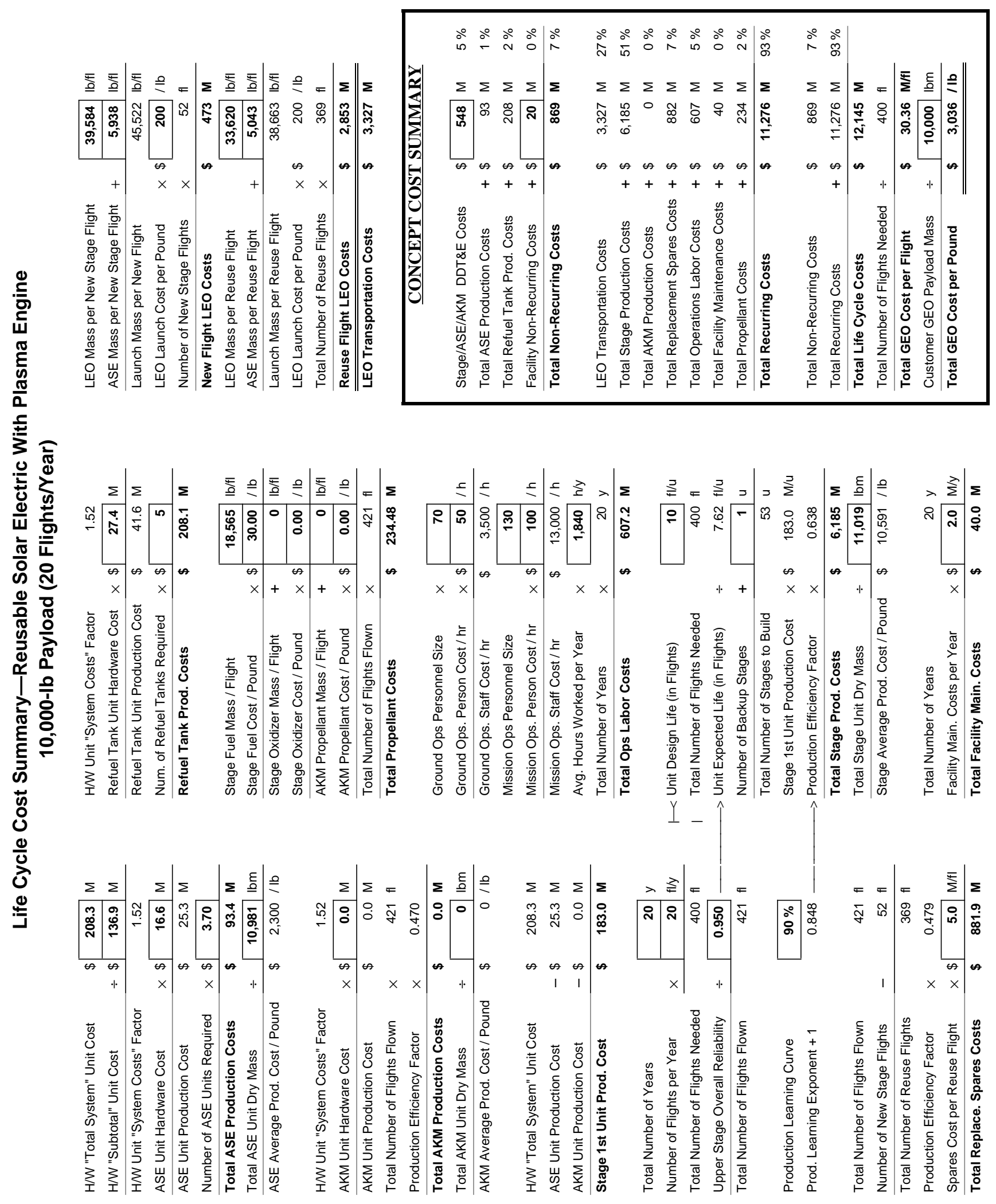




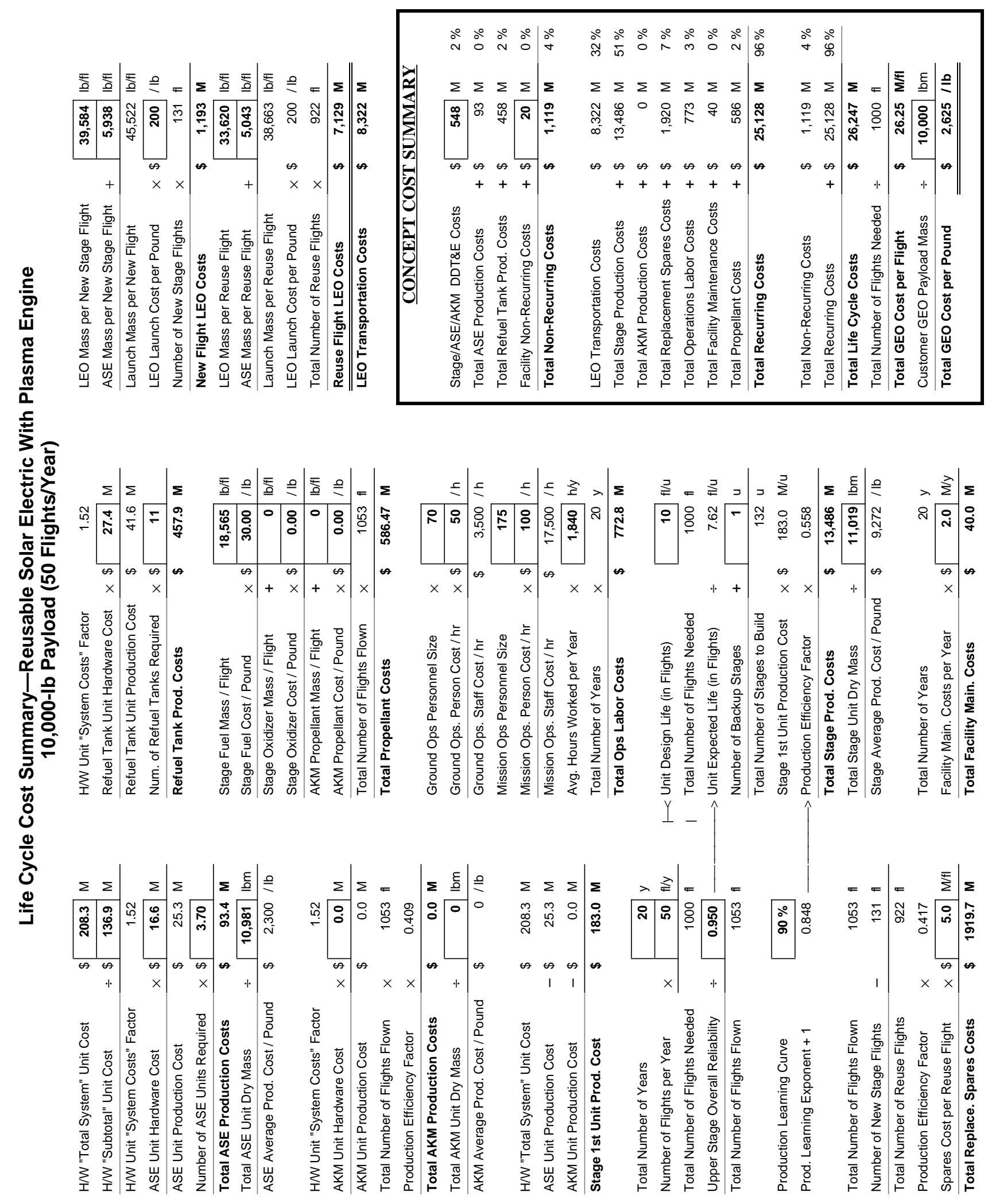




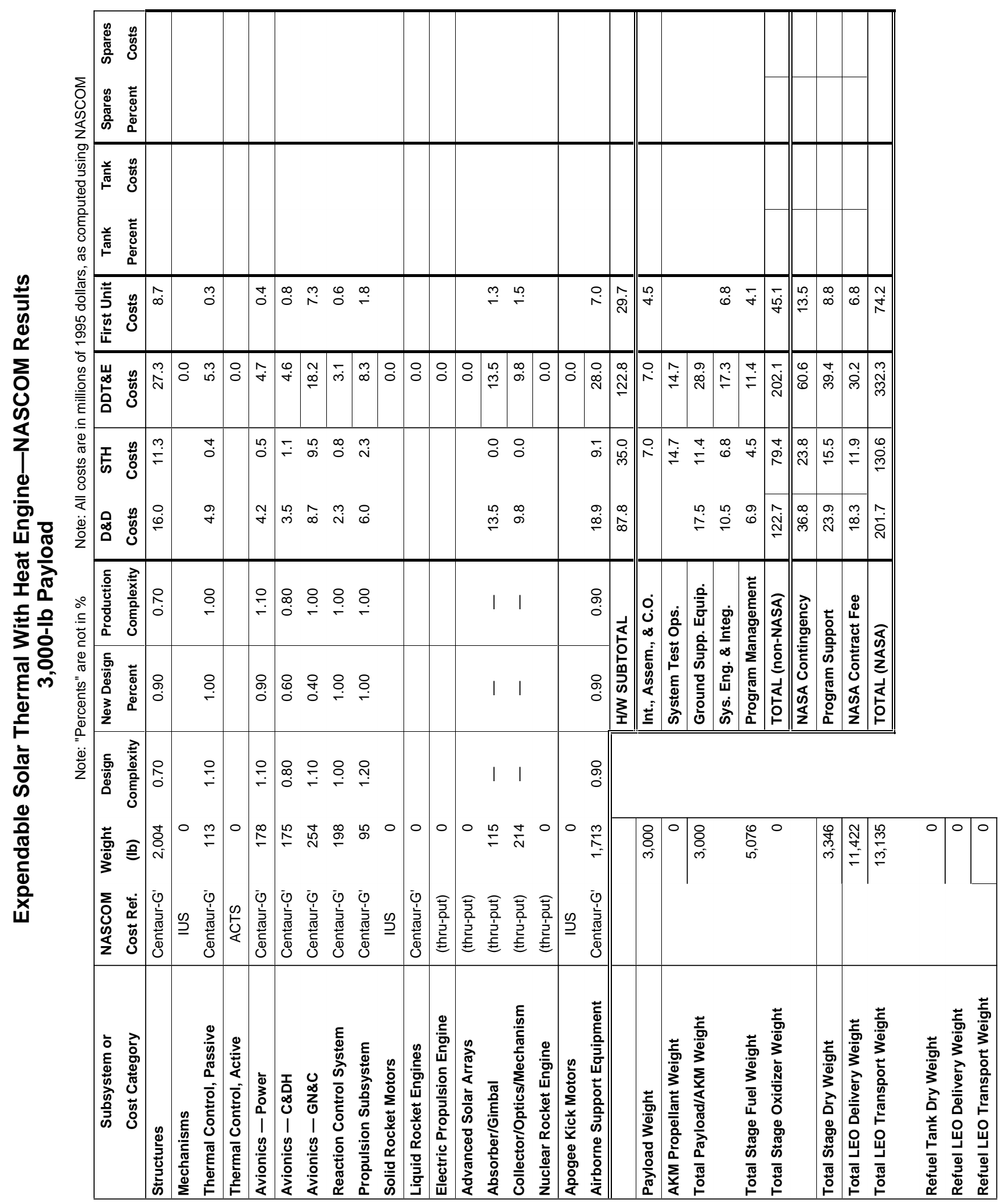




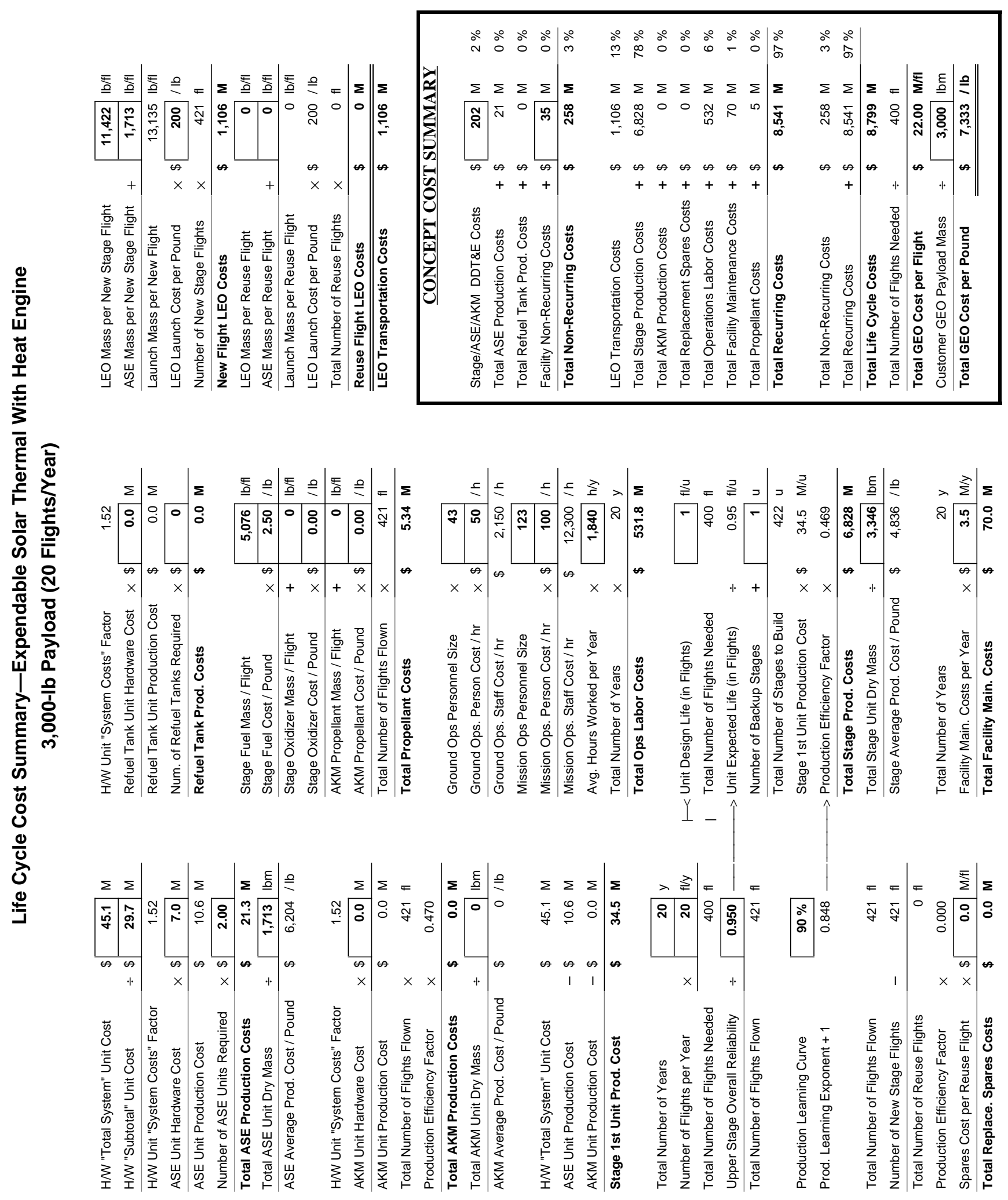




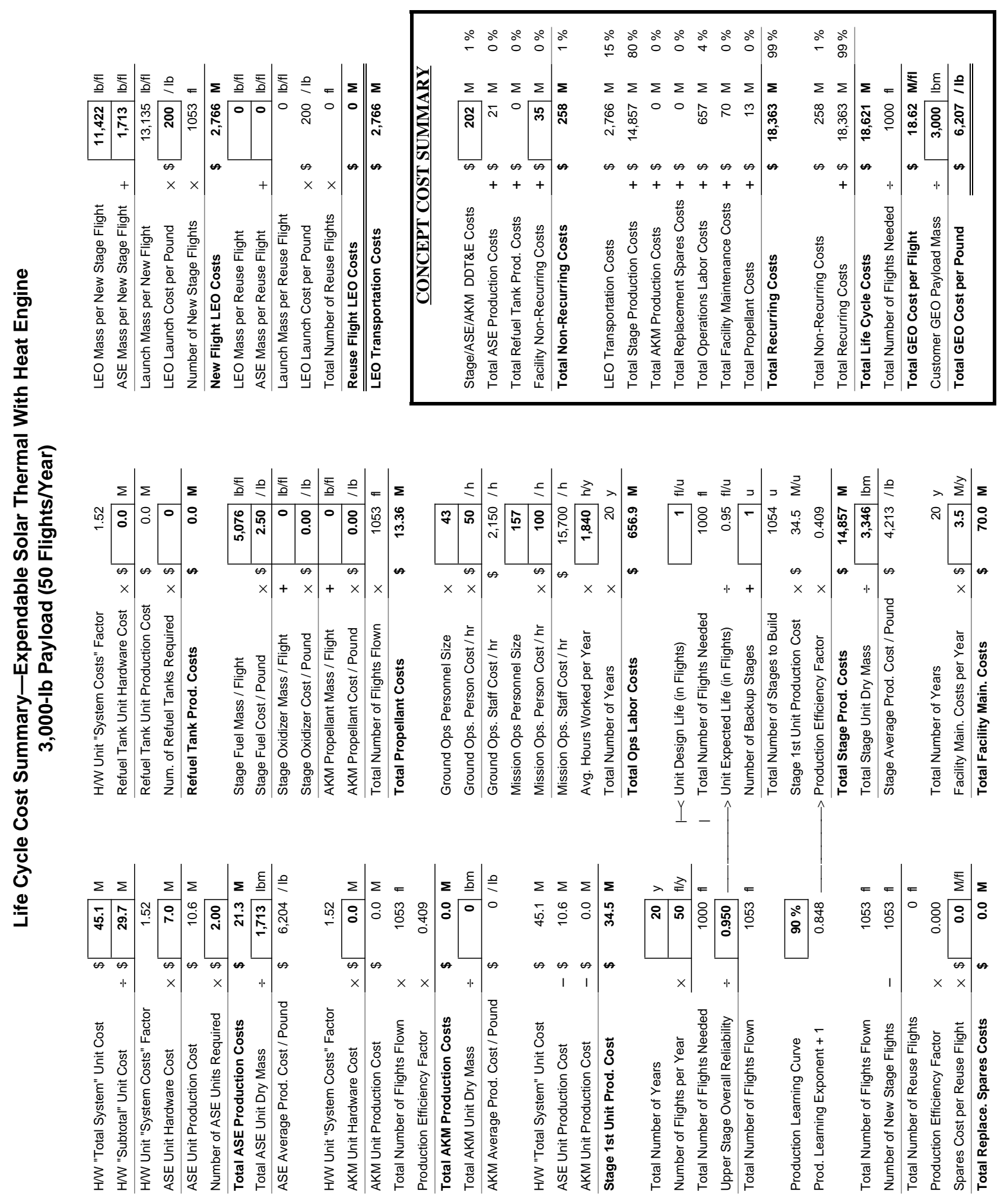




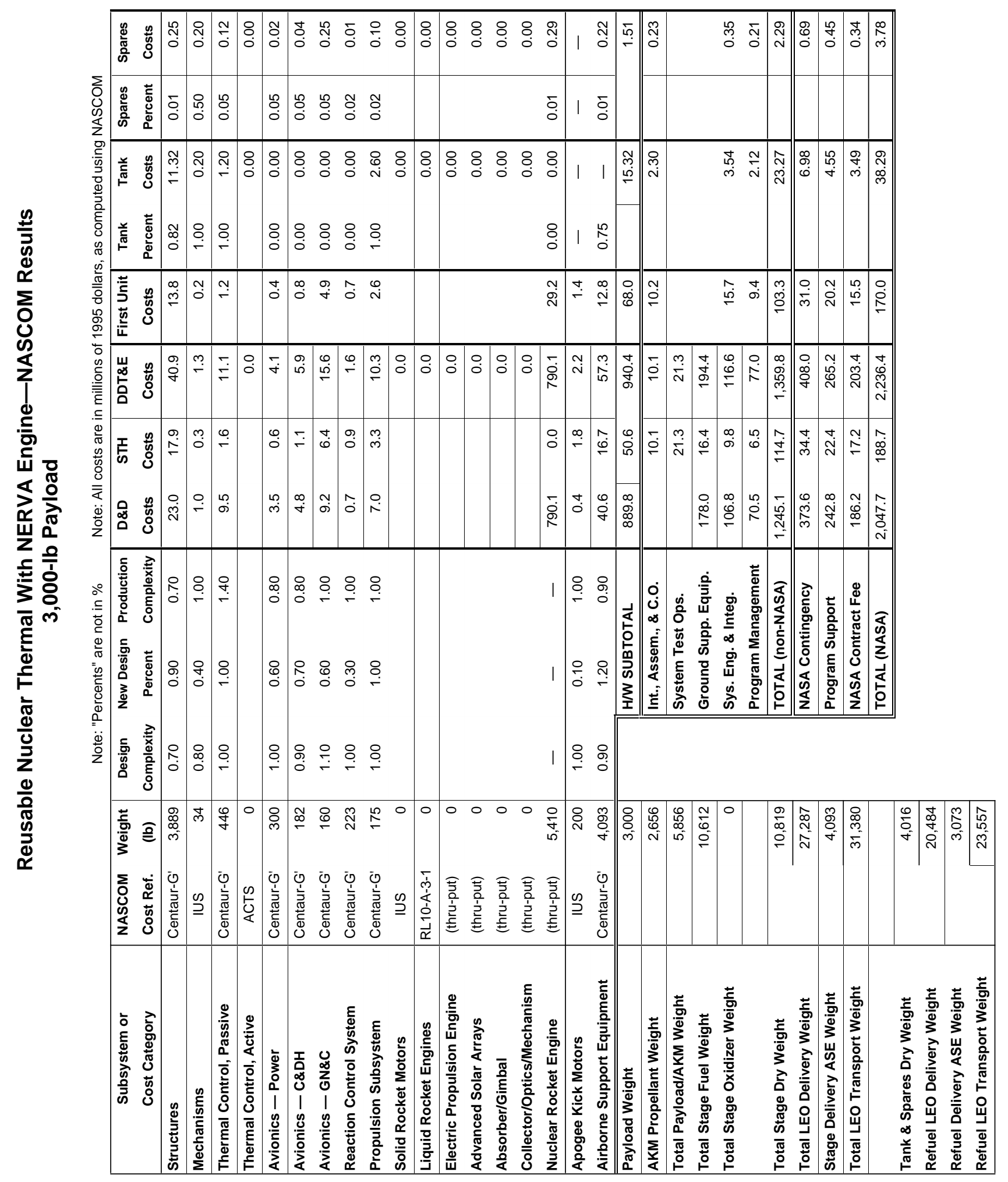




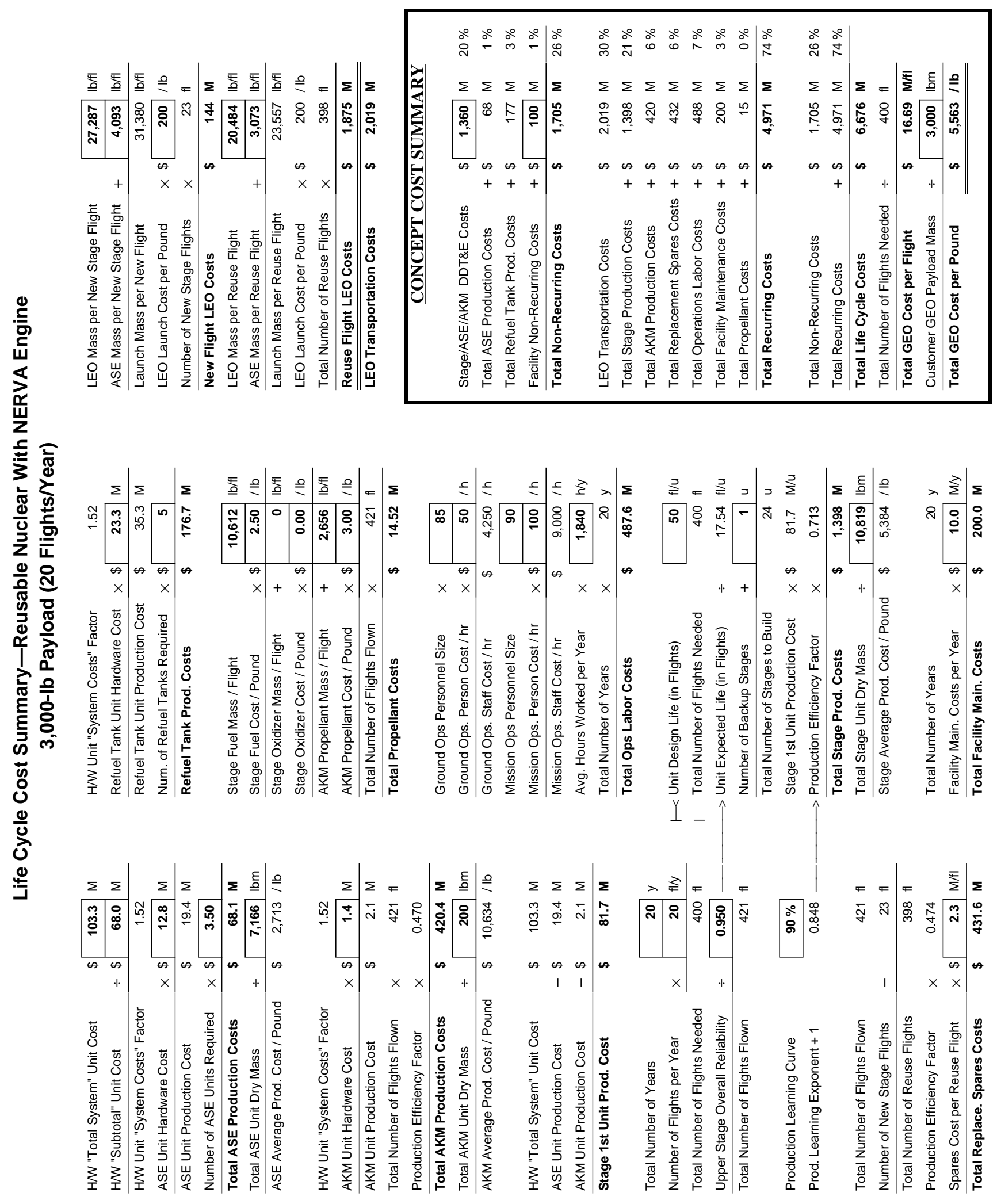




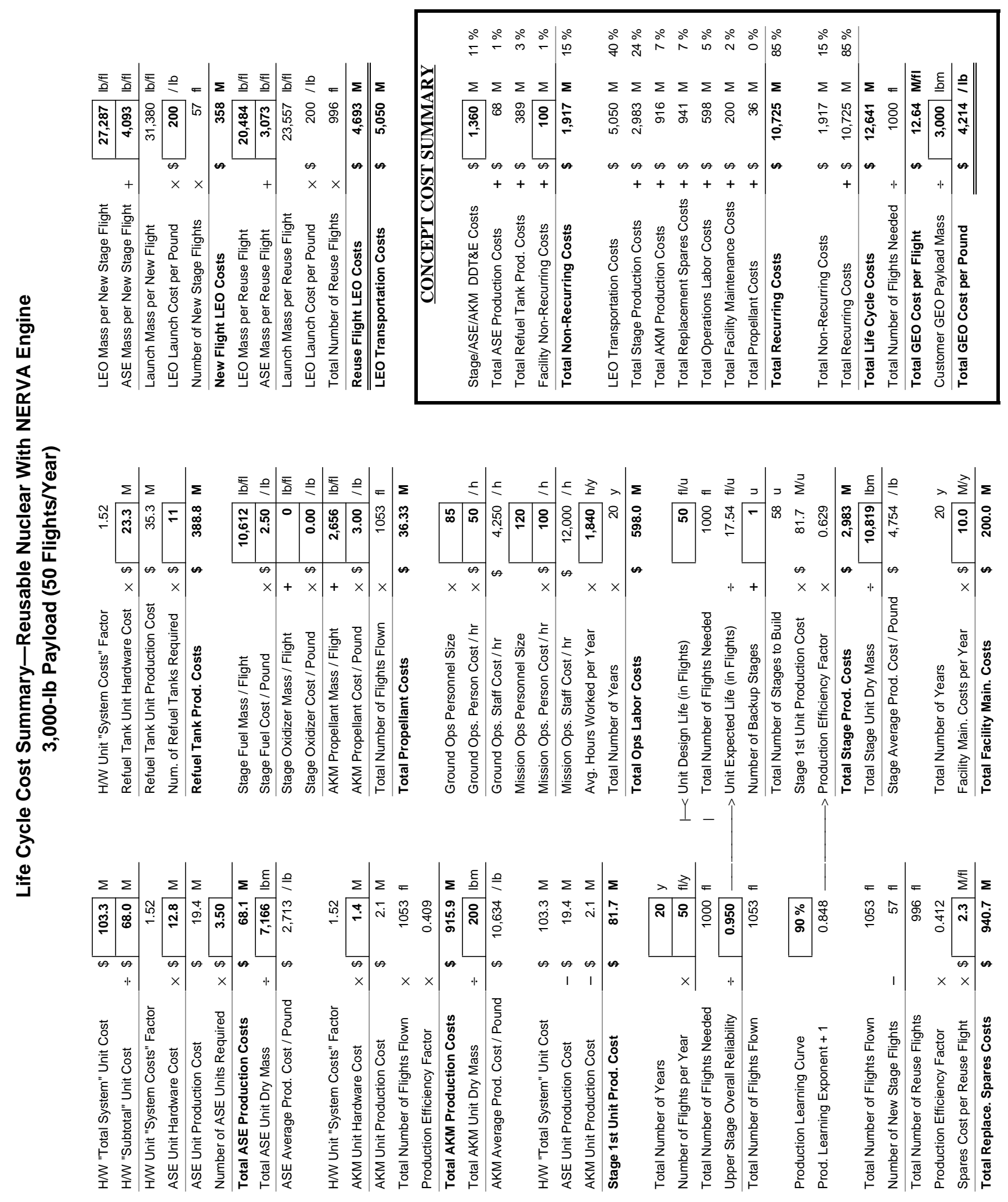




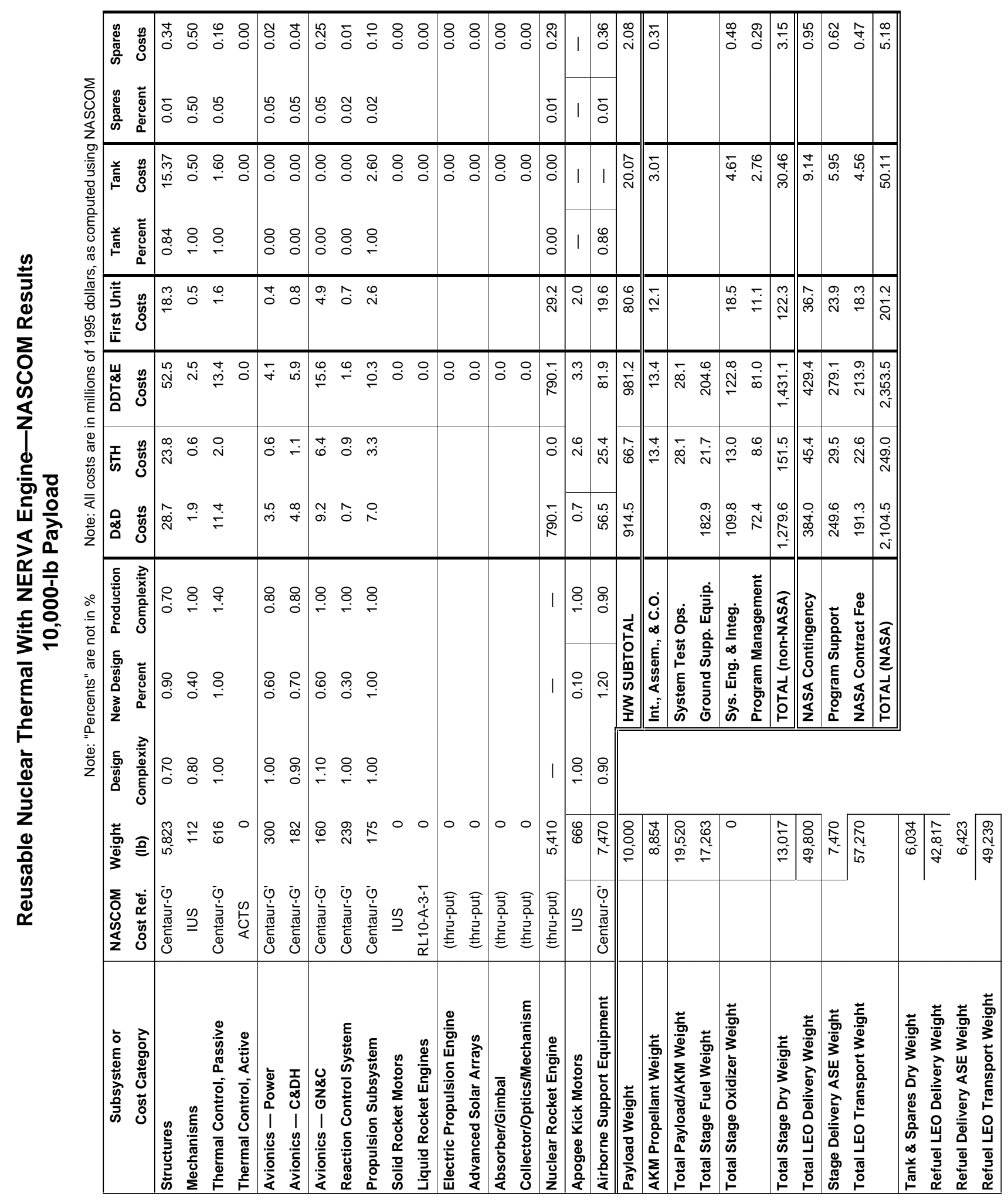




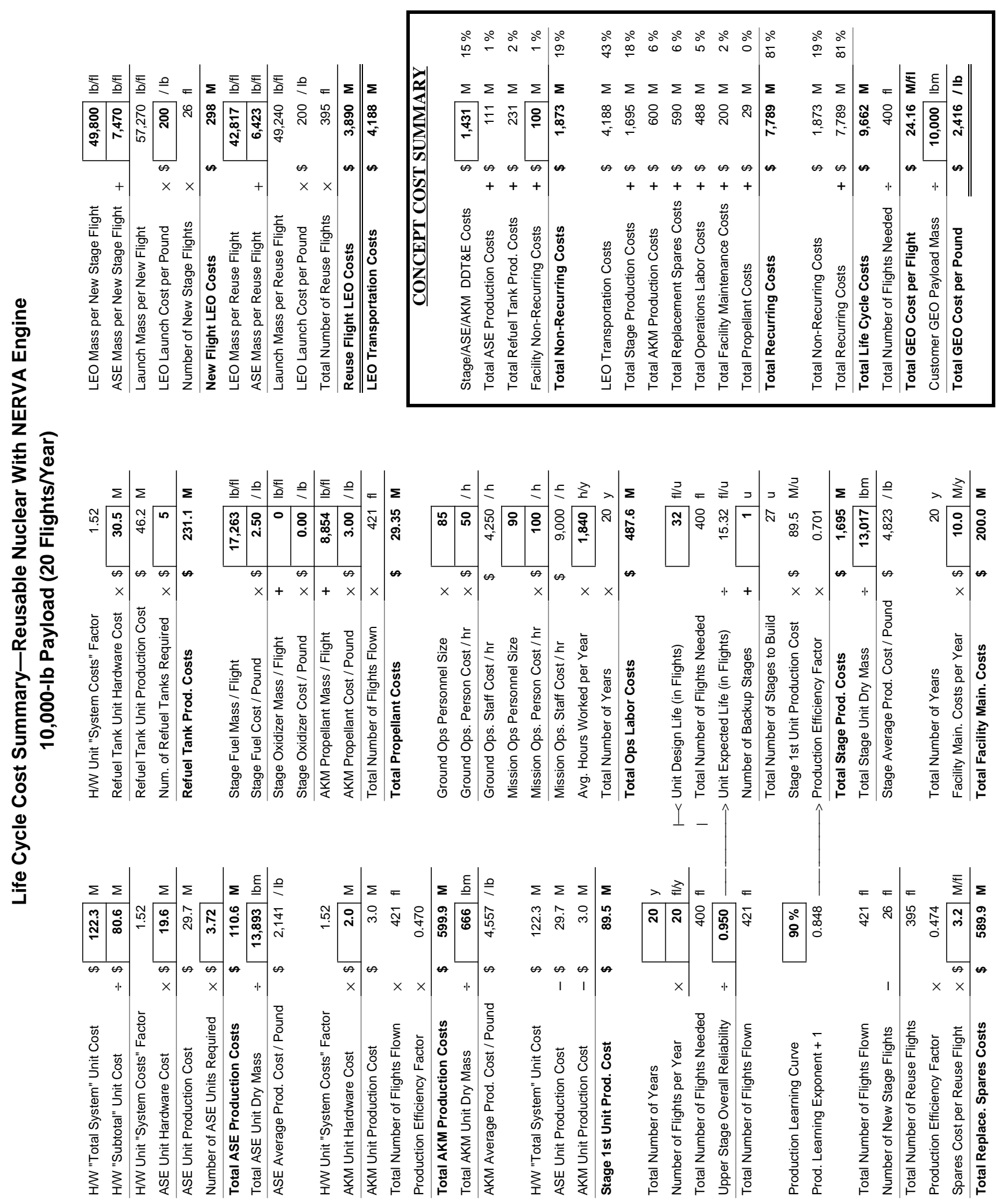




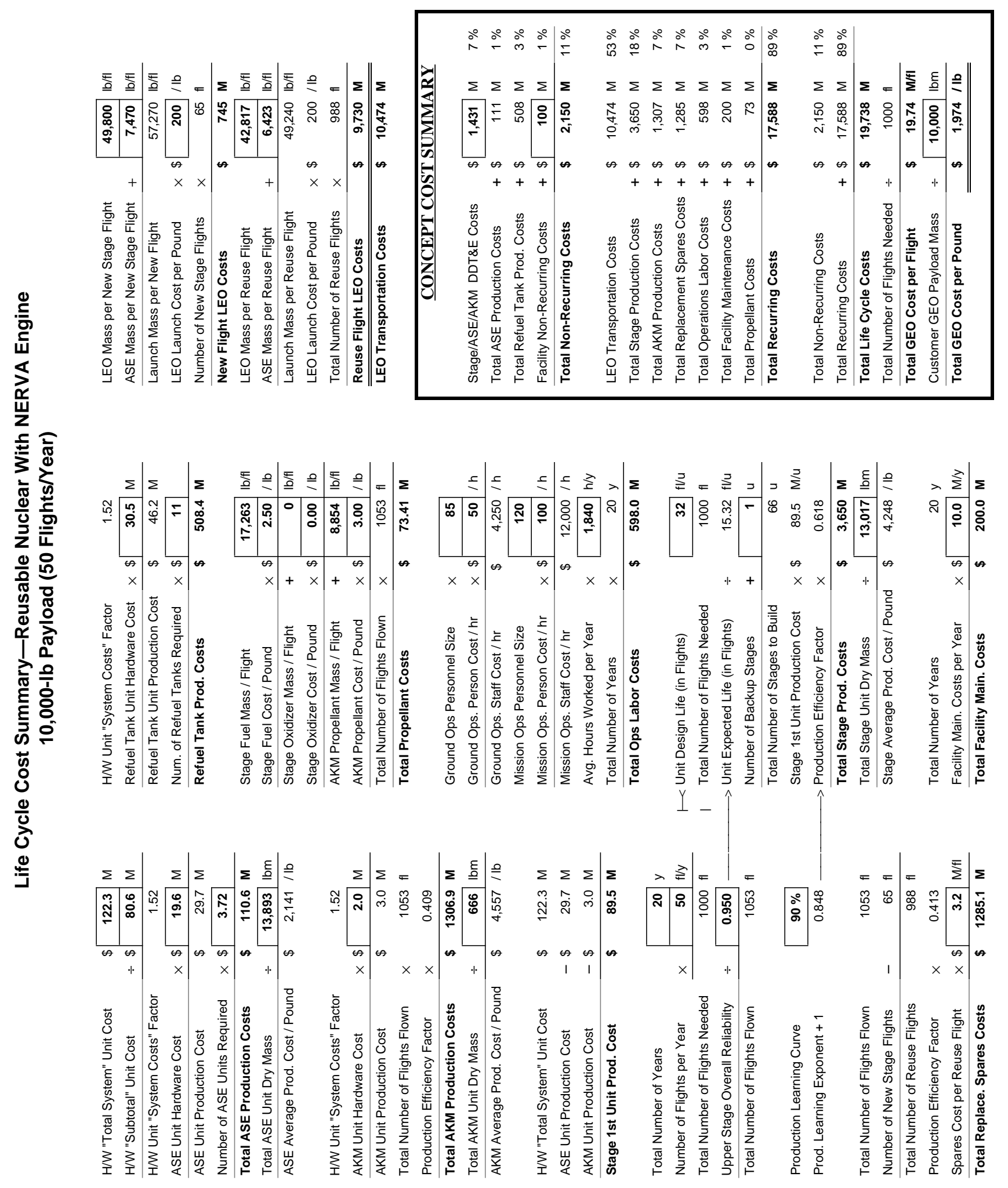




\section{APPENDIX K}

\section{MASS REDUCTIONS}

Mass estimates used in this study were relatively conservative. They are based on today's design practice and experience, not on some future practice or very advanced technology. Therefore, it makes sense to see what might be achieved in mass reduction.

Figure K-1 shows the effects of inert mass reduction on the reusable cryogenic system initial mass, according to the "split payload" equation. The plot point from this study's more detailed mass estimating is also shown. This point is at about 23,000-lb launched mass. Recall that launched mass must be brought down to $15,000 \mathrm{lb}$ simply to reduce the Earth-to-orbit cost contribution to the target of $\$ 1,000 / \mathrm{lb}$.

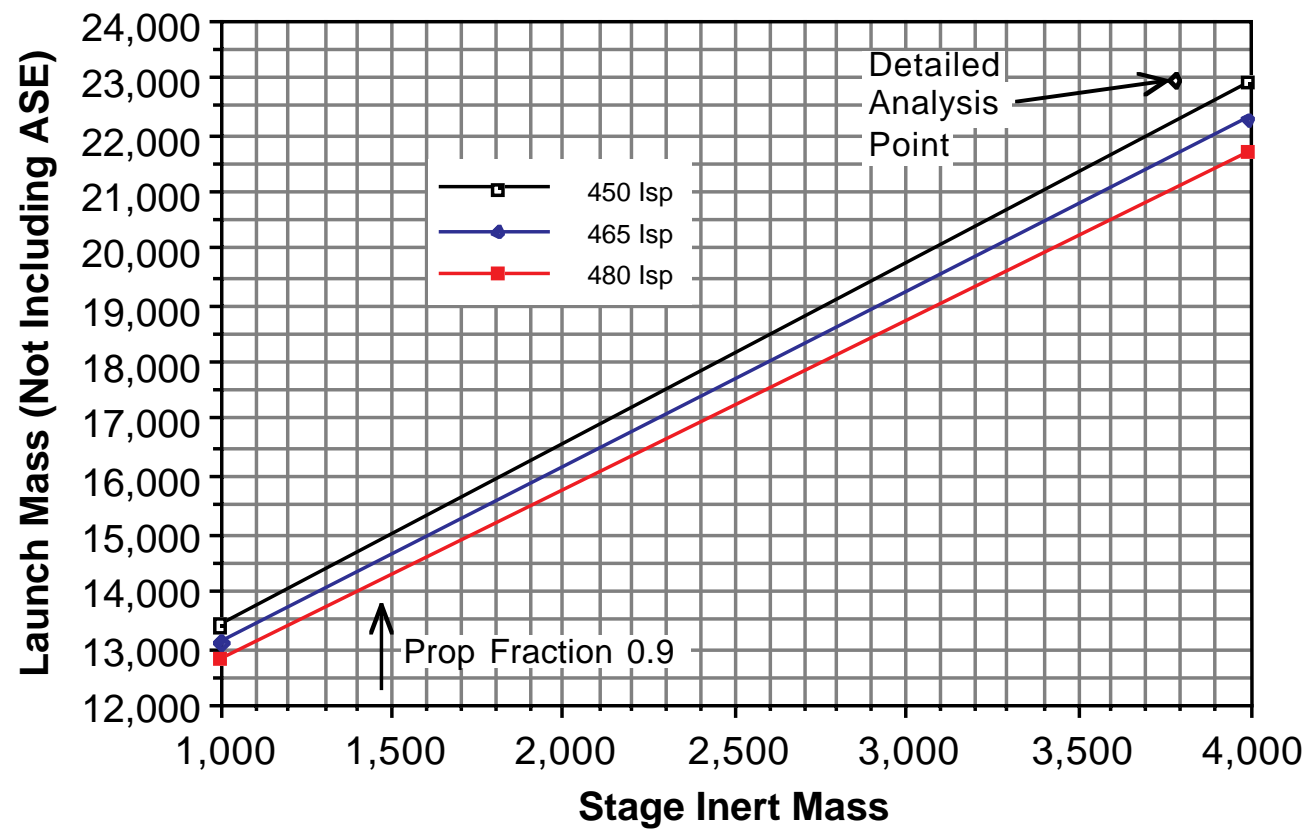

Figure K-1. "Split-payload" equation prediction of reusable cryo launch mass, 3,000-lb payload with AKM.

It is popular to believe that chemical propulsion stages can be built with propellant fractions of 0.9 or better. Large ones can and have been built. Small stages cannot reach this inert mass performance level for a variety of reasons, especially if hydrogen is the fuel used. The mass fraction projected for the 3,000$\mathrm{lb}$ delivery stage in this study is about 0.77 . A review of mass estimates, presuming use of all graphite construction including the hydrogen tank and use of very advanced (new-millennium-class) low power avionics, suggests that the stage dry mass might be brought down from 3,770 to about 2,500 lb. Referring to the figure, this brings the launched mass down to $18,000 \mathrm{lb}$, still not low enough.

Part of the difficulty is that an AKM with low Isp is used; the actual payload to GTO for the reusable cryo system is almost twice the GEO payload. One thought is to let the cryo system go all the way to GEO and return. However, if this is done with an all-propulsive system, the "split-payload" equation predicts a launch mass of about $28,000 \mathrm{lb}$. The problem is the mission delta $\mathrm{V}$ for the cryo system goes from 5,100 to $8,400 \mathrm{~m} / \mathrm{s}$. Aerobraking could reduce the delta $\mathrm{V}$ but small aerobrakes have poor mass fractions. Changing the mission profile does not appear promising.

Another approach is to let the AKM place the payload into an elliptic orbit with apogee at GEO and perigee about 7,000-km altitude, above the most severe radiation belts. The payload propulsion system, which is presumed to be high-efficiency electric propulsion operating on the payload's solar arrays, would 
raise the perigee and effect the needed plane change. The kick motor delta $\mathrm{V}$ is reduced from 1,765 to about $500 \mathrm{~m} / \mathrm{s}$. It is estimated that this could reduce the launched mass to about 13,500 lb. This is below the upper limit but leaves almost no margin for other costs.

In some respects the SEP system mass estimate is also very conservative, especially structure and avionics. The solar array itself is intentionally optimistic relative to current technology. There is little definition of the structural system. An advanced structural design and materials coupled with new-millenniumclass avionics were estimated to reduce the mass of the SEP by about 40 percent. The SEP already goes all the way to GEO without an apogee kick motor. It was further estimated that launched mass might be reduced by 25 percent to roughly 12,000 lb. This still does not leave a comfortable margin for other costs.

Since SEP technology is in its infancy, greater advances could be projected in the state of the art. If array performance could be obtained on the order of $500 \mathrm{~W} / \mathrm{kg}$, the Isp would optimize at higher values. While no estimates were developed, it is likely that launch masses could be projected in the range 8,000 to $10,000 \mathrm{lb}$.

There is only a meager data base for dynamic tethers, and resources of this study did not permit an adequate depth of analysis or design. In concept, the dynamic tether appears to derive benefits using electric propulsion minus some of the drawbacks. Electric propulsion provides, in most cases, continuous low-thrust reboost for the tether "launcher." Periodically, available momentum and energy are transferred to the payload by a reusable tether. The payload is placed into a GEO transfer orbit. Like the other highthrust systems, an AKM is used for GEO circularization. The tether is reeled in and usually recovered a few days after payload deployment. The energy and momentum transferred to the tether may be significant but is recovered with the tether. The tether platform should have sufficient mass so that its orbit is not excessively degraded by a payload deployment, including the dynamics of the deployed tether.

Since electric propulsion, in a dynamic tether system, provides energy and momentum only to the payload (and not to an electric propulsion stage and its propellant), it is much more efficient, in principle, than a conventional electric propulsion vehicle. Also note that since energy/momentum impartation to the payload and energy/momentum makeup are decoupled, payloads are not constrained to long trip times. 